\title{
The neutral photochemistry of nitriles, amines and imines in the atmosphere of Titan
}

\author{
J.C. Loison ${ }^{\mathrm{c}, \mathrm{d}}$, E. Hébrard ${ }^{\mathrm{a}, \mathrm{b}}$, M. Dobrijevic ${ }^{\mathrm{a}, \mathrm{b}, *}$, K.M. Hickson $^{\mathrm{c}, \mathrm{d}}, \mathrm{F}$.

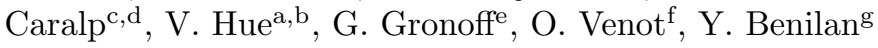 \\ ${ }^{a}$ Université de Bordeaux, Laboratoire d'Astrophysique de Bordeaux, UMR 5804, F-33270 \\ Floirac, France \\ ${ }^{b}$ CNRS, Laboratoire d'Astrophysique de Bordeaux, UMR 5804, F-33270, Floirac, France \\ ${ }^{c}$ Université de Bordeaux, Institut des Sciences Moléculaires, UMR 5255, F-33400 Talence, \\ France \\ ${ }^{d}$ CNRS, Institut des Sciences Moléculaires, UMR 5255, F-33400 Talence, France \\ ${ }^{e}$ SSAI/NASA LaRC, Hampton, Va, USA \\ ${ }^{f}$ Katholieke Univ Leuven, Inst Sterrenkunde, B-3001 Louvain, Belgium \\ ${ }^{g}$ Laboratoire Interuniversitaire des Systèmes Atmosphériques, UMR CNRS 7583, \\ Universités Paris Est Créteil (UPEC) et Paris Diderot (UPD), Créteil, France
}

\begin{abstract}
The photochemistry of $\mathrm{N}_{2}$ and $\mathrm{CH}_{4}$ in the atmosphere of Titan leads to a very rich chemistry which is not well understood. The aim of our study is to improve our understanding of the production of nitrogen compounds and to predict the abundances of those with high molar mass with better accuracy. We have made a careful investigation of the neutral nitrogen photochemistry to improve current chemical schemes including the most abundant species and the most efficient reactions. We also studied the propagation of uncertainties on rate constants in our model and determined the key reactions from a global sensitivity analysis. Our photochemical model contains 124 species, 60 of which are nitrogen containing compounds, and 1141 reactions. Our results are in reasonable agreement with Cassini/INMS data in the higher atmosphere but our model overestimates the mole fractions of several nitriles in the lower stratosphere. New species such as $\mathrm{CH}_{3} \mathrm{C}_{3} \mathrm{~N}$ and $\mathrm{C}_{3} \mathrm{H}_{7} \mathrm{CN}$ could be relatively abundant in Titan's atmosphere. Uncertainties on some nitrogen compounds are important and further studies of the key reactions that we have identified are needed to improve the predictivity of photochemical models. Meridional transport is expected to be an efficient process to govern the abundances of several nitriles in the lower stratosphere.
\end{abstract}

Keywords: Titan, Photochemistry, Atmospheres, Nitrogen compounds

\footnotetext{
*Tel: +33-5-5777-6124

Email address: Michel.Dobrijevic@obs.u-bordeaux1.fr (M. Dobrijevic)
} 


\section{Introduction}

The atmosphere of Titan can be regarded as chemical reactor on the planetary scale. It produces a variety of molecules through the coupled chemistry occurring between hydrocarbons, oxygen and nitrogen containing species. The various chemical processes taking place at different atmospheric levels are so efficient that they ultimately produce aerosols, which then sink down to the surface. Several simple molecules found in Titan's atmosphere have been followed over a period of many years, allowing us to study their spatial and temporal variations. One of the dominant processes driving the production of these chemical species is neutral photochemistry starting with the photolysis of methane $\left(\mathrm{CH}_{4}\right)$ and molecular nitrogen $\left(\mathrm{N}_{2}\right)$ in the upper atmosphere. To a lesser extent, the photochemistry of water $\left(\mathrm{H}_{2} \mathrm{O}\right)$ resulting from the injection of oxygen into the upper atmosphere (in the form of $\mathrm{O}^{+}, \mathrm{OH}$ and/or $\mathrm{H}_{2} \mathrm{O}$ ) also participates to this complexification (Hörst et al., 2008; Dobrijevic et al., 2014). Many photochemical models have been developed to explain the presence of detected compounds and to predict the abundance of as yet undetected ones. Several recent studies have improved the chemical scheme of photochemical models of Titan's atmosphere by introducing new reactions and new compounds. Vuitton et al. (2012) introduced several association reactions in their model showing that the mole fractions of certain species could change locally by as much as an order of magnitude. Hébrard et al. (2012) introduced several new reactions in their model to explain the presence of $\mathrm{HNC}$, a newly detected nitrile (Moreno et al., 2011), which was not previously present in photochemical models. Hébrard et al. (2013) carefully examined the photochemistry of $\mathrm{C}_{3} \mathrm{H}_{p}$ compounds in the atmosphere of Titan (including both photolysis and neutral-neutral thermal reactions), improving and updating the existing network for hydrocarbon chemistry. They demonstrated the noticeable impact that such an improvement could have on the calculated abundances of many hydrocarbons (for $\mathrm{C}_{3^{-}}$and $\mathrm{C}_{2}$-hydrocarbons alike) whilst predicting that as yet undetected compounds such as the carbon trimer $\left(\mathrm{C}_{3}\right)$, cyclopropenylidene $\left(\mathrm{c}-\mathrm{C}_{3} \mathrm{H}_{2}\right)$ and the propargyl radical $\left(\mathrm{C}_{3} \mathrm{H}_{3}\right)$ could be abundant enough to be contribute to Cassini/INMS data. Dobrijevic et al. (2014) improved the photochemistry of oxygen species, introducing in particular a coupling between the chemistries of hydrocarbons, oxygen and nitrogen containing species. They predicted the presence of new and as yet undetected compounds such as NO (nitric oxide), HNO (nitrosyl hydride), $\mathrm{HNCO}$ (isocyanic acid) and $\mathrm{N}_{2} \mathrm{O}$ (nitrous oxide) and showed that the abundance profiles of these compounds depend on the nature and the source of oxygen compounds in the atmosphere. All of these recent models have shown that the improvement of neutral chemical schemes used in photochemical models is necessary for several reasons: it allows us to better understand which processes drive the chemistry of Titan's atmosphere, it improves the chemistry of coupled neutral-ion models, it allows us to predict the presence of undetected compounds, and it places additional constraints on different physical parameters such as transport and external inputs. In the present paper, we extend these previous studies, updating and improving the photochemical scheme for 
nitrogen containing compounds with a particular focus on nitriles that have already been detected. Several nitrile compounds ( $\mathrm{HCN}, \mathrm{HNC}, \mathrm{HC}_{3} \mathrm{~N}, \mathrm{CH}_{3} \mathrm{CN}$ and $\mathrm{C}_{2} \mathrm{~N}_{2}$ ) have been firmly detected in Titan's atmosphere and their altitude profiles have been determined by spectroscopic observations. Other nitrogen containing compounds have been detected by (or tentatively suggested by) the Ion and Neutral Mass Spectrometer (INMS) instrument aboard the Cassini orbiter and their abundances have been inferred from analysis of the spectra and the use of photochemical models that include ion and neutral chemistry (references are given below). Among these compounds, we can highlight certain nitriles $\left(\mathrm{C}_{2} \mathrm{H}_{3} \mathrm{CN}, \mathrm{C}_{2} \mathrm{H}_{5} \mathrm{CN}, \mathrm{HC}_{5} \mathrm{~N}\right.$ and probably $\left.\mathrm{CH}_{3} \mathrm{C}_{3} \mathrm{~N}\right)$, one amine $\left(\mathrm{NH}_{3}\right)$ and one imine $\left(\mathrm{CH}_{2} \mathrm{NH}\right)$. Three other compounds have been found to be present in INMS spectra $\left(\mathrm{C}_{5} \mathrm{H}_{5} \mathrm{~N}, \mathrm{C}_{6} \mathrm{H}_{3} \mathrm{~N}, \mathrm{C}_{6} \mathrm{H}_{7} \mathrm{~N}\right)$ but many isomers are possible for these molecules. Upper limits for a few compounds have also been inferred from the INMS data (two amines: $\mathrm{CH}_{3} \mathrm{NH}_{2}, \mathrm{~N}_{2} \mathrm{H}_{4}$ and one nitrile: $\mathrm{C}_{4} \mathrm{H}_{5} \mathrm{~N}$ ). $\mathrm{C}_{4} \mathrm{~N}_{2}$ has been detected only as $\mathrm{C}_{4} \mathrm{~N}_{2}$ ice in Titan's North polar stratosphere.

Our methodology to improve the chemical scheme, which includes new calculations as well as an extensive literature review, is presented in section 2. The photochemical model is briefly presented in section 3 , highlighting only those parts which are different from our previous model. In section 4 , we use the recent determination of the altitude profiles of six hydrocarbons in the equatorial region (including the new detection of propene) by Nixon et al. (2013) and the water profile determined by Moreno et al. (2012) to constrain the eddy diffusion coefficient before presenting the main reaction pathways for the production of nitriles, amines and imines. A review of available observations for all the nitrogen compounds detected so far is given. For each compound, the model results with their associated uncertainties, due to uncertainties on chemical rate constants are presented. Some as yet undetected nitrogen compounds are also highlighted. In section 5 , we pinpoint the reactions that require further investigation to improve the predictivity of photochemical models. In section 6 , several important aspects of the nitrogen photochemistry in Titan's atmosphere are discussed before presenting our conclusions in section 7 .

\section{Chemical scheme}

Several recent modeling studies of Titan's atmosphere (Vuitton et al., 2012; Hébrard et al., 2012; Hébrard et al., 2013; Dobrijevic et al., 2014), have shown that current chemical schemes used in photochemical models are far from complete. Previous work (Hébrard et al., 2006, 2007; Hébrard et al., 2009; Dobrijevic et al., 2008) has also underlined the importance of uncertainties on reaction rates. Indeed, the propagation of these uncertainties in such highly non-linear systems is responsible for important deviations of the model results, weakening the possibility to constrain some physical parameters. As a consequence, we consider that the improvement of chemical schemes is an important prerequisite (1) to increase the accuracy and precision of $1 \mathrm{D}$ photochemical models (for a better interpretation and preparation of observations) and (2) to construct basic chemical schemes that could be introduced into 2D or 3D models. Indeed, the 
development of a reduced scheme that could be used in such complex models should be based on a nominal chemical scheme for which we are confident of its completeness and predictivity.

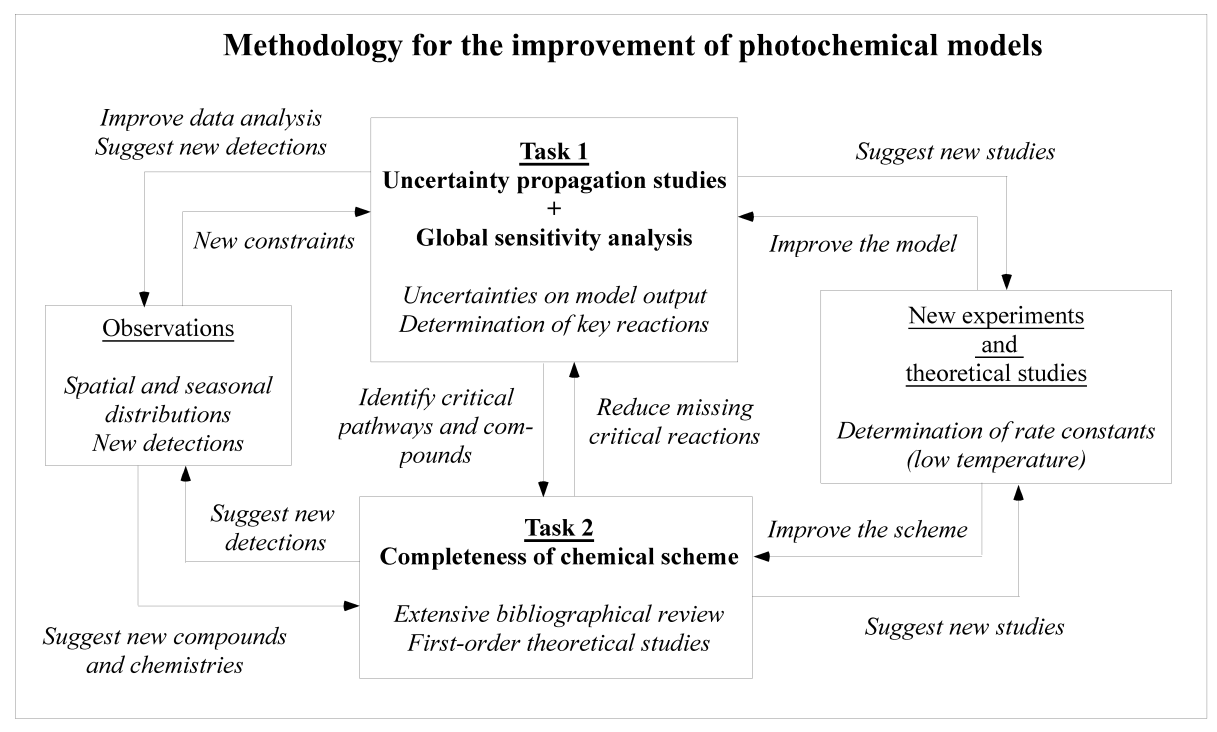

Figure 1: Methodology based on two tasks to improve the chemical networks of photochemical models. These two tasks serve as an efficient basis for new studies focused on selected reactions, which in return can improve significantly the chemical scheme used in models. Improvement of models favor new detection attempts and put better constraints on physical parameters.

The methodology we have developed during the last few years to improve chemical schemes is based on two complementary tasks (see Figure 1): (1) the determination of key reactions through uncertainty propagation studies and global sensitivity analyses, (2) the completeness of the chemical scheme. Key reactions are reactions which have a noticeable effect on model results because their uncertainty factors are relatively important and/or because they are strongly coupled with the main compounds. Determining these key reactions is an important aspect of this approach since it promotes new theoretical and/or experimental studies to provide better estimation of the reaction rates and product branching ratios at low temperature. These new data can then quantitatively improve photochemical models (see Hébrard et al. (2009) as an example). Many reactions included in current networks remain to be studied by theoretical or experimental means. For many others, very few data are available under physical conditions that are directly relevant to the atmosphere of Titan. However, by considering the abundance and reactivity of some species, it is quite clear that many missing reactions are likely to be important and should not be neglected in photochemical models. By introducing these new reactions with an estimation of their rate constant and the associated uncertainty factor, it is possible - thanks to uncertainty propagation studies and global sensitivity 
analyses (task 1) - to conclude whether these reactions are important or not. For the reactions that are considered to be important, further in depth theoretical and experimental studies will be necessary (see Hébrard et al. (2013) and Dobrijevic et al. (2014) as examples).

The methodology we propose is iterative, when task (2) is performed, task (1) should be repeated to determine a new list of key reactions. Moreover, following the publication of new rate constants and their uncertainty factors, both tasks (1) and (2) should also be repeated. The improvement of chemical schemes for low mass compounds should be realized first to obtain a firm chemical scheme which could then allow its extension to higher mass species.

In the present paper, we follow this methodology to improve the neutral photochemistry of nitrogen compounds in Titan's atmosphere. To get a nitrogen chemical scheme as complete as possible we reformulate the chemical reaction scheme leading to complex nitrile formation. This scheme, which is initiated by the photodissociation of $\mathrm{N}_{2}$ and $\mathrm{CH}_{4}$ is presented in Appendix $\mathrm{C}$ (main processes are summarized in Figure 8), and is based in part on the reaction networks of previous models (Wilson and Atreya, 2004; Hébrard et al., 2006; Lavvas et al., 2008; Krasnopolsky, 2009; Vuitton et al., 2006, 2007). At each step we consider all the main reactions (determined from the calculations of production and loss rates) for the various species produced from the previous step, as well as some secondary reactions. For atoms and radicals we consider systematically the reactions with $\mathrm{N}_{2}$ (almost negligible), $\mathrm{CH}_{4}, \mathrm{C}_{2} \mathrm{H}_{2}, \mathrm{C}_{2} \mathrm{H}_{4}, \mathrm{HCN}$, $\mathrm{HNC}, \mathrm{H}, \mathrm{CH}_{3}$ and N. For closed-shell molecules with double or triple $\mathrm{CC}$ bond $\left(\mathrm{HC}_{3} \mathrm{~N}, \mathrm{CH}_{2} \mathrm{NCH}, \mathrm{C}_{2} \mathrm{H}_{3} \mathrm{CN}, \mathrm{CH}_{3} \mathrm{C}_{3} \mathrm{~N}, \mathrm{C}_{4} \mathrm{~N}_{2}\right)$ we consider photodissociations and reactions with $\mathrm{H}$ atoms through three body associations. For saturated nitriles ( $\mathrm{HCN}, \mathrm{CH}_{3} \mathrm{CN}, \mathrm{C}_{2} \mathrm{H}_{5} \mathrm{CN}, \mathrm{C}_{3} \mathrm{H}_{7} \mathrm{CN}$ ), which react slowly with $\mathrm{H}$ atoms, we consider photodissociations and reactions with highly reactive atoms and radicals produced in Titan's atmosphere (thus mainly involving $\mathrm{N}\left({ }^{2} \mathrm{D}\right)$ atoms but also $\mathrm{CH}, \mathrm{CN}$ and $\mathrm{C}_{2} \mathrm{H}$ radicals but neglecting the reactions with ${ }^{1} \mathrm{CH}_{2}, \mathrm{C}$, $\mathrm{C}_{2} \mathrm{~N}, \mathrm{C}_{3} \mathrm{~N}, \mathrm{C}_{4} \mathrm{H}$ as they play only a minor role). We consider also the reactivity of saturated nitriles with $\mathrm{C}_{2} \mathrm{H}_{3}$ for which the rates deduced from the studies of Monks et al. (1993) and Petrie (2002) are likely to be overestimated and are the subject of theoretical calculations performed in that work. For each important reaction we perform an extensive bibliographic review including chemical databases such as the KIDA database, Wakelam et al. (2012). When no information exists, we calculate the presence and the value of the entrance barrier using Density Functional Theory (DFT) calculations with the hybrid M06-2X functional developed by Zhao and Truhlar (2008), which is well suited for calculations involving molecules and radicals with $\mathrm{C}, \mathrm{N}, \mathrm{H}$ and $\mathrm{O}$ atoms, associated with aug-cc-pVTZ basis sets (Dunning Jr, 1989) using Gaussian09. 23 reactions were studied using DFT calculations; these reactions concern mainly $\mathrm{H}$ + nitriles and $\mathrm{C}_{2} \mathrm{H}_{3}$ reactions with $\mathrm{H}_{2}, \mathrm{CH}_{4}, \mathrm{C}_{2} \mathrm{H}_{6}, \mathrm{C}_{3} \mathrm{H}_{6}, \mathrm{C}_{4} \mathrm{H}_{2}, \mathrm{HCN}, \mathrm{HNC}$, $\mathrm{HC}_{3} \mathrm{~N}$. For barrierless reactions, the rate constants $k(T)$ are calculated using capture rate theory, which leads to an upper limit value of the rate constant (Georgievskii and Klippenstein, 2005). For reactions with a barrier, the rate constants are calculated using conventional Transition State Theory. For mi- 
nor secondary reactions, the rate constants are generally deduced from similar reactions. Particular attention should be paid to photodissociation processes. Indeed, the branching ratios for nitrile photolysis are poorly known, except for $\mathrm{HCN}$, leading to large uncertainties. Moreover, the nitriles present a low energy triplet state which may be responsible for non-negligible absorption in the 200-350 nm range (Rianda et al., 1984) and may lead to photodissociation. In that case, such a process will strongly increase the overall photodissociation efficiency. In this study we neglect the reactivity of metastable $\mathrm{N}_{2}^{* *}$. Since $\mathrm{N}_{2}$ in its ground state is very unreactive, almost all nitrogen chemistry arises from $\mathrm{N}_{2}$ dissociation (photodissociation and dissociation by collision with high kinetic energy electrons) (Lavvas et al., 2011). In this study we do not describe ionic chemistry. However, $\mathrm{N}_{2}$ dissociation results mainly in the formation of $\mathrm{N}^{+}$and $\mathrm{N}_{2}^{+}$(Lavvas et al., 2011). Fortunately, the main reactions involving these ions are limited in Titan's atmosphere. $\mathrm{N}^{+}$reacts mainly with $\mathrm{CH}_{4}$ leading to $\mathrm{CH}_{3}^{+}$ $+\mathrm{NH}, \mathrm{HCNH}^{+}+\mathrm{H}_{2}$ and $\mathrm{HCN}^{+}+\mathrm{H}_{2}+\mathrm{H}$ (Anicich, 2003). $\mathrm{CH}_{3}^{+}$reacts with $\mathrm{CH}_{4}, \mathrm{C}_{2} \mathrm{H}_{2}$ and $\mathrm{C}_{2} \mathrm{H}_{4}$ leading only to hydrocarbons, and $\mathrm{HCN}^{+}$reacts mainly with $\mathrm{CH}_{4}$ and $\mathrm{H}_{2}$ leading to $\mathrm{HCNH}^{+}$(Anicich, 2003). As a result, $\mathrm{N}^{+}$chemistry leads mainly to two nitrogen products: $\mathrm{NH}$ and $\mathrm{HCNH}^{+}$. $\mathrm{As} \mathrm{HCNH}^{+}$mostly gives back HCN (through dissociative electronic recombination and reaction with other neutral nitrile species) and $\mathrm{NH}$ reacts mainly with $\mathrm{CH}_{3}$ leading ultimately to $\mathrm{HCN}$, we consider that $\mathrm{N}^{+}$behaves as $\mathrm{N}\left({ }^{4} \mathrm{~S}\right)$ in our model. It is even more simple for $\mathrm{N}_{2}^{+}$(the main dissociation product) as it reacts mainly with $\mathrm{CH}_{4}$ leading to $\mathrm{CH}_{2}^{+}$and $\mathrm{CH}_{3}^{+}$(and $\mathrm{N}_{2}$ ), and with $\mathrm{H}_{2}$ leading to $\mathrm{N}_{2} \mathrm{H}^{+}$. So as $\mathrm{CH}_{2}^{+}$and $\mathrm{CH}_{3}^{+}$will lead only to hydrocarbon formation and $\mathrm{N}_{2} \mathrm{H}^{+}$reacts with $\mathrm{CH}_{4}$ to give $\mathrm{CH}_{5}^{+}+\mathrm{N}_{2}, \mathrm{~N}_{2}^{+}$reactions do not lead to the formation of nitrogen compounds but give back $\mathrm{N}_{2}$ instead. We consider that $\mathrm{N}_{2}$ dissociation through VUV photons and cosmic rays produces $50 \%$ ground-state $\mathrm{N}\left({ }^{4} \mathrm{~S}\right)$ atoms and $50 \%$ long-lived and metastable-state $\mathrm{N}\left({ }^{2} \mathrm{D}\right)$ and $\mathrm{N}\left({ }^{2} \mathrm{P}\right)$ atoms (Dutuit et al., 2013). As $\mathrm{N}\left({ }^{2} \mathrm{P}\right)$ state is much less reactive than the $\mathrm{N}\left({ }^{2} \mathrm{D}\right)$ state, with rate constants lower by several orders of magnitude, we consider that $\mathrm{N}\left({ }^{2} \mathrm{P}\right)$ mainly relaxes toward $\mathrm{N}\left({ }^{2} \mathrm{D}\right)$ and that $\mathrm{N}_{2}$ photodissociation produces $50 \%$ ground-state $\mathrm{N}\left({ }^{4} \mathrm{~S}\right)$ atoms and $50 \%$ long-lived $\mathrm{N}\left({ }^{2} \mathrm{D}\right)$ atoms.

The present chemical scheme contains 124 species, 969 reactions, 171 photolysis processes and 1 dissociation by galactic cosmic rays. The list of species is given in Table 1 for the different families of compounds and divided into 4 main groups: $\mathrm{H}-\mathrm{C}, \mathrm{H}-\mathrm{C}-\mathrm{O}, \mathrm{H}-\mathrm{N}-\mathrm{O}$ and $\mathrm{H}-\mathrm{C}-\mathrm{N}$. The complete list of reactions is given in Appendix $\mathrm{C}$ with references or information regarding the estimation of rate constants and their uncertainty factors.

\section{Photochemical model}

We present in the following section the various modifications that we have performed compared to the model presented in Dobrijevic et al. (2014). 
Table 1: Complete list of species considered in the present model.

\begin{tabular}{|c|c|c|}
\hline Family & Number & Species \\
\hline & 3 & $\mathrm{H}, \mathrm{H}_{2}, \mathrm{Ar}$ \\
\hline $\mathrm{H}-\mathrm{C}$ & 45 & 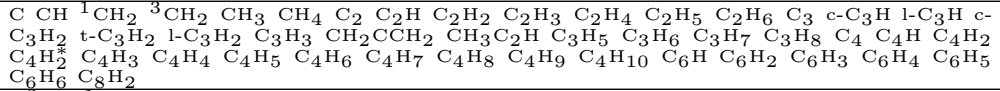 \\
\hline $\mathrm{H}-\mathrm{C}-\mathrm{O}$ & 16 & 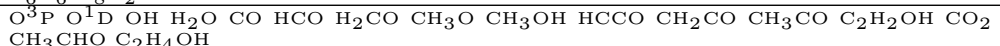 \\
\hline $\mathrm{H}-\mathrm{N}-\mathrm{O}$ & 6 & $\mathrm{NO} \mathrm{HNO} \mathrm{NCO} \mathrm{HNCO} \mathrm{N}_{2} \mathrm{OCH}_{3} \mathrm{NO}$ \\
\hline $\mathrm{H}-\mathrm{C}-\mathrm{N}$ & 54 & 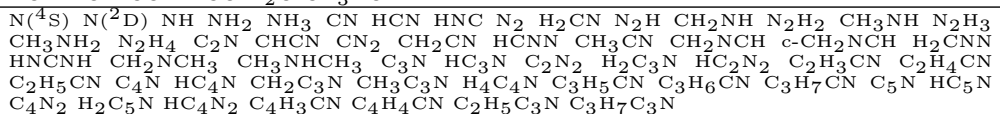 \\
\hline Total & & \\
\hline
\end{tabular}

\subsection{Atmospheric profile}

In the present study, we use the recommended atmospheric profile of the engineering model of Waite et al. (2013). In our previous studies (i.e. Hébrard et al. (2013); Dobrijevic et al. (2014)), we used the atmospheric profile of Moreno et al. (2012). The present modification has no noticeable effect on the model results.

\subsection{Boundary conditions}

We use a model similar to scenario IM1 of Dobrijevic et al. (2014) for oxygen compounds as the nominal model, i.e. a fixed value for the mole fraction of $\mathrm{CO}$ at the lower boundary $\left(y_{C O}=5.1 \times 10^{5}\right)$, an external flux of $\mathrm{O}\left({ }^{3} \mathrm{P}\right)$ (at the top of the atmosphere) and $\mathrm{OH}$ (from micrometeoritic ablation) equal respectively to $1.6 \times 10^{6}$ and $5.2 \times 10^{5} \mathrm{~cm}^{-2} \mathrm{~s}^{-1}$ (values referred to the surface). The $\mathrm{OH}$ flux has been slightly modified to obtain a water mole fraction profile in good agreement with Moreno et al. (2012). This difference with Dobrijevic et al. (2014) is due to modifications of the chemical scheme.

Krasnopolsky (2009) stated that $\mathrm{H}_{2}$ could be produced photochemically in the atmosphere and that it was not necessary to fix its mole fraction at the lower boundary. We confirm this statement, $\mathrm{H}_{2}$ being efficiently produced through $\mathrm{CH}_{4}$ and $\mathrm{C}_{2} \mathrm{H}_{4}$ photodissociations and through $\mathrm{H}+\mathrm{CH}_{2}$ and $\mathrm{H}+\mathrm{C}_{2} \mathrm{H}_{3}$ reactions. Considering that there is no hydrodynamical escape of $\mathrm{CH}_{4}$ (or for higher mass species) in the current model, the mole fraction of $\mathrm{H}_{2}$ reaches a steady state of $1.7 \times 10^{-3}$ after $10^{16} \mathrm{~s}$, in agreement with the minimal value of $1.0 \times 10^{-3}$ derived by Waite et al. (2013). For simplicity, when considering the propagation of uncertainties, we have fixed the mole fraction of $\mathrm{H}_{2}$ at the lower boundary with the recommended value of $3.0 \times 10^{-3}$ (Waite et al., 2013). This has no effect on the abundances of other species.

The mole fractions of $\mathrm{CH}_{4}$ and $\mathrm{Ar}$ are fixed at the lower boundary following the recommended model of Waite et al. (2013) $\left(y_{\mathrm{CH} 4}=1.48 \times 10^{-2}\right.$ and $y_{\mathrm{Ar}}=$ $\left.3.39 \times 10^{-5}\right)$. The mole fraction of $\mathrm{N}_{2}$ is simply given by: $y_{N_{2}}=1-\left(y_{C O}+\right.$ $\left.y_{H_{2}}+y_{C H_{4}}+y_{A r}\right)$. 
We assumed a zero flux as an upper boundary condition for all species, except for atomic hydrogen $(\mathrm{H})$ and molecular hydrogen $\mathrm{H}_{2}$, which were allowed to escape with velocities following Jean's thermal escape mechanism (and except for $\mathrm{OH}$ and $\mathrm{O}\left({ }^{3} \mathrm{P}\right)$, see above).

\subsection{Condensation}

Some nitrogen compounds may condense in the lower stratosphere of Titan. The expressions we use to obtain the saturated vapor pressure of various species are given in Table 2. For $\mathrm{CH}_{2} \mathrm{NH}, \mathrm{CH}_{3} \mathrm{C}_{3} \mathrm{~N}$ and $\mathrm{HC}_{5} \mathrm{~N}$, we were unable to find any experimental data in the literature regarding their saturated vapor pressure profile as a function of temperature. We have thus estimated that $\mathrm{CH}_{2} \mathrm{NH}$ has the same saturated vapor pressure as $\mathrm{CH}_{3} \mathrm{OH}$ and that $\mathrm{CH}_{3} \mathrm{C}_{3} \mathrm{~N}$ and $\mathrm{HC}_{5} \mathrm{~N}$ have the same saturated vapor pressure as $\mathrm{HC}_{3} \mathrm{~N}$. We have also considered that the HNC saturated vapor pressure is the same than HCN.

Table 2: Expressions of saturated vapor pressure over ice or liquid (depending on the triple point temperature) for nitrogen compounds.

\begin{tabular}{|c|c|c|}
\hline species & Saturated vapor pressure & Comments and References \\
\hline $\mathrm{CH}_{3} \mathrm{NH}_{2}$ & $\begin{array}{c}\log (P)=15.96-\frac{3.537 \times 10^{3}}{T}-\frac{3.310 \times 10^{4}}{T^{2}}+\frac{1.742 \times 10^{6}}{T^{3}}-\frac{2.995 \times 10^{7}}{T^{4}} \\
\log (P)=19.413-\frac{3333.325}{T}\end{array}$ & $\begin{array}{l}P \text { in bar, } T \in[15,195.41] \mathrm{K} \\
\quad(\text { Fray and Schmitt, 2009) } \\
P \text { in mbar, } T \in[196.45-266.55] \mathrm{K} \\
\text { (Lide and Kehiaian }(1994) ; \text { fit) }\end{array}$ \\
\hline $\mathrm{N}_{2} \mathrm{O}$ & $\log (P)=16.22-\frac{2.971 \times 10^{3}}{T}$ & $\begin{array}{l}P \text { in bar, } T<182.3 \mathrm{~K} \\
\text { (Fray and Schmitt, 2009) }\end{array}$ \\
\hline $\mathrm{HCN}$ & $\log (P)=23.055-\frac{4522.242}{T}$ & $\begin{array}{c}P \text { in mbar, } T \in[196.15-298.55] \mathrm{K} \\
\text { (Lide and Kehiaian (1994); Clausius-Clapeyron formula) }\end{array}$ \\
\hline $\mathrm{HC}_{3} \mathrm{~N}$ & $\log (P)=23.72-\frac{5087.52}{T}$ & $\begin{array}{c}P \text { in mbar, } T \in[214.45-315.15] \mathrm{K} \\
\text { (Lide and Kehiaian (1994); Clausius-Clapeyron formula) }\end{array}$ \\
\hline $\begin{array}{l}\mathrm{CH}_{3} \mathrm{CN} \\
\mathrm{C}_{2} \mathrm{H}_{3} \mathrm{CN}\end{array}$ & $\begin{array}{c}\log (P)=18.2432-\frac{4017.098}{T} \\
\log _{10}(P)=21.058-\frac{2371.0}{T}-1.560 \times \log (T)\end{array}$ & $\begin{array}{c}P \text { in mbar, } T \in[294.55-354.35] \mathrm{K} \\
\text { (Lide and Kehiaian }(1994) ; \text { Clausius-Clapeyron formula) } \\
P \text { in Pa, } T \in[290.85-350.15] \mathrm{K} \\
\text { (Lide and Kehiaian, 1994) }\end{array}$ \\
\hline $\mathrm{C}_{2} \mathrm{H}_{5} \mathrm{CN}$ & $\log (P)=18.7211-\frac{4352.66}{T}$ & $\begin{array}{c}P \text { in mbar, } T \in[203.75-370.55] \mathrm{K} \\
\text { (Lide and Kehiaian (1994), Clausius-Clapeyron formula) }\end{array}$ \\
\hline $\mathrm{C}_{3} \mathrm{H}_{5} \mathrm{CN}$ & $\log _{10}(P)=4.38253-\frac{1526.272}{T-43.316}$ & $\begin{array}{c}P \text { in bar, } T \in[282.45-391.55] \mathrm{K} \\
\text { (Lide and Kehiaian }(1994), \text { Antoine formula) }\end{array}$ \\
\hline $\begin{array}{c}\mathrm{C}_{3} \mathrm{H}_{7} \mathrm{CN} \\
\mathrm{C}_{2} \mathrm{~N}_{2}\end{array}$ & $\begin{array}{c}\log _{10}(P)=19.169-\frac{4739.935}{T} \\
\log _{10}(P)=21.381-\frac{2031.0}{T}-1.502 \times \log (T)\end{array}$ & $\begin{array}{c}P \text { in mbar, } T \in[325.45-390.35] \mathrm{K} \\
\text { (Lide and Kehiaian }(1994) ; \text { Clausius-Clapeyron formula) } \\
P \text { in Pa, } T \in[146.15-251.75] \mathrm{K} \\
\text { (Lide and Kehiaian, 1994) }\end{array}$ \\
\hline $\mathrm{C}_{4} \mathrm{~N}_{2}$ & $\log _{10}(P)=8.269-\frac{2155.0}{T}$ & $\begin{array}{c}P \text { in } \underset{\text { (Lara et al. }}{\mathrm{mmHg}, T} T \in[149-162] \mathrm{K} \\
\text { (199)) }\end{array}$ \\
\hline $\mathrm{CH}_{3} \mathrm{NHCH}_{3}$ & $\log (P)=20.633-\frac{3781.856}{T}$ & $\begin{array}{l}P \text { in mbar, } T \in[196.45-266.55] \mathrm{K} \\
\quad(\text { Lide and Kehiaian }(1994) ; \text { fit })\end{array}$ \\
\hline
\end{tabular}

\subsection{Galactic Cosmic Rays}

The production of $\mathrm{N}$ atoms $\left(\mathrm{N}\left({ }^{2} \mathrm{D}\right)\right.$ and $\left.\mathrm{N}\left({ }^{4} \mathrm{~S}\right)\right)$ by Galactic Cosmic Rays (GCR) comes from Gronoff et al. (2011) and from Gronoff et al. (2012) for cross sections. The products from the interaction of GCR with $\mathrm{N}_{2}$ and their yields are taken from Lellouch et al. (1994): $65 \%$ for ion production and $35 \%$ for $\mathrm{N}\left({ }^{2} \mathrm{D}\right)$ and $\mathrm{N}\left({ }^{4} \mathrm{~S}\right)$. Considering the large uncertainty of cosmic ray effects we do not consider cosmic ray ion formation in this study. The total loss rate of $\mathrm{N}_{2}$ by UV and GCR is presented in Figure 2. We do not consider Saturn's magnetospheric 
protons and electrons in the model. According to Krasnopolsky (2009), this contributes only a few percent to the total $\mathrm{N}$ atom production.

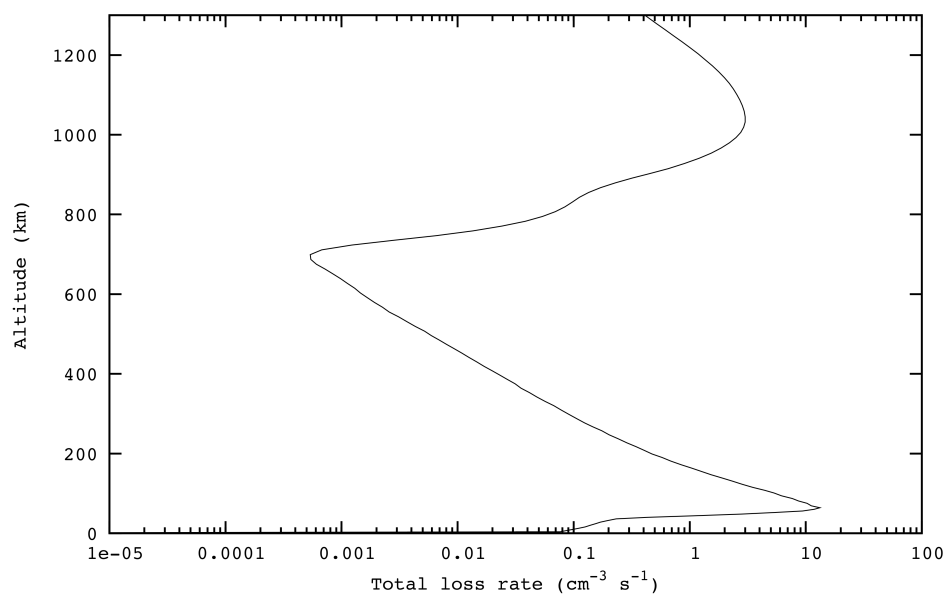

Figure 2: Total $\mathrm{N}_{2}$ loss rate as a function of altitude. The photodissociation of $\mathrm{N}_{2}$ contributes exclusively at high altitude where as the dissociation by cosmic rays is the dominant process in the lower atmosphere. Each mechanism produces $50 \%$ of $\mathrm{N}\left({ }^{4} \mathrm{~S}\right)$ and $50 \%$ of $\mathrm{N}\left({ }^{2} \mathrm{D}\right)$.

\subsection{Actinic flux}

We use a 3D radiative transfer model to compute the actinic flux as a function of altitude and latitude in the atmosphere of Titan. The code accounts for absorption by gases and aerosols (see section below) as well as multiple Rayleigh scattering based on a Monte-Carlo procedure. We assume that the atmosphere is homogeneous and that its composition is given by the results of our photochemical model. Three iterations are performed between the radiative transfer code and the photochemical code to yield consistent results. In the following, we use the recent analysis of hydrocarbon observations by Nixon et al. (2013) to constrain the eddy diffusion coefficient profile. Nixon et al. (2013) based their analysis on observations restricted to latitudes between $30^{\circ} \mathrm{S}$ and $10^{\circ} \mathrm{N}$ at times from July 1st 2004 and July 1st 2010. They used these observations to have good homogeneity within the sample since low latitudes show the least seasonal variation. Between these two dates, the subsolar point on Titan moved from $24^{\circ} \mathrm{S}$ to $5^{\circ} \mathrm{N}$ and the season moved from the end of winter in the northern hemisphere to the equinox. We calculated the actinic flux in a region located $10^{\circ}$ around the subsolar point located at the equator. To account for the day and night side alternance, we calculated the mean actinic flux between the atmospheric column at the subsolar point and the one at the anti-subsolar point. As a consequence, results presented in the following correspond to daily averaged conditions at the equator and at the equinox. The normalized actinic flux profile 
(ratio between the solar flux at the top of the atmosphere and the actinic flux at a given altitude) is presented in Figure 3 for several wavelengths.

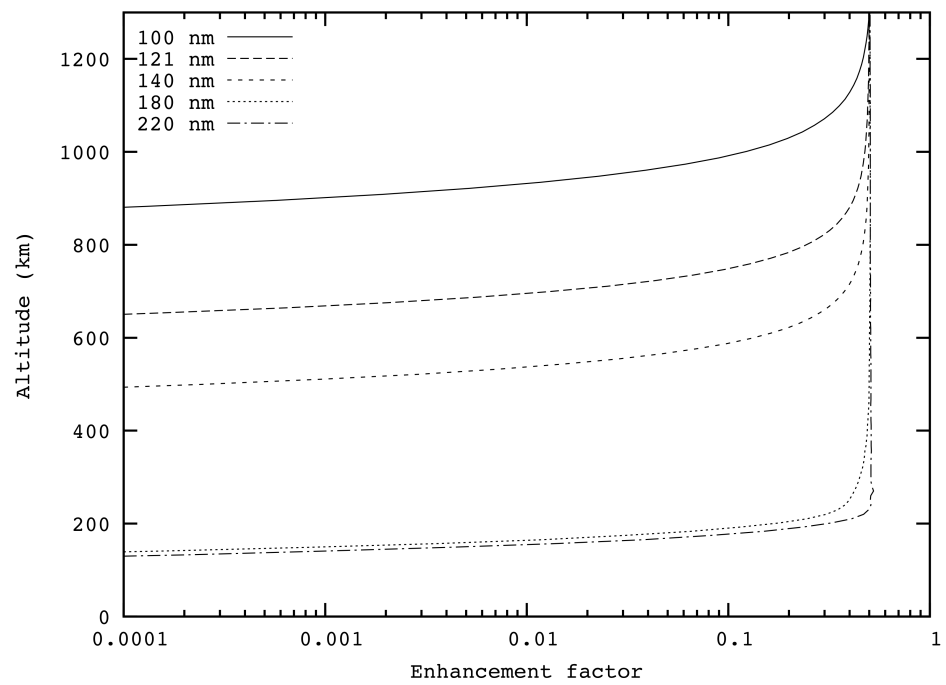

Figure 3: Normalized actinic flux as a function of altitude for several wavelengths in the atmosphere of Titan corresponding to daily average conditions at the equator and at the equinox. The normalized actinic flux is the ratio of the actinic flux at a given altitude and the solar flux at the top of the atmosphere.

\subsection{Attenuation by aerosols}

In addition to the extinction of solar radiation by gases due to absorption and Rayleigh scattering, we included the absorption due to aerosols using an optical depth given by:

$$
\tau(z, \lambda)= \begin{cases}\frac{(z-250)^{2}}{7500} & \text { if } z \in[60,250] \mathrm{km} \text { and } \lambda<500 \mathrm{~nm} \\ \frac{(z-250)^{2}}{7500} \times \exp \left(-\frac{\lambda-500}{320}\right) & \text { if } z \in[60,250] \mathrm{km} \text { and } \lambda \geq 500 \mathrm{~nm}\end{cases}
$$

This expression is in agreement with the optical depth inferred by Toon et al. (1992) and Barth and Toon (2003) above $60 \mathrm{~km}$ of altitude. They obtained an optical depth around 5 between 200 and $500 \mathrm{~nm}$ and an exponential decrease beyond with a value around 0.7-1.5 at $1000 \mathrm{~nm}$.

\subsection{Propagation of uncertainties}

It has been demonstrated in several previous studies (see Hébrard et al. (2012); Hébrard et al. (2013) and Dobrijevic et al. (2014) for the most recent ones) that uncertainties on rate constants have noticeable effects on some photochemical model outputs. We study the propagation of uncertainties on the 
chemical rate constants according to the methodology presented in those papers. We performed 500 Monte-Carlo runs to obtain statistically significant results and the integration time for each run was set to $10^{12} \mathrm{~s}$ for simplicity and to limit the computation time. This time allows steady state to be attained for most of the compounds with a very good accuracy. As a result, we obtain for each compound a statistical set of mole fraction profiles as a function of altitude. Since the distributions of these profiles are not always normal or lognormal for a given altitude, we use the 5th and 15th 20-quantiles and the 1st and 19th 20-quantiles (which represent the intervals containing respectively $50 \%$ and $90 \%$ of the mole fraction profiles) to represent the results in a simple way. We also depict the mean value of the distribution. The nominal profile corresponds to the result of the model using the unperturbed rate constants. For some compounds, the mean profile can be different from the nominal profile because their distributions are bimodal (or multimodal) (see below).

\section{Results}

\subsection{Eddy diffusion coefficient profile}

Our one dimensional photochemical model computes the abundance of various compounds as a function of altitude, under daily-averaged conditions at the equator and at the equinox. Dynamical processes in the homosphere are parameterized by a vertical eddy diffusion at similar conditions. The eddy diffusion coefficient profile $K(z)$ is fitted as a function of altitude in order to reproduce the observations gathered under similar conditions. Several earlier studies (see for example Lavvas et al. (2008)) have already faced the difficulty to simulate the $\mathrm{HCN}, \mathrm{HC}_{3} \mathrm{~N}$ and $\mathrm{C}_{2} \mathrm{H}_{x=2,4,6}$ abundances with a unique mixing profile. This may be due to meridional circulation, dominated by global Hadley cells, responsible for an intense stratospheric zonal flow, as computed in the multidimensional treatment by Hourdin et al. (2004), Rannou et al. (2005) and Crespin et al. (2008). Subsidence of stratospheric air, where photochemical production processes occur, lead to the enrichment of air in the North winter polar region. Rising air from the troposphere at low latitudes is depleted of condensable species as the temperature at the tropopause is close to $70 \mathrm{~K}$ (see Teanby et al. (2006, 2009), Vinatier et al. (2010), ...). In this paper we have then constrained $K(z)$ using species which present low polar enrichment values, namely $\mathrm{C}_{2} \mathrm{H}_{2}, \mathrm{C}_{2} \mathrm{H}_{6}, \mathrm{C}_{3} \mathrm{H}_{4}, \mathrm{C}_{3} \mathrm{H}_{6}, \mathrm{C}_{3} \mathrm{H}_{8}$ and $\mathrm{H}_{2} \mathrm{O}$ in the lower atmosphere and Ar and $\mathrm{CH}_{4}$ in the upper atmosphere. The use of water in particular has the added advantage that the chemistry is relatively well known (Hörst et al. (2008), Dobrijevic et al. (2014)).

Nixon et al. (2013) recently reported the detection of propene $\left(\mathrm{C}_{3} \mathrm{H}_{6}\right)$ in Titan's stratosphere using spectra from the Composite Infrared Spectrometer (CIRS) on Cassini. Until then, propyne $\left(\mathrm{CH}_{3} \mathrm{C}_{2} \mathrm{H}\right)$ and propane $\left(\mathrm{C}_{3} \mathrm{H}_{8}\right)$ were the only $\mathrm{C}_{3}$-hydrocarbons to have been identified in the stratosphere. The detection of a new $\mathrm{C}_{3}$-hydrocarbon gives valuable new constraints for photochemical models, allowing us to better understand which chemical processes drive hydrocarbon production in Titan's atmosphere. In addition to $\mathrm{C}_{3} \mathrm{H}_{6}$, Nixon et al. 


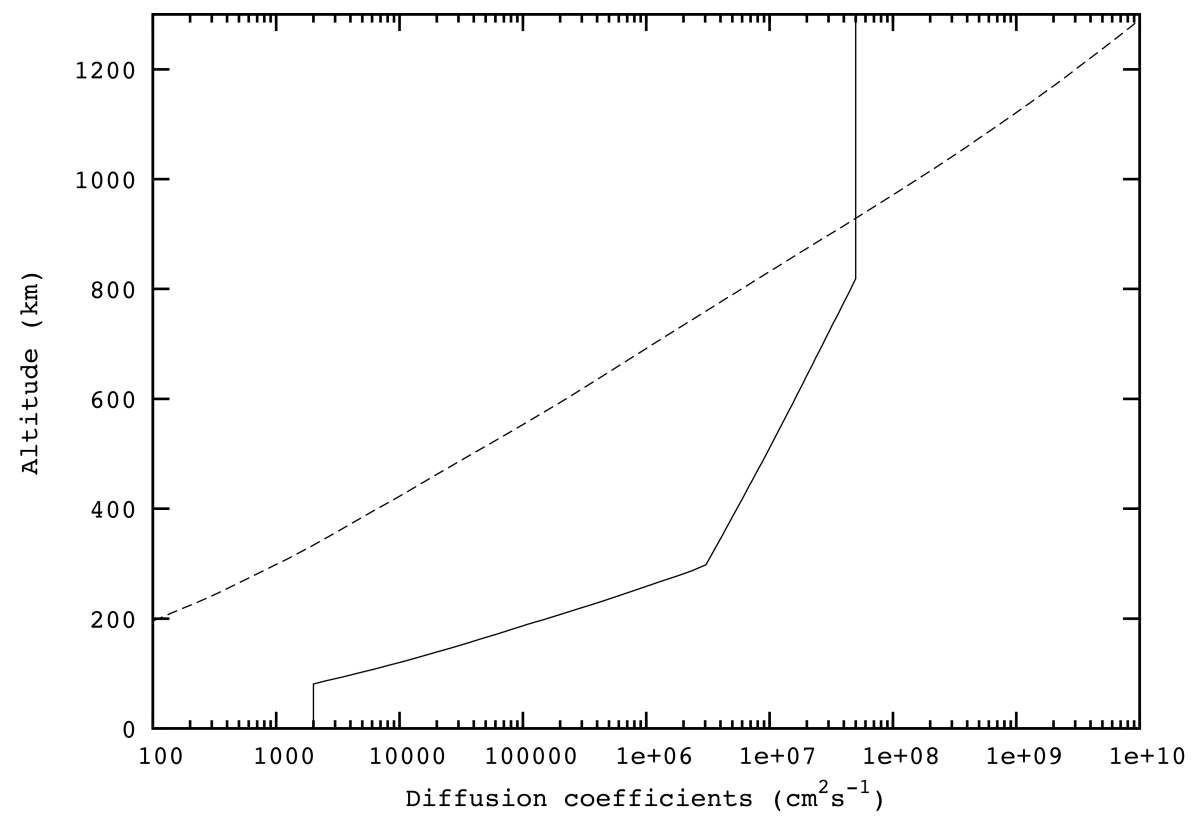

Figure 4: . Eddy (solid line) and $\mathrm{CH}_{4}$ (dashed line) diffusion coefficient profiles as a function of altitude. This eddy diffusion coefficient has been constrained by the abundances of $\mathrm{H}_{2} \mathrm{O}$ and hydrocarbons (like $\mathrm{C}_{2} \mathrm{H}_{6}$ ) in the lower atmosphere and $\mathrm{CH}_{4}$ and $\mathrm{Ar}$ in the higher atmosphere. 
(2013) retrieved the abundance profiles of 5 other hydrocarbon species previously detected in Titan's stratosphere from the same Cassini/CIRS dataset: acetylene $\left(\mathrm{C}_{2} \mathrm{H}_{2}\right)$, ethylene $\left(\mathrm{C}_{2} \mathrm{H}_{4}\right)$, ethane $\left(\mathrm{C}_{2} \mathrm{H}_{6}\right), \mathrm{CH}_{3} \mathrm{C}_{2} \mathrm{H}$ and $\mathrm{C}_{3} \mathrm{H}_{8}$. We take advantage of the averaged abundance profiles as a function of altitude for these 6 hydrocarbons using a single instrument, as such observations are more suitable for comparison with photochemical models than individual observations gathered from various instruments at different times and locations. We also used the recent water observation derived by the Herschel telescope (Moreno et al., 2012) to constrain eddy diffusion in the lower atmosphere. The water observations of Moreno et al. (2012) are preferred to the results derived by Cottini et al. (2012) because the former should be in principle more representative of a global average abundance. However, it is interesting to note that the $\mathrm{CO}_{2}$ mole fraction we obtain is in a better agreement with $\mathrm{CO}_{2}$ observations when we use a higher $\mathrm{OH}$ influx in agreement with the Cottini et al. (2012) water profile (see Dobrijevic et al. (2014) for a detailed discussion of this point). As argon is a chemically inert species, it is a good tracer of diffusive processes in the atmosphere. In particular, the abundance profile of argon in the upper atmosphere depends on the location of the homopause. We obtain a satisfactory argon profile compared to Waite et al. (2013), using an argon homopause located around $915 \mathrm{~km}$. At this level, the eddy diffusion is $5.0 \times 10^{7} \mathrm{~cm}^{2} \mathrm{~s}^{-1}$. Our methane profile is then also in agreement with Waite et al. (2013). It is possible to obtain a better profile introducing a hydrodynamic escape of methane equal to $1.2 \times 10^{9} \mathrm{~cm}^{-2} \mathrm{~s}^{-1}$ at $1300 \mathrm{~km}$ (about two times lower than the value inferred by Yelle et al. (2008)). The introduction of methane escape at the upper boundary has no effect on neutral atmospheric chemistry since the peak of methane photodissociation, located around $800 \mathrm{~km}$, is unchanged. Our nominal $K(z)$ is presented in Figure 4 and results for the main species are presented in Figures 5,6 and 7 .

\subsection{Nitrogen chemistry}

In this section, we present a simple overview of neutral nitrogen chemistry in Titan which is developed in detail in Appendix A and is presented as a flow graph in Figure 8. Neutral nitrogen chemistry is mostly initiated by nitrogen atoms in the ground $\mathrm{N}\left({ }^{4} \mathrm{~S}\right)$ state and in the excited $\mathrm{N}\left({ }^{2} \mathrm{D}\right)$ state produced by $\mathrm{N}_{2}$ photodissociation and dissociation by cosmic rays. In Titan's atmosphere, $\mathrm{N}\left({ }^{4} \mathrm{~S}\right)$ reacts mainly with $\mathrm{CH}_{3}$ radicals leading ultimately to $\mathrm{HCN} . \mathrm{N}\left({ }^{2} \mathrm{D}\right)$ atoms react mainly with $\mathrm{CH}_{4}, \mathrm{C}_{2} \mathrm{H}_{2}, \mathrm{C}_{2} \mathrm{H}_{4}$ and with $\mathrm{HCN}$. The reaction of $\mathrm{N}\left({ }^{2} \mathrm{D}\right)$ with $\mathrm{CH}_{4}$ also mainly leads to $\mathrm{HCN}$ formation (with low $\mathrm{CH}_{2} \mathrm{NH}$ steady state concentrations). The $\mathrm{N}\left({ }^{2} \mathrm{D}\right)+\mathrm{C}_{2} \mathrm{H}_{4}$ reaction does not give $\mathrm{H}+\mathrm{CH}_{3} \mathrm{CN}$ products, yielding $\mathrm{H}+\mathrm{CH}_{2} \mathrm{NCH}$ and $\mathrm{H}+\mathrm{c}_{-} \mathrm{CH}_{2}(\mathrm{~N}) \mathrm{CH}$ (cyclic compound) (Balucani et al., 2012; Lee et al., 2011), $\mathrm{CH}_{2} \mathrm{NCH}$ and $\mathrm{c}-\mathrm{CH}_{2}(\mathrm{~N}) \mathrm{CH}$ leading quickly to $\mathrm{HCN}$ in Titan's atmosphere conditions. The reaction of $\mathrm{N}\left({ }^{2} \mathrm{D}\right)$ with $\mathrm{C}_{2} \mathrm{H}_{2}$ produces HCCN (Takayanagi et al., 1998; Herron, 1999) which is quickly transformed into CCN through reaction with $\mathrm{H}$ atoms (Osamura and Petrie, 2004; Takayanagi et al., 1998), initiating the formation of complex nitriles in Titan's upper atmosphere. The reaction of $\mathrm{N}\left({ }^{2} \mathrm{D}\right)$ atoms with $\mathrm{HCN}$ should lead to $\mathrm{CH}$ 


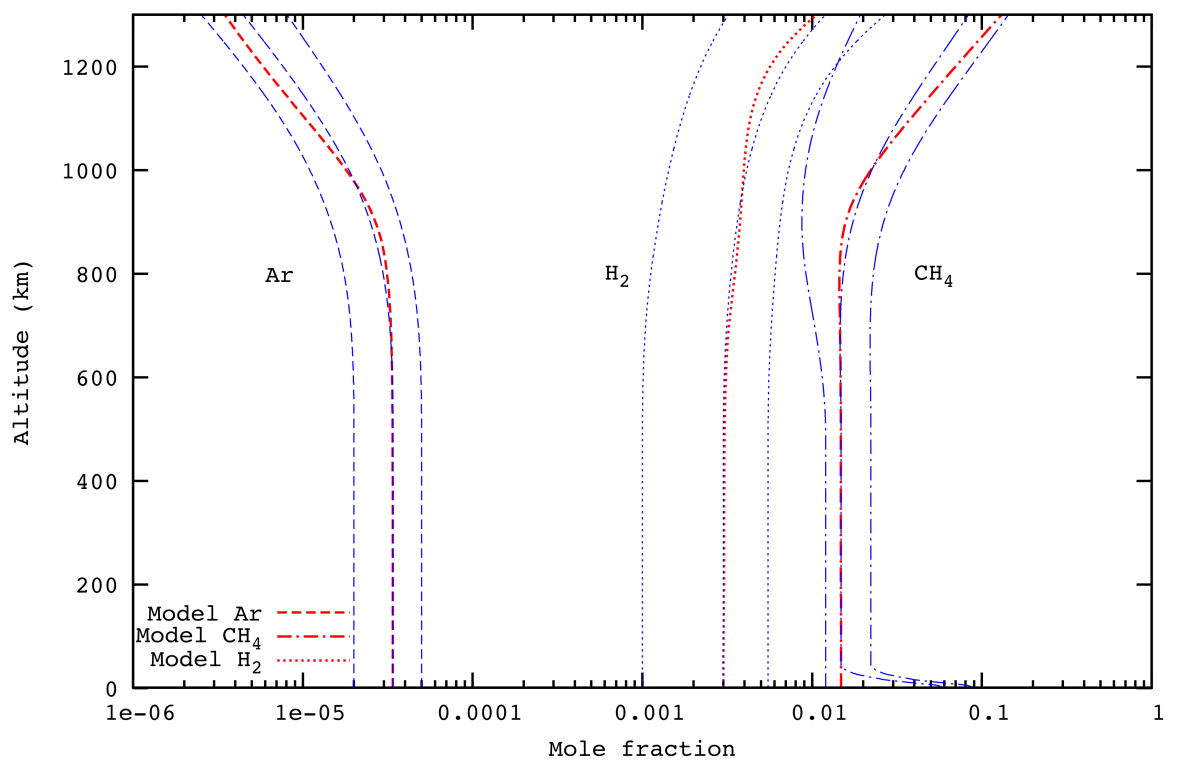

Figure 5: Mole fraction profiles of $\mathrm{Ar}, \mathrm{H}_{2}$ and $\mathrm{CH}_{4}$ from our nominal model (red) and comparison with the engineering model of Waite et al. (2013) (blue) showing the recommended, minimal and maximal profiles. Model uncertainties on our nominal profiles are low and are not presented. 


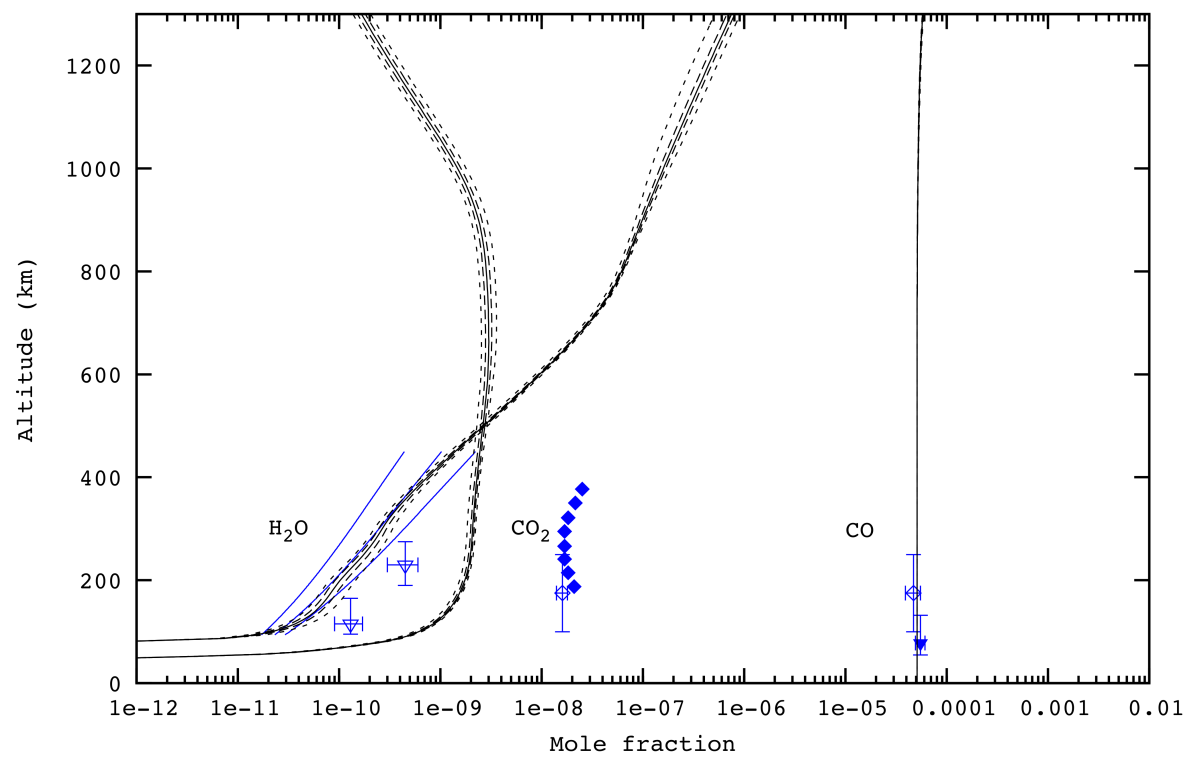

Figure 6: Mole fraction profiles of $\mathrm{H}_{2} \mathrm{O}, \mathrm{CO}_{2}$ and $\mathrm{CO}$ and comparison with some observations. The eddy diffusion coefficient has been constrained in the lower atmosphere to fit the $\mathrm{H}_{2} \mathrm{O}$ observations of Moreno et al. (2012) (see text). Dashed lines and dotted lines give the intervals containing respectively $50 \%$ and $90 \%$ of the abundance profiles. Observations (in blue) of Moreno et al. (2012) (solid lines for mean and 1- $\sigma$ uncertainty), Cottini et al. (2012) (open triangles) for $\mathrm{H}_{2} \mathrm{O}$, observations of $\mathrm{CO}$ and $\mathrm{CO}_{2}$ from de Kok et al. (2007) (open diamonds), $\mathrm{CO}_{2}$ observations from Vinatier et al. (2010) (filled diamonds) and the CO observation of Teanby et al. (2010) (star) are shown for comparison. 

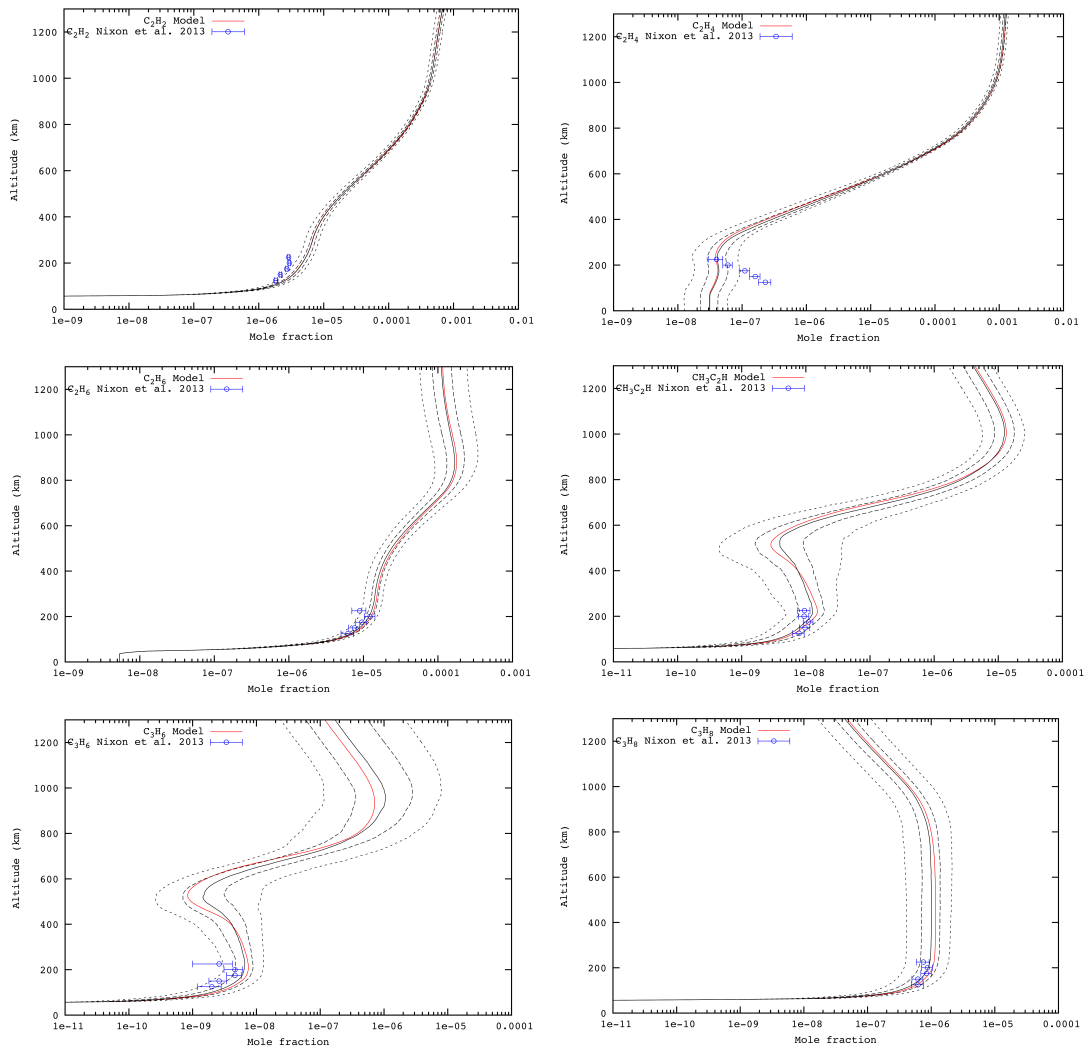

Figure 7: Mole fraction profiles of the main $\mathrm{C}_{2}$ and $\mathrm{C}_{3}$ hydrocarbons and comparison with the recent observations of Nixon et al. (2013) (in blue). Red solid line: Nominal profile. Black solid line: Mean profile. Dashed lines and dotted lines give the intervals containing respectively $50 \%$ and $90 \%$ of the abundance profiles. 
$+\mathrm{N}_{2}$ (Hébrard et al., 2012) and is therefore a net loss of nitrile species. The photodissociation of $\mathrm{HCN}$, which is the main nitrogen containing compound in Titan's atmosphere, leads to the formation of $\mathrm{HC}_{3} \mathrm{~N}$ and $\mathrm{C}_{2} \mathrm{H}_{3} \mathrm{CN} . \mathrm{HC}_{3} \mathrm{~N}$ photodissociates to $\mathrm{H}+\mathrm{C}_{3} \mathrm{~N}$ and as $\mathrm{C}_{3} \mathrm{~N}$ reacts quickly with $\mathrm{CH}_{4}$ (Fournier et al., 2014) gives back $\mathrm{HC}_{3} \mathrm{~N}$. Therefore, $\mathrm{HC}_{3} \mathrm{~N}$ photodissociation is not an efficient destruction pathway of $\mathrm{HC}_{3} \mathrm{~N}$ and does not lead to substantial new chemistry. $\mathrm{C}_{2} \mathrm{H}_{3} \mathrm{CN}$ is easily photodissociated in the UV producing ultimately $\mathrm{HCN}, \mathrm{CH}_{3} \mathrm{CN}$ and $\mathrm{C}_{2} \mathrm{H}_{5} \mathrm{CN}$. The neutral nitrogen chemistry in Titan's atmosphere leads mainly to nitriles because once formed, the triple $\mathrm{CN}$ bond is not easily broken by photodissociation and is not very sensitive to chemical attack except from $\mathrm{N}\left({ }^{2} \mathrm{D}\right)$ which leads to relatively low loss rates. Even if $\mathrm{N}\left({ }^{2} \mathrm{D}\right)$ atom reactions lead to imine formation, the steady state concentrations of imines are low as they absorb and photodissociate in the UV (Teslja et al., 2004). Moreover, in contrast to the ion chemistry of Titan's atmosphere (Yelle et al., 2010), the neutral nitrogen chemistry does not result in significant amine formation.

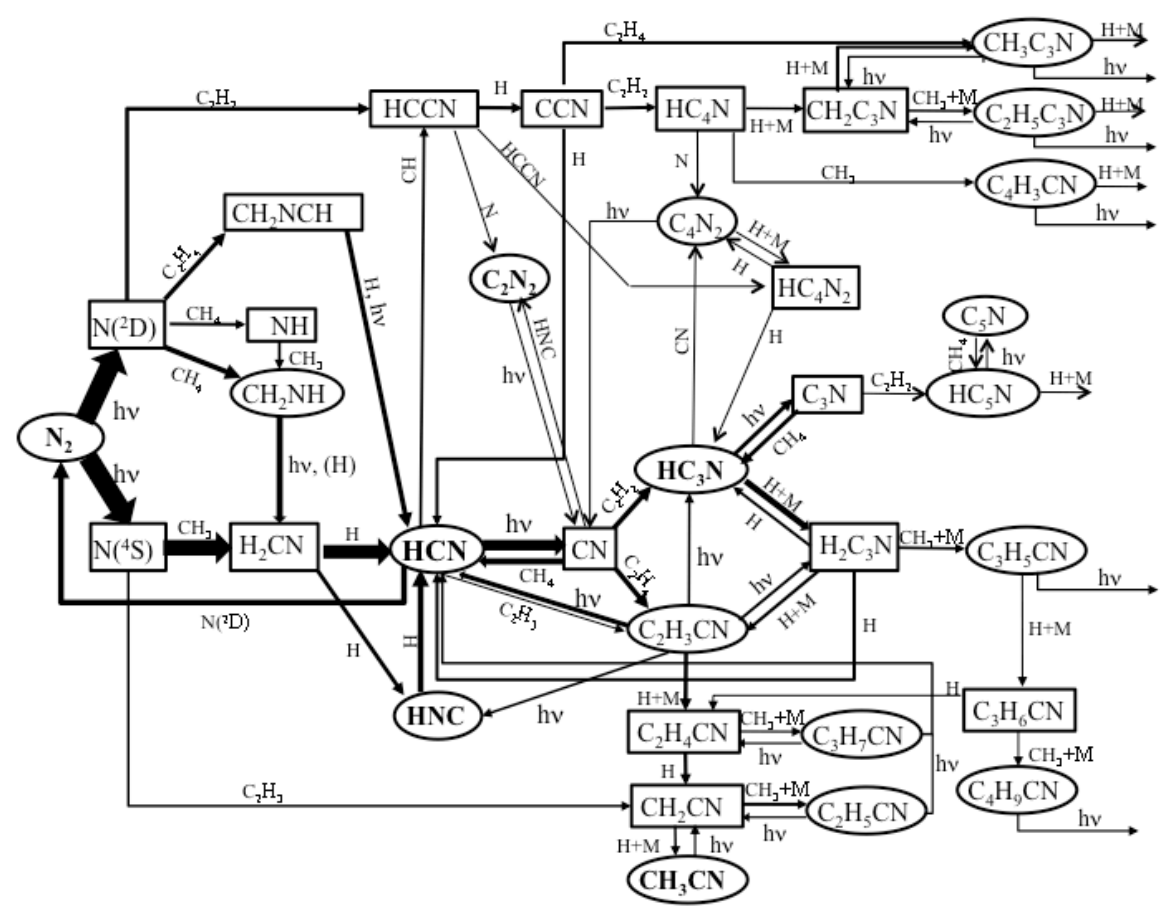

Figure 8: Schematic diagram highlighting the important neutral reaction pathways for the production of the main nitriles and imines. The thickness of each arrow is proportional to the integral of the total production rate over the atmosphere. The reactions of $\mathrm{N}\left({ }^{2} \mathrm{D}\right)$ with $\mathrm{C}_{2} \mathrm{H}_{2}$ and $\mathrm{C}_{2} \mathrm{H}_{4}$ are mainly localized in the upper atmosphere (corresponding roughly to the top part of the figure) whereas association reactions involving $\mathrm{H}$ and $\mathrm{CH}_{3}$ are mainly localized in the stratosphere. For each pathway, the main reactant is given. Compounds that have been detected are highlighted in bold. Radicals are shown in boxes, whereas stable compounds are shown in circles. 


\subsection{Main nitrogen species profiles}

In this section, we present the results of our model for the main nitrogen species in Titan's atmosphere. For each species, we give the nominal mole fraction profiles (with unperturbed rate constants) and the Monte-Carlo profiles generated by our uncertainty propagation procedure. We also summarize for each species the different observations that have been published so far, allowing us to present our current knowledge of the atmospheric composition as well as to highlight the various discrepancies. Our 1D photochemical model is best suited to reproduce averaged profiles located near the equator. Consequently, we emphasize in particular the comparison of our model results with observations which correspond to global average abundances or equatorial profiles. Additionally, we give some details about the main reactions for the production and loss of each species and emphasize the differences with earlier models. A critical review of the rate constants and branching ratios for the different products is presented and the importance of ionic chemistry is discussed when it is considered as important.

\subsubsection{Hydrogen cyanide (HCN)}

Coustenis et al. (1991) inferred from Voyager 1 infrared spectra the vertical distribution of HCN in Titan's North polar region $\left(70^{\circ} \mathrm{N}\right)$. They obtained a mixing ratio of $\left(2.3_{-1.4}^{+1.8}\right) \times 10^{-6}$ at $0.1 \mathrm{mbar}$ (around $300 \mathrm{~km}$ ) and $\left(4.0_{-2.2}^{+2.8}\right) \times 10^{-7}$ at 1.5 mbar (around $170 \mathrm{~km}$ ). High-resolution submillimetric observations performed with the SPIRE instrument on the Herschel satellite allowed Courtin et al. (2011) to derive the HCN stratospheric profile. Their analysis confirms the profile inferred by Marten et al. (2002) from whole-disk millimetric observations. The disk integrated SPIRE observations are mostly sensitive to the equatorial and mid-latitude regions. Analysis of Cassini-CIRS mid infrared limb spectra corresponding to $15^{\circ} \mathrm{S}$ latitude (Vinatier et al., 2007) are also in good agreement with these profiles. Gurwell (2004) conducted interferometric observations of the atmosphere of Titan with the Submillimeter Array to investigate the global average vertical distributions of HCN above the tropopause. The vertical profile of $\mathrm{HCN}$ increases from 30 parts per billion at the condensation altitude $(\sim 83 \mathrm{~km})$ to $5 \mathrm{ppm}$ at $\sim 300 \mathrm{~km}$, in quite close agreement with Marten et al. (2002) in that part of the atmosphere. Koskinen et al. (2011) used stellar occultations observed by the Cassini/UVIS instrument to probe the mesosphere and thermosphere of Titan at altitudes between 400 and $1000 \mathrm{~km}$. They analyzed data obtained between flybys Tb in December 2004 and T58 in July 2009. In particular, they derived the mole fraction of HCN (from small absorption peaks near 142-145 nm) for T41 I flyby which correspond to a latitude of $6^{\circ} \mathrm{S}$. The mole fraction of $\mathrm{HCN}$ decreases with altitude in the mesosphere from around $5.5 \times 10^{-4}$ at $900 \mathrm{~km}$ to $2.0 \times 10^{-5}$ at $55 \mathrm{~km}$. The latter value is one order of magnitude greater than the value obtained by CIRS data at $400 \mathrm{~km}$. The neutral composition of Titan's upper atmosphere between 1000 and 1100 $\mathrm{km}$ has been inferred from the interpretation of Cassini Ion and Neutral Mass Spectrometer (INMS) measurements by Magee et al. (2009). In particular, the 
global average mixing ratio of $\mathrm{HCN}$ at $1050 \mathrm{~km}$ is $(2.44 \pm 0.10) \times 10^{-4}$. Previous interpretation of INMS data from Vuitton et al. (2007) gave a similar abundance of HCN of $2.0 \times 10^{-4}$ at $1100 \mathrm{~km}$, with an uncertainty factor of 2-3. Geballe et al. (2003) detected HCN emission features in a high resolution spectrum near $3 \mu \mathrm{m}$ acquired at the Keck II telescope. These data were re-analyzed by Yelle and Griffith (2003) with a model for fluorescence in the $\nu 3$ band of HCN and by Kim et al. (2005) with an updated model. Their results were in agreement in the upper atmosphere. The HCN mixing ratio is from $(1-3) \times 10^{-3}$ around 1000 $\mathrm{km}$. The density of HCN between 600 and $1000 \mathrm{~km}$ has been also inferred by Shemansky et al. (2005) from observations of stellar occultations by the atmosphere of Titan using the Cassini Ultraviolet Imaging Spectrometer (UVIS). The HCN mixing ratio at $1000 \mathrm{~km}$ is about $4 \times 10^{-3}$. Recently, Adriani et al. (2011) used the limb observations of the Visual and Infrared Mapping Spectrometer (VIMS) onboard the Cassini spacecraft to retrieve vertical profiles of HCN from its $3 \mu \mathrm{m}$ non-LTE emission in the region from 600 to $1100 \mathrm{~km}$ altitude during the daytime. The mixing ratio of $\mathrm{HCN}$ is about $(5.5 \pm 1.5) \times 10^{-3}$ at $1050 \mathrm{~km}$. This result is in agreement with the upper value of the HCN profile derived by Yelle and Griffith (2003) and Kim et al. (2005). HCN has been also detected in Titan's upper atmosphere in the ultraviolet by the UltraViolet Spectrometer (UVS) instrument aboard Voyager 1 (Vervack et al., 2004). The mixing ratio of $\mathrm{HCN}$ is around $10^{-4}$ at $500 \mathrm{~km}$ (about 20 times higher than other observations) and then increases with altitude leading to a value in agreement with all the other observations (but with large uncertainties).

The HCN molecule is the main nitrile in Titan's atmosphere and there is a relatively wide consensus for its main formation and loss pathways (Lavvas et al., 2008a,b; Krasnopolsky, 2009, 2012; Vuitton et al., 2006; Wilson and Atreya, 2004; Hébrard et al., 2012) despite the fact that uni-dimensional models tend to overestimate its abundance. It is efficiently produced through the neutral $\mathrm{N}+\mathrm{CH}_{3} \rightarrow \mathrm{H}_{2} \mathrm{CN}+\mathrm{H}$ reaction followed by the $\mathrm{H}_{2} \mathrm{CN}+\mathrm{H}$ reaction but also from important secondary reactions such as $\mathrm{HNC}+\mathrm{H}, \mathrm{CCN}+\mathrm{H}, \mathrm{H}_{2} \mathrm{C}_{3} \mathrm{~N}$ $+\mathrm{H}$, photodissociations such as $\mathrm{C}_{2} \mathrm{H}_{3} \mathrm{CN}+\mathrm{h} \nu$ and $\mathrm{CH}_{2} \mathrm{NCH}+\mathrm{H}$ and less importantly through ionic reactions (Krasnopolsky, 2009) leading to $\mathrm{HCNH}^{+}$ followed by the dissociative electronic recombination reaction $\mathrm{HCNH}^{+}+\mathrm{e}^{-}$ and proton transfer $\left(\mathrm{HCNH}^{+}+\mathrm{CH}_{2} \mathrm{NH} \rightarrow \mathrm{HCN}+\mathrm{CH}_{2} \mathrm{NH}^{+}, \ldots\right)$. Most of the $\mathrm{N}_{2}$ photodissociation products lead to $\mathrm{HCN}$ formation. As $\mathrm{N}_{2}$ is photolysed in the upper atmosphere, $\mathrm{HCN}$ is mainly produced in the upper atmosphere. The main $\mathrm{HCN}$ loss reaction is photodissociation leading to $\mathrm{H}+\mathrm{CN}$. CN reacts mostly with $\mathrm{CH}_{4}$ and $\mathrm{C}_{2} \mathrm{H}_{6}$ leading back to $\mathrm{HCN}$, acting to recycle back to $\mathrm{HCN}$ and producing $\mathrm{CH}_{3}$ and $\mathrm{C}_{2} \mathrm{H}_{5}$, whilst a small fraction of the $\mathrm{CN}$ radicals react with $\mathrm{C}_{2} \mathrm{H}_{2}$ and $\mathrm{C}_{2} \mathrm{H}_{4}$ leading to $\mathrm{HC}_{3} \mathrm{~N}$ and $\mathrm{C}_{2} \mathrm{H}_{3} \mathrm{CN}$ production. In our previous study of the HNC molecule (Hébrard et al., 2012) we introduced the $\mathrm{N}\left({ }^{2} \mathrm{D}\right)+\mathrm{HCN} \rightarrow \mathrm{CH}+\mathrm{N}_{2}$ reaction which is indeed the main $\mathrm{HCN}$ loss process as $\mathrm{CN}$ reactions mainly give back $\mathrm{HCN}$, either directly through reaction with $\mathrm{CH}_{4}$ and $\mathrm{C}_{2} \mathrm{H}_{6}$, or indirectly through the photodissociation of complex nitriles such as $\mathrm{C}_{2} \mathrm{H}_{3} \mathrm{CN}+\mathrm{h} \nu \rightarrow \mathrm{HCN}+\mathrm{C}_{2} \mathrm{H}_{2}$. One important difference with other recent models is the $\mathrm{C}_{2} \mathrm{H}_{3}+\mathrm{HCN}$ reaction which has been considered to be 
an important source of $\mathrm{C}_{2} \mathrm{H}_{3} \mathrm{CN}$. The rate constant for the $\mathrm{C}_{2} \mathrm{H}_{3}+\mathrm{HCN} \rightarrow$ $\mathrm{C}_{2} \mathrm{H}_{3} \mathrm{CN}+\mathrm{H}$ reaction is generally taken from Monks et al. (1993). However the data of Monks et al. (1993), at room temperature only, are very imprecise and their rate constant for the $\mathrm{C}_{2} \mathrm{H}_{3}+\mathrm{HCN}$ reaction is notably higher than the rate constant of reactions of $\mathrm{C}_{2} \mathrm{H}_{3}$ with unsaturated hydrocarbons (Wang and Frenklach, 1994; Knyazev et al., 1996a; Callear and Smith, 1986; Ismail et al., 2007 ) which is a surprising result as several other atoms and radicals $\left(\mathrm{C}_{2}, \mathrm{C}_{2} \mathrm{H}\right.$, $\mathrm{CN}, \mathrm{OH}, \mathrm{F}, \mathrm{Cl}$ ) are significantly less reactive with HCN (Frost et al., 1986; Hoobler and Leone, 1997; Fukuzawa and Osamura, 1997; Sander et al., 2011) than with unsaturated hydrocarbons (Nesbitt et al., 1994; Li et al., 2006a,b; Paramo et al., 2008; Daugey et al., 2008; Canosa et al., 2007; Lee et al., 2000; Vakhtin et al., 2001c; Sims et al., 1993; Gannon et al., 2007; Atkinson et al., 2004; McKee et al., 2007; Nesbitt et al., 1999; Gu et al., 2006; Mebel et al., 2006; Bouwman et al., 2012; Golden, 2012). We performed theoretical calculations for this reaction finding a barrier in the entrance valley equal to $18.0 \mathrm{~kJ} / \mathrm{mol}$ at the DFT level (M06-2X/cc-pVTZ), in good agreement with Petrie (2002), and classical transition state theory leads to a rate constant equal to $k\left(\mathrm{C}_{2} \mathrm{H}_{3}+\mathrm{HCN}\right)$ $=1.0 \times 10^{-12} \exp (-2300 / T) \mathrm{cm}^{3}$ molecule ${ }^{-1} \mathrm{~s}^{-1}$, a much lower value than Monks et al. (1993). It should be noted also that in their work, Monks et al. (1993) determined a branching ratio for the $\mathrm{CN}+\mathrm{C}_{2} \mathrm{H}_{4} \rightarrow \mathrm{C}_{2} \mathrm{H}_{3} \mathrm{CN}+\mathrm{H}$ equal to $20 \pm 10 \%$ in poor agreement with the recent reliable result of Gannon et al. (2007) leading to $100 \pm 4 \%$.

The use of the new $\mathrm{N}_{2}$ dissociation efficiency derived from Lavvas et al. (2011) gives a simulated HCN abundance in relatively good agreement with Cassini and microwave observations in the lower atmosphere as well as with the value from INMS (Magee et al., 2009) and with the one derived from $\mathrm{HCNH}^{+}$ modeling (Vuitton et al., 2007), but it is smaller than the abundance derived from UV absorption in the upper atmosphere. However, it should be noted that the HCN contribution to UV absorption is low which gives rise to substantial uncertainties. An earlier study (Krasnopolsky, 2009) estimated that the total $\mathrm{HCN}$ production by the $\mathrm{N}^{+}+\mathrm{CH}_{4}$ reaction represents approximately $25 \%$ of the total integrated HCN production in Titan's atmosphere. The inclusion of $\mathrm{N}^{+}$in the form of $\left.\mathrm{N}^{4} \mathrm{~S}\right)$ in the present work takes into account most of this $\mathrm{HCN}$ production. Precise quantification of the role of ionic chemistry requires a fully coupled neutral and ionic chemistry model, but the difference between the simulated and observed abundances in the upper atmosphere is unlikely to originate from ionic chemistry itself. Another possibility is the effect of the meridional circulation. Titan's atmosphere is dominated by global Hadley cells, responsible for an intense stratospheric zonal flow, as computed in the multidimensional treatments by Hourdin et al. (2004) and Rannou et al. (2005). The subsidence of stratospheric air, from altitudes where photochemical production processes are important, leads to the enrichment of the North winter polar region. In contrast, rising air from the troposphere at low latitudes is depleted of condensable species as the temperature at the tropopause is close to $70 \mathrm{~K}$ (see Teanby et al. (2006, 2009); Vinatier et al. (2010)). If meridional circulation and/or depletion are molecule dependent, the use of a unique eddy 
coefficient for all the species may explain the relative disagreement between observations and models for HCN compared to hydrocarbon molecules. It should be noted however that this argument does not seem convincing considering the good agreement between observations and models for $\mathrm{C}_{2} \mathrm{H}_{2}, \mathrm{C}_{2} \mathrm{H}_{4}, \mathrm{C}_{2} \mathrm{H}_{6}, \mathrm{C}_{3} \mathrm{H}_{4}$, $\mathrm{C}_{3} \mathrm{H}_{6}, \mathrm{C}_{3} \mathrm{H}_{8}, \mathrm{CO}_{2}$ and $\mathrm{H}_{2} \mathrm{O}$.
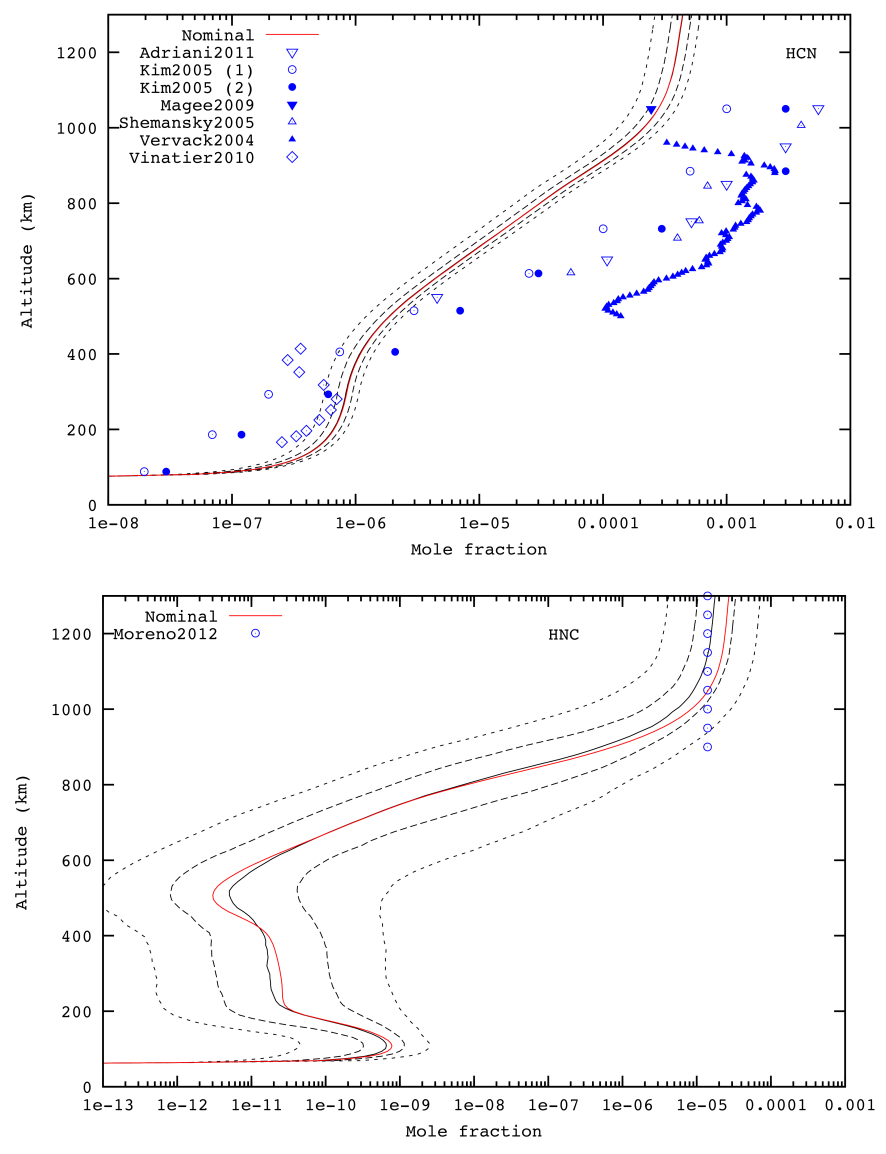

Figure 9: Top: Mole fraction profiles of $\mathrm{HCN}$ and comparison with some observations. Error bars for observations are not depicted for clarity. Bottom: Mole fraction profiles of HNC and comparison with an example of one profile retrieved from Moreno et al. (2011) observations (see also Hébrard et al. (2012)). Dashed lines and dotted lines give the intervals containing respectively $50 \%$ and $90 \%$ of the abundance profiles. See text for references and complementary observations.

\subsubsection{Hydrogen isocyanide (HNC)}

Moreno et al. (2011) reported the first identification of HNC in Titan's atmosphere from observations using the HIFI instrument on the Herschel Space 
Observatory. The column density of HNC inferred from these observations is in the range $(0.6-1.5) \times 10^{13} \mathrm{~cm}^{-2}$ for altitudes between 400 and $1000 \mathrm{~km}$. It was not possible to constrain the vertical profile of HNC from these data since several constant profiles of HNC give a satisfactory agreement with the observations depending on the mixing ratio and the altitude cut-off. As an example, possible profiles are constant mixing ratios of $6.0 \times 10^{-5}$ above $1000 \mathrm{~km}$ or $1.4 \times 10^{-5}$ above $900 \mathrm{~km}$ (see Figure 9 ).

The chemistry of HNC, an isomer of HCN, has been described in detail in a previous study (Hébrard et al., 2012). It is mainly produced by the $\mathrm{H}_{2} \mathrm{CN}+$ $\mathrm{H}$ reaction, as a minor product, the main products being $\mathrm{HCN}+\mathrm{H}_{2}$. Its main loss reaction is thought to be isomerization toward HCN through its reaction with H atoms (Talbi and Ellinger, 1996; Sumathi and Nguyen, 1998; Petrie, 2002). There is likely to be another efficient neutral HNC production mechanism: $\mathrm{C}_{2} \mathrm{H}_{3} \mathrm{CN}$ photodissociation. Indeed, Wilhelm et al. (2009) detected unambiguously $\mathrm{HNC}$ IR emission in their $\mathrm{C}_{2} \mathrm{H}_{3} \mathrm{CN}$ photodissociation experiment at $193 \mathrm{~nm}$ with a $\mathrm{HCN} / \mathrm{HNC}$ ratio equal to 3.34 in good agreement with theoretical calculations from Homayoon et al. (2011) as well as direct HNC absorption by the Chirped-Pulse millimetre-Wave study of $\mathrm{C}_{2} \mathrm{H}_{3} \mathrm{CN}$ photodissociation (Prozument et al., 2013). The dissociative recombination reaction of $\mathrm{HCNH}^{+}$is an efficient source of $\mathrm{HNC}$ as $\mathrm{HCNH}^{+}$is the main ion in Titan's upper atmosphere and the branching ratio for HNC production is estimated to be close to 30\% (Semaniak et al., 2001; Mendes et al., 2012; Barger et al., 2003). However, the situation is more complicated. Indeed, in Titan's upper atmosphere, the $\mathrm{HCNH}^{+}$ion is abundant so that $\mathrm{HNC}$ will react with $\mathrm{HCNH}^{+}$ leading to $\mathrm{HCN}+\mathrm{HCNH}^{+}$products (Cotton et al., 2013). Then, net production of $\mathrm{HNC}$ from this ionic reaction is reduced. Cosmic ray induced nitrogen chemistry is important in the lower stratosphere where the $\mathrm{H}$ atom abundance falls. Then in our model HNC reaches a non negligible concentration around $100-150 \mathrm{~km}$ and as HNC absorbs strongly in the IR in the Cassini window (464 $\mathrm{cm}^{-1}$, Maki and Mellau (2001)), it could be interesting to evaluate the upper limits for this species from Cassini observations.

\subsubsection{Cyanoacetylene $\left(\mathrm{HC}_{3} \mathrm{~N}\right)$}

Coustenis et al. (1991) inferred from Voyager 1 infrared spectra the vertical distribution of $\mathrm{HC}_{3} \mathrm{~N}$ in Titan's north polar region $\left(70^{\circ} \mathrm{N}\right)$. They obtained a mixing ratio of $\left(2.5_{-1.0}^{+1.1}\right) \times 10^{-7}$ at 0.1 mbar (around $300 \mathrm{~km}$ ) and $\left(8.4_{-3.5}^{+3.0}\right) \times 10^{-8}$ at 1.5 mbar (around $170 \mathrm{~km}$ ). Five individual lines of $\mathrm{HC}_{3} \mathrm{~N}$ were measured with the IRAM 30-m telescope by Marten et al. (2002), allowing them to retrieve disk-averaged vertical profiles for $\mathrm{HC}_{3} \mathrm{~N}$ up to $500 \mathrm{~km}$. The mole fraction of $\mathrm{HC}_{3} \mathrm{~N}$ is about $6.0 \times 10^{-8}$ at $500 \mathrm{~km}$ and $3.0 \times 10^{-13}$ at the condensation level (around $70 \mathrm{~km}$ ). Using the Submillimeter Array, Gurwell (2004) performed interferometric observations of the atmosphere of Titan. The $\mathrm{HC}_{3} \mathrm{~N}$ transitions they observed were consistent with the Marten et al. (2002) profile for all the model temperature profiles. Early Cassini infrared observations of Titan from Flasar et al. (2005) confirmed the enhancement of $\mathrm{HC}_{3} \mathrm{~N}$ in northern latitudes. They obtained a mole fraction around $1.0 \times 10^{-9}$ between $30^{\circ} \mathrm{S}$ and $30^{\circ} \mathrm{N}$ and 

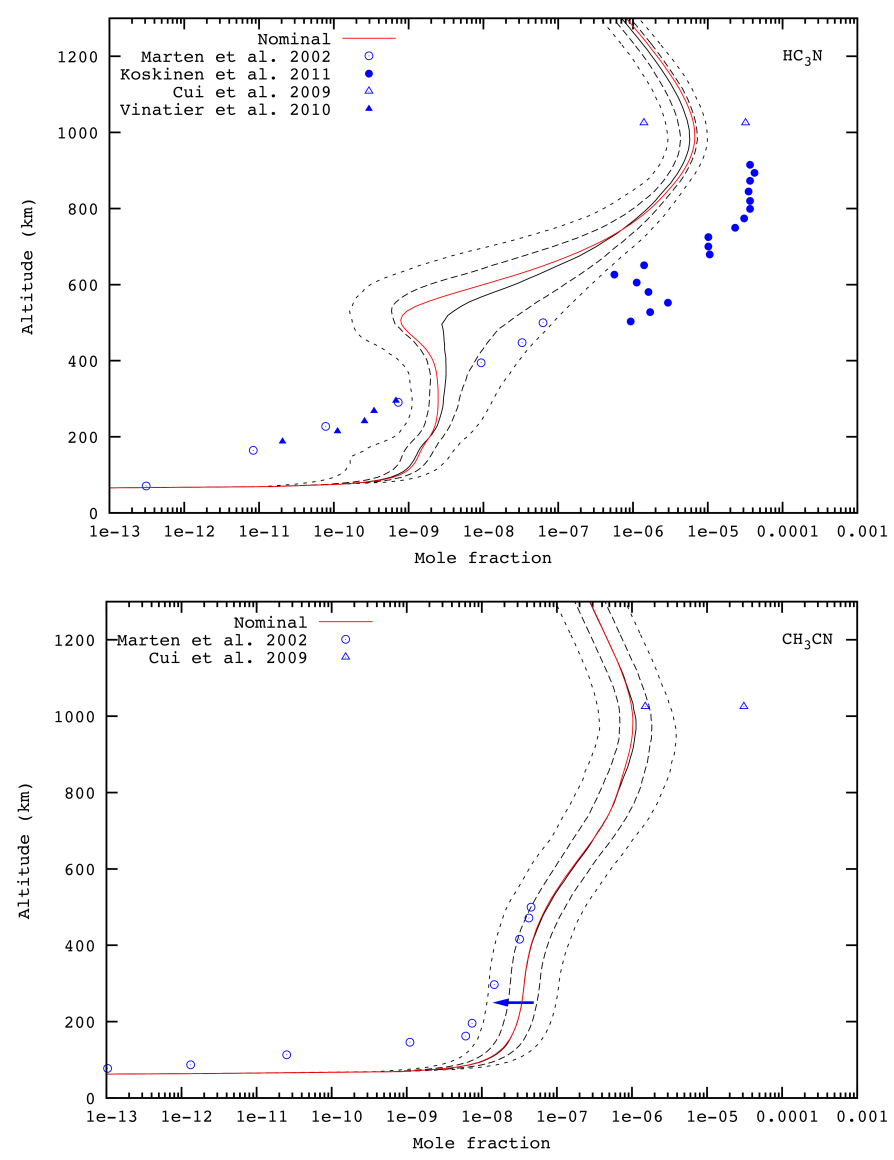

Figure 10: Top: Mole fraction profiles of $\mathrm{HC}_{3} \mathrm{~N}$ and comparison with some observations. Bottom: Mole fraction profiles of $\mathrm{CH}_{3} \mathrm{CN}$ and comparison with some observations. The upper limit of Nixon et al. (2013) at $25^{\circ} \mathrm{S}$ is also given. Both corrected and uncorrected data of Cui et al. (2009) are presented. Dashed lines and dotted lines give the intervals containing respectively $50 \%$ and $90 \%$ of the abundance profiles. See text for references and complementary observations. 
$4.5 \times 10^{-9}$ at $60^{\circ} \mathrm{N}$. Teanby et al. (2006) used mid- and far-infrared spectra from Cassini/CIRS covering three different flybys to infer the vertical profiles of $\mathrm{HC}_{3} \mathrm{~N}$ at different latitudes. They showed that $\mathrm{HC}_{3} \mathrm{~N}$ displays a very sharp increase towards the North Pole, where it has a mixing ratio of around $4.0 \times 10^{-8}$ at $60^{\circ} \mathrm{N}$ at the $0.1 \mathrm{mbar}$ level. Teanby et al. (2007) used mid-infrared limb spectra in the range $600-1400 \mathrm{~cm}^{-1}$ taken with Cassini/CIRS to determine new vertical profiles of $\mathrm{HC}_{3} \mathrm{~N}$ at different latitudes. The profile retrieved from observations at $15^{\circ} \mathrm{S}$ was in agreement with the ground based disc-average profile of Marten et al. (2002). They also observed a large increase in $\mathrm{HC}_{3} \mathrm{~N}$ northward of $60^{\circ} \mathrm{N}$ which was attributed to a subsidence of nitrile rich air from high altitude where it is produced in the mesosphere and thermosphere by photochemical reactions. Vinatier et al. (2010) analysed limb data of Cassini/CIRS acquired during nine different flybys to derive the latitudinal distribution of the $\mathrm{HC}_{3} \mathrm{~N}$ vertical profile in the pressure range $5-0.001$ mbar $(130-500 \mathrm{~km})$. They confirmed that $\mathrm{HC}_{3} \mathrm{~N}$ has a very steep vertical profile, particularly in the southern hemisphere, and an important enrichment toward the North Pole. $\mathrm{HC}_{3} \mathrm{~N}$ has also been detected in the higher atmosphere by UV Voyager data analysis (Vervack et al., 2004) and by Cassini/INMS (Vuitton et al., 2007; Cui et al., 2009; Magee et al., 2009). From INMS/Cassini ion spectra obtained during the T5 flyby, Vuitton et al. (2007) derived a mole fraction of $4.0 \times 10^{-5}$ at $1100 \mathrm{~km}$. Cui et al. (2009) obtained $(1.96 \pm 0.08) \times 10^{-6}$ at $981 \mathrm{~km}$ and $(1.43 \pm 0.06) \times 10^{-6}$ at $1025 \mathrm{~km}$ (or $(3.2 \pm 0.7) \times 10^{-5}$ at $1025 \mathrm{~km}$ correcting for potential wall adsorption/desorption effects). Magee et al. (2009) obtained a value of $(1.48 \pm 0.09) \times 10^{-6}$ at 1050 $\mathrm{km}$ in agreement with the uncorrected value of Cui et al. (2009). UV data allowed Vervack et al. (2004) to study intermediate altitudes between those probed by the Cassini/INMS and Cassini/CIRS instruments. Large error bars were reported by Vervack et al. (2004). They obtained $\mathrm{HC}_{3} \mathrm{~N}$ mole fractions of about $6.0 \times 10^{-6}$ at $850 \mathrm{~km}$ and $4.5 \times 10^{-7}$ at $500 \mathrm{~km}$. Koskinen et al. (2011) used stellar occultations observed by the Cassini/UVIS instrument to probe the mesosphere and thermosphere of Titan at altitudes between 400 and $1000 \mathrm{~km}$. They derived the mole fractions of $\mathrm{HC}_{3} \mathrm{~N}$ from absorption between 142 and $148 \mathrm{~nm}$. The mole fraction of $\mathrm{HC}_{3} \mathrm{~N}$ decreases from $4.0 \times 10^{-5}$ at $900 \mathrm{~km}$ (in agreement with corrected INMS data) to $1.0 \times 10^{-6}$ at $500 \mathrm{~km}$ (about 15 times greater than the value derived by Marten et al. (2002)) .

The main source of the $\mathrm{HC}_{3} \mathrm{~N}$ molecule in our model is the $\mathrm{CN}+\mathrm{C}_{2} \mathrm{H}_{2}$ $\rightarrow \mathrm{HC}_{3} \mathrm{~N}+\mathrm{H}$ reaction, which presents no barrier in the entrance valley (Sims et al., 1993) with a 100\% yield of atomic hydrogen (Gannon et al., 2007). We performed RRKM calculations showing that even at $150 \mathrm{~K}$ the three body association is negligible below 5 Torr in good agreement with the results of Gannon et al. (2007) so that the steep decrease of the $\mathrm{HC}_{3} \mathrm{~N}$ abundance below 200 $\mathrm{km}$ cannot be attributed to the lower relative yield of bimolecular products at higher pressures. As the $\mathrm{HCN}$ concentration is large in the stratosphere and it is not fully shielded by $\mathrm{CH}_{4}$ and $\mathrm{C}_{2} \mathrm{H}_{2}, \mathrm{HCN}$ photolysis is an efficient $\mathrm{HC}_{3} \mathrm{~N}$ production mechanism preventing any decrease at low altitude due to the absence of any new loss processes. $\mathrm{C}_{2} \mathrm{H}_{3} \mathrm{CN}$ photodissociation is a secondary source of $\mathrm{HC}_{3} \mathrm{~N}$ although as the $\mathrm{HCN}+\mathrm{C}_{2} \mathrm{H}_{3}$ reaction has a small rate 
constant, the $\mathrm{C}_{2} \mathrm{H}_{3} \mathrm{CN}$ abundance is lower than in earlier photochemical models so that $\mathrm{HC}_{3} \mathrm{~N}$ production by $\mathrm{C}_{2} \mathrm{H}_{3} \mathrm{CN}$ photodissociation is correspondingly small. The photodissociation of $\mathrm{HC}_{3} \mathrm{~N}$ in Titan's atmosphere leads mainly to $\mathrm{H}+\mathrm{C}_{3} \mathrm{~N}$ (Seki et al., 1996; Luo et al., 2008; Silva et al., 2009), although the photodissociation is thought to be a minor pathway with respect to absorption, leading to metastable $\mathrm{HC}_{3} \mathrm{~N}^{* *}$ formation (Clarke and Ferris, 1995; Seki et al., 1996; Halpern et al., 1988). A new experiment, using the CRESU method, has shown that the experimental rate constant for the $\mathrm{C}_{3} \mathrm{~N}+\mathrm{CH}_{4} \rightarrow \mathrm{HC}_{3} \mathrm{~N}+\mathrm{CH}_{3}$ reaction increases at low temperature (Fournier et al., 2014). As a result, photodissociation does not lead to $\mathrm{HC}_{3} \mathrm{~N}$ loss. $\mathrm{HC}_{3} \mathrm{~N}$ reacts without a barrier with $\mathrm{C}_{2} \mathrm{H}$ and $\mathrm{CN}$ (Cheikh Sid Ely et al., 2013) and very likely also with $\mathrm{N}\left({ }^{2} \mathrm{D}\right)$ but the main $\mathrm{HC}_{3} \mathrm{~N}$ loss process is though the addition of an $\mathrm{H}$ atom followed by the reaction of the $\mathrm{H}_{2} \mathrm{C}_{3} \mathrm{~N}$ adduct with another $\mathrm{H}$ atom leading to $\mathrm{HCN}+\mathrm{C}_{2} \mathrm{H}_{2}$ and $\mathrm{C}_{2} \mathrm{H}_{3} \mathrm{CN}$. For the $\mathrm{H}+\mathrm{HC}_{3} \mathrm{~N}$ reaction we use the $k_{\infty}$ value from Parker et al. (2004). We performed preliminary DFT/RRKM calculations showing a much smaller $k_{0}$ for $\mathrm{H}+\mathrm{HC}_{3} \mathrm{~N}$ than for $\mathrm{H}+\mathrm{C}_{4} \mathrm{H}_{2}$. We use $k_{0}=0.002 \times k_{0}(\mathrm{H}$ $+\mathrm{C}_{4} \mathrm{H}_{2}$ ) (equivalent to $k_{0}(300 \mathrm{~K})=500 \times k_{0}\left(\mathrm{H}+\mathrm{C}_{2} \mathrm{H}_{2}\right)$ ), and $k_{0}\left(\mathrm{H}+\mathrm{C}_{2} \mathrm{H}_{2}\right.$, $\mathrm{C}_{4} \mathrm{H}_{2}$ ) taken from Vuitton et al. (2012). Even if the reaction of $\mathrm{H}$ atoms with $\mathrm{HC}_{3} \mathrm{~N}$ is an efficient pathway for $\mathrm{HC}_{3} \mathrm{~N}$ loss, it leads partly back to $\mathrm{HC}_{3} \mathrm{~N}+\mathrm{H}_{2}$ (by comparison with $\mathrm{H}+\mathrm{C}_{2} \mathrm{H}_{3}$ ) and partly back to $\mathrm{HCN}$ and $\mathrm{C}_{2} \mathrm{H}_{3} \mathrm{CN}$ which both give back some $\mathrm{HC}_{3} \mathrm{~N}$. Polymerization cannot be invoked to explain the sharp decrease of $\mathrm{HC}_{3} \mathrm{~N}$ below $400 \mathrm{~km}$ as reactions with radicals are already included in the model and reactions with molecules such as $\mathrm{HCN}$ and $\mathrm{C}_{2} \mathrm{H}_{2}$ involve high energy transition states (Smith et al., 2001) considering $\mathrm{HC}_{3} \mathrm{~N}$ in its ground state. Moreover, the low temperature associated with the low density of $\mathrm{HC}_{3} \mathrm{~N}$ lead to a very improbable concerted trimerization (or polymerization), which has been observed for $\mathrm{CH}_{3} \mathrm{CHO}$ in the gas phase leading to paraldehyde (Busfield et al., 1973; Zhu et al., 2008). It should be noted however that, as for $\mathrm{C}_{4} \mathrm{H}_{2}$ (Zwier and Allen, 1996), the reactivity may be enhanced for $\mathrm{HC}_{3} \mathrm{~N}$ in excited electronic or vibrational states, which should be the main products of the interaction of $\mathrm{HC}_{3} \mathrm{~N}$ with photons (Clarke and Ferris, 1995; Seki et al., 1996; Halpern et al., 1988). Another possible explanation for the decrease of $\mathrm{HC}_{3} \mathrm{~N}$ below $400 \mathrm{~km}$ is the effect of the meridional circulation if the depletion of the rising air coming from the tropopause is molecule dependent as suggested by Hourdin et al. (2004) who found that the altitude level at which species are removed by condensation controls a large fraction of the magnitude of equatorial stratospheric depletion. However, this behaviour should also apply to other easily condensable species. Another possibility may be the sticking of $\mathrm{HC}_{3} \mathrm{~N}$ on aerosols (Liang et al., 2007) but in this case the sticking should also apply to polar (like $\mathrm{HCN}, \mathrm{H}_{2} \mathrm{O}$ ) or easily polarizable molecules.

\subsubsection{Acetonitrile $\left(\mathrm{CH}_{3} \mathrm{CN}\right)$}

The $\mathrm{CH}_{3} \mathrm{CN}(12-11)$ rotational line has been detected in 1999 by Marten et al. (2002) using the IRAM 30-m telescope. They obtained a disk-averaged vertical profile of $\mathrm{CH}_{3} \mathrm{CN}$ from the condensation level up to $500 \mathrm{~km}$ (mostly representative of the equatorial region of Titan). The mixing ratio of $\mathrm{CH}_{3} \mathrm{CN}$ 
reaches $4.0 \times 10^{-8}$ at $450 \mathrm{~km}$ for instance, comparable to $\mathrm{HC}_{3} \mathrm{~N}$ but 10 times lower than HCN (two compounds also detected by Marten et al. (2002)). Nixon et al. (2013) reported the search for $\mathrm{CH}_{3} \mathrm{CN}$ using the CIRS/Cassini instrument for 3 different flybys between May 2009 and September 2010. They obtained the following mole fraction upper limits: $49 \mathrm{ppb}$ at $25^{\circ} \mathrm{S}$ and $0.27 \mathrm{mbar}(\sim 250$ $\mathrm{km}), 660 \mathrm{ppb}$ at $76^{\circ} \mathrm{N}$ and $0.018 \mathrm{mbar}(\sim 385 \mathrm{~km}), 53 \mathrm{ppb}$ at $76^{\circ} \mathrm{N}$ and $0.3 \mathrm{mbar}$ $(\sim 240 \mathrm{~km})$. Interpretation of INMS/Cassini spectra performed by Vuitton et al. (2007) allowed the detection of $\mathrm{CH}_{3} \mathrm{CN}$ in the ionosphere. From an ionospheric model, they obtained a mole fraction at $1100 \mathrm{~km}$ equal to $3.0 \times 10^{-6}$ (with an estimated uncertainty factor of 3). Cui et al. (2009) proposed an average value of $3.0 \times 10^{-5}$ around $1100 \mathrm{~km}$ from the INMS/Cassini analysis of 15 flybys, arguing that some important reactions were probably missing in Vuitton et al. (2007). On the other hand, Magee et al. (2009) did not include $\mathrm{CH}_{3} \mathrm{CN}$ in their analysis of INMS data.

The $\mathrm{CH}_{3} \mathrm{CN}$ molecule is not produced in our model by the $\mathrm{N}\left({ }^{2} \mathrm{D}\right)+\mathrm{C}_{2} \mathrm{H}_{4}$ reaction but through the association reaction $\mathrm{H}+\mathrm{CH}_{2} \mathrm{CN}$ (Balucani et al., 2012; Lee et al., 2011). We calculated the rate constant from our semi-empirical model for association reactions (Hébrard et al., 2013), the $\mathrm{CH}_{2} \mathrm{CN}$ radical being produced by the $\mathrm{H}+\mathrm{C}_{2} \mathrm{H}_{4} \mathrm{CN}$ reaction (this work, $\mathrm{C}_{2} \mathrm{H}_{4} \mathrm{CN}$ itself being the product of the $\mathrm{H}+\mathrm{C}_{2} \mathrm{H}_{3} \mathrm{CN}$ association) and the $\mathrm{N}+\mathrm{C}_{2} \mathrm{H}_{3}$ reaction (Payne et al., 1996). The main loss reactions are photodissociation (we consider a similar low reactivity with $\mathrm{C}_{2} \mathrm{H}_{3}$ as for $\mathrm{HCN}$ and the reaction between $\mathrm{C}_{2} \mathrm{H}$ and $\mathrm{CH}_{3} \mathrm{CN}$ presents a notable barrier (Nizamov and Leone, 2004a,b)). The simulated $\mathrm{CH}_{3} \mathrm{CN}$ abundance is slightly higher than the one obtained by microwave observations and is less than the upper atmospheric observations, although most of the observations fall within the uncertainty range of the simulations. As outlined above this small difference could originate from the same low latitude stratospheric depletion of condensable species as for $\mathrm{HCN}$ and $\mathrm{HC}_{3} \mathrm{~N}$.

\subsubsection{Propionitrile $\left(\mathrm{C}_{2} \mathrm{H}_{5} \mathrm{CN}\right)$}

Marten et al. (2002) proposed an upper limit of $2.0 \times 10^{-9}$ from millimeter heterodyne observations obtained with the IRAM 30-m telescope for altitudes between 100 and $300 \mathrm{~km}$ and de Kok et al. (2008) estimated an upper limit of $8.0 \times 10^{-9}$ for latitudes above $70^{\circ} \mathrm{N}$. The detection of $\mathrm{C}_{2} \mathrm{H}_{5} \mathrm{CNH}^{+}$at $74^{\circ} \mathrm{N}$ and $1100 \mathrm{~km}$ was reported by Vuitton et al. (2007) from the Cassini/INMS ions spectrum obtained during the Cassini T5 flyby. From the analysis of the mass spectrum, they inferred a mole fraction of $\mathrm{C}_{2} \mathrm{H}_{5} \mathrm{CN}$ equal to $5.0 \times 10^{-7} \cdot \mathrm{C}_{2} \mathrm{H}_{5} \mathrm{CN}$ was excluded from the spectral analysis of Cui et al. (2009). In contrast, Magee et al. (2009) reported a mixing ratio of $(1.54 \pm 0.48) \times 10^{-7}$ at $1050 \mathrm{~km}$.

Our model clearly overestimates the production of $\mathrm{C}_{2} \mathrm{H}_{5} \mathrm{CN}$ in the lower atmosphere, as well as in the upper atmosphere although it is in agreement with the value derived from ionic spectra by Vuitton et al. (2007). We ignore ionic chemistry which likely acts as a sink for this compound. The most probable reactions are the following: $\mathrm{C}_{2} \mathrm{H}_{5} \mathrm{CN}+\mathrm{HCNH}^{+} \rightarrow \mathrm{C}_{2} \mathrm{H}_{5} \mathrm{CNH}^{+}+\mathrm{HCN}$ followed by $\mathrm{C}_{2} \mathrm{H}_{5} \mathrm{CNH}^{+}+\mathrm{e}^{-}$which is unlikely to give $100 \%$ of $\mathrm{C}_{2} \mathrm{H}_{5} \mathrm{CN}+\mathrm{H}$ products. However ionic chemistry is unlikely to explain the large overestimation in the 
lower atmosphere. The main source of $\mathrm{C}_{2} \mathrm{H}_{5} \mathrm{CN}$ is the association reaction between $\mathrm{CH}_{2} \mathrm{CN}$ and $\mathrm{CH}_{3}$, and is then directly correlated to $\mathrm{CH}_{3} \mathrm{CN}$ production. The main loss processes are photodissociation and reaction with $\mathrm{C}_{2} \mathrm{H}$. The rate constant for the $\mathrm{C}_{2} \mathrm{H}+\mathrm{C}_{2} \mathrm{H}_{5} \mathrm{CN}$ reaction is estimated to be similar to the one for the $\mathrm{C}_{2} \mathrm{H}+\mathrm{C}_{2} \mathrm{H}_{6}$ reaction. The $\mathrm{C}_{2} \mathrm{H}+\mathrm{CH}_{3} \mathrm{CN}$ rate constant (Nizamov and Leone, 2004a,b) is similar to the $\mathrm{C}_{2} \mathrm{H}+\mathrm{CH}_{4}$ rate constant (Paramo et al., 2008; Richardson and Francisco, 1994; Matsugi et al., 2010; Canosa et al., 2007; Horner et al., 1995) indicating little effect of the -CN group. We consider a similar low reactivity with $\mathrm{C}_{2} \mathrm{H}_{3}$ as for $\mathrm{HCN}$. The calculated $\mathrm{C}_{2} \mathrm{H}_{5} \mathrm{CN}$ abundance is two orders of magnitude higher than the upper limit derived from microwave observations. There is little doubt regarding the relative $\mathrm{CH}_{2} \mathrm{CN}+\mathrm{H}+\mathrm{M} \rightarrow$ $\mathrm{CH}_{3} \mathrm{CN}+\mathrm{M}$ and $\mathrm{CH}_{2} \mathrm{CN}+\mathrm{CH}_{3}+\mathrm{M} \rightarrow \mathrm{C}_{2} \mathrm{H}_{5} \mathrm{CN}+\mathrm{M}$ rate constants leading to similar $\mathrm{CH}_{3} \mathrm{CN}$ and $\mathrm{C}_{2} \mathrm{H}_{5} \mathrm{CN}$ production fluxes. However, the absorption cross section of $\mathrm{C}_{2} \mathrm{H}_{5} \mathrm{CN}$ is not well known (we use Kanda et al. (1999)) and may be larger for $\mathrm{C}_{2} \mathrm{H}_{5} \mathrm{CN}$ than for $\mathrm{CH}_{3} \mathrm{CN}$ as indicated by EOM-CCSD(T) calculations. There is a clear need for measurements of the cross section for $\mathrm{C}_{2} \mathrm{H}_{5} \mathrm{CN}$ to get a reliable modeled abundance. Moreover, in a similar manner to $\mathrm{CH}_{3} \mathrm{CN}$ and $\mathrm{HC}_{3} \mathrm{~N}$, the low latitude stratospheric depletion of condensable species may also play a role. in this case, $\mathrm{C}_{2} \mathrm{H}_{5} \mathrm{CN}$ could show a large enrichment near the North pole (although this has not yet been observed with an upper limit estimated to $8.0 \times 10^{-9}$ for latitudes above $70^{\circ} \mathrm{N}$ (de Kok et al., 2008)) . Khanna (2005) proposed that $\mathrm{C}_{2} \mathrm{H}_{5} \mathrm{CN}$ could be one of the main components of the Haze B layer (the definition of the Haze B layer can be found in de Kok et al. (2007)). Despite the good agreement between the laboratory infrared band of $\mathrm{C}_{2} \mathrm{H}_{5} \mathrm{CN}$ ice and the $221 \mathrm{~cm}^{-1}$ band of Haze $\mathrm{B}, \mathrm{C}_{2} \mathrm{H}_{5} \mathrm{CN}$ cannot be the only component of Haze $\mathrm{B}$ as the $100 \mathrm{~cm}^{-1}$ infrared band of $\mathrm{C}_{2} \mathrm{H}_{5} \mathrm{CN}$ ice, corresponding to a lattice vibration, is not present in Cassini observations (de Kok et al., 2008). However, this lattice vibration of pure $\mathrm{C}_{2} \mathrm{H}_{5} \mathrm{CN}$ ice will be strongly affected in the case of mixed ices $\left(\mathrm{C}_{2} \mathrm{H}_{5} \mathrm{CN}, \mathrm{HC}_{3} \mathrm{~N}, \mathrm{HCN}, \mathrm{C}_{4} \mathrm{~N}_{2}\right.$ being most probable candidates).

\subsubsection{Acrylonitrile $\left(\mathrm{C}_{2} \mathrm{H}_{3} \mathrm{CN}\right)$}

Marten et al. (2002) proposed an upper limit of $2.0 \times 10^{-9}$ from millimeter heterodyne observations obtained with the IRAM 30-m telescope for altitudes between 100 and $300 \mathrm{~km}$. Analysis of Cassini/INMS spectra acquired during several different flybys allowed Cui et al. (2009) to derive an upper limit of $4.0 \times 10^{-7}$ at $1025 \mathrm{~km}$ (or a corrected value of $1.8 \times 10^{-5}$ at $1077 \mathrm{~km}$ ). Magee et al. (2009) obtained a mixing ratio of $(3.46 \pm 0.51) \times 10^{-7}$ at $1050 \mathrm{~km}$. It should be noted than the value derived from ionic spectra by Vuitton et al. $(2007)$ is $1.0 \times 10^{-5}$ at $1100 \mathrm{~km}$.

In the middle atmosphere, we obtain a great diversity of profiles from our uncertainty propagation procedure. This result shows that many chemical pathways are possible due to the current uncertainties in rate constants. The main source of the $\mathrm{C}_{2} \mathrm{H}_{3} \mathrm{CN}$ molecule in our nominal model is the $\mathrm{CN}+\mathrm{C}_{2} \mathrm{H}_{4} \rightarrow$ $\mathrm{C}_{2} \mathrm{H}_{3} \mathrm{CN}+\mathrm{H}$ reaction which shows no barrier in the entrance valley (Sims et al., 1993) with $100 \%$ of $\mathrm{H}$ production (Gannon et al., 2007). There are also 

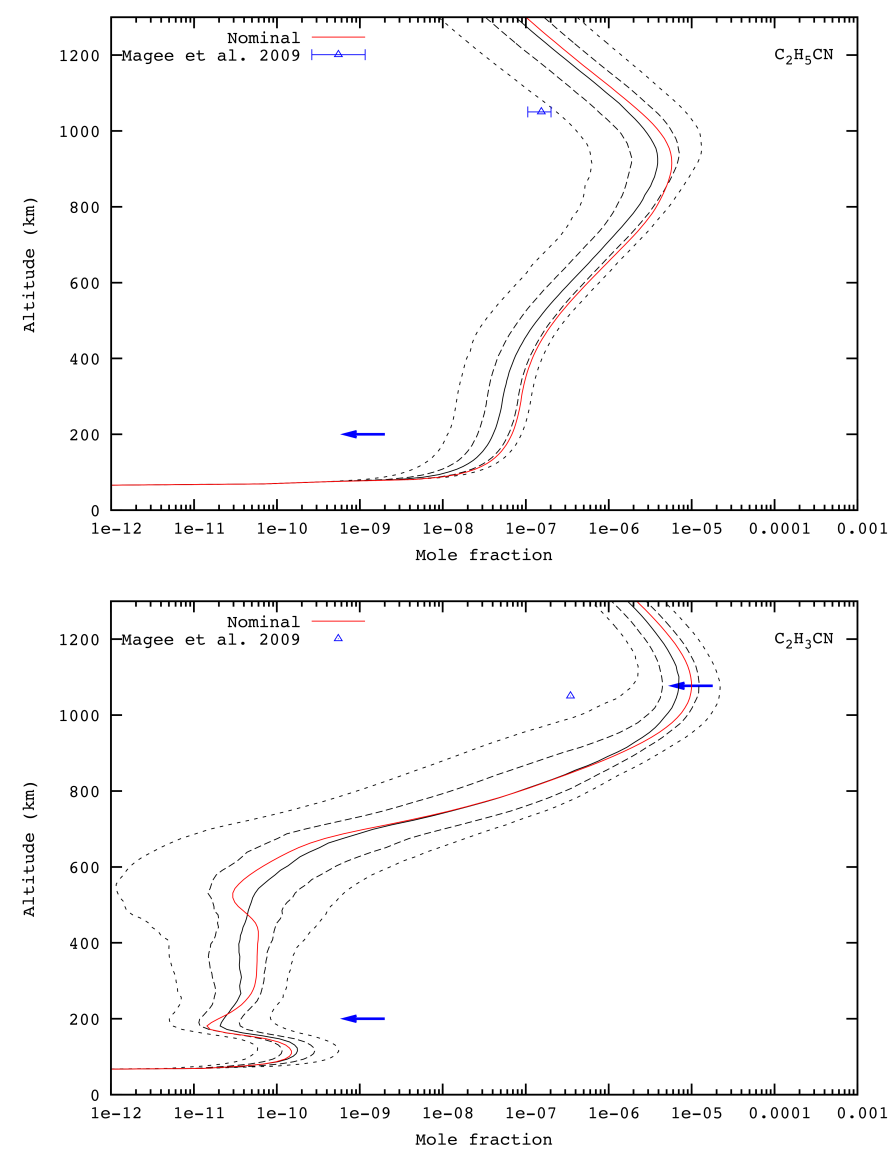

Figure 11: Top: Mole fraction profiles of $\mathrm{C}_{2} \mathrm{H}_{5} \mathrm{CN}$ and comparison with INMS observations. The upper limit of Marten et al. (2002) in the lower atmosphere is presented. Bottom: Mole fraction profiles of $\mathrm{C}_{2} \mathrm{H}_{3} \mathrm{CN}$ and comparison with INMS observations. Upper limit of Cui et al. (2009) in the higher atmosphere and Marten et al. (2002) in the lower atmosphere are presented. Dashed lines and dotted lines give the intervals containing respectively $50 \%$ and $90 \%$ of the abundance profiles. See text for references and complementary observations. 
two secondary sources, the reactions $\mathrm{H}+\mathrm{HC}_{3} \mathrm{~N}+\mathrm{M} \rightarrow \mathrm{H}_{2} \mathrm{C}_{3} \mathrm{~N}+\mathrm{M}$ followed by $\mathrm{H}+\mathrm{H}_{2} \mathrm{C}_{3} \mathrm{~N}+\mathrm{M} \rightarrow \mathrm{C}_{2} \mathrm{H}_{3} \mathrm{CN}+\mathrm{M}$, which are efficient in the stratosphere, and the $\mathrm{C}_{2} \mathrm{H}_{3}+\mathrm{HCN}$ reaction (relatively minor considering the newly reduced rate constant calculated by a classical TST calculation in compared with the previous estimation from Monks et al. (1993)). The main loss process is photodissociation leading to $\mathrm{HCN}+\mathrm{C}_{2} \mathrm{H}_{2}, \mathrm{HNC}+\mathrm{C}_{2} \mathrm{H}_{2}, \mathrm{HC}_{3} \mathrm{~N}+\mathrm{H}_{2}$ and $\mathrm{H}_{2} \mathrm{C}_{3} \mathrm{~N}+\mathrm{H}$ (see Appendix B) and also reaction with $\mathrm{H}$ atoms leading to $\mathrm{C}_{2} \mathrm{H}_{4} \mathrm{CN}$ adduct formation. The rate constants for $\mathrm{H}$ atom addition are taken to be equal to $k_{\infty}=k_{\infty}\left(\mathrm{H}+\mathrm{C}_{2} \mathrm{H}_{4}\right)$ and $k_{0}=10 \times k_{0}\left(\mathrm{H}+\mathrm{C}_{2} \mathrm{H}_{4}\right)$ (Vuitton et al., 2012) considering the height of the entrance barrier calculated at the M06-2X/cc-pVTZ level and the size of the system. As $\mathrm{C}_{2} \mathrm{H}_{4} \mathrm{CN}$ should react quickly with $\mathrm{H}$ atoms leading to $\mathrm{CH}_{3}+\mathrm{CH}_{2} \mathrm{CN}$, the $\mathrm{H}+\mathrm{C}_{2} \mathrm{H}_{3} \mathrm{CN}$ reaction is a net $\mathrm{C}_{2} \mathrm{H}_{3} \mathrm{CN}$ loss.

\subsubsection{Cyanogen $\left(C_{2} N_{2}\right)$}

Coustenis et al. (1991) inferred from Voyager 1 infrared spectra the vertical distribution of $\mathrm{C}_{2} \mathrm{~N}_{2}$ in Titan's North polar region $\left(70^{\circ} \mathrm{N}\right)$. They obtained a mixing ratio of $\left(1.6_{-1.0}^{+2.6}\right) \times 10^{-8}$ at $0.1 \mathrm{mbar}$ (around $300 \mathrm{~km}$ ) and $\left(5.5_{-2.2}^{+5.0}\right) \times 10^{-9}$ at $1.5 \mathrm{mbar}$ (around $170 \mathrm{~km}$ ). Analysing several Voyager 1 infrared spectral averages covering Titan's disk from $53^{\circ} \mathrm{S}$ to $70^{\circ} \mathrm{N}$, Coustenis and Bezard (1995) detected $\mathrm{C}_{2} \mathrm{~N}_{2}$ near the North Pole but not at latitudes southward of $50^{\circ} \mathrm{N}$. These observations suggest at least a tenfold enhancement in the $\mathrm{C}_{2} \mathrm{~N}_{2}$ mole fraction. They inferred a mole fraction upper limit of about $1.5 \times 10^{-9}$ near the equator around $18 \mathrm{mbar}$ ( $80 \mathrm{~km}$ of altitude) and a mole fraction of $(1.5 \pm$ $0.2) \times 10^{-8}$ and $(2.2 \pm 0.3) \times 10^{-8}$ at $50^{\circ} \mathrm{N}$ and $70^{\circ} \mathrm{N}$ respectively. Teanby et al. (2006) detected $\mathrm{C}_{2} \mathrm{~N}_{2}$ from Cassini/CIRS data. They obtained a value of around $9.0 \times 10^{-10}$ at $48^{\circ} \mathrm{N}$ at the 3 mbar level (145 km of altitude) and $1-\sigma$ upper limits of $5.0 \times 10^{-10}$ at $30^{\circ} \mathrm{S}$ and $30^{\circ} \mathrm{N}$. Teanby et al. (2009) used four years of far-IR data from Cassini/CIRS to provide measurements of $\mathrm{C}_{2} \mathrm{~N}_{2}$ in Titan's atmosphere. The $\mathrm{C}_{2} \mathrm{~N}_{2}$ mole fraction reaches a maximum value of $3.5 \times 10^{-9}$ in Titan's northern hemisphere around a pressure level of 10 mbar $(100 \mathrm{~km}$ of altitude). At southern and equatorial latitudes they find average mole fractions of $(5.5 \pm 1.4) \times 10^{-11}$ from limb data and $(6 \pm 3) \times 10^{-11}$ from nadir data (with a 3 - $\sigma$ upper limit of $<17 \times 10^{-11}$ from nadir data). From Cassini/INMS data, Cui et al. (2009) inferred a $\mathrm{C}_{2} \mathrm{~N}_{2}$ mixing ratio of $(1.70 \pm 0.07) \times 10^{-6}$ at $1025 \mathrm{~km}$ (or $(4.8 \pm 0.8) \times 10^{-5}$ at $1077 \mathrm{~km}$ correcting for possible wall adsorption/desorption effects) and Magee et al. (2009) obtained a value of $(2.14 \pm 0.12) \times 10^{-6}$ at 1050 $\mathrm{km}$.

The model slightly overestimate the $\mathrm{C}_{2} \mathrm{~N}_{2}$ abundance at low altitude with a strong influence of cosmic rays, and underestimate the $\mathrm{C}_{2} \mathrm{~N}_{2}$ abundance at high altitude. The measured $\mathrm{C}_{2} \mathrm{~N}_{2}$ abundances in the upper atmosphere are uncertain although no error bars were associated with these observations. The $\mathrm{C}_{2} \mathrm{~N}_{2}$ molecule is mainly produced in our model by the reactions $\mathrm{N}+\mathrm{HCCN}$ and $\mathrm{CN}+\mathrm{HNC}$. There is no experimental or theoretical information for the $\mathrm{N}+$ HCCN reaction which should not show any barrier as a radical-radical reaction, forming in first step the $\mathrm{NC}(\mathrm{H}) \mathrm{CN}$ adduct which should lead to $\mathrm{HCN}+\mathrm{CN}$ and $\mathrm{H}+\mathrm{C}_{2} \mathrm{~N}_{2}$ products, a part of $\mathrm{HCN}$ will likely isomerize into $\mathrm{HNC}$ due to 
the large amount of internal HCN energy. We estimated the rate constant using capture theory (rate constant similar to the $\mathrm{N}+\mathrm{CH}_{2}$ reaction which is also a quadruplet + triplet reaction), the branching ratio being in favor of $\mathrm{C}_{2} \mathrm{~N}_{2}$ due to the larger exothermicity. For the $\mathrm{CN}+\mathrm{HNC}$ reaction we also considered a rate constant given by capture rate theory as Petrie and Osamura (2004) found no barrier in the entrance valley. It should be noted that the $\mathrm{CN}+\mathrm{HCN}$ reaction is not an efficient way to produce $\mathrm{C}_{2} \mathrm{~N}_{2}$ due to the low rate constant (Zabarnick, 1989; Yang et al., 1992a,b). The main losses of $\mathrm{C}_{2} \mathrm{~N}_{2}$ are through photodissociation. The reaction with $\mathrm{H}$ atoms needs to be considered. Basiuk and Kobayashi (2004) found a barrier equal to $14 \mathrm{~kJ} / \mathrm{mol}$ for $\mathrm{H}$ atom addition but DFT calculations (M06-2X/cc-pVTZ) lead to a barrier equal to $30 \mathrm{~kJ} / \mathrm{mol}$. There is one experimental measurement at $300 \mathrm{~K}$ (Phillips, 1978) leading to $0.01 \times k\left(\mathrm{H}+\mathrm{C}_{2} \mathrm{H}_{2}\right)$ but at $150 \mathrm{~K}$ the reaction occurs mostly by tunneling. We propose $k_{0}$ and $k_{\infty}=0.1 \times k_{\infty}\left(\mathrm{H}+\mathrm{C}_{2} \mathrm{H}_{2}\right)$ from Vuitton et al. (2012), taking into account the higher TS in the entrance valley and the smaller $\Delta H_{r}$. There are large uncertainties associated with this rate constant but $\mathrm{H}+\mathrm{C}_{2} \mathrm{~N}_{2}$ is likely to be a minor loss process.

\subsubsection{Dicyanoacetylene $\left(C_{4} N_{2}\right)$}

Samuelson et al. (1997) detected $\mathrm{C}_{4} \mathrm{~N}_{2}$ ice from IRIS/Voyager observations. The non-detection of gaseous $\mathrm{C}_{4} \mathrm{~N}_{2}$ allowed them to determine an upper limit of $4.0 \times 10^{-10}$ for the vapour mole fraction above the cloud top located at 90 $\mathrm{km}$. Khlifi et al. (1997) obtained also from IRIS/Voyager data an upper limit of $5.6 \times 10^{-9}$. More recently, using CIRS/Cassini observations, de Kok et al. (2008) obtained an upper limit of $9.0 \times 10^{-9}$.

The mean profile and the nominal profile do not overlap at some altitudes because the distributions of the logarithm of the mole fractions at these altitudes are not symmetric with the existence of a kind of a bimodal distribution. The $\mathrm{C}_{4} \mathrm{~N}_{2}$ molecule is mainly produced by the $\mathrm{N}+\mathrm{HC}_{4} \mathrm{~N}$ and $\mathrm{CN}+\mathrm{HC}_{3} \mathrm{~N}$ reactions as well as by the reactions $\mathrm{HCCN}+\mathrm{HCCN} \rightarrow \mathrm{H}+\mathrm{HC}_{4} \mathrm{~N}_{2}$ followed by $\mathrm{H}+$ $\mathrm{HC}_{4} \mathrm{~N}_{2} \rightarrow \mathrm{H}_{2}+\mathrm{C}_{4} \mathrm{~N}_{2}$. The $\mathrm{CN}+\mathrm{HC}_{3} \mathrm{~N}$ reaction has been recently studied at low temperature (Cheikh Sid Ely et al., 2013) leading to a high value of the rate constant at low temperature. There is no information for the $\mathrm{N}+\mathrm{HC}_{4} \mathrm{~N}$ and $\mathrm{HCCN}+\mathrm{HCCN}$ reactions but as they are radical-radical reactions (similar to like $\mathrm{N}+\mathrm{CH}_{2}$ and $\mathrm{N}+\mathrm{HCCN}$ reactions, all being quadruplet + triplet reactions) they should not show any barrier in the entrance valley. The rate of the HCCN + HCCN reaction includes a steric hindrance factor by comparison with alkyl + alkyl reactions (Klippenstein et al., 2006). As the $\mathrm{HC}_{4} \mathrm{~N}+\mathrm{H}$ reaction has no exothermic bimolecular exit channel, $\mathrm{HC}_{4} \mathrm{~N}$, produced through the quick $\mathrm{CCN}+\mathrm{C}_{2} \mathrm{H}_{2}$ reaction (Zhu et al., 2003a; Wang et al., 2006), reaches a nonnegligible concentration in the upper atmosphere so that the $\mathrm{N}+\mathrm{HC}_{4} \mathrm{~N}$ reaction is an important source of $\mathrm{C}_{4} \mathrm{~N}_{2} \cdot \mathrm{C}_{4} \mathrm{~N}_{2}$ is mainly lost by photodissociation and through reaction with $\mathrm{H}$ atoms. Due to the large size of $\mathrm{C}_{4} \mathrm{~N}_{2}$ compared to $\mathrm{C}_{2} \mathrm{~N}_{2}$ and to the fact that $\mathrm{H}$ addition on the $\mathrm{CC}$ triple bond shows a smaller barrier than $\mathrm{H}$ addition on the $\mathrm{CN}$ triple bond, the rate for $\mathrm{H}$ addition should be larger for $\mathrm{H}+\mathrm{C}_{4} \mathrm{~N}_{2}$ than for $\mathrm{H}+\mathrm{C}_{2} \mathrm{~N}_{2}$. We use $k_{\infty}=0.2 \times k_{\infty}\left(\mathrm{H}+\mathrm{C}_{2} \mathrm{H}_{2}\right)$ as the 

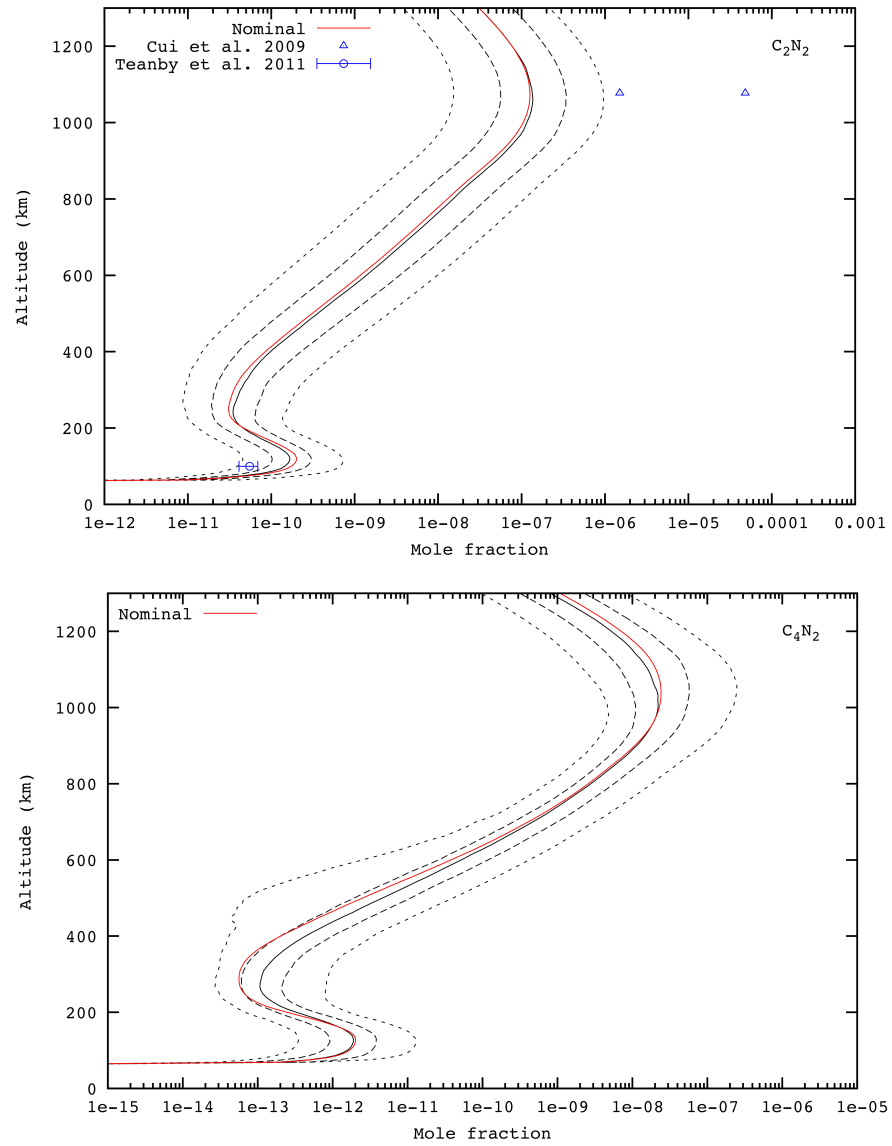

Figure 12: Top: Mole fraction profiles of $\mathrm{C}_{2} \mathrm{~N}_{2}$ and comparison with some observations. Both corrected and uncorrected data of Cui et al. (2009) are presented. Bottom: Mole fraction profiles of $\mathrm{C}_{4} \mathrm{~N}_{2}$. Dashed lines and dotted lines give the intervals containing respectively $50 \%$ and $90 \%$ of the abundance profiles. See text for references and complementary observations. 
entrance barrier is higher for $\mathrm{H}+\mathrm{C}_{4} \mathrm{~N}_{2}$ at the DFT level (M06-2X/cc-pVTZ) and $k_{0}=10 \times k_{0}\left(\mathrm{H}+\mathrm{C}_{2} \mathrm{H}_{4}\right)$ considering the relative sizes of the systems. As $k_{0}\left(\mathrm{H}+\mathrm{C}_{4} \mathrm{~N}_{2}\right)$ is much larger than $k_{0}\left(\mathrm{H}+\mathrm{C}_{2} \mathrm{~N}_{2}\right)$, the reaction $\mathrm{H}+\mathrm{C}_{4} \mathrm{~N}_{2} \rightarrow$ $\mathrm{HC}_{4} \mathrm{~N}_{2}$ followed by the reaction $\mathrm{H}+\mathrm{HC}_{4} \mathrm{~N}_{2} \rightarrow \mathrm{HCN}+\mathrm{C}_{3} \mathrm{~N}$ is an important sink for $\mathrm{C}_{4} \mathrm{~N}_{2}$ in the lower atmosphere, leading to $\mathrm{C}_{4} \mathrm{~N}_{2}$ abundances which are much lower than the $\mathrm{C}_{2} \mathrm{~N}_{2}$ ones. However, the rate constant for the critical H $+\mathrm{C}_{4} \mathrm{~N}_{2}$ reaction is only poorly known and may be considerably smaller, leading to larger $\mathrm{C}_{4} \mathrm{~N}_{2}$ abundances. As for the other large nitriles, $\mathrm{C}_{4} \mathrm{~N}_{2}$ should condense in the lower stratosphere, leading to a depletion at mid-latitudes and an enrichment in the North polar region. If $\mathrm{C}_{4} \mathrm{~N}_{2}$ condenses very efficiently, it should form $\mathrm{C}_{4} \mathrm{~N}_{2}$ ice when reaching the polar troposphere, potentially explaining the detection of $\mathrm{C}_{4} \mathrm{~N}_{2}$ ice. The condensation of $\mathrm{C}_{4} \mathrm{~N}_{2}$ thereby leads to very low $\mathrm{C}_{4} \mathrm{~N}_{2}$ abundances near the lower equatorial stratosphere preventing its detection in the infrared region. Nevertheless, a recent modeling study by de Kok et al. (2008) could not explain the low gas phase $\mathrm{C}_{4} \mathrm{~N}_{2}$ abundances through $\mathrm{C}_{4} \mathrm{~N}_{2}$ ice formation.

\subsubsection{Ammonia $\left(\mathrm{NH}_{3}\right)$}

Ammonia has not been detected yet in the lower atmosphere and has not yet been detected spectroscopically. Using the SPIRE/Herschel spectrometer, Teanby et al. (2013) obtained a 3- $\sigma$ upper limit on the $\mathrm{NH}_{3}$ abundance of 0.19 ppb for altitudes $65-110 \mathrm{~km}$ (with a peak of sensitivity at $75 \mathrm{~km}$ ) considering a constant mole fraction with altitude. Data from CIRS/Cassini limb observations obtained during two flybys of Titan (T55 at $25^{\circ} \mathrm{S}$ and T64 at $75^{\circ} \mathrm{N}$ ) gave upper limits on the abundances of $\mathrm{NH}_{3}$ (Nixon et al., 2013). The upper limit is 0.59 ppb at 7.6 mbar $(\sim 110 \mathrm{~km}$, T55 flyby) and $2.0 \mathrm{ppb}$ at $0.26 \mathrm{mbar}(\sim 250$ $\mathrm{km}$, T64 flyby). Data from INMS/Cassini ion spectra obtained during the T5 flyby of Titan by the Cassini spacecraft suggested the presence of $\mathrm{NH}_{3}$ in the ionosphere of Titan (Vuitton et al., 2007) with a model dependent mole fraction at $1100 \mathrm{~km}$ equal to $7.0 \times 10^{-6}$ (required to match the density of $\mathrm{NH}_{4}^{+}$). Cui et al. (2009) claimed a firm detection of $\mathrm{NH}_{3}$ in the ionosphere from an indepth study of the distributions of various neutral species in Titan's upper atmosphere, between 950 and $1200 \mathrm{~km}$. These analyses were based on a large sample of Cassini/INMS measurements in the Closed Source Neutral (CSN) mode, obtained during 15 close flybys of Titan. They obtained a global average mixing ratio of $(3-4) \times 10^{-5}$ below $1100 \mathrm{~km}$, one order of magnitude greater than the value derived by Vuitton et al. (2007). Cui et al. (2009) stated that claims of $\mathrm{NH}_{3}$ detection in Titan's upper atmosphere should be taken cautiously, since a significant fraction of the observed $\mathrm{NH}_{3}$ molecules might have been formed on the chamber walls from $\mathrm{N}$ and $\mathrm{H}$ radicals in the ambient atmosphere. Magee et al. (2009) stated that the source of $\mathrm{NH}_{3}$ seen by INMS was a topic of debate and noticed that it is conceivable that small amounts of $\mathrm{NH}_{3}$ may reach the INMS antechamber from spent hydrazine fuel.

We obtain large uncertainties on the $\mathrm{NH}_{3}$ mole fraction profile and our model underestimates the production of $\mathrm{NH}_{3}$ compared to the potentially erroneous value derived by Cui et al. (2009) (see above). Our model is in agreement with upper limits obtained in the lower atmosphere (Teanby et al. (2013) for instance) 
although some Monte-Carlo profiles are greater than these upper limits. Neutral chemistry is not an efficient process to produce ammonia (see also Appendix A) because it systematically involves the $\mathrm{NH}_{2}$ radical which is inefficiently produced through neutral chemistry as NH reacts mainly in Titan's atmosphere with the $\mathrm{CH}_{3}$ radical to form $\mathrm{CH}_{2} \mathrm{NH}$. However, as shown by Yelle et al. (2010), $\mathrm{CH}_{2} \mathrm{NH}$ is an important $\mathrm{NH}_{2}$ source in the upper atmosphere through ionic reactions. Indeed, the high proton affinity value of $\mathrm{CH}_{2} \mathrm{NH}$ leads to its easy protonation through reactions with the major ions in Titan's upper atmosphere $\left(\mathrm{HCNH}^{+}\right.$, $\left.\mathrm{CH}_{5}^{+}, \mathrm{C}_{2} \mathrm{H}_{5}^{+}, \mathrm{HC}_{3} \mathrm{NH}^{+}\right)$. The dissociative electronic recombination reaction of $\mathrm{CH}_{2} \mathrm{NH}_{2}^{+}$, which has never been studied, should then lead to $\mathrm{CH}_{2}+\mathrm{NH}_{2}$ products acting as a sink for $\mathrm{CH}_{2} \mathrm{NH}$ and an important source of $\mathrm{NH}_{2}$. The absence of ion reactions in our model leads to an overestimation of $\mathrm{CH}_{2} \mathrm{NH}$ and an underestimation of $\mathrm{NH}_{3}$ in the upper atmosphere.

\subsection{Other nitrogen species profiles}

In addition to the compounds previously presented, several nitrogen compounds were suspected to be present and their densities have been inferred from the analysis of the Cassini/INMS data by Vuitton et al. (2007). These compounds $\left(\mathrm{CH}_{2} \mathrm{NH}, \mathrm{C}_{4} \mathrm{H}_{3} \mathrm{~N}, \mathrm{HC}_{5} \mathrm{~N}, \mathrm{C}_{5} \mathrm{H}_{5} \mathrm{~N}, \mathrm{C}_{6} \mathrm{H}_{3} \mathrm{~N}\right.$ and $\left.\mathrm{C}_{6} \mathrm{H}_{7} \mathrm{~N}\right)$ were not reported in latter analyses of INMS spectra.

\subsection{1. $\left(\mathrm{CH}_{2} \mathrm{NH}\right)$}

$\mathrm{CH}_{2} \mathrm{NH}$ is mainly produced by the $\mathrm{N}\left({ }^{2} \mathrm{D}\right)+\mathrm{CH}_{4}$ reaction (Herron, 1999) (there is a typographical error in the Herron paper: we should read $A=$ $4.8 \times 10^{-11}$ instead of $4.8 \times 10^{-12}$ in Table 3 ) (see also Ouk et al. (2011); Takayanagi and Kurosaki (1999); Takayanagi et al. (1999); Balucani et al. (2009)) and by the $\mathrm{NH}+\mathrm{CH}_{3}$ reaction (Redondo et al., 2006), with a secondary contribution from the $\mathrm{N}\left({ }^{2} \mathrm{D}\right)+\mathrm{C}_{2} \mathrm{H}_{6}$ reaction (Herron, 1999; Balucani et al., 2010). $\mathrm{CH}_{2} \mathrm{NH}$ is mainly lost through photodissociation. The photodissociation cross section has been calculated at the EOM-CCSD(T)/aug-cc-pV5Z level (as well as at the MRCI+Q/aug-ccpVTZ level) and has been scaled to the experimental spectrum between 235 and $260 \mathrm{~nm}$ (Teslja et al., 2004). The branching ratios in Hébrard et al. (2012) were deduced from theoretical calculations (Zhou and Schlegel, 2009; Nguyen et al., 1996; Hébrard et al., 2012), the main products being $\mathrm{H}+\mathrm{H}_{2} \mathrm{CN}$ (the UV absorption dominates the photodissociation). The reaction of $\mathrm{CH}_{2} \mathrm{NH}$ with $\mathrm{H}$ atoms was suspected to be an important $\mathrm{CH}_{2} \mathrm{NH}$ loss process (Lavvas et al., 2008a,b). The $\mathrm{H}+\mathrm{CH}_{2} \mathrm{NH}$ reaction can lead to association $\left(\mathrm{CH}_{2} \mathrm{NH}_{2}\right.$ and $\left.\mathrm{CH}_{3} \mathrm{NH}\right)$ or to abstraction. There is one theoretical calculation for the association Blitz et al. (2012) leading to a barrier equal to $20 \mathrm{~kJ} / \mathrm{mol}$ and one estimation of the abstraction rate constant for combustion (Tomeczek and Gradon, 2003) leading to a relatively small activation barrier. The addition channel is of minor importance here as $\mathrm{CH}_{2} \mathrm{NH}$ is mainly produced in upper atmosphere where the pressure is low. We use the rate constant for $\mathrm{H}+$ $\mathrm{C}_{2} \mathrm{H}_{4}$ from Vuitton et al. (2012) considering only one isomer for the adduct. For the abstraction pathway we calculate the barrier at the M06-2X/cc-pVTZ level 

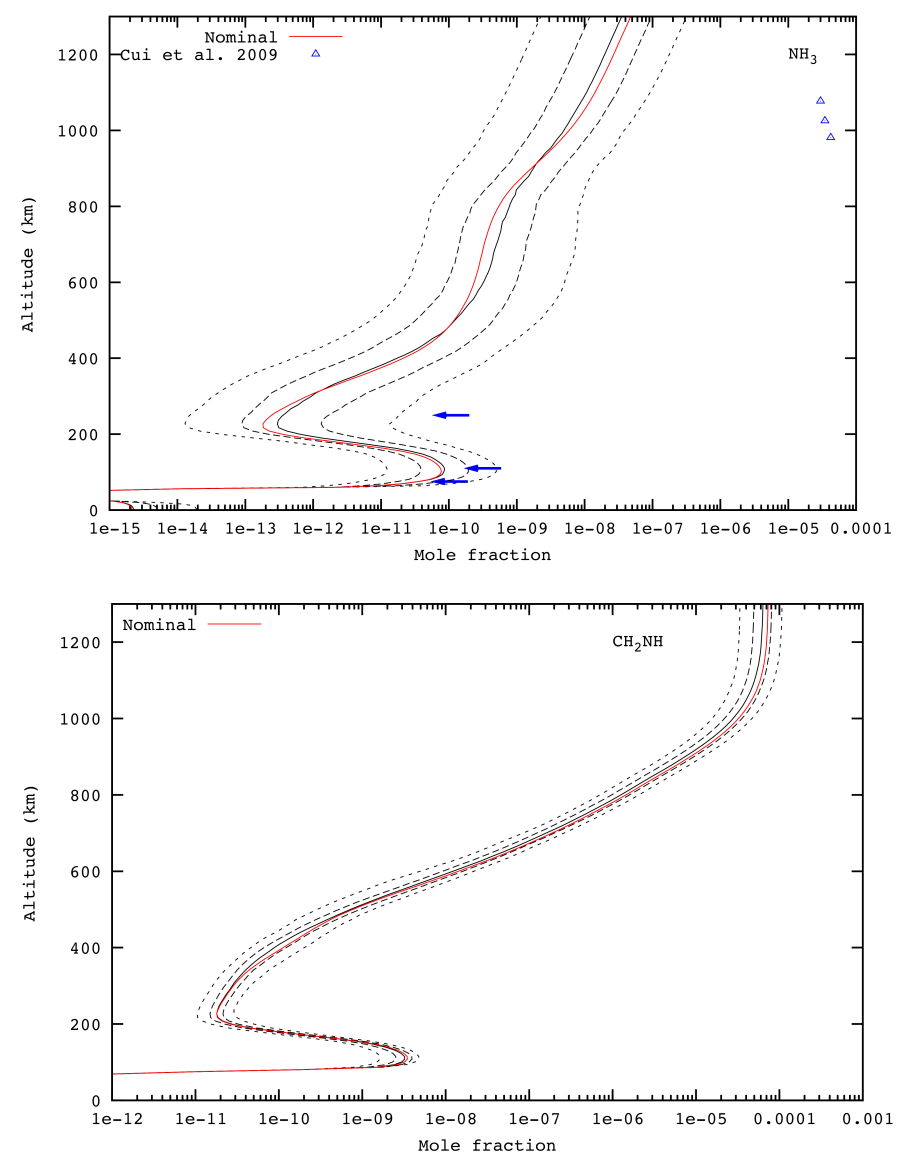

Figure 13: Top: Mole fraction profiles of $\mathrm{NH}_{3}$ and comparison with some observations. Only upper limits are available in the lower atmosphere. Bottom: Mole fraction profiles of $\mathrm{CH}_{2} \mathrm{NH}$.

Dashed lines and dotted lines give the intervals containing respectively $50 \%$ and $90 \%$ of the abundance profiles. See text for references and complementary observations. 
and the rate using classical TST, leading to a smaller rate constant value than the previous estimation by Tomeczek and Gradon (2003). The loss of $\mathrm{CH}_{2} \mathrm{NH}$ by reaction with $\mathrm{H}$ atoms is significantly smaller than its loss by photodissociation in our model. $\mathrm{CH}_{2} \mathrm{NH}$ is mainly formed in upper atmosphere with a contribution from cosmic rays induced dissociation of $\mathrm{N}_{2}$ in the stratosphere. The simulations overestimate $\mathrm{CH}_{2} \mathrm{NH}$ mole fractions compared to the values obtained by Vuitton et al. (2007) and this may be attributed to ionic reactions which should play an important role for $\mathrm{CH}_{2} \mathrm{NH}$ due to its high Protonic Affinity (Yelle et al., 2010) as explained above, leading eventually to $\mathrm{CH}_{2}+$ $\mathrm{NH}_{2}$ products. The mole fraction of $\mathrm{CH}_{2} \mathrm{NH}$ between 100 and $200 \mathrm{~km}$ (induced by cosmic rays (CR) photochemistry) is around $10^{-9}$ and it will be interesting to have upper limit value from Cassini measurements $\left(\mathrm{CH}_{2} \mathrm{NH}\right.$ absorbs in the 1040-1150 $\mathrm{cm}^{-1}$ range (Halonen et al., 1986)) to estimate the importance of CR induced photochemistry (even if ionic chemistry is likely to be very different in the stratosphere than in upper atmosphere as most of the electrons should stick to aerosols, the loss of $\mathrm{CH}_{2} \mathrm{NH}$ through protonation followed by $\mathrm{CH}_{2} \mathrm{NH}_{2}^{+}$ sticking to negatively charged aerosols should lead to similar loss rates to the DR reaction but without producing ammonia).

\subsection{2. $\left(\mathrm{HC}_{5} \mathrm{~N}\right)$}

Marten et al. (2002) proposed an upper limit for the $\mathrm{HC}_{5} \mathrm{~N}$ mole fraction of $4.0 \times 10^{-10}$ from millimeter heterodyne observations obtained with the IRAM $30-\mathrm{m}$ telescope assuming a uniform distribution of this compound in the lower stratosphere. The calculated mole fraction profile of $\mathrm{HC}_{5} \mathrm{~N}$ is uniform with altitude in the stratosphere, with a similar shape to the calculated $\mathrm{HC}_{3} \mathrm{~N}$ mole fraction. Our model is in agreement with this upper limit. There are three equivalent $\mathrm{HC}_{5} \mathrm{~N}$ production pathways: $\mathrm{CN}+\mathrm{C}_{4} \mathrm{H}_{2} \rightarrow \mathrm{HC}_{5} \mathrm{~N}+\mathrm{H}, \mathrm{C}_{3} \mathrm{~N}+$ $\mathrm{C}_{2} \mathrm{H}_{2} \rightarrow \mathrm{HC}_{5} \mathrm{~N}+\mathrm{H}, \mathrm{C}_{2} \mathrm{H}+\mathrm{HC}_{3} \mathrm{~N} \rightarrow \mathrm{HC}_{5} \mathrm{~N}+\mathrm{H}$. In addition to a secondary one in the upper atmosphere: $\mathrm{C}_{2} \mathrm{H}+\mathrm{CH}_{3} \mathrm{C}_{3} \mathrm{~N} \rightarrow \mathrm{HC}_{5} \mathrm{~N}+\mathrm{CH}_{3}$. However, all these reactions (without barriers in the entrance valley) lead to relatively small production rates and consequently to a relatively low $\mathrm{HC}_{5} \mathrm{~N}$ concentration. The main difference compared to previous models is the fact that $\mathrm{C}_{3} \mathrm{~N}$ reacts quickly with $\mathrm{CH}_{4}$ (Fournier et al., 2014) leading to a small steady state $\mathrm{C}_{3} \mathrm{~N}$ concentration and a low production rate from the $\mathrm{C}_{3} \mathrm{~N}+\mathrm{C}_{2} \mathrm{H}_{2}$ reaction. The main $\mathrm{HC}_{5} \mathrm{~N}$ losses are unlikely to be photodissociation by comparison with $\mathrm{HC}_{3} \mathrm{~N}$ $\left(\mathrm{HC}_{5} \mathrm{~N}\right.$ photodissociation leads mainly to $\mathrm{C}_{5} \mathrm{~N}$ which should react quickly with $\mathrm{CH}_{4}$ leading back to $\mathrm{HC}_{5} \mathrm{~N}$ ) but rather by association with $\mathrm{H}$ atoms followed by the $\mathrm{H}_{2} \mathrm{C}_{5} \mathrm{~N}$ adduct reaction with another $\mathrm{H}$ atom leading to $\mathrm{HCN}+\mathrm{C}_{4} \mathrm{H}_{2}$, $\mathrm{HC}_{3} \mathrm{~N}+\mathrm{C}_{2} \mathrm{H}_{2}$ and $\mathrm{C}_{2} \mathrm{H}_{3} \mathrm{C}_{3} \mathrm{~N}$.

\subsection{3. $\left(\mathrm{CH}_{3} \mathrm{C}_{3} \mathrm{~N}\right)$}

Detection of $\mathrm{C}_{4} \mathrm{H}_{3} \mathrm{NH}^{+}$isomers, likely to be $\mathrm{CH}_{3} \mathrm{C}_{3} \mathrm{NH}^{+}$, at $74^{\circ} \mathrm{N}$ and 1100 $\mathrm{km}$ were reported by Vuitton et al. (2007) from the Cassini/INMS data obtained on the Cassini T5 flyby. From the analysis of the mass spectrum, they inferred

a mole fraction of $\mathrm{C}_{4} \mathrm{H}_{3} \mathrm{~N}\left(\mathrm{CH}_{3} \mathrm{C}_{3} \mathrm{~N}\right)$ equal to $4.0 \times 10^{-6}$. Our model is in agreement with this value. 
In the middle atmosphere, we obtain for $\mathrm{CH}_{3} \mathrm{C}_{3} \mathrm{~N}$ a huge diversity of profiles from our uncertainty propagation procedure illustrated by the remarkable difference between the mean profile and the nominal profile. This result shows that many chemical pathways are possible due to the current uncertainties on several rate constants. There are two $\mathrm{CH}_{3} \mathrm{C}_{3} \mathrm{~N}$ production pathways in our nominal model, both arising from $\mathrm{CCN}$ radical reactions (formed by the $\mathrm{H}+$ HCCN reaction (Osamura and Petrie, 2004; Takayanagi et al., 1998)) and therefore localized in the upper atmosphere. $\mathrm{CH}_{3} \mathrm{C}_{3} \mathrm{~N}$ is directly produced by the $\mathrm{CCN}+\mathrm{C}_{2} \mathrm{H}_{4}$ reaction (Zhu et al., 2003a) and is also formed by the reactions $\mathrm{CCN}+\mathrm{C}_{2} \mathrm{H}_{2} \rightarrow \mathrm{HC}_{4} \mathrm{~N}+\mathrm{H}$ (Zhu et al., 2003a; Wang et al., 2006) followed by $\mathrm{HC}_{4} \mathrm{~N}+\mathrm{H}+\mathrm{M} \rightarrow \mathrm{CH}_{2} \mathrm{C}_{3} \mathrm{~N}+\mathrm{M}$ and $\mathrm{CH}_{2} \mathrm{C}_{3} \mathrm{~N}+\mathrm{H}+\mathrm{M} \rightarrow \mathrm{CH}_{3} \mathrm{C}_{3} \mathrm{~N}$ $+\mathrm{M}$ (this work). As there is no bimolecular exit channel for the $\mathrm{H}+\mathrm{HC}_{4} \mathrm{~N}$ reaction in contrast to the $\mathrm{H}+\mathrm{HCCN}$ reaction, both ways to produce $\mathrm{CH}_{3} \mathrm{C}_{3} \mathrm{~N}$ are efficient. The photodissociation of $\mathrm{CH}_{3} \mathrm{C}_{3} \mathrm{~N}$ has never been studied. The absorption cross section should be similar to $\mathrm{HC}_{3} \mathrm{~N}$, but the products which are likely to be mainly $\mathrm{CH}_{2} \mathrm{C}_{3} \mathrm{~N}+\mathrm{H}$ and $\mathrm{CH}_{3}+\mathrm{C}_{3} \mathrm{~N}$, do not react quickly with $\mathrm{CH}_{4}$ to give back $\mathrm{CH}_{3} \mathrm{C}_{3} \mathrm{~N}$ so photodissociation becomes a sink, in contrast to $\mathrm{HC}_{3} \mathrm{~N}$. As our model is limited to neutral reactions, it cannot describe correctly nitriles in the upper atmosphere where ionic reactions are important. The proton affinity of $\mathrm{CH}_{3} \mathrm{C}_{3} \mathrm{~N}$ is calculated to be equal to $788 \mathrm{~kJ} / \mathrm{mol}$ at the M06-2X/cc-pVTZ level so $\mathrm{CH}_{3} \mathrm{C}_{3} \mathrm{~N}$ will react quickly with $\mathrm{C}_{2} \mathrm{H}_{5}^{+}, \mathrm{HCNH}^{+}$and $\mathrm{HC}_{3} \mathrm{NH}^{+}$leading to $\mathrm{CH}_{3} \mathrm{C}_{3} \mathrm{NH}^{+}$(the $\mathrm{CH}_{3} \mathrm{C}_{3} \mathrm{NH}^{+}$ion could be the " $\mathrm{C}_{4} \mathrm{H}_{3} \mathrm{NH}^{+}$" identified in INMS spectra). Further evolution of $\mathrm{CH}_{3} \mathrm{C}_{3} \mathrm{NH}^{+}$will be controlled by the competition between $\mathrm{H}^{+}$exchange with $\mathrm{CH}_{2} \mathrm{NH}$ and $\mathrm{NH}_{3}$, the two main species having proton affinities larger than $\mathrm{CH}_{3} \mathrm{C}_{3} \mathrm{~N}$, and $\mathrm{DR}$ reactions. The branching ratio giving back $\mathrm{CH}_{3} \mathrm{C}_{3} \mathrm{~N}$ for the $\mathrm{DR}$ reaction of $\mathrm{CH}_{3} \mathrm{C}_{3} \mathrm{NH}^{+}$is unknown but it is almost certainly less than 1 so that ionic reactions act mainly as loss processes for $\mathrm{CH}_{3} \mathrm{C}_{3} \mathrm{~N}$. It should be noted that a large part of the rich nitrile chemistry in the upper atmosphere (concerning $\mathrm{CH}_{3} \mathrm{C}_{3} \mathrm{~N}$ as well as $\mathrm{C}_{2} \mathrm{H}_{5} \mathrm{C}_{3} \mathrm{~N}$ and $\mathrm{C}_{4} \mathrm{H}_{3} \mathrm{C}_{3} \mathrm{~N}$ ) is directly dependent on the $\mathrm{HCCN}+\mathrm{H}$ reaction which is not well known despite the theoretical studies of Osamura and Petrie (2004) and Takayanagi et al. (1998). It should also be noted that various isomers can be synthesized in the $\mathrm{CCN}+\mathrm{C}_{2} \mathrm{H}_{4}$ and $\mathrm{CCN}+\mathrm{C}_{2} \mathrm{H}_{2}$ reactions.

\subsection{4. $\left(\mathrm{C}_{3} \mathrm{H}_{7} \mathrm{CN}\right)$}

$\mathrm{C}_{3} \mathrm{H}_{7} \mathrm{CNH}^{+}$ion is found to be 700 less abundant than $\mathrm{CH}_{3} \mathrm{CNH}^{+}$and 50 times less abundant than $\mathrm{C}_{2} \mathrm{H}_{5} \mathrm{CNH}^{+}$, in INMS ions spectra reported by Vuitton et al. (2007) from Cassini/INMS measurements obtained on the Cassini T5 flyby. Our model leads to elevated abundances of $\mathrm{C}_{3} \mathrm{H}_{7} \mathrm{CN}$ in both the lower and upper atmosphere. The $\mathrm{CH}_{3} \mathrm{CN} / \mathrm{C}_{2} \mathrm{H}_{5} \mathrm{CN} / \mathrm{C}_{3} \mathrm{H}_{7} \mathrm{CN}$ abundances given by our model are in relatively good agreement with the INMS data deduced from the protonated form, particularly considering that ionic chemistry acts as sinks for these compounds ( $\mathrm{R}-\mathrm{CN}+\mathrm{HCNH}^{+} \rightarrow \mathrm{RCNH}^{+}+\mathrm{HCN}$ followed by $\mathrm{R}-\mathrm{CNH}^{+}$ $+\mathrm{e}^{-}$which do not give $100 \% \mathrm{RCNH}+\mathrm{H}$ ). The main production of $\mathrm{C}_{3} \mathrm{H}_{7} \mathrm{CN}$ molecule is through the association reaction between $\mathrm{C}_{2} \mathrm{H}_{4} \mathrm{CN}$ and $\mathrm{CH}_{3}$, so this species is then directly correlated to $\mathrm{CH}_{3} \mathrm{CN}$ and $\mathrm{C}_{2} \mathrm{H}_{5} \mathrm{CN}$. The main losses are 
photodissociation and reaction with $\mathrm{C}_{2} \mathrm{H}$, the rate constant being taken to be similar to the $\mathrm{C}_{2} \mathrm{H}+\mathrm{C}_{2} \mathrm{H}_{6}$ reaction. The calculated $\mathrm{C}_{3} \mathrm{H}_{7} \mathrm{CN}$ abundance is very likely to be overestimated by comparison with $\mathrm{CH}_{3} \mathrm{CN}$ and $\mathrm{C}_{2} \mathrm{H}_{5} \mathrm{CN}$. Firstly, the association rate constant for the $\mathrm{C}_{2} \mathrm{H}_{4} \mathrm{CN}+\mathrm{CH}_{3}+\mathrm{M} \rightarrow \mathrm{C}_{2} \mathrm{H}_{5} \mathrm{CN}+\mathrm{M}$ reaction is unknown and has been estimated using our semi-empirical model. Secondly, the photodissociation cross section of $\mathrm{C}_{3} \mathrm{H}_{7} \mathrm{CN}$ is unknown so we use the same value as for $\mathrm{C}_{2} \mathrm{H}_{5} \mathrm{CN}$. Moreover, as $\mathrm{C}_{3} \mathrm{H}_{7} \mathrm{CN}$ condenses in the lower stratosphere, its mole fraction should be very low at mid latitudes as discussed for other nitriles like $\mathrm{HCN}$. This effect may be very strong for $\mathrm{C}_{3} \mathrm{H}_{7} \mathrm{CN}$ as it should condense at higher altitudes. Then, $\mathrm{C}_{3} \mathrm{H}_{7} \mathrm{CN}$ should also show a large enrichment near the North pole and might be a component of the Haze B layer.

\subsection{Chemical and dynamical lifetimes}

Chemical and dynamical lifetimes are useful characteristics of the model, in particular to determine whether transport (vertical or horizontal) could be the dominant process at a given altitude in the atmosphere. Figure 15 shows the chemical and dynamical lifetimes of major nitrogen compounds as a function of altitude. The chemical lifetime is defined as $\tau_{\text {chem }}(z)=1 / L(z)$ where $L(z)$ is the total loss rate $\left(\right.$ in $\mathrm{s}^{-1}$ ) at altitude $z$. The dynamical lifetime $\tau_{d y n_{i}}(z)$ for species $i$ at altitude $z$ takes both eddy diffusion and molecular diffusion processes into account and is expressed as : $1 / \tau_{d y n_{i}}(z)=1 / \tau_{D_{i}(z)}+1 / \tau_{K(z)}$ for each species $i$, with $\tau_{K(z)}=H(z)^{2} / K(z)$ and $\tau_{D_{i}(z)}=H(z)^{2} / D_{i}(z) . H(z)$ is the atmospheric scale height, $K(z)$ the eddy diffusion coefficient and $D_{i}(z)$ the molecular diffusion coefficient in $\mathrm{N}_{2}$ for species $i$. We see that some species are very stable from a chemical point of view, like $\mathrm{HCN}, \mathrm{CH}_{3} \mathrm{CN}, \mathrm{C}_{2} \mathrm{H}_{5} \mathrm{CN}$ and $\mathrm{C}_{2} \mathrm{~N}_{2}$ throughout the whole atmosphere. For other species, there is an alternate between regions dominated by photochemical equilibrium and those dominated by dynamical equilibrium with altitude. We note also that the chemical lifetimes of all the species depicted in Figure 15 have a strong dependance with altitude below $200 \mathrm{~km}$ since this quantity increases by 4 orders of magnitude (at least). Wilson and Atreya (2004) published the chemical lifetimes of several nitrogen species at $300 \mathrm{~km}\left(\mathrm{HCN}, \mathrm{CH}_{3} \mathrm{CN}, \mathrm{C}_{2} \mathrm{~N}_{2}, \mathrm{HC}_{3} \mathrm{~N}, \mathrm{C}_{2} \mathrm{H}_{3} \mathrm{CN}\right.$ and $\left.\mathrm{C}_{4} \mathrm{~N}_{2}\right)$. Our results (at least at this altitude) are somewhat different since we obtain nominal values which differ by factors of roughly 1.5 (for $\mathrm{HCN}, \mathrm{CH}_{3} \mathrm{CN}, \mathrm{C}_{4} \mathrm{~N}_{2}$ ), 2.5 $\left(\mathrm{C}_{2} \mathrm{H}_{3} \mathrm{CN}\right), 4\left(\mathrm{HC}_{3} \mathrm{~N}\right)$ and $6\left(\mathrm{C}_{2} \mathrm{~N}_{2}\right)$.

\section{Key reactions}

From an uncertainty propagation study and a global sensitivity analysis (see Hébrard et al. (2009) for instance), we have determined a list of the key reactions for the main nitrogen species of our model. These key reactions (which can be different from reactions that give the main production rates), are the ones which are responsible for the uncertainties on the mole fraction profiles calculated from our model. They are consequently the reactions that should be studied in priority to improve photochemical models of Titan's atmosphere. The key 

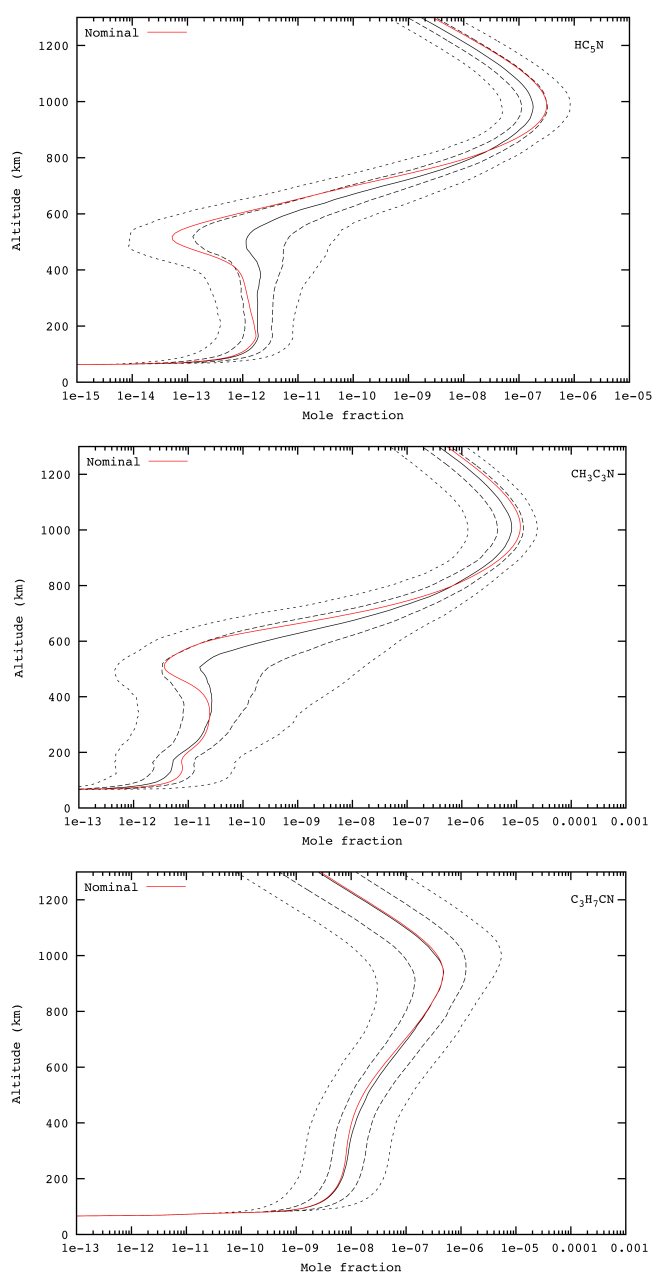

Figure 14: Top: Mole fraction profiles of $\mathrm{HC}_{5} \mathrm{~N}$. Middle: Mole fraction profiles of $\mathrm{CH}_{3} \mathrm{C}_{3} \mathrm{~N}$. Bottom: Mole fraction profiles of $\mathrm{C}_{3} \mathrm{H}_{7} \mathrm{CN}$. Dashed lines and dotted lines give the intervals containing respectively $50 \%$ and $90 \%$ of the abundance profiles. 

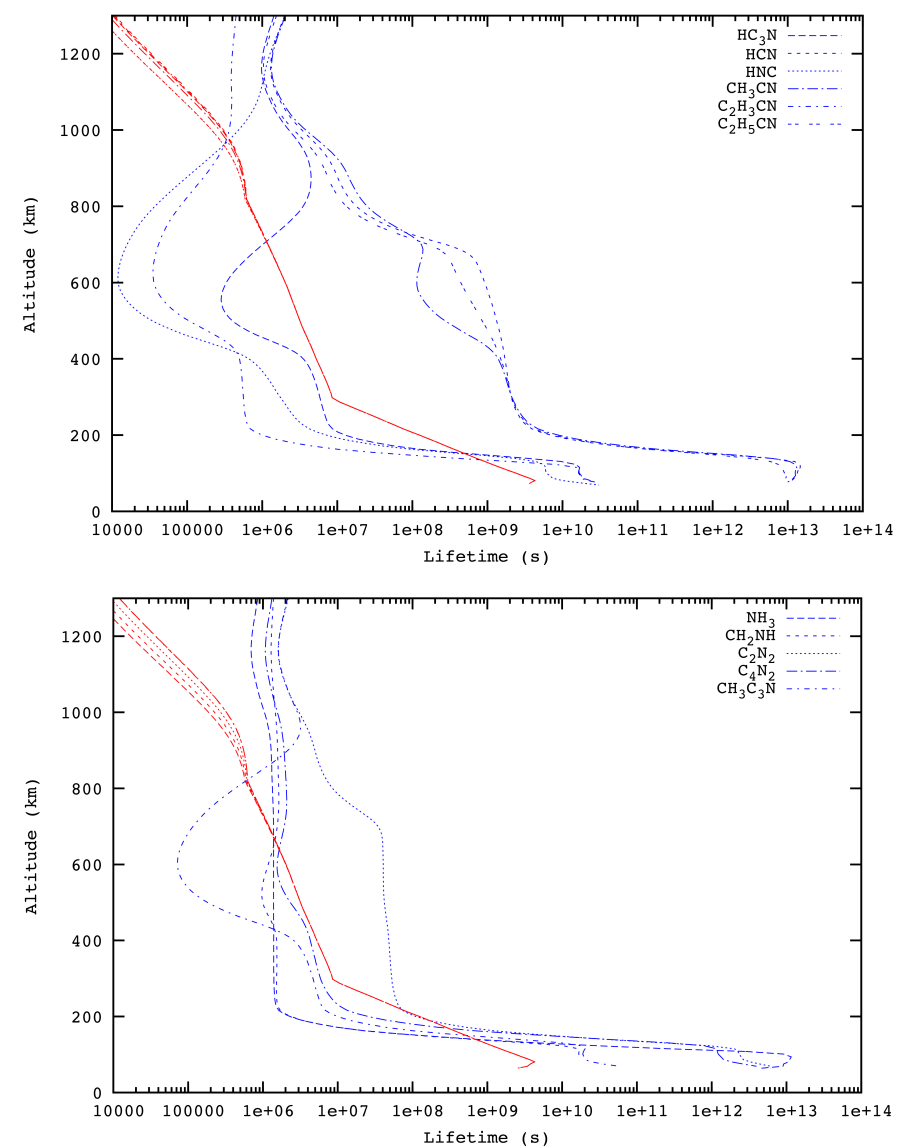

Figure 15: Chemical and dynamical lifetimes of $\mathrm{HC}_{3} \mathrm{~N}, \mathrm{HCN}, \mathrm{HNC}, \mathrm{CH}_{3} \mathrm{CN}, \mathrm{C}_{2} \mathrm{H}_{3} \mathrm{CN}$ and $\mathrm{C}_{2} \mathrm{H}_{5} \mathrm{CN}$ (top) and $\mathrm{NH}_{3}, \mathrm{CH}_{2} \mathrm{NH}, \mathrm{C}_{2} \mathrm{~N}_{2}, \mathrm{C}_{4} \mathrm{~N}_{2}, \mathrm{CH}_{3} \mathrm{C}_{3} \mathrm{~N}$ (bottom) as a function of altitude for the nominal model. The cut-off in the lower atmosphere corresponds to the condensation altitude of the corresponding compounds. The dynamical lifetime takes both eddy diffusion and molecular diffusion into account. The homopause is localized around $900 \mathrm{~km}$ (see Figure $4)$. 
reactions for the main nitrogen compounds are given in Table 3 and Table 4 for 3 different altitudes. Many reactions which are important for the production of these species and discussed in Appendix A are also reactions that are not well known. As a consequence, they appear as key reactions. In particular, this is the case for numerous association reactions with $\mathrm{H}$. Some other reactions are critical: $\mathrm{N}\left({ }^{2} \mathrm{D}\right)+\mathrm{HCN}, \mathrm{H}+\mathrm{HNC}$ and reactions with $\mathrm{C}_{2} \mathrm{~N}$ which is a key species in the production of several nitriles.

Table 3: Key reactions responsible for uncertainties on major nitrogen compounds at altitude of 900, 500 and $100 \mathrm{~km}$. Only reactions with an absolute RCC (Rank Correlation Coefficient) value greater than 0.2 are given. A blank means that the absolute value of the RCC is lower than 0.2 and it is not given for clarity. Some compounds are just considered as products and are not included in our model.

\begin{tabular}{|c|c|c|c|}
\hline \multicolumn{4}{|l|}{$\mathrm{NH}_{3}$} \\
\hline \multirow[t]{2}{*}{ Reaction } & \multicolumn{3}{|c|}{$\mathrm{RCC}$} \\
\hline & at $900 \mathrm{~km}$ & at $500 \mathrm{~km}$ & at $100 \mathrm{~km}$ \\
\hline $\begin{array}{c}\mathrm{N}\left({ }^{4} \mathrm{~S}\right)+\mathrm{NH}_{2} \rightarrow \mathrm{N}_{2}+\mathrm{H}+\mathrm{H} \\
\mathrm{NH}+\mathrm{H}_{2} \mathrm{CN} \rightarrow \mathrm{NH}_{2}+\mathrm{HCN}\end{array}$ & -0.21 & & $\begin{array}{c}-0.30 \\
0.29\end{array}$ \\
\hline $\mathrm{NH}_{2}+\mathrm{H}_{2} \mathrm{CN} \rightarrow \mathrm{HCN}+\mathrm{NH}_{3}$ & 0.35 & & 0.36 \\
\hline $\mathrm{CH}_{2} \mathrm{NH}+\mathrm{H} \rightarrow \mathrm{CH}_{3} \mathrm{NH}$ & 0.61 & 0.48 & \\
\hline $\mathrm{NH}_{2}+\mathrm{C}_{2} \mathrm{H}_{3} \rightarrow \mathrm{NH}_{3}+\mathrm{C}_{2} \mathrm{H}_{2}$ & 0.34 & 0.61 & 0.36 \\
\hline $\mathrm{NH}_{2}^{2}+\mathrm{C}_{2}^{2} \mathrm{H}_{5} \rightarrow \mathrm{NH}_{3}+\mathrm{C}_{2}^{2} \mathrm{H}_{4}^{2}$ & & 0.34 & \\
\hline $\begin{array}{l}\mathrm{NH}+\mathrm{C}_{2} \mathrm{H}_{5} \rightarrow \mathrm{NH}_{2}+\mathrm{C}_{2} \mathrm{H}_{4} \\
\mathrm{NH}+\mathrm{C}_{2} \mathrm{H}_{3} \rightarrow \mathrm{NH}_{2}+\mathrm{C}_{2} \mathrm{H}_{2}\end{array}$ & & & $\begin{array}{l}0.22 \\
0.23\end{array}$ \\
\hline \multicolumn{4}{|l|}{$\mathrm{HCN}$} \\
\hline $\mathrm{N}\left({ }^{2} \mathrm{D}\right)+\mathrm{C}_{2} \mathrm{H}_{4} \rightarrow \mathrm{CH}_{2} \mathrm{NCH}+\mathrm{H}$ & 0.31 & 0.24 & 0.23 \\
\hline $\mathrm{N}\left({ }^{2} \mathrm{D}\right)+\mathrm{HCN} \rightarrow \mathrm{CH}+\mathrm{N}_{2}$ & -0.83 & -0.84 & -0.83 \\
\hline $\mathrm{C}_{2} \mathrm{H}_{3} \mathrm{CN}+\mathrm{H} \rightarrow \mathrm{C}_{2} \mathrm{H}_{4} \mathrm{CN}$ & & -0.20 & \\
\hline \multicolumn{4}{|l|}{ HNC } \\
\hline $\mathrm{HNC}+\mathrm{H} \rightarrow \mathrm{HCN}+\mathrm{H}$ & -0.94 & -0.89 & -0.74 \\
\hline $\mathrm{N}\left({ }^{4} \mathrm{~S}\right)+{ }^{3} \mathrm{CH}_{2} \rightarrow \mathrm{HNC}+\mathrm{H}$ & & & 0.22 \\
\hline \multirow{2}{*}{\multicolumn{4}{|c|}{ 等 }} \\
\hline & & & \\
\hline $\mathrm{N}\left({ }^{2} \mathrm{D}\right)+\mathrm{HCN} \rightarrow \mathrm{CH} \mathrm{v} \mathrm{N}_{2}$ & -0.43 & & \\
\hline $\mathrm{CN}+\mathrm{C}_{2} \mathrm{H}_{2} \rightarrow \mathrm{HC}_{3} \mathrm{~N}+\mathrm{H}$ & 0.30 & & \\
\hline $\mathrm{CN}+\mathrm{C}_{2} \mathrm{H}_{4} \rightarrow \mathrm{C}_{2} \mathrm{H}_{3} \mathrm{CN}+\mathrm{H}$ & -0.33 & & \\
\hline $\mathrm{HC}_{3} \mathrm{~N}+\mathrm{H} \rightarrow \mathrm{H}_{2} \mathrm{C}_{3} \mathrm{~N}$ & -0.36 & -0.83 & -0.38 \\
\hline $\mathrm{C}_{2} \mathrm{H}_{3} \mathrm{CN}+\mathrm{H} \rightarrow \mathrm{C}_{2} \mathrm{H}_{4} \mathrm{CN}$ & -0.34 & & \\
\hline $\mathrm{HC}_{4} \mathrm{~N}+\mathrm{H} \rightarrow \mathrm{CH}_{2} \mathrm{C}_{3} \mathrm{~N}$ & -0.22 & & \\
\hline $\begin{aligned} \mathrm{H}+\mathrm{C}_{2} \mathrm{H}_{4} & \rightarrow \mathrm{C}_{2} \mathrm{H}_{5} \\
\mathrm{~N}\left({ }^{4} \mathrm{~S}\right)+\mathrm{CH}_{2} \mathrm{CN} & \rightarrow \mathrm{H}_{2} \mathrm{CN}+\mathrm{CN}\end{aligned}$ & & 0.20 & 0.23 \\
\hline $\mathrm{HC}_{3} \mathrm{~N}+\mathrm{C}_{2} \mathrm{H}_{3} \rightarrow \mathrm{C}_{2} \mathrm{H}_{3} \mathrm{C}_{3} \mathrm{~N}$ (product) $+\mathrm{H}$ & & & -0.44 \\
\hline $\mathrm{H}+\mathrm{C}_{2} \mathrm{H}_{2} \rightarrow \mathrm{C}_{2} \mathrm{H}_{3}$ & & & 0.21 \\
\hline \multicolumn{4}{|c|}{$\mathrm{CH}_{3} \mathrm{CN}$} \\
\hline $\mathrm{N}\left({ }^{2} \mathrm{D}\right)+\mathrm{C}_{2} \mathrm{H}_{4} \rightarrow \mathrm{c}-\mathrm{CH}_{2} \mathrm{NCH}+\mathrm{H}$ & 0.36 & 0.35 & 0.27 \\
\hline $\mathrm{CH}_{2} \mathrm{NH}+\mathrm{CH} \rightarrow \mathrm{CH}_{3} \mathrm{CN}+\mathrm{H}$ & 0.25 & & \\
\hline $\mathrm{c}-\mathrm{CH}_{2} \mathrm{NCH}+\mathrm{H} \rightarrow \mathrm{CH}_{3} \mathrm{CN}+\mathrm{H}$ & 0.27 & & \\
\hline $\mathrm{CH}_{2} \mathrm{CN}+\mathrm{H} \rightarrow \mathrm{CH}_{3} \mathrm{CN}$ & 0.52 & 0.62 & \\
\hline $\begin{array}{l}\mathrm{CH}_{2} \mathrm{CN}+\mathrm{CH}_{3} \rightarrow \mathrm{C}_{2} \mathrm{H}_{5} \mathrm{CN} \\
\mathrm{NH}+\mathrm{C}_{2} \mathrm{H}_{3} \rightarrow \mathrm{CH}_{3} \mathrm{CN}+\mathrm{H}\end{array}$ & -0.28 & -0.25 & $\begin{array}{c}-0.20 \\
0.26\end{array}$ \\
\hline \multicolumn{4}{|c|}{$\mathrm{C}_{2} \mathrm{H}_{3} \mathrm{CN}$} \\
\hline $\mathrm{CHCN}+\mathrm{H} \rightarrow \mathrm{C}_{2} \mathrm{~N}+\mathrm{H}_{2}$ & -0.22 & & \\
\hline $\mathrm{C}_{2} \mathrm{H}_{3} \mathrm{CN}+\mathrm{H} \rightarrow \mathrm{C}_{2} \mathrm{H}_{4} \mathrm{CN}$ & -0.89 & -0.71 & \\
\hline $\mathrm{H}_{2} \mathrm{C}_{3} \mathrm{~N}+\mathrm{H} \rightarrow \mathrm{C}_{2} \mathrm{H}_{3} \mathrm{CN}$ & & 0.40 & \\
\hline $\mathrm{H}_{2} \mathrm{C}_{3} \mathrm{~N}+\mathrm{H} \rightarrow \mathrm{HCN}+\mathrm{C}_{2} \mathrm{H}_{2}$ & & -0.21 & \\
\hline $\mathrm{H}_{2} \mathrm{C}_{3} \mathrm{~N}+\mathrm{H} \rightarrow \mathrm{HC}_{3} \mathrm{~N}+\mathrm{H}_{2}$ & & -0.21 & \\
\hline $\mathrm{N}\left({ }^{4} \mathrm{~S}\right)+\mathrm{C}_{3} \mathrm{H}_{5} \rightarrow \mathrm{C}_{2} \mathrm{H}_{3} \mathrm{CN}+\mathrm{H}_{2}$ & & & 0.48 \\
\hline $\mathrm{HCN}+\mathrm{C}_{2} \mathrm{H}_{3} \rightarrow \mathrm{C}_{2} \mathrm{H}_{3} \mathrm{CN}+\mathrm{H}^{2}$ & & & 0.30 \\
\hline \multicolumn{4}{|c|}{$\mathrm{C}_{2} \mathrm{H}_{5} \mathrm{CN}$} \\
\hline $\mathrm{CH}_{2} \mathrm{CN}+\mathrm{H} \rightarrow \mathrm{CH}_{3} \mathrm{CN}$ & -0.21 & -0.39 & \\
\hline $\mathrm{CH}_{2} \mathrm{CN}+\mathrm{CH}_{3} \rightarrow \mathrm{C}_{2} \mathrm{H}_{5} \mathrm{CN}$ & 0.28 & & \\
\hline $\mathrm{C}_{2} \mathrm{H}_{3} \mathrm{CN}+\mathrm{H} \rightarrow \mathrm{C}_{2} \mathrm{H}_{4} \mathrm{CN}$ & 0.72 & 0.49 & \\
\hline $\mathrm{N}\left({ }^{2} \mathrm{D}\right)+\mathrm{HCN} \rightarrow \mathrm{CH}+\mathrm{N}_{2}$ & & -0.24 & -0.23 \\
\hline
\end{tabular}


Table 4: Continued.

\begin{tabular}{|c|c|c|c|}
\hline \multicolumn{4}{|l|}{$\mathrm{CH}_{2} \mathrm{NH}$} \\
\hline $\mathrm{N}\left({ }^{2} \mathrm{D}\right)+\mathrm{N}_{2} \rightarrow \mathrm{N}\left({ }^{4} \mathrm{~S}\right)+\mathrm{N}_{2}$ & -0.22 & & -0.70 \\
\hline $\mathrm{N}\left({ }^{2} \mathrm{D}\right)+\mathrm{CH}_{4} \rightarrow \mathrm{NH}+\mathrm{CH}_{3}$ & 0.24 & & \\
\hline $\mathrm{N}\left({ }^{2} \mathrm{D}\right)+\mathrm{CH}_{4} \rightarrow \mathrm{CH}_{2} \mathrm{NH}+\mathrm{H}$ & 0.51 & 0.33 & 0.50 \\
\hline $\mathrm{N}\left({ }^{2} \mathrm{D}\right)+\mathrm{C}_{2} \mathrm{H}_{4} \rightarrow \mathrm{CH}_{2} \mathrm{NCH}+\mathrm{H}$ & -0.43 & -0.29 & \\
\hline $\mathrm{N}\left({ }^{2} \mathrm{D}\right)+\mathrm{C}_{2} \mathrm{H}_{6} \rightarrow \mathrm{CH}_{2} \mathrm{NH}+\mathrm{CH}_{3}$ & 0.25 & & \\
\hline $\begin{aligned} \mathrm{N}\left({ }^{2} \mathrm{D}\right)+\mathrm{HCN} & \rightarrow \mathrm{CH}+\mathrm{N}_{2} \\
\mathrm{H}+\mathrm{C}_{2} \mathrm{H}_{4} & \rightarrow \mathrm{C}_{2} \mathrm{H}_{5}\end{aligned}$ & -0.38 & $\begin{array}{c}-0.30 \\
0.31\end{array}$ & \\
\hline $\mathrm{CH}_{2} \mathrm{NH}+\mathrm{H} \rightarrow \mathrm{CH}_{3} \mathrm{NH}$ & & -0.32 & -0.26 \\
\hline \multicolumn{4}{|l|}{$\mathrm{CH}_{3} \mathrm{C}_{3} \mathrm{~N}$} \\
\hline${ }^{\mathrm{I}} \mathrm{CH}_{2}+\mathrm{CH}_{4} \rightarrow \mathrm{CH}_{3}+\mathrm{CH}_{3}$ & -0.26 & & \\
\hline $\mathrm{C}_{2} \mathrm{~N}+\mathrm{H} \rightarrow \mathrm{HCN}+\mathrm{C}$ & -0.51 & & \\
\hline $\mathrm{C}_{2} \mathrm{~N}+\mathrm{C}_{2} \mathrm{H}_{4} \rightarrow \mathrm{CH}_{3} \mathrm{C}_{3} \mathrm{~N}+\mathrm{H}$ & 0.39 & & \\
\hline $\mathrm{CHCN}+\mathrm{H} \rightarrow \mathrm{C}_{2} \mathrm{~N}+\mathrm{H}_{2}$ & 0.30 & & \\
\hline $\mathrm{CHCN}+\mathrm{CH}_{3} \rightarrow \mathrm{C}_{2} \mathrm{H}_{3} \mathrm{CN}+\mathrm{H}$ & -0.20 & & \\
\hline $\mathrm{CH}_{3} \mathrm{C}_{3} \mathrm{~N}+\mathrm{H} \rightarrow \mathrm{H}_{4} \mathrm{C}_{4} \mathrm{~N}$ & -0.25 & -0.84 & -0.46 \\
\hline $\mathrm{C}_{2} \mathrm{H}+\mathrm{C}_{2} \mathrm{H}_{2} \rightarrow \mathrm{C}_{4} \mathrm{H}_{2}+\mathrm{H}$ & & & 0.20 \\
\hline $\mathrm{N}\left({ }^{4} \mathrm{~S}\right)+\mathrm{C}_{4} \mathrm{H}_{3} \rightarrow \mathrm{CH}_{2} \mathrm{C}_{3} \mathrm{~N}+\mathrm{H}$ & & & 0.31 \\
\hline $\mathrm{CH}_{2} \mathrm{C}_{3} \mathrm{~N}+\mathrm{H} \rightarrow \mathrm{CH}_{3} \mathrm{C}_{3} \mathrm{~N}$ & & & 0.47 \\
\hline \multicolumn{4}{|l|}{$\mathrm{C}_{2} \mathrm{~N}_{2}$} \\
\hline${ }^{1} \mathrm{CH}_{2}+\mathrm{CH}_{4} \rightarrow \mathrm{CH}_{3}+\mathrm{CH}_{3}$ & -0.28 & -0.28 & \multirow{6}{*}{0.23} \\
\hline${ }^{1} \mathrm{CH}_{2}+\mathrm{N}_{2} \rightarrow{ }^{3} \mathrm{CH}_{2}+\mathrm{N}_{2}$ & 0.25 & 0.24 & \\
\hline $\mathrm{N}\left({ }^{4} \mathrm{~S}\right)+\mathrm{CHCN} \rightarrow \mathrm{C}_{2} \mathrm{~N}_{2}+\mathrm{H}$ & 0.37 & 0.36 & \\
\hline $\mathrm{CN}+\mathrm{HNC} \rightarrow \mathrm{C}_{2} \mathrm{~N}_{2}+\mathrm{H}$ & 0.37 & 0.37 & \\
\hline $\mathrm{HNC}+\mathrm{H} \rightarrow \mathrm{HCN}^{2}+\mathrm{H}$ & -0.25 & -0.27 & \\
\hline $\mathrm{CHCN}+\mathrm{H} \rightarrow \mathrm{C}_{2} \mathrm{~N}+\mathrm{H}_{2}$ & -0.25 & -0.24 & \\
\hline $\mathrm{N}\left({ }^{4} \mathrm{~S}\right)+\mathrm{CH}_{2} \mathrm{CN} \rightarrow \mathrm{H}_{2} \mathrm{CN}+\mathrm{CN}$ & & & -0.21 \\
\hline $\mathrm{N}\left({ }^{4} \mathrm{~S}\right)+\mathrm{CH}_{2} \mathrm{CN} \rightarrow \mathrm{HC}_{2} \mathrm{~N}_{2}+\mathrm{H}$ & & & 0.56 \\
\hline $\mathrm{HC}_{2} \mathrm{~N}_{2}+\mathrm{H} \rightarrow \mathrm{C}_{2} \mathrm{~N}_{2}+\mathrm{H}_{2}$ & & & 0.28 \\
\hline $\mathrm{HC}_{2} \mathrm{~N}_{2}+\mathrm{H} \rightarrow \mathrm{HCN}+\mathrm{HNC}$ & & & -0.43 \\
\hline \multicolumn{4}{|l|}{$\mathrm{C}_{4} \mathrm{~N}_{2}$} \\
\hline${ }^{1} \mathrm{CH}_{2}+\mathrm{CH}_{4} \rightarrow \mathrm{CH}_{3}+\mathrm{CH}_{3}$ & -0.36 & -0.20 & \multirow{7}{*}{0.35} \\
\hline${ }^{1} \mathrm{CH}_{2}+\mathrm{N}_{2} \rightarrow{ }^{3} \mathrm{CH}_{2}+\mathrm{N}_{2}$ & 0.25 & & \\
\hline $\mathrm{N}\left({ }^{4} \mathrm{~S}\right)+\mathrm{HC}_{4} \mathrm{~N} \rightarrow \mathrm{C}_{4} \mathrm{~N}_{2}+\mathrm{H}$ & 0.23 & & \\
\hline $\mathrm{N}\left({ }^{2} \mathrm{D}\right)+\mathrm{HCN} \rightarrow \mathrm{CH}+\mathrm{N}_{2}$ & -0.34 & -0.27 & \\
\hline $\mathrm{HCN}+\mathrm{C}_{3} \mathrm{~N} \rightarrow \mathrm{C}_{4} \mathrm{~N}_{2}+\mathrm{H}$ & 0.26 & 0.25 & \\
\hline $\mathrm{CHCN}+\mathrm{CH}_{3} \rightarrow \mathrm{C}_{2} \mathrm{H}_{3}{ }^{2 \mathrm{CN}}+\mathrm{H}$ & -0.33 & & \\
\hline $\mathrm{HC}_{4} \mathrm{~N}+\mathrm{H} \rightarrow \mathrm{CH}_{2} \mathrm{C}_{3} \mathrm{~N}$ & -0.20 & & \\
\hline $\begin{array}{c}\mathrm{C}_{4} \mathrm{~N}_{2}+\mathrm{H} \rightarrow \mathrm{HC}_{4} \mathrm{~N}_{2} \\
\mathrm{~N}\left({ }^{4} \mathrm{~S}\right)+\mathrm{CHCN} \rightarrow \mathrm{C}_{2} \mathrm{~N}_{2}+\mathrm{H}\end{array}$ & & -0.58 & \\
\hline $\mathrm{N}\left({ }^{2} \mathrm{D}\right)+\mathrm{N}_{2} \rightarrow \mathrm{N}\left({ }^{4} \mathrm{~S}\right)+\mathrm{N}_{2}$ & & & -0.31 \\
\hline $\mathrm{CHCN}+\mathrm{H} \rightarrow \mathrm{C}_{2} \mathrm{~N}+\mathrm{H}_{2}$ & & & 0.33 \\
\hline
\end{tabular}




\section{Discussion}

\subsection{Sensitivity to Galactic Cosmic Rays}

The production of nitrogen atoms in the lower stratosphere by GCR increases the production of many nitrogen compounds. We show in Figure 16 the mole fractions of the most abundant species which are affected by this process. The contribution of GCR in the production of amines like $\mathrm{NH}_{3}, \mathrm{CH}_{3} \mathrm{NH}_{2}$ and $\mathrm{CH}_{3} \mathrm{NHCH}_{3}$ or imines like $\mathrm{CH}_{2} \mathrm{NH}$ is particularly remarkable since their mole fractions decrease by about 3 orders of magnitude when turning off the production of $\mathrm{N}$ atoms by GCR. Some nitriles like $\mathrm{HNC}, \mathrm{C}_{2} \mathrm{~N}_{2}, \mathrm{C}_{4} \mathrm{~N}_{2}$ and $\mathrm{C}_{2} \mathrm{H}_{3} \mathrm{CN}$ are also efficiently produced by chemical processes following the interaction of GCR with $\mathrm{N}_{2}$. The effect for other species is much less pronounced or negligible. It is also important to pinpoint that the GCR precipitation spectrum in the atmosphere of Titan depends on the solar activity. The production of $\mathrm{N}$ atoms by GCR considered in the present study corresponds to a low solar activity (high GCR production rate). For a high solar activity, the GCR production rate can be $30 \%$ lower (Gronoff et al., 2011). The nitrogen chemistry induced by GCR is very similar to the nitrogen chemistry induced by $\mathrm{N}_{2}$ photodissociation as GCR lead to the formation of $\left.\mathrm{N}^{4} \mathrm{~S}\right)$ and $\mathrm{N}\left({ }^{2} \mathrm{D}\right)$ (considering the large uncertainty of cosmic ray effects we do not consider cosmic ray ion formation in this study). The chemistry induced by GCR is mainly localized in the lower stratosphere. The $\mathrm{N}_{2}$ dissociation flux induced by GCR is smaller than the $\mathrm{N}_{2}$ photodissociation flux. For very stable species, such HCN which is formed efficiently in the upper atmosphere and transported to lower altitudes by diffusion, the supplementary lower atmosphere production by GCR does not drastically change the abundance profile. However, for photo-sensible species (amines and imines) and for reactive species ( $\mathrm{HNC}, \mathrm{C}_{2} \mathrm{H}_{3} \mathrm{CN}$ ) which do not have time to diffuse, lower atmospheric production by GCR leads to a notable increase of their abundance in the lower stratosphere. $\mathrm{C}_{2} \mathrm{~N}_{2}$ is a special case, the production from $\mathrm{N}+$ $\mathrm{HCCN}$ in the lower stratosphere is comparable to transport as the $\mathrm{H}$ atom concentration decreases in the lower stratosphere due to the $\mathrm{H}+\mathrm{C}_{2} \mathrm{H}_{2}$ reaction so that the main HCCN loss process, the $\mathrm{H}+\mathrm{HCCN}$ reaction, is less efficient.

\subsection{Epistemic bimodalities}

More or less pronounced epistemic bimodalities are present in the distribution of Monte-Carlo profiles generated by our uncertainty propagation study for some compounds (like $\mathrm{HC}_{3} \mathrm{~N}$ and $\mathrm{C}_{2} \mathrm{H}_{5} \mathrm{CN}$ ) at some altitudes. These bimodalities are called epistemic because they are due to the uncertainties on certain key reaction rates. Bimodalities were observed in Dobrijevic et al. (2008) for $\mathrm{C}_{2} \mathrm{H}_{2}$ and $\mathrm{C}_{2} \mathrm{H}_{4}$ but subsequent improvements of the chemical scheme have removed these effects. In the present study, the introduction of new compounds and reactions to improve the chemical scheme of nitrogen compounds cause the appearance of some new bimodalities for some nitrogen compounds. The key reactions that are responsible of this behaviour are given in Tables 3 and 4 . These reactions need to be investigated to lower the current uncertainties in our model. 

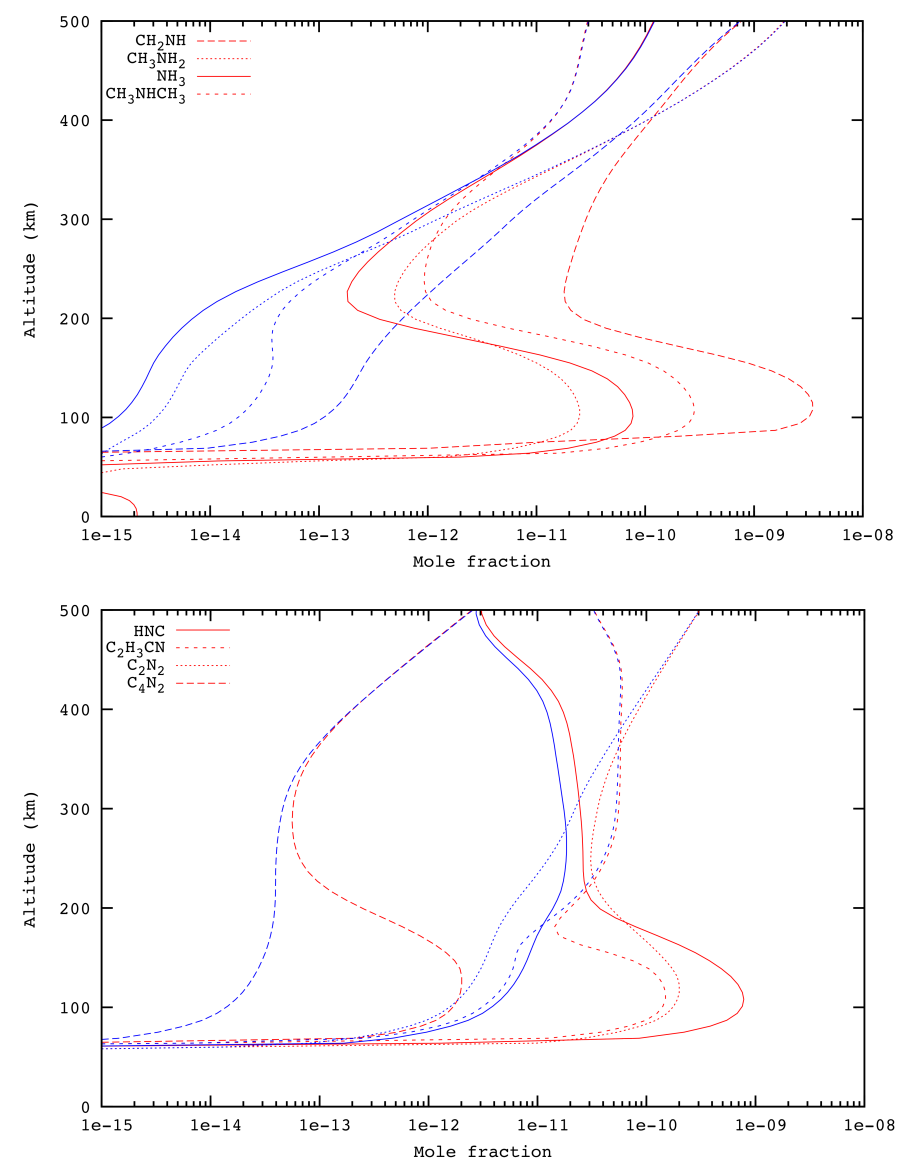

Figure 16: Effect of Galactic Cosmic Rays (GCR) on the production of several nitrogen compounds in the lower atmosphere of Titan. Red: nominal model with $\mathrm{N}$ atoms produced by GCR. Blue: model with no GCR. 


\subsection{Towards higher complexity}

A large fraction of the nitriles formed in Titan's atmosphere are unsaturated nitriles $\left(\mathrm{C}_{2} \mathrm{H}_{3} \mathrm{CN}, \mathrm{HC}_{3} \mathrm{~N}, \mathrm{CH}_{3} \mathrm{C}_{3} \mathrm{~N}, \mathrm{HC}_{5} \mathrm{~N}, \mathrm{C}_{4} \mathrm{H}_{3} \mathrm{CN}, \mathrm{C}_{4} \mathrm{H}_{5} \mathrm{CN}\right)$ which then react relatively quickly with $\mathrm{H}$ atoms leading to adducts. These adducts will react quickly with $\mathrm{H}$ atoms and $\mathrm{CH}_{3}$ radicals, but also with hydrocarbon radicals $\mathrm{C}_{2} \mathrm{H}_{3}, \mathrm{C}_{2} \mathrm{H}_{5}, \mathrm{C}_{3} \mathrm{H}_{7}$, leading either to $\mathrm{HCN}$ and hydrocarbons or to larger nitriles. Moreover, unsaturated nitriles photodissociate in the 190-230 nm range for which the solar flux is strong down to low altitudes forming some HCN and hydrocarbon radicals. $\mathrm{H}$ atoms (or $\mathrm{CH}_{3}$ radicals) are also lost with a nitrile radical species as the coproduct which can go on to form larger nitriles through reaction with hydrocarbon radicals. It is difficult to describe this full network in detail but there is no doubt that a large variety of nitriles are synthesized in Titan's atmosphere. Nevertheless, only the saturated ones $\left(\mathrm{HCN}, \mathrm{CH}_{3} \mathrm{CN}\right.$ and probably $\mathrm{C}_{2} \mathrm{H}_{5} \mathrm{CN}$ and $\mathrm{C}_{3} \mathrm{H}_{7} \mathrm{CN}$ ) can reach high abundances because they are not easily photodissociated and do not react with $\mathrm{H}$ atoms.

\subsection{Hot topics and new insights}

- In our model $\mathrm{C}_{2} \mathrm{H}_{3} \mathrm{CN}, \mathrm{HC}_{5} \mathrm{~N}$ and $\mathrm{C}_{4} \mathrm{~N}_{2}$ do not reach large concentrations in the gas-phase, in agreement with the non-detection of these compounds: $\mathrm{C}_{2} \mathrm{H}_{3} \mathrm{CN}$ is easily photodissociated and the rate constant of the $\mathrm{C}_{2} \mathrm{H}_{3}+$ $\mathrm{HCN}$ reaction is much slower than in previous models; for $\mathrm{HC}_{5} \mathrm{~N}$, the $\mathrm{C}_{3} \mathrm{~N}+\mathrm{C}_{2} \mathrm{H}_{2}$ reaction involves low rates as $\mathrm{C}_{3} \mathrm{~N}$ reacts quickly with $\mathrm{CH}_{4}$; $\mathrm{C}_{4} \mathrm{~N}_{2}$ reacts quickly with $\mathrm{H}$ atoms leading to $\mathrm{HCN}+\mathrm{HC}_{3} \mathrm{~N}$ (the high reactivity of $\mathrm{C}_{4} \mathrm{~N}_{2}$ with $\mathrm{H}$ atoms is questionable and should be confirmed by experimental and additional theoretical studies). The low abundance of $\mathrm{HC}_{5} \mathrm{~N}$ and $\mathrm{C}_{2} \mathrm{H}_{3} \mathrm{CN}$ in the stratosphere has a low uncertainty which is not the case for $\mathrm{C}_{4} \mathrm{~N}_{2}$.

- $\mathrm{CH}_{3} \mathrm{C}_{3} \mathrm{~N}$, formed through the $\mathrm{CCN}+\mathrm{C}_{2} \mathrm{H}_{2}$ and $\mathrm{CCN}+\mathrm{C}_{2} \mathrm{H}_{4}$ reactions, reaches a high concentration in the upper atmosphere. The HCCN $+\mathrm{H}$ reaction is critical and further experimental and theoretical studies are needed.

- $\mathrm{C}_{2} \mathrm{H}_{5} \mathrm{CN}$ and $\mathrm{C}_{3} \mathrm{H}_{7} \mathrm{CN}$ reach high concentrations in the stratosphere but their photodissociation cross sections are poorly known and should be studied. These compounds could give an interesting constraint for the model of Hourdin et al. (2004), since they should present a high polar enrichment.

- Nitriles present a low energy triplet state, which may be responsible for non negligible absorption in the 200-350 nm range. In particular, cross sections of $\mathrm{CH}_{3} \mathrm{CN}, \mathrm{C}_{2} \mathrm{H}_{5} \mathrm{CN}$ and $\mathrm{C}_{3} \mathrm{H}_{7} \mathrm{CN}$ at ambient and low temperature are needed. The quantum yields of $\mathrm{C}_{2} \mathrm{H}_{3} \mathrm{CN}$ photolysis are not well-known. It is important in particular to evaluate the yield for $\mathrm{HNC}$ production. Also, the quantum yields for $\mathrm{CH}_{4}$ and $\mathrm{C}_{2} \mathrm{H}_{2}$ in the full wavelength range where they are dissociated is required to better compute the abundances of hydrocarbons and $\mathrm{H}$ atoms. 
- The excited state chemistry of some molecules is required, in particular for $\mathrm{C}_{2} \mathrm{H}_{2}^{* *}$.

- The abundances of all nitriles are directly dependent on the photodissociation of $\mathrm{N}_{2}$ which is not well known and depends on the variation of the solar flux.

- The large decrease of the $\mathrm{HC}_{3} \mathrm{~N}$ abundance below $400 \mathrm{~km}$ is not well described by our 1D photochemical model and seems not to be related to chemical processes.

- Cosmic rays induce a relatively active nitrogen chemistry in the stratosphere leading to notable $\mathrm{CH}_{2} \mathrm{NH}$ and non-negligible $\mathrm{NH}_{3}$ and $\mathrm{CH}_{3} \mathrm{NH}_{2}$ concentrations. Ionic chemistry is likely to be very different in this region than in the upper atmosphere as most of the electrons should stick to aerosols. Due to their high proton affinity, $\mathrm{CH}_{2} \mathrm{NH}, \mathrm{NH}_{3}$ and $\mathrm{CH}_{3} \mathrm{NH}_{2}$ should easily be protonated. Nevertheless, the main $\mathrm{CH}_{2} \mathrm{NH}_{2}^{+}, \mathrm{NH}_{4}^{+}$and $\mathrm{CH}_{3} \mathrm{NH}_{3}^{+}$reactions will not be dissociative electronic recombination but rather sticking to negatively charged aerosols leading to a net loss. In particular, $\mathrm{CH}_{2} \mathrm{NH}$ will probably not lead to $\mathrm{NH}_{3}$ formation in the lower atmosphere.

\section{Conclusion}

We have made a careful investigation of the neutral chemistry of nitrogen compounds in the atmosphere of Titan. Our model includes 60 species containing nitrogen atoms with the heaviest molecule reaching a molar mass of 93 amu. We have built a consistent chemical scheme based on the abundances of the main species and their reactivity. Many rate constants and their uncertainty factors have been calculated or estimated based on theoretical considerations. Based on this new scheme, we have computed the mole fraction profiles for all of these compounds and we have studied how associated rate constant uncertainties affect these profiles. For some species like HCN, uncertainties on model results are reasonable. For other nitrogen containing species (like $\mathrm{HC}_{3} \mathrm{~N}$, $\mathrm{C}_{2} \mathrm{H}_{3} \mathrm{CN}, \mathrm{CH}_{3} \mathrm{C}_{3} \mathrm{~N}$ ), uncertainties are very large. We carried out a global sensitivity analysis to determine the key reactions that are responsible for these uncertainties. Most of the key reactions are reactions that have yet to be studied at low temperature, many of these involve reactions with $\mathrm{H}$ atoms. Several species newly introduced into our photochemical model have not been detected yet and are relatively abundant (like $\mathrm{CH}_{3} \mathrm{C}_{3} \mathrm{~N}$ and $\mathrm{C}_{3} \mathrm{H}_{7} \mathrm{CN}$ ). Our study shows that the photolysis of several compounds plays a crucial role in the chemistry of nitriles and should be studied in depth, with particular reference to $\mathrm{CH}_{3} \mathrm{CN}$, $\mathrm{C}_{2} \mathrm{H}_{5} \mathrm{CN}, \mathrm{C}_{3} \mathrm{H}_{7} \mathrm{CN}$ and $\mathrm{C}_{2} \mathrm{H}_{2}$. Compared to observations, our model overestimates the abundances of several species in the lower stratosphere for equatorial and equinoxial conditions. This is particularly marked for $\mathrm{HC}_{3} \mathrm{~N}$ and $\mathrm{C}_{2} \mathrm{H}_{5} \mathrm{CN}$. Since our 1D photochemical model gives satisfactory results for many compounds $\left(\mathrm{C}_{2^{-}}\right.$and $\mathrm{C}_{3}$-hydrocarbons, water $)$, this discrepancy is thought not to 
be brought about by a poor description of the chemistry but could rather be explained by meridional transport and condensation in the polar region as proposed for instance by Hourdin et al. (2004). If we consider that this model is correct and following our own results, we predict that $\mathrm{C}_{2} \mathrm{H}_{5} \mathrm{CN}$ and $\mathrm{C}_{3} \mathrm{H}_{7} \mathrm{CN}$ should also present high polar enrichment factors. For most of the species, good agreement is obtained between our 1D photochemical model and INMS data in the higher atmosphere despite the fact that we do not take ionic reactions into account. For all the main nitrogen compounds, we have identified the main production and loss pathways. We find that nitrile photolysis is important in the overall nitrogen chemistry. However, the absorption cross sections for many compounds are not well known. In particular, the cross section for wavelengths greater than $150 \mathrm{~nm}$ for $\mathrm{CH}_{3} \mathrm{CN}, \mathrm{C}_{2} \mathrm{H}_{5} \mathrm{CN}$ and $\mathrm{C}_{3} \mathrm{H}_{7} \mathrm{CN}$ and the absorption of $\mathrm{CH}_{3} \mathrm{C}_{3} \mathrm{~N}$ are unknown. Quantum yields as a function of wavelength for almost all the species are not determined. We have identified two main chemical pathways in the complexification of nitrogen compounds. Most of the nitrogen atoms produced by the dissociation of $\mathrm{N}_{2}$ lead to the production of $\mathrm{HCN}$. Its photolysis leads to the production of $\mathrm{CN}$ radicals which are the precursors for numerous nitriles (including $\mathrm{HC}_{3} \mathrm{~N}, \mathrm{C}_{2} \mathrm{H}_{3} \mathrm{CN}, \mathrm{CH}_{3} \mathrm{CN} \ldots$ ), which are produced along the pathways to more complex nitrogen containing compounds. Another distinct pathway for the complexification of nitrogen compounds goes through $\mathrm{C}_{2} \mathrm{~N}$, which is also a precursor for many other complex nitriles (like $\mathrm{CH}_{3} \mathrm{C}_{3} \mathrm{~N}$...). The next step for these neutral photochemical modeling studies should be the coupling with a ionospheric model. Many nitrogen species would be affected by this coupling in the higher atmosphere. As shown by Plessis et al. (2012); Krasnopolsky (2009); Vuitton et al. (2006), ionic chemistry contributes significantly to the production of neutral compounds, despite only a minor production of $\mathrm{HCN}$ initiated by $\mathrm{N}^{+}$reactions. Moreover, as ionic chemistry is driven mainly by $\mathrm{H}^{+}$transfer between ions and neutrals with large protonic affinity, ionic chemistry act as a sink for large nitriles and $\mathrm{CH}_{2} \mathrm{NH}$ as the corresponding protonated form reacts mainly with electrons leading back to the neutral form at levels less than $100 \%$. Secondly, negative ion chemistry involves nitrogen containing anions $\left(\mathrm{CN}^{-}\right.$and $\mathrm{C}_{3} \mathrm{~N}^{-}$, Vuitton et al. (2009)) so it will be interesting to couple our coherent neutral scheme with anion chemistry too.

\section{Acknowledgement}

We thank the Programme National de Plantologie (PNP) of the Institut National des Sciences de l'Univers (INSU) for funding a part of this work. O.V. acknowledges support from the KU Leuven IDO project IDO/10/2013 and from the FWO Postdoctoral Fellowship program.

\section{Appendix A. Nitrogen chemistry overview}

In this section, we highlight the main chemical pathways leading to the production of the most abundant nitrogen species in Titan's atmosphere. 
Appendix A.1. Primary nitrogen chemistry

Nitrogen chemistry is mostly initiated by nitrogen atoms in the ground state $\mathrm{N}\left({ }^{4} \mathrm{~S}\right)$ and excited state $\mathrm{N}\left({ }^{2} \mathrm{D}\right)$ produced by $\mathrm{N}_{2}$ photodissociation and dissociation by cosmic rays. In Titan's upper atmosphere, $\mathrm{N}\left({ }^{4} \mathrm{~S}\right)$ reacts mainly with $\mathrm{CH}_{3}$ radicals leading to $\mathrm{H}_{2} \mathrm{CN}+\mathrm{H}$ and $\mathrm{HCN}+\mathrm{H}+\mathrm{H}$ (Hébrard et al., 2012; Dutuit et al., 2013). $\mathrm{H}_{2} \mathrm{CN}$ then reacts quickly with atomic hydrogen (and $\mathrm{CH}_{3}$ radicals) leading mainly to $\mathrm{HCN}$ and some $\mathrm{HNC}$, which is efficiently converted to HCN through reaction with H atoms (Talbi and Ellinger, 1996; Sumathi and Nguyen, 1998; Petrie, 2002). At this point, HCN can only be lost through photodissociation or through minor reactions with $\mathrm{N}\left({ }^{2} \mathrm{D}\right)$ and $\mathrm{CH}$ radicals (Hébrard et al., 2012). HCN is therefore stable in Titan's upper atmosphere and its steady state concentration is relatively high. Below $200 \mathrm{~km}$ the situation is more complex: $\mathrm{N}\left({ }^{4} \mathrm{~S}\right)$ (produced in the lower atmosphere by $\mathrm{N}_{2}$ dissociation by cosmic rays) reacts not only with $\mathrm{CH}_{3}$ radicals but also with the numerous alkyl radicals that are efficiently produced through three body association reactions with $\mathrm{H}$ atoms. For $\mathrm{N}\left({ }^{2} \mathrm{D}\right)$, the situation is almost the opposite in complexity. In Titan's upper atmosphere, $\mathrm{N}\left({ }^{2} \mathrm{D}\right)$ atoms react mainly with $\mathrm{HCN}$ (albeit with a large associated uncertainty (Hébrard et al., 2012)), with $\mathrm{CH}_{4}, \mathrm{C}_{2} \mathrm{H}_{2}$ and $\mathrm{C}_{2} \mathrm{H}_{4}$ (Herron, 1999) and are also partly relaxed to $\mathrm{N}\left({ }^{4} \mathrm{~S}\right)$ (Herron, 1999). Below 200 $\mathrm{km}$ however, $\mathrm{N}\left({ }^{2} \mathrm{D}\right)$ reacts almost exclusively with $\mathrm{CH}_{4}$. The reaction of $\mathrm{N}\left({ }^{2} \mathrm{D}\right)$ atoms with $\mathrm{HCN}$ should lead to $\mathrm{CH}+\mathrm{N}_{2}$ (Hébrard et al., 2012) and is therefore a net loss of nitriles. The reaction of $\mathrm{N}\left({ }^{2} \mathrm{D}\right)$ with $\mathrm{CH}_{4}$ leads to $\mathrm{CH}_{2} \mathrm{NH}+\mathrm{H}$ and $\mathrm{CH}_{3}+\mathrm{NH}$ (Herron, 1999; Ouk et al., 2011; Takayanagi and Kurosaki, 1999; Takayanagi et al., 1999; Balucani et al., 2009). NH radicals mainly react with $\mathrm{CH}_{3}$ leading to $\mathrm{CH}_{2} \mathrm{NH}+\mathrm{H}$ (Redondo et al., 2006) with a minor contribution from the $\mathrm{N}\left({ }^{4} \mathrm{~S}\right)+\mathrm{NH}$ reaction leading to $\mathrm{N}_{2}+\mathrm{H}$ (Hack et al., 1994; Caridade et al., 2005; Frankcombe and Nyman, 2007). $\mathrm{CH}_{2} \mathrm{NH}$ is easily photodissociated in the UV (Teslja et al., 2004) leading to $\mathrm{H}_{2} \mathrm{CN}+\mathrm{H}, \mathrm{HCN}+\mathrm{H}+\mathrm{H}$ and $\mathrm{HNC}+\mathrm{H}_{2}$ (Zhou and Schlegel, 2009; Nguyen et al., 1996) or reacts with $\mathrm{H}$ atoms leading to $\mathrm{H}_{2} \mathrm{CN}+\mathrm{H}_{2}$ (Tomeczek and Gradon, 2003). As already noted, $\mathrm{H}_{2} \mathrm{CN}$ reacts mainly with $\mathrm{H}$ atoms leading mainly to $\mathrm{HCN}$ and some $\mathrm{HNC}$, which is efficiently converted into $\mathrm{HCN}$ through reaction with $\mathrm{H}$ atoms. As a result, reaction of $\mathrm{N}\left({ }^{2} \mathrm{D}\right)$ with $\mathrm{CH}_{4}$ leads mainly to $\mathrm{HCN}$ with only low $\mathrm{HNC}$ and $\mathrm{CH}_{2} \mathrm{NH}$ steady state abundances. The $\mathrm{N}\left({ }^{2} \mathrm{D}\right)+\mathrm{C}_{2} \mathrm{H}_{4}$ reaction has been studied experimentally and theoretically (Sato et al., 1999; Takayanagi et al., 1998; Lee et al., 2011; Balucani et al., 2000b, 2012). Contrary to what is considered in usual models of Titan's atmosphere (Lebonnois et al., 2001; Wilson and Atreya, 2004; Lavvas et al., 2008; Krasnopolsky, 2009), the products are not $\mathrm{H}$ $+\mathrm{CH}_{3} \mathrm{CN}$, but rather $\mathrm{H}+\mathrm{CH}_{2} \mathrm{NCH}$ and $\mathrm{H}+\mathrm{c}_{-} \mathrm{CH}_{2}(\mathrm{~N}) \mathrm{CH}$ (cyclic compound) (Balucani et al., 2012; Lee et al., 2011). This non-production of $\mathrm{CH}_{3} \mathrm{CN}$ is of crucial importance as it was thought to be the main (if not only) source of $\mathrm{CH}_{3} \mathrm{CN}$. In this study we use the RRKM results of Balucani et al. (2012) leading to $74 \%$ of $\mathrm{CH}_{2} \mathrm{NCH}$ production and $26 \%$ of $\mathrm{c}-\mathrm{CH}_{2}(\mathrm{~N}) \mathrm{CH}$ production. We then introduced these new compounds and developed their chemical networks relevant for Titan chemistry. $\mathrm{CH}_{2} \mathrm{NCH}$ is a diradical with a singlet ground state $\left(\mathrm{H}_{2} \mathrm{C} \cdot \mathrm{N}=\mathrm{C} \cdot \mathrm{H} \leftrightarrow \mathrm{H}_{2} \mathrm{C}=\mathrm{N}-\mathrm{C} \cdot \mathrm{H}\right)$ and should react quickly with atoms and rad- 
icals, particularly with $\mathrm{H}$ atoms as shown by theoretical calculations (Balucani et al., 2012; Lee et al., 2011) probably leading to $\mathrm{CH}_{3}+\mathrm{HCN}$. As there is likely to be no barrier in the entrance valley for the $\mathrm{CH}_{2} \mathrm{NCH}+\mathrm{H}$ reaction we consider a rate constant deduced from capture rate theory. We also consider the $\mathrm{CH}_{2} \mathrm{NCH}+\mathrm{CH}_{3} \rightarrow \mathrm{C}_{2} \mathrm{H}_{5}+\mathrm{HCN}$ reaction with a rate constant of $2.0 \times 10^{-11}$ $\mathrm{cm}^{3}$ molecule ${ }^{-1} \mathrm{~s}^{-1}$. c- $\mathrm{CH}_{2}(\mathrm{~N}) \mathrm{CH}$ is a closed-shell molecule and much less reactive than $\mathrm{CH}_{2} \mathrm{NCH}$. Balucani et al. (2012); Lee et al. (2011) found a barrier close to $14 \mathrm{~kJ} \mathrm{~mol}^{-1}$ for $\mathrm{H}$ addition leading to $\mathrm{c}-\mathrm{CH}_{2}(\mathrm{~N}) \mathrm{CH}_{2}$ or $\mathrm{c}-\mathrm{CH}_{2}(\mathrm{NH}) \mathrm{CH}$. The c- $\mathrm{CH}_{2}(\mathrm{~N}) \mathrm{CH}_{2}$ production channel seems to have no bimolecular exit channel and as $\mathrm{c}-\mathrm{CH}_{2}(\mathrm{~N}) \mathrm{CH}$ is formed at high altitude where the pressure is low and stabilization is weak then we neglect this channel as $\mathrm{c}-\mathrm{CH}_{2}(\mathrm{~N}) \mathrm{CH}_{2}$ will backdissociate into $\mathrm{c}-\mathrm{CH}_{2}(\mathrm{~N}) \mathrm{CH}+\mathrm{H}$. The other adduct, $\mathrm{c}-\mathrm{CH}_{2}(\mathrm{NH}) \mathrm{CH}$, is described in the theoretical calculations of Balucani et al. (2012) and should isomerize toward $\mathrm{CH}_{2} \mathrm{CHNH}$ and then lead to $\mathrm{CH}_{2} \mathrm{CNH}+\mathrm{H}$ through a loose barrier or isomerize toward $\mathrm{CH}_{3} \mathrm{CNH}$ and then $\mathrm{CH}_{3} \mathrm{CN}+\mathrm{H}$. $\mathrm{CH}_{2} \mathrm{CNH}$ formation will be favored due to loose transition state. Considering the theoretical calculations we propose a global rate constant equal to $1.0 \times 10^{-10} \exp (-1600 / T)$, close to the rate of the $\mathrm{H}+\mathrm{C}_{2} \mathrm{H}_{4}$ reaction, with $70 \%$ of $\mathrm{CH}_{2} \mathrm{CNH}+\mathrm{H}$ production and $30 \% \mathrm{CH}_{3} \mathrm{CN}+\mathrm{H}$ production. As c- $\mathrm{CH}_{2}(\mathrm{~N}) \mathrm{CH}$ reacts relatively slowly with $\mathrm{H}$ atoms we need to consider $\mathrm{c}-\mathrm{CH}_{2}(\mathrm{~N}) \mathrm{CH}$ photodissociation, the absorption spectrum being calculated at the EOM-CCSD/cc-pVTZ level using Gaussian 2009; the photodissociation products being $\mathrm{c}-{ }^{1} \mathrm{CH}_{2}(\mathrm{~N}) \mathrm{CH}+\mathrm{h} \nu \rightarrow{ }^{1} \mathrm{CH}_{2}+{ }^{1} \mathrm{HCN}$. We also consider the reactions of $\mathrm{c}-\mathrm{CH}_{2}(\mathrm{~N}) \mathrm{CH}$ with highly reactive radicals $\mathrm{N}\left({ }^{2} \mathrm{D}\right), \mathrm{CH}, \mathrm{C}_{2} \mathrm{H}, \mathrm{CN}$ estimating rate constants equal to the rate constants for the corresponding reactions with $\mathrm{C}_{2} \mathrm{H}_{4}$. The main reactions of $\mathrm{c}-\mathrm{CH}_{2}(\mathrm{~N}) \mathrm{CH}$ are photodissociation and reaction with $\mathrm{H}$ atoms. $\mathrm{CH}_{2} \mathrm{NCH}$ and $\mathrm{c}-\mathrm{CH}_{2}(\mathrm{~N}) \mathrm{CH}$ have low steady state concentrations because they are efficiently converted into $\mathrm{HCN}$. The reaction of $\mathrm{N}\left({ }^{2} \mathrm{D}\right)$ with $\mathrm{C}_{2} \mathrm{H}_{2}$ leads to $\mathrm{HCCN}$ formation (Takayanagi et al., 1998; Herron, 1999). HCCN, a di-radical with a triplet ground state, should have low reactivity with closed-shell molecules (Adamson et al., 1997) so it will react in Titan's atmosphere mainly with $\mathrm{H}$ atoms leading to CCN $+\mathrm{H}_{2}$ (Osamura and Petrie, 2004; Takayanagi et al., 1998). CCN is a very reactive radical (Wang et al., 2006) but not with $\mathrm{CH}_{4}$ (Zhu et al., 2003a,b). As a result, in Titan's atmosphere $\mathrm{CCN}$ radicals will react mainly with $\mathrm{C}_{2} \mathrm{H}_{2}$ (leading to $\mathrm{HC}_{4} \mathrm{~N}$ (Wang et al., 2006)), with $\mathrm{C}_{2} \mathrm{H}_{4}$ (leading to $\mathrm{CH}_{3} \mathrm{C}_{3} \mathrm{~N}$ (Wang et al., 2006)) and with $\mathrm{H}$ atoms (leading to $\mathrm{HCN}+\mathrm{C}$ (Mebel and Kaiser, 2002; Takahashi and Takayanagi, 2006)). $\mathrm{HC}_{4} \mathrm{~N}$ is a strongly bound radical and is likely to be unreactive with closed-shell molecules by comparison with HCCN and without bimolecular exit channels for reaction with $\mathrm{H}$ atoms. Then in the low pressures of Titan's upper atmosphere where it is formed, $\mathrm{HC}_{4} \mathrm{~N}$ will slowly react, through addition, with $\mathrm{H}$ atoms leading to $\mathrm{CH}_{2} \mathrm{C}_{3} \mathrm{~N}$, with $\mathrm{CH}_{3}$ (leading likely to $\mathrm{C}_{4} \mathrm{H}_{3} \mathrm{CN}+\mathrm{H}$ atom) and with $\mathrm{N}\left({ }^{4} \mathrm{~S}\right)$ (leading likely mainly to $\mathrm{C}_{4} \mathrm{~N}_{2}+$ $\mathrm{H})$. The reactions of $\mathrm{N}\left({ }^{4} \mathrm{~S}\right)$ with $\mathrm{HCCN}$ and $\mathrm{HC}_{4} \mathrm{~N}$ are the main $\mathrm{C}_{2} \mathrm{~N}_{2}$ and $\mathrm{C}_{4} \mathrm{~N}_{2}$ production pathways in the present model. As there is no exothermic bimolecular exit channel for the $\mathrm{H}+\mathrm{HC}_{4} \mathrm{~N}$ reaction, in contrast to $\mathrm{H}+\mathrm{HCCN}, \mathrm{HC}_{4} \mathrm{~N}$ should reach a non-negligible steady state abundance leading to relatively large 
$\mathrm{C}_{4} \mathrm{~N}_{2}$ abundance. In the upper atmosphere, the production of $\mathrm{CN}$ and $\mathrm{CCN}$ radicals leads to a rich nitrile chemistry $\left(\mathrm{HC}_{3} \mathrm{~N}, \mathrm{C}_{2} \mathrm{H}_{3} \mathrm{C}_{3} \mathrm{~N} \mathrm{CH}_{3} \mathrm{C}_{3} \mathrm{~N}, \mathrm{C}_{4} \mathrm{H}_{3} \mathrm{CN}\right.$, $\mathrm{C}_{2} \mathrm{H}_{5} \mathrm{C}_{3} \mathrm{~N}$ ) which is enhanced by the addition of $\mathrm{H}$ atoms to double and triple $\mathrm{CC}$ bonds $\left(\mathrm{H}+\mathrm{CH}_{3} \mathrm{C}_{3} \mathrm{~N} \rightarrow \mathrm{CH}_{3} \mathrm{CH}=\mathrm{C}-\mathrm{CN}\right.$, followed by $\mathrm{H}+\mathrm{CH}_{3} \mathrm{CH}=\mathrm{C}-\mathrm{CN}$ $\rightarrow \mathrm{CH}_{3} \mathrm{CH}=\mathrm{CH}-\mathrm{CN}$ and $\left.\mathrm{CH}_{3}+\mathrm{CH}_{3} \mathrm{CH}=\mathrm{C}-\mathrm{CN} \rightarrow \mathrm{CH}_{3} \mathrm{CH}=\mathrm{C}\left(\mathrm{CH}_{3}\right)-\mathrm{CN}\right)$ as their barriers are relatively low and the size of the molecules leads to relatively high rate constant at the low pressure limit $k_{0}$. The chemistry of $\mathrm{N}$ atoms thus leads mainly to $\mathrm{HCN}$ formation with some $\mathrm{CH}_{2} \mathrm{NH}, \mathrm{HNC}, \mathrm{CH}_{3} \mathrm{C}_{3} \mathrm{~N}$ (also $\mathrm{C}_{4} \mathrm{H}_{3} \mathrm{CN}, \mathrm{C}_{2} \mathrm{H}_{5} \mathrm{C}_{3} \mathrm{~N}, \ldots$ ), $\mathrm{CH}_{2} \mathrm{NCH}$ (or $\mathrm{CH}_{3} \mathrm{CN}$ ), $\mathrm{C}_{2} \mathrm{~N}_{2}$ and $\mathrm{C}_{4} \mathrm{~N}_{2}$ formation.

\section{Appendix A.2. Secondary nitrogen chemistry}

Secondary nitrogen chemistry is driven by HCN photodissociation (leading to H + CN (Herzberg, 1957; Lee, 1980; Guo et al., 2000; West and Berry, 1974)). $\mathrm{CN}$ radicals react mainly with $\mathrm{C}_{2} \mathrm{H}_{2}$ (leading to $\mathrm{H}+\mathrm{HC}_{3} \mathrm{~N}$ ) and $\mathrm{C}_{2} \mathrm{H}_{4}$ (leading to $\mathrm{H}+\mathrm{C}_{2} \mathrm{H}_{3} \mathrm{CN}$ ) in the upper atmosphere and with $\mathrm{C}_{2} \mathrm{H}_{2}$ (leading to $\mathrm{H}+$ $\mathrm{HC}_{3} \mathrm{~N}$ ) and with $\mathrm{CH}_{4}$ and $\mathrm{C}_{2} \mathrm{H}_{6}$ (leading back to $\mathrm{HCN}$ ) at low altitude. $\mathrm{CN}$ radicals also react quickly with $\mathrm{HNC}$ and $\mathrm{HC}_{3} \mathrm{~N}$ leading to additional secondary sources of $\mathrm{C}_{2} \mathrm{~N}_{2}$ and $\mathrm{C}_{4} \mathrm{~N}_{2}$. Therefore, secondary nitrogen chemistry, induced by $\mathrm{HCN}$ photodissociation, leads to $\mathrm{HC}_{3} \mathrm{~N}$ and $\mathrm{C}_{2} \mathrm{H}_{3} \mathrm{CN}$ formation. It should be noted that as HCN has a long chemical lifetime, it diffuses to low altitude. Since it is not shielded by $\mathrm{CH}_{4}$ the photodissociation flux of $\mathrm{HCN}$ is larger in the stratosphere than in the upper atmosphere leading to efficient $\mathrm{CN}$ chemistry at low altitude. $\mathrm{HC}_{3} \mathrm{~N}$ is photodissociated in the UV leading mainly to $\mathrm{H}+\mathrm{C}_{3} \mathrm{~N}$ with a low fraction of $\mathrm{C}_{2} \mathrm{H}+\mathrm{CN}$ products. As $\mathrm{C}_{3} \mathrm{~N}$ reacts quickly with $\mathrm{CH}_{4}$ (Fournier et al., 2014), its steady state abundance is very low, and the $\mathrm{C}_{3} \mathrm{~N}+\mathrm{C}_{2} \mathrm{H}_{2} \rightarrow \mathrm{HC}_{5} \mathrm{~N}+\mathrm{H}$ and $\mathrm{C}_{3} \mathrm{~N}+\mathrm{C}_{2} \mathrm{H}_{4} \rightarrow \mathrm{C}_{2} \mathrm{H}_{3} \mathrm{C}_{3} \mathrm{~N}+\mathrm{H}$ reactions have low fluxes. Therefore, $\mathrm{HC}_{3} \mathrm{~N}$ photodissociation does not lead to substantial new chemistry and the $\mathrm{CN}+\mathrm{HC}_{3} \mathrm{~N}$ pathway is only an additional minor $\mathrm{C}_{4} \mathrm{~N}_{2}$ source. $\mathrm{HC}_{3} \mathrm{~N}$ is lost mainly through reaction with $\mathrm{H}$ atoms in the lower atmosphere leading to $\mathrm{H}_{2} \mathrm{C}_{3} \mathrm{~N}$. $\mathrm{H}_{2} \mathrm{C}_{3} \mathrm{~N}$ radicals react mainly with $\mathrm{H}$ atom to form excited $\mathrm{C}_{2} \mathrm{H}_{3} \mathrm{CN}^{* *}$ which can either stabilize or form $\mathrm{HCN}+\mathrm{C}_{2} \mathrm{H}_{2}$ or $\mathrm{HC}_{3} \mathrm{~N}$ $+\mathrm{H}_{2}$ products. $\mathrm{C}_{2} \mathrm{H}_{3} \mathrm{CN}$ is a key molecule for nitriles chemistry. $\mathrm{C}_{2} \mathrm{H}_{3} \mathrm{CN}$ is produced by the $\mathrm{CN}+\mathrm{C}_{2} \mathrm{H}_{4}$ reaction (and in a minor way by the $\mathrm{C}_{2} \mathrm{H}_{3}+\mathrm{HCN}$ reaction). $\mathrm{C}_{2} \mathrm{H}_{3} \mathrm{CN}$ is easily photodissociated in the UV leading to $\mathrm{H}+\mathrm{H}_{2} \mathrm{C}_{4} \mathrm{~N}$ (also produced by $\mathrm{H}+\mathrm{HC}_{3} \mathrm{~N}$ reaction), $\mathrm{H}_{2}+\mathrm{HC}_{3} \mathrm{~N}, \mathrm{C}_{2} \mathrm{H}_{2}+\mathrm{HCN}$ and $\mathrm{C}_{2} \mathrm{H}_{2}$ + HNC. Apart from photodissociation, $\mathrm{C}_{2} \mathrm{H}_{3} \mathrm{CN}$ is mostly lost through its association with $\mathrm{H}$ atoms leading to $\mathrm{C}_{2} \mathrm{H}_{4} \mathrm{CN}$. $\mathrm{C}_{2} \mathrm{H}_{4} \mathrm{CN}$ reacts mainly with $\mathrm{H}$ atoms producing $\mathrm{CH}_{2} \mathrm{CN}+\mathrm{CH}_{3}$ and $\mathrm{C}_{2} \mathrm{H}_{5} \mathrm{CN}$ at low altitude. $\mathrm{C}_{2} \mathrm{H}_{4} \mathrm{CN}$ reacts also with $\mathrm{CH}_{3}$ leading to $\mathrm{C}_{3} \mathrm{H}_{7} \mathrm{CN}$. The $\mathrm{H}+\mathrm{C}_{2} \mathrm{H}_{4} \mathrm{CN}$ reaction is the main source of $\mathrm{CH}_{2} \mathrm{CN}$ (with a contribution of $\mathrm{N}\left({ }^{4} \mathrm{~S}\right)+\mathrm{C}_{2} \mathrm{H}_{3}$ between $100 \mathrm{~km}$ and $200 \mathrm{~km}$ ) and the $\mathrm{CH}_{2} \mathrm{CN}$ radical lead to $\mathrm{CH}_{3} \mathrm{CN}$ production through reaction with $\mathrm{H}$ and to $\mathrm{C}_{2} \mathrm{H}_{5} \mathrm{CN}$ through reaction with $\mathrm{CH}_{3}$. As there are no bimolecular exit channels for these two reactions, they are efficient $\mathrm{CH}_{3} \mathrm{CN}$ and $\mathrm{C}_{2} \mathrm{H}_{5} \mathrm{CN}$ production pathways. The $\mathrm{C}_{2} \mathrm{H}_{3} \mathrm{CN}+\mathrm{H}$ reaction is indeed the source of $\mathrm{CH}_{3} \mathrm{CN}$ in the present model as $\mathrm{CH}_{3} \mathrm{CN}$ is not produced by the $\mathrm{N}\left({ }^{2} \mathrm{D}\right)+\mathrm{C}_{2} \mathrm{H}_{4}$ reaction,

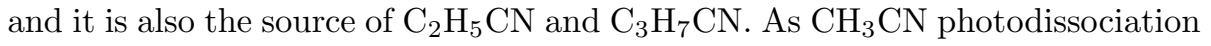


leads to $\mathrm{CH}_{2} \mathrm{CN}+\mathrm{H}$ (Eden et al., 2003; McElcheran et al., 1958; Moriyama et al., 1998) and $\mathrm{C}_{2} \mathrm{H}_{5} \mathrm{CN}$ photodissociation leads to $\mathrm{C}_{2} \mathrm{H}_{4} \mathrm{CN}+\mathrm{H}$ and $\mathrm{CH}_{2} \mathrm{CN}$ $+\mathrm{CH}_{3}$ and eventually to $\mathrm{C}_{2} \mathrm{H}_{4}+\mathrm{HCN}, \mathrm{CH}_{3} \mathrm{CN}$ and $\mathrm{C}_{2} \mathrm{H}_{5} \mathrm{CN}$ do not lead to the formation of new species, the ratio between $\mathrm{CH}_{3} \mathrm{CN}$ and $\mathrm{C}_{2} \mathrm{H}_{5} \mathrm{CN}$ depending on their losses by photodissociation and on the efficiency of $\mathrm{H}$ and $\mathrm{CH}_{3}$ addition reactions. It should be noted that there is a high level of correlation between $\mathrm{HC}_{3} \mathrm{~N}, \mathrm{C}_{2} \mathrm{H}_{3} \mathrm{CN}, \mathrm{C}_{2} \mathrm{H}_{5} \mathrm{CN}, \mathrm{C}_{3} \mathrm{H}_{7} \mathrm{CN}$ and $\mathrm{CH}_{3} \mathrm{CN}$. The third step of nitrogen chemistry leads to $\mathrm{CH}_{3} \mathrm{CN}, \mathrm{C}_{2} \mathrm{H}_{5} \mathrm{CN}$ and $\mathrm{C}_{3} \mathrm{H}_{7} \mathrm{CN}$ formation (and little $\mathrm{C}_{3} \mathrm{H}_{5} \mathrm{CN}, \mathrm{HC}_{5} \mathrm{~N}$ and $\left.\mathrm{C}_{2} \mathrm{H}_{3} \mathrm{C}_{3} \mathrm{~N}\right)$.

The neutral nitrogen chemistry in Titan's atmosphere leads mainly to nitriles because once formed, the triple $\mathrm{CN}$ bond is not easily broken by photodissociation and it is not very sensitive to chemical attack except from $\mathrm{N}\left({ }^{2} \mathrm{D}\right)$ which leads to relatively low loss rates. There are also minor production routes for imine and amine formation.

\section{Appendix A.3. The production of imines and amines}

The reactions of $\mathrm{N}\left({ }^{2} \mathrm{D}\right)$ with alkanes leads to imine formation (Herron, 1999; Balucani et al., 2009, 2010). However, except for $\mathrm{CH}_{2} \mathrm{NH}$, which is the main product of the $\mathrm{N}\left({ }^{2} \mathrm{D}\right)+\mathrm{CH}_{4}$ and $\mathrm{N}\left({ }^{2} \mathrm{D}\right)+\mathrm{C}_{2} \mathrm{H}_{6}$ reactions, the formation of other imines is weak $\left(\mathrm{N}\left({ }^{2} \mathrm{D}\right)+\mathrm{C}_{2} \mathrm{H}_{6} \rightarrow \mathrm{CH}_{3} \mathrm{CHNH}+\mathrm{H}\right.$ has a branching ratio of $12 \%$ only (Balucani et al., 2010)) and as imines absorb and photodissociate in the UV (Teslja et al., 2004) the steady state abundances are low. In the stratosphere, the three body association reaction $\mathrm{H}_{2} \mathrm{CN}+\mathrm{CH}_{3} \rightarrow \mathrm{H}_{2} \mathrm{CNCH}_{3}$ has a nonnegligible flux but $\mathrm{H}_{2} \mathrm{CNCH}_{3}$ should absorb in the UV by comparison with $\mathrm{CH}_{2} \mathrm{NH}$ (Teslja et al., 2004), probably leading to $\mathrm{H}_{2} \mathrm{CN}+\mathrm{CH}_{3}$ products rather than to $\mathrm{H}_{2} \mathrm{CNCH}_{2}+\mathrm{H}(58 \mathrm{~kJ} / \mathrm{mol}$ more endothermic $)$ and also eventually to $\mathrm{HCN} / \mathrm{HNC}+\mathrm{CH}_{4}$. As a result, the steady state abundance of this compound is also low.

In contrast to the ion chemistry of Titan's atmosphere, the neutral nitrogen chemistry leads to low amine abundances. Firstly, amines are very sensitive to photodissociation as they absorb in the 180-220 $\mathrm{nm}$ range (Edvardsson et al., 1999; Hubin-Franskin et al., 2002). They lead mainly to $\mathrm{N}_{2}$ formation through the $\mathrm{N}+\mathrm{NH}_{2} \rightarrow \mathrm{N}_{2}+\mathrm{H}+\mathrm{H}$ reaction at least in Titan's upper atmosphere. Secondly, amine formation systematically involves $\mathrm{NH}_{2}$ radicals $\left(\mathrm{NH}_{2}\right.$ $+\mathrm{H}_{2} \mathrm{CN}, \mathrm{C}_{2} \mathrm{H}_{5}, \mathrm{C}_{2} \mathrm{H}_{3}$ to form ammonia $\mathrm{NH}_{3}$ or $\mathrm{NH}_{2}+\mathrm{CH}_{3}$ to form methylamine $\left.\mathrm{CH}_{3} \mathrm{NH}_{2}\right) \cdot \mathrm{NH}_{2}$ is formed, through neutral chemistry, from $\mathrm{NH}$ radicals ( $\mathrm{NH}+\mathrm{H}_{2} \mathrm{CN}, \mathrm{C}_{2} \mathrm{H}_{5}, \mathrm{C}_{2} \mathrm{H}_{3}$ ) which involves low fluxes as $\mathrm{NH}$ reacts mainly in Titan's atmosphere with $\mathrm{CH}_{3}$ radicals to form $\mathrm{CH}_{2} \mathrm{NH}$. However, as shown by Yelle et al. (2010), $\mathrm{CH}_{2} \mathrm{NH}$ is an important source of $\mathrm{NH}_{2}$ in the upper atmosphere through ionic reactions. Indeed, due to the very high value of its proton affinity (Hunter and Lias, 1998), $\mathrm{CH}_{2} \mathrm{NH}$ is easily protonated through reaction with the major cations in Titan's upper atmosphere $\left(\mathrm{HCNH}^{+}, \mathrm{CH}_{5}^{+}, \mathrm{C}_{2} \mathrm{H}_{5}^{+}\right.$, $\mathrm{HC}_{3} \mathrm{NH}^{+}$) (Vuitton et al., 2007; Yelle et al., 2010)). Then electronic recombination of $\mathrm{CH}_{2} \mathrm{NH}_{2}^{+}$may lead to $\mathrm{CH}_{2}+\mathrm{NH}_{2}$ despite the lack of any information (Yelle et al., 2010). This process therefore also acts as a sink for $\mathrm{CH}_{2} \mathrm{NH}$. The absence of ionic reactions in our model leads to an overestimation of $\mathrm{CH}_{2} \mathrm{NH}$ 
and an underestimation of $\mathrm{NH}_{3}$ in upper atmosphere. In the lower atmosphere, cosmic rays are thought to induce a relatively rich nitrogen chemistry with the formation of $\mathrm{NH}$ through the $\mathrm{N}\left({ }^{2} \mathrm{D}\right)+\mathrm{CH}_{4}, \mathrm{~N}\left({ }^{2} \mathrm{D},{ }^{4} \mathrm{~S}\right)+\mathrm{C}_{2} \mathrm{H}_{3}, \mathrm{~N}+\mathrm{C}_{2} \mathrm{H}_{5}$ and $\mathrm{N}\left({ }^{2} \mathrm{D},{ }^{4} \mathrm{~S}\right)+\mathrm{H}_{2} \mathrm{CN}$ reactions, and with the formation of $\mathrm{NH}_{2}$ through the $\mathrm{NH}+\mathrm{C}_{2} \mathrm{H}_{3}, \mathrm{NH}+\mathrm{C}_{2} \mathrm{H}_{5}$ and $\mathrm{NH}+\mathrm{H}_{2} \mathrm{CN}$ reactions, as well as through the reactions $\mathrm{CH}_{2} \mathrm{NH}+\mathrm{H} \rightarrow \mathrm{CH}_{3} \mathrm{NH} / \mathrm{CH}_{2} \mathrm{NH}_{2}$ followed by $\mathrm{CH}_{3} \mathrm{NH} / \mathrm{CH}_{2} \mathrm{NH}_{2}+$ $\mathrm{H} \rightarrow \mathrm{CH}_{3}+\mathrm{NH}_{2}$. Although the $\mathrm{NH}$ and $\mathrm{NH}_{2}$ production rates increase, their loss rates also increase through the $\mathrm{N}\left({ }^{2} \mathrm{D},{ }^{4} \mathrm{~S}\right)+\mathrm{NH}$ and $\mathrm{N}\left({ }^{2} \mathrm{D},{ }^{4} \mathrm{~S}\right)+\mathrm{NH}_{2}$ reactions, and through the reactions of $\mathrm{NH}$ and $\mathrm{NH}_{2}$ with alkyls radicals $\left(\mathrm{C}_{2} \mathrm{H}_{3}\right.$, $\mathrm{C}_{2} \mathrm{H}_{5}, \ldots$ abundant in the stratosphere) which should lead to adduct formation at high pressures. The various complex amines and imines are all sensitive to photodissociation, so ultimately, $\mathrm{HCN} / \mathrm{HNC}$ or $\mathrm{N}_{2}$ formation occurs.

\section{Appendix A.4. Importance of $H$ atoms reactions}

$\mathrm{H}$ atom reactions play a critical role in Titan's atmosphere, either for bimolecular reactions $\left(\mathrm{H}+\mathrm{CH}_{2}, \mathrm{H}+\mathrm{H}_{2} \mathrm{CN}, \ldots\right)$ or through three body reactions $\left(\mathrm{H}+\mathrm{C}_{2} \mathrm{H}_{2}, \mathrm{C}_{2} \mathrm{H}_{4}, \mathrm{HC}_{3} \mathrm{~N}, \ldots\right)$ as these represent the main loss processes for most unsaturated hydrocarbons. In particular, the concentration of $\mathrm{H}$ atoms is critical for many nitrogen compounds like $\mathrm{HNC}, \mathrm{HC}_{3} \mathrm{~N}, \mathrm{CH}_{2} \mathrm{NH}, \mathrm{C}_{4} \mathrm{~N}_{2}, \mathrm{C}_{2} \mathrm{H}_{3} \mathrm{CN}$. It is then crucial to determine precisely the $\mathrm{H}$ atom concentration throughout the atmosphere of Titan. Its concentration is controlled by its production (mainly through $\mathrm{CH}_{4}$ and $\mathrm{C}_{2} \mathrm{H}_{2}$ photodissociation) and loss (mainly from $\mathrm{H}+\mathrm{C}_{2} \mathrm{H}_{2}$ and $\mathrm{H}+\mathrm{CH}_{2}$ reactions with minor contributions from $\mathrm{H}+\mathrm{C}_{2} \mathrm{H}_{3}, \mathrm{C}_{2} \mathrm{H}_{4}, \mathrm{C}_{4} \mathrm{H}_{2}$ ). Despite the significant body of work for $\mathrm{CH}_{4}$ and $\mathrm{C}_{2} \mathrm{H}_{2}$ photodissociations, there are still large uncertainties on their branching ratios. $\mathrm{CH}_{4}$ photodissociation at Lyman- $\alpha\left(\mathrm{L}_{\alpha}\right)$ and $118.2 \mathrm{~nm}$ has been recently revisited (Gans et al., 2011) leading to a total production of $\mathrm{H}$ atoms at $\mathrm{L}_{\alpha}$ equal to $(55 \pm 17) \%$. Even if methane is mainly photodissociated at $\mathrm{L}_{\alpha}$, the $\mathrm{L}_{\alpha}-140 \mathrm{~nm}$ photodissociation range accounts for about $30 \%$ of the photolysis rate. There is no measurement of branching ratio for photodissociation above $\mathrm{L}_{\alpha}$, but considering theoretical works (Mebel et al., 1997) we consider a branching ratio of $(50 \pm 30) \%$ for $\mathrm{CH}_{3}$ $+\mathrm{H}$ production and $(50 \pm 30) \%$ for ${ }^{1} \mathrm{CH}_{2}+\mathrm{H}_{2}$ production in the $\mathrm{L}_{\alpha}-140 \mathrm{~nm}$ range. $\mathrm{H}$ atom production from $\mathrm{CH}_{4}$ is then equal to $(53 \pm 20) \%$ of the total. The case of $\mathrm{C}_{2} \mathrm{H}_{2}$ photodissociation is even more critical. $\mathrm{C}_{2} \mathrm{H}_{2}$ photodissociation has been studied since the early 1960's (Stief et al., 1965), leading to a total production of $\mathrm{H}$ atoms varying from $6 \%$ (Okabe, 1983) to 100\% (Läuter et al., 2002; Kovacs et al., 2010). There is definitively no consensus even at $193.3 \mathrm{~nm}$ which is the most studied photodissociation wavelength but not the most important one for Titan's atmosphere. In Hébrard et al. (2013), $\mathrm{C}_{2} \mathrm{H}_{2}$ photodissociation was reconsidered using the latest measurements, which lead exclusively to the formation of $\mathrm{C}_{2} \mathrm{H}+\mathrm{H}$ at $\mathrm{L}_{\alpha}$ and $193 \mathrm{~nm}$ (Läuter et al., 2002; Kovacs et al., 2010). In our present nominal model, we use instead Satyapal and Bersohn (1991); Shin and Michael (1991); Seki and Okabe (1993) to derive photodissociation branching ratios of $30 \%$ for $\mathrm{C}_{2} \mathrm{H}+\mathrm{H}$ and $70 \%$ for metastable $\mathrm{C}_{2} \mathrm{H}_{2}^{* *}$. 


$$
\begin{aligned}
& \mathrm{C}_{2} \mathrm{H}_{2}+\mathrm{h} \nu \rightarrow \mathrm{C}_{2} \mathrm{H}+\mathrm{H}, q_{1}=0.3 \\
& \mathrm{C}_{2} \mathrm{H}_{2}+\mathrm{h} \nu \rightarrow \mathrm{C}_{2} \mathrm{H}_{2}^{* *} \rightarrow \mathrm{C}_{2} \mathrm{H}_{2}, q_{2}=0.7
\end{aligned}
$$

In the model, $\mathrm{C}_{2} \mathrm{H}_{2}^{* *}$ gives back $\mathrm{C}_{2} \mathrm{H}_{2}$ even if $\mathrm{C}_{2} \mathrm{H}_{2}^{* *}$ (supposed to be a triplet state) may react with $\mathrm{C}_{2} \mathrm{H}_{2}$ (Laufer, 1983; Seki et al., 1986; Seki and Okabe, 1993). There are no obvious reasons to choose one particular branching ratio as there are potential experimental bias in all experiments. Production of $\mathrm{C}_{4} \mathrm{H}_{2}$ from $\mathrm{C}_{2} \mathrm{H}_{2}^{* *}+\mathrm{C}_{2} \mathrm{H}_{2} \rightarrow \mathrm{C}_{4} \mathrm{H}_{2}+\mathrm{H}_{2}$ reactions with a rate constant estimated around $3.0 \times 10^{-13}$ to $5.0 \times 10^{-13}$ (Laufer, 1983; Seki et al., 1986; Seki and Okabe, 1993) seems established and may explain the $\mathrm{C}_{4} \mathrm{H}_{2}$ " tongue distribution" observed near Titan's North pole by Teanby et al. (2008). However this reaction is likely to be not very efficient as $\mathrm{C}_{2} \mathrm{H}_{2}^{* *}$ will be efficiently quenched by $\mathrm{N}_{2}$ (Seki and Okabe, 1993). Nevertheless, we have tested the influence of the photolysis of $\mathrm{C}_{2} \mathrm{H}_{2}$ using $q_{1}=1.0$ and $q_{2}=0.0$. The mole fractions of the main $\mathrm{C}_{2} \mathrm{H}_{x}$ and $\mathrm{C}_{3} \mathrm{H}_{x}$ compounds do not differ significantly from the nominal results since their abundance profiles lie within the error bars of the models, but the general agreement is rather less good. In particular, a $100 \%$ yield for $\mathrm{H}$ production from $\mathrm{C}_{2} \mathrm{H}_{2}$ photodissociation increases notably the $\mathrm{CH}_{3}$ abundance due to the following cycle

$$
\begin{aligned}
& \mathrm{C}_{2} \mathrm{H}_{2}+\mathrm{h} \nu \rightarrow \mathrm{C}_{2} \mathrm{H}+\mathrm{H} \\
& \mathrm{C}_{2} \mathrm{H}+\mathrm{CH}_{4} \rightarrow \mathrm{C}_{2} \mathrm{H}_{2}+\mathrm{CH}_{3}
\end{aligned}
$$

leading to an overproduction of $\mathrm{C}_{2} \mathrm{H}_{6}$ and $\mathrm{C}_{3} \mathrm{H}_{8}$ in the lower atmosphere through addition reactions with $\mathrm{CH}_{3}$. For uncertainty propagation we consider an uncertainty of $20 \%$ for all photodissociations, a specific study of the large uncertainties on this branching ratio is beyond the scope of this work but should be performed in the future to pinpoint the key photolysis processes.

Among the main $\mathrm{H}$ atom loss processes, the $\mathrm{H}+\mathrm{CH}_{2}$ reaction is relatively well known despite being an atom + radical reaction (Fulle and Hippler, 1997; Böhland et al., 1987; Boullart and Peeters, 1992) and we consider an uncertainty of $50 \%$ on the rate constant at low temperature. The other main $\mathrm{H}$ loss is the $\mathrm{H}$ $+\mathrm{C}_{2} \mathrm{H}_{2} \rightarrow \mathrm{C}_{2} \mathrm{H}_{3}$ reaction which has been the subject of various theoretical and experimental studies. As already noted by Moses et al. (2005) the Baulch et al. $(2005,1994)$ expressions are not valid at low temperature, so that other modeling studies (Lavvas et al., 2008a,b; Krasnopolsky, 2009, 2012) have tended to underestimate the rate of this reaction. Recently, Vuitton et al. (2012) extended previous theoretical work of Miller and Klippenstein (2004) to the low temperatures relevant to Titan leading to rate constants valid down to $50 \mathrm{~K}$. We use this latter work with slightly modified $k_{0}$ and $F_{c}$ factors to fit the experimental data from Payne and Stief (1976) and Keil et al. (1976). Our expressions for $k_{0}$ and $k_{\infty}$ are indeed very close to the Model C of Moses et al. (2005) and notably larger than Lavvas et al. (2008a,b) and Krasnopolsky (2009, 2012) leading to smaller $\mathrm{H}$ atom abundances in the stratosphere. The $\mathrm{H}$ atom heterogeneous recombination scheme proposed by Sekine et al. (2008a,b) was not included in our model but may substantially reduce the $\mathrm{H}$ atom concentration. 


\section{Appendix B. Photolysis processes of some selected nitrile compounds}

In this section, we present a short review of the available data concerning the photolysis of several nitriles (see Table B.5). References for the cross sections and quantum yields we use in the present model are given and we discuss how we have completed the missing data when needed.

\section{Appendix B.1. $\mathrm{CH}_{3} \mathrm{CN}$}

The absorption spectrum has been recorded by Eden et al. (2003) between $115 \mathrm{~nm}$ and $320 \mathrm{~nm}$, the low absorption above $190 \mathrm{~nm}$, attributed to the first triplet excited states (Rianda et al., 1984), is ambiguous and is neglected here. McElcheran et al. (1958) found indirect evidence for both $\mathrm{CH}_{2} \mathrm{CN}+\mathrm{H}$ and $\mathrm{CH}_{3}$ $+\mathrm{CN}$ formation in the $184.9 \mathrm{~nm}$ photodissociation of $\mathrm{CH}_{3} \mathrm{CN}$. Moriyama et al. (1998) studied the $\mathrm{CH}_{3} \mathrm{CN}$ photodissociation at $121.56 \mathrm{~nm}$ showing that both $\mathrm{H}$ atoms and $\mathrm{CN}\left(\mathrm{B}^{2} \Sigma^{+}\right)$were produced and also that the Rydberg state formed by the photoabsorption was converted to the vibrationally excited molecule by a fast intramolecular process prior to the statistical elimination of the $\mathrm{H}$ atom. The isotope effect on this channel is consistent with statistical dissociation. Considering that photodissociation occurs on a vibrationally excited ground state, both $\mathrm{H}+\mathrm{CH}_{2} \mathrm{CN}$ and $\mathrm{CH}_{3}+\mathrm{CN}$ channels will compete, although the $\mathrm{H}$ atom production channel may be favored (more exothermic channel) as noted by Schwell et al. (2008).

\section{Appendix B.2. $\mathrm{HC}_{3} \mathrm{~N}$}

The $\mathrm{HC}_{3} \mathrm{~N}$ photodissociation has been studied between 185 and $254 \mathrm{~nm}$, with the main channel suspected to be metastable $\mathrm{HC}_{3} \mathrm{~N}^{* *}$ (Clarke and Ferris, 1995; Seki et al., 1996; Halpern et al., 1988) with a quantum yield equal to $70 \%$ at $193 \mathrm{~nm}$ (Seki et al., 1996). At $193 \mathrm{~nm}, \mathrm{H}+\mathrm{C}_{3} \mathrm{~N}$ products represent the other $30 \%$ quantum yield, with the $\mathrm{C}_{2} \mathrm{H}+\mathrm{CN}$ products being very minor (Seki et al., 1996). Using theoretical work (Luo et al., 2008; Silva et al., 2009) we can assume that $\mathrm{H}+\mathrm{C}_{3} \mathrm{~N}$ is always the main bimolecular exit channel, although the $\mathrm{C}_{2} \mathrm{H}+\mathrm{CN}$ channel may not be negligible at high energy (below $160 \mathrm{~nm}$ ).

\section{Appendix B.3. $\mathrm{C}_{2} \mathrm{H}_{3} \mathrm{CN}$}

$\mathrm{C}_{2} \mathrm{H}_{3} \mathrm{CN}$ exhibits a strong absorption in the UV range (Eden et al., 2003) so it should be easily photodissociated in Titan's atmosphere. There have been various branching ratio measurements, mostly at $193 \mathrm{~nm}$ (Fahr and Laufer, 1992; North and Hall, 1996; Blank et al., 1998; Wilhelm et al., 2009), with an early study at $213.9 \mathrm{~nm}$ (Gandini and Hackett, 1978). Among the various products, CN production is always very minor and is neglected here. The various studies lead only to qualitative results, except for $\mathrm{CN}$ and for the work of (Gandini and Hackett, 1978) which leads to quantitative branching ratios, equal to $50 \%$ for $\mathrm{C}_{2} \mathrm{H}_{4}+\mathrm{HCN}$ and $31 \%$ for $\mathrm{HC}_{3} \mathrm{~N}+\mathrm{H}_{2}$ after photodissociation at $213.9 \mathrm{~nm}$. In the same study the authors also performed preliminary measurement at $206.5 \mathrm{~nm}$ showing a drop in the $\mathrm{HC}_{3} \mathrm{~N}+\mathrm{H}_{2}$ quantum yield 
suggesting the onset of a competitive radical dissociation channel that may attributed to $\mathrm{H}_{2} \mathrm{C}_{3} \mathrm{~N}+\mathrm{H}$ from theoretical calculations (Derecskei-Kovacs and North, 1999; Homayoon et al., 2011). Wilhelm et al. (2009) performed spectral modeling of the IR emission from the products of $\mathrm{C}_{2} \mathrm{H}_{3} \mathrm{CN}$ photodissociation at $193 \mathrm{~nm}$ detecting $\mathrm{HCN}, \mathrm{HNC}, \mathrm{C}_{2} \mathrm{H}_{2}$ and probably $\mathrm{H}_{2} \mathrm{C}_{3} \mathrm{~N}$ but not $\mathrm{HC}_{3} \mathrm{~N}$. The ratio HCN/HNC was found to be equal to 3.34 in good agreement with the theoretical calculations of Homayoon et al. (2011), but not with the calculated value of 126 from Rice-Ramsperger-Kassel-Marcus analysis by Derecskei-Kovacs and North (1999). The lack of cyanoacetylene detection is either because it is formed relatively cold (no IR emission) or it is produced at only a minor level with respect to acetylene, hydrogen cyanide, and hydrogen isocyanide products. Nevertheless, the study of Blank et al. (1998) has clearly shown the presence of cyanoacetylene as a photofragment so that it is more likely that a four-center transition state dominates the cyanoacetylene elimination channel, in contrast to the observation that a three-center transition state dominates the acetylene elimination channel. A recent study of $\mathrm{C}_{2} \mathrm{H}_{3} \mathrm{CN}$ photodissociation at 193 nm using Chirped-Pulse millimetre-Wave (Prozument et al., 2013) absorption spectroscopy clearly shows the production of HCN and HNC but without quantifying the relative yields of these two species. The branching ratios used in the present work are estimated, taking into account the various experimental studies. It should be noted that $\mathrm{C}_{2} \mathrm{H}_{3} \mathrm{CN}$ photodissociation may contribute to a non-negligible production of $\mathrm{HNC}$.

\section{Appendix B.4. $\mathrm{C}_{2} \mathrm{H}_{5} \mathrm{CN}$}

The absorption spectrum of $\mathrm{C}_{2} \mathrm{H}_{5} \mathrm{CN}$ has been recorded between $115 \mathrm{~nm}$ and $150 \mathrm{~nm}$ (Kanda et al., 1999). The absorption above $190 \mathrm{~nm}$, attributed to the first triplet excited state (Rianda et al., 1984) is neglected here but may play a crucial role. The branching ratios are highly speculative; the $\mathrm{CH}_{3}+\mathrm{CH}_{2} \mathrm{CN}$ channel may be favored.

Table B.5: Quantum yields (in \%) for photolysis of $\mathrm{CH}_{3} \mathrm{CN}, \mathrm{HC}_{3} \mathrm{~N}, \mathrm{C}_{2} \mathrm{H}_{3} \mathrm{CN}, \mathrm{C}_{2} \mathrm{H}_{5} \mathrm{CN}$ as a function of wavelength.

\begin{tabular}{|c|c|c|c|c|}
\hline $\mathrm{CH}_{3} \mathrm{CN}+h \nu \rightarrow$ & $\begin{array}{l}\mathrm{CH}_{3}+\mathrm{CN} \\
\mathrm{CH}_{2} \mathrm{CN}+\mathrm{H} \\
\mathrm{CH}_{2}+\mathrm{HCN}\end{array}$ & & $\begin{array}{c}308-235 \mathrm{~nm} \\
0 \\
100 \\
0 \\
\end{array}$ & $\begin{array}{c}<235 \mathrm{~nm} \\
20 \\
80 \\
0 \\
\end{array}$ \\
\hline $\mathrm{HC}_{3} \mathrm{~N}+h \nu \rightarrow$ & $\begin{array}{l}\mathrm{H}+\mathrm{C}_{3} \mathrm{~N} \\
\mathrm{C}_{2} \mathrm{H}+\mathrm{CN} \\
\mathrm{C}_{2}+\mathrm{HCN} \\
\mathrm{HC}_{3} \mathrm{~N}^{* *} \\
\end{array}$ & $\begin{array}{c}220-185 \mathrm{~nm} \\
30 \\
0 \\
0 \\
70 \\
\end{array}$ & $\begin{array}{c}185-160 \mathrm{~nm} \\
30 \\
25 \\
0 \\
45 \\
\end{array}$ & $\begin{array}{r}<160 \mathrm{~nm} \\
30 \\
25 \\
10 \\
35 \\
\end{array}$ \\
\hline $\mathrm{C}_{2} \mathrm{H}_{3} \mathrm{CN}+h \nu \rightarrow$ & $\begin{array}{l}\mathrm{HC}_{3} \mathrm{~N}+\mathrm{H}_{2} \\
\mathrm{HCN}+\mathrm{C}_{2} \mathrm{H}_{2} \\
\mathrm{HNC}+\mathrm{C}_{2} \mathrm{H}_{2} \\
\mathrm{H}_{2} \mathrm{C}_{3} \mathrm{~N}+\mathrm{H}+\mathrm{H} \\
\mathrm{C}_{2} \mathrm{H}_{3}+\mathrm{CN}\end{array}$ & & $\begin{array}{c}261-240 \mathrm{~nm} \\
0 \\
0 \\
0 \\
100 \\
0\end{array}$ & $\begin{array}{c}<240 \mathrm{~nm} \\
20 \\
60 \\
10 \\
10 \\
0\end{array}$ \\
\hline $\mathrm{C}_{2} \mathrm{H}_{5} \mathrm{CN}+h \nu \rightarrow$ & $\begin{array}{l}\mathrm{C}_{2} \mathrm{H}_{5}+\mathrm{CN} \\
\mathrm{CH}_{3}+\mathrm{CH}_{2} \mathrm{CN} \\
\mathrm{C}_{2} \mathrm{H}_{4} \mathrm{CN} \\
\mathrm{C}_{2} \mathrm{H}_{4}+\mathrm{HCN} \\
\mathrm{C}_{2} \mathrm{H}_{3} \mathrm{CN}+\mathrm{H}_{2}\end{array}$ & & $\begin{array}{c}347-280 \mathrm{~nm} \\
0 \\
100 \\
0 \\
0 \\
0\end{array}$ & $\begin{array}{c}<280 \mathrm{~nm} \\
0 \\
20 \\
0 \\
40 \\
40\end{array}$ \\
\hline
\end{tabular}


Appendix C. List of reactions 
Table C.6: Neutral-neutral reactions.
$k=\alpha \times(T / 300)^{\beta} \times \exp (-\gamma / T)$ in $\mathrm{cm}^{3}$ molecule $^{-1} \mathrm{~s}^{-1}$ or $\mathrm{cm}^{6}$ molecule $\mathrm{s}^{-1}, \quad k \operatorname{comprised}$ between $k \times[F(300 K) \times \exp (g \times|1 / T-1 / 300|)]$ and $k /[F(300 K) \times \exp (g \times|1 / T-1 / 300|)] . k_{\text {adduct }}=\left(k_{0}[M] F+k_{r}\right) k_{\infty} / k_{0}[M]+k_{\infty}$ with $\log (F)=\log \left(F_{C}\right) / 1+\left[\log \left(k_{0}[M]+k_{c a p t u r e}\right) / N\right]^{2}, F_{C}=0.60$ and $N=1$. Please refer to Hébrard et al. [2013] for details about our semi-empirical model.

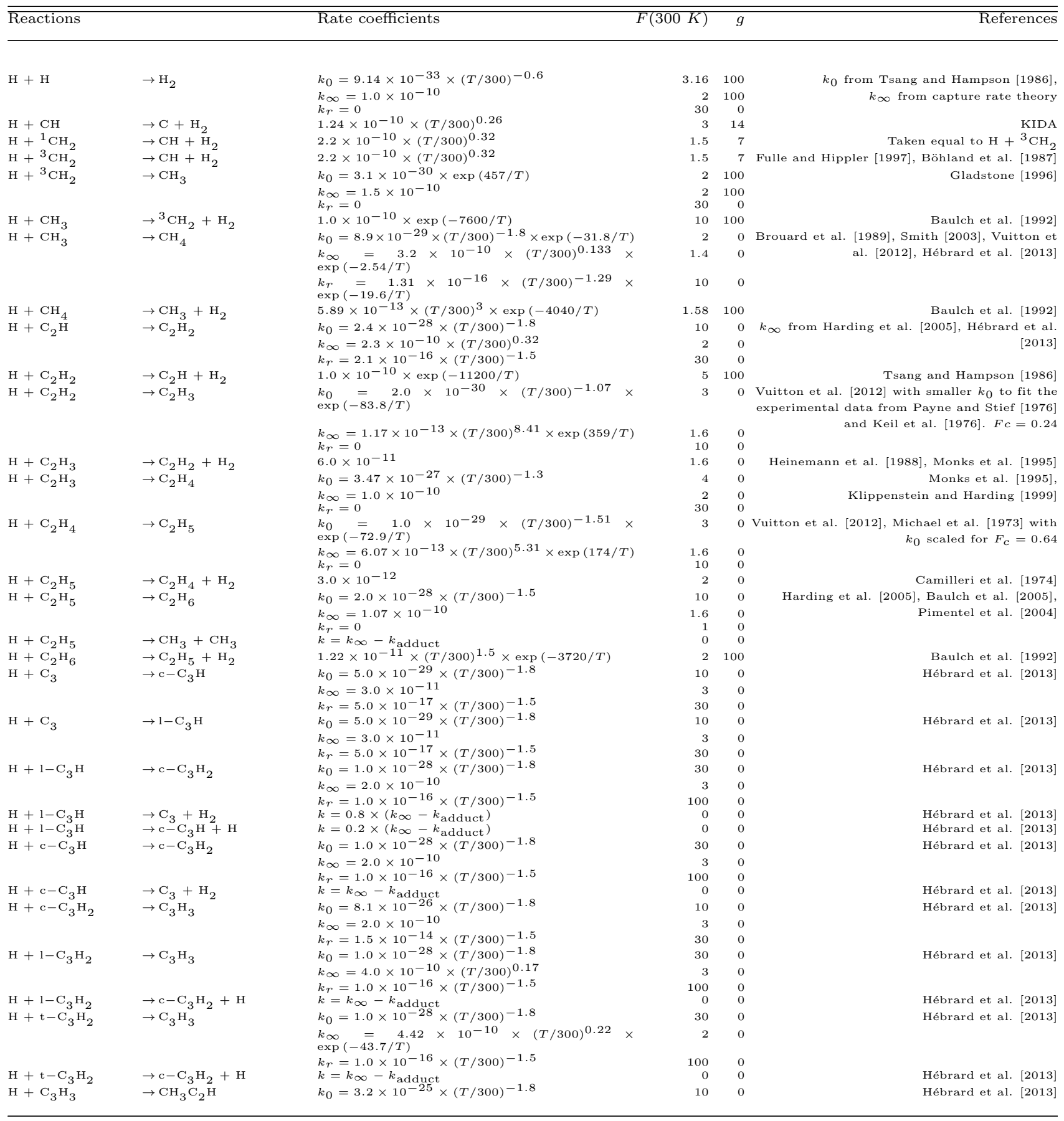




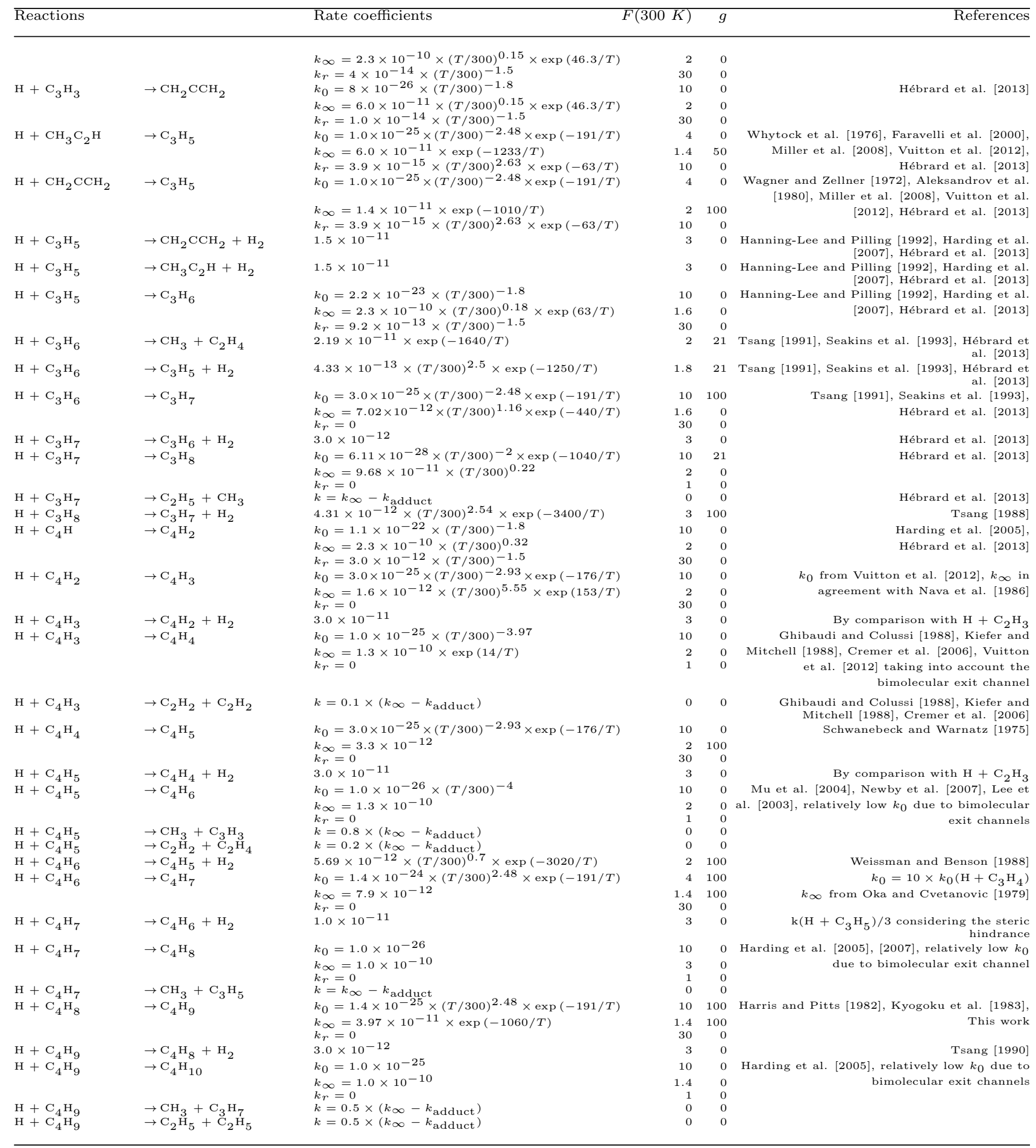




\begin{tabular}{|c|c|c|c|c|c|}
\hline Reactions & & Rate coefficients & $F(300 K)$ & $g$ & References \\
\hline \multirow[t]{2}{*}{$\mathrm{H}+\mathrm{C}_{6} \mathrm{H}$} & \multirow[t]{2}{*}{$\rightarrow \mathrm{C}_{6} \mathrm{H}_{2}$} & $k_{0}=2.64 \times 10^{-26} \times(T / 300)^{-3.1} \times \exp (-721 / T)$ & 2 & 100 & \multirow[t]{2}{*}{ Kiefer and von Drasek [1990] } \\
\hline & & $\begin{array}{l}k_{\infty}=3.0 \times 10^{-10} \\
k_{r}=0\end{array}$ & $\begin{array}{r}2 \\
30\end{array}$ & $\begin{array}{r}100 \\
0\end{array}$ & \\
\hline \multirow[t]{3}{*}{$\mathrm{H}+\mathrm{C}_{6} \mathrm{H}_{2}$} & \multirow[t]{3}{*}{$\rightarrow \mathrm{C}_{6} \mathrm{H}_{3}$} & $k_{0}=3.0 \times 10^{-24} \times(T / 300)^{-2.93} \times \exp (-176 / T)$ & 10 & 0 & \multirow{3}{*}{$\begin{array}{r}k_{0}=10 \times k_{0}\left(\mathrm{H}+\mathrm{C}_{4} \mathrm{H}_{2}\right) \\
k_{\infty}=k_{\infty}\left(\mathrm{H}+\mathrm{C}_{4} \mathrm{H}_{2}\right.\end{array}$} \\
\hline & & $k_{\infty}=1.6 \times 10^{-12} \times(T / 300)^{5.55} \times \exp (153 / T)$ & 2 & 0 & \\
\hline & & $k_{r}=5.6 \times 10^{-12} \times(T / 300)^{2.75} \times \exp (-50.3 / T)$ & 30 & 0 & \\
\hline $\mathrm{H}+\mathrm{C}_{6} \mathrm{H}_{3}$ & $\rightarrow \mathrm{C}_{6} \mathrm{H}_{2}+\mathrm{H}_{2}$ & $1.0 \times 10^{-12}$ & 10 & 0 & \multirow{4}{*}{$\begin{array}{r}\text { We consider mostly addition rather than } \mathrm{H} \\
\text { abstraction considering the size of the species. } \\
k_{0} \text { from Hébrard et al. [2013], } k_{\infty} \text { from } \\
\text { capture rate theory, see also Moskaleva et al. } \\
\text { [1999], Deng et al. [1998] }\end{array}$} \\
\hline \multirow[t]{3}{*}{$\mathrm{H}+\mathrm{C}_{6} \mathrm{H}_{3}$} & \multirow{3}{*}{$\rightarrow \mathrm{C}_{6} \mathrm{H}_{4}$} & $k_{0}=1.0 \times 10^{-23}$ & 3 & 0 & \\
\hline & & $k_{\infty}=1.4 \times 10^{-10}$ & 3 & 0 & \\
\hline & & $k_{r}=1.2 \times 10^{-12}$ & 10 & 0 & \\
\hline $\mathrm{H}+\mathrm{C}_{6} \mathrm{H}_{3}$ & $\rightarrow \mathrm{C}_{2} \mathrm{H}_{2}+\mathrm{C}_{4} \mathrm{H}_{2}$ & $k=k_{\infty}-k_{\text {adduct }}$ & 0 & 0 & \multirow{3}{*}{ Estimated using Madden et al. [1997] } \\
\hline \multirow[t]{2}{*}{$\mathrm{H}+\mathrm{C}_{6} \mathrm{H}_{4}$} & \multirow{2}{*}{$\rightarrow \mathrm{C}_{6} \mathrm{H}_{5}$} & $k_{0}=1.0 \times 10^{-25}$ & 100 & 0 & \\
\hline & & $\begin{array}{l}k_{\infty}=1.0 \times 10^{-11} \\
k_{r}=0\end{array}$ & $\begin{array}{l}10 \\
30\end{array}$ & $\begin{array}{l}0 \\
0\end{array}$ & \\
\hline \multirow[t]{3}{*}{$\mathrm{H}+\mathrm{C}_{6} \mathrm{H}_{5}$} & \multirow[t]{3}{*}{$\rightarrow \mathrm{C}_{6} \mathrm{H}_{6}$} & $k_{0}=4 \times 10^{-18} \times(T / 300)^{-2.54} \times \exp (-122 / T)$ & 10 & 0 & \multirow[t]{3}{*}{ Vuitton et al. [2012] } \\
\hline & & $k_{\infty}=1.4 \times 10^{-10} \times \exp (14 / T)$ & 2 & 0 & \\
\hline & & $k_{r}=1.4 \times 10^{-10} \times \exp (14 / T)$ & 30 & 0 & \\
\hline $\mathrm{H}+\mathrm{C}_{6} \mathrm{H}_{6}$ & $\rightarrow \mathrm{C}_{6} \mathrm{H}_{5}+\mathrm{H}_{2}$ & $4.15 \times 10^{-10} \times \exp (-8050 / T)$ & 2 & 100 & \multirow{3}{*}{$\begin{array}{r}\text { Wang and Frenklach }[1997 \\
\text { By comparison with } \mathrm{H}+\mathrm{C}_{2} \mathrm{H}_{2} \\
\text { Mebel et al. }[1997\end{array}$} \\
\hline \multirow{2}{*}{$\mathrm{H}+\mathrm{C}_{6} \mathrm{H}_{6}$} & \multirow{2}{*}{$\rightarrow \mathrm{C}_{6} \mathrm{H}_{7}$} & $k_{0}=3.3 \times 10^{-30} \times \exp (-740 / T)$ & 10 & 100 & \\
\hline & & $\begin{array}{l}k_{\infty}=5.27 \times 10^{-11} \times \exp (-1600 / T) \\
k_{r}=0\end{array}$ & $\begin{array}{r}2 \\
30\end{array}$ & $\begin{array}{r}100 \\
0\end{array}$ & \\
\hline \multirow{2}{*}{$\mathrm{C}+\mathrm{H}_{2}$} & \multirow{2}{*}{$\rightarrow{ }^{3} \mathrm{CH}_{2}$} & $k_{0}=7.0 \times 10^{-32} \times(T / 300)^{-1.5}$ & 2 & 100 & \multirow{2}{*}{ Husain and Young [1975], Harding et al. [1993] } \\
\hline & & $\begin{array}{l}k_{\infty}=2.06 \times 10^{-11} \times \exp (-57 / T) \\
k_{r}=0\end{array}$ & $\begin{array}{r}3 \\
30\end{array}$ & $\begin{array}{r}100 \\
0\end{array}$ & \\
\hline \multirow[t]{2}{*}{$\mathrm{C}+\mathrm{C}$} & $\rightarrow \mathrm{C}_{2}$ & $k_{0}=5.3 \times 10^{-31} \times(T / 300)^{-1.6}$ & 2 & 100 & Slack et al. [1976], Martinotti et al. [1968] \\
\hline & & $\begin{array}{l}k_{\infty}=2.16 \times 10^{-11} \\
k_{r}=0\end{array}$ & $\begin{array}{r}2 \\
30\end{array}$ & $\begin{array}{r}100 \\
0\end{array}$ & \\
\hline $\mathrm{C}+\mathrm{C}_{2} \mathrm{H}_{2}$ & $\rightarrow \mathrm{C}_{3}+\mathrm{H}_{2}$ & $2.6 \times 10^{-10} \times(T / 300)^{-0.07}$ & 1.2 & 0.9 & $\begin{array}{r}\text { Bergeat and Loison [2001], Costes et al. [2009], } \\
\text { Mebel et al. [2007] }\end{array}$ \\
\hline $\mathrm{C}+\mathrm{C}_{2} \mathrm{H}_{2}$ & $\rightarrow \mathrm{c}-\mathrm{C}_{3} \mathrm{H}+\mathrm{H}$ & $4.1 \times 10^{-11} \times(T / 300)^{-0.39} \times \exp (-2 / T)$ & 1.4 & 0.8 & $\begin{array}{r}\text { Bergeat and Loison [2001], Costes et al. [2009], } \\
\text { Mebel et al. }[2007]\end{array}$ \\
\hline $\mathrm{C}+\mathrm{C}_{2} \mathrm{H}_{2}$ & $\rightarrow 1-\mathrm{C}_{3} \mathrm{H}+\mathrm{H}$ & $7.8 \times 10^{-12} \times(T / 300)^{1.08}$ & 1.8 & 2 & $\begin{array}{r}\text { Bergeat and Loison [2001], Costes et al. [2009], } \\
\text { Mebel et al. }[2007]\end{array}$ \\
\hline $\mathrm{C}+\mathrm{C}_{2} \mathrm{H}_{3}$ & $\rightarrow \mathrm{c}-\mathrm{C}_{3} \mathrm{H}_{2}+\mathrm{H}$ & $4.0 \times 10^{-11}$ & 3 & 0 & $\begin{array}{l}\text { Nguyen et al. [2001a], Nguyen et al. }[2001 \mathrm{~b}], \\
\text { Crider et al. }[2009], \text { Wilson et al. }\end{array}$ \\
\hline $\mathrm{C}+\mathrm{C}_{2} \mathrm{H}_{3}$ & $\rightarrow 1-\mathrm{C}_{3} \mathrm{H}_{2}+\mathrm{H}$ & $2.0 \times 10^{-11}$ & 3 & 0 & $\begin{array}{l}\text { Nguyen et al. [2001a], Nguyen et al. [2001b], } \\
\text { Crider et al. [2009], Wilson et al. [2012] }\end{array}$ \\
\hline $\mathrm{C}+\mathrm{C}_{2} \mathrm{H}_{3}$ & $\rightarrow \mathrm{t}-\mathrm{C}_{3} \mathrm{H}_{2}+\mathrm{H}$ & $3.0 \times 10^{-11}$ & 3 & 0 & $\begin{array}{l}\text { Nguyen et al. [2001a], Nguyen et al. }[2001 \mathrm{~b}], \\
\text { Crider et al. [2009], Wilson et al. [2012] }\end{array}$ \\
\hline $\mathrm{C}+\mathrm{C}_{2} \mathrm{H}_{3}$ & $\rightarrow \mathrm{c}-\mathrm{C}_{3} \mathrm{H}+\mathrm{H}_{2}$ & $1.0 \times 10^{-11}$ & 3 & 0 & $\begin{array}{l}\text { Nguyen et al. [2001a], Nguyen et al. [2001b], } \\
\text { Crider et al. [2009], Wilson et al. }[2012]\end{array}$ \\
\hline $\mathrm{C}+\mathrm{C}_{2} \mathrm{H}_{3}$ & $\rightarrow 1-\mathrm{C}_{3} \mathrm{H}+\mathrm{H}_{2}$ & $1.0 \times 10^{-11}$ & 3 & 0 & $\begin{array}{l}\text { Nguyen et al. [2001a], Nguyen et al. [2001b], } \\
\text { Crider et al. [2009], Wilson et al. }\end{array}$ \\
\hline $\mathrm{C}+\mathrm{C}_{2} \mathrm{H}_{4}$ & $\rightarrow \mathrm{C}_{3} \mathrm{H}_{3}+\mathrm{H}$ & $2.1 \times 10^{-10} \times(T / 300)^{-0.11}$ & 1.4 & 0 & $\begin{array}{l}\text { Chastaing et al. [1999], Chastaing et al. } \\
\text { [2001], Bergeat and Loison [2001], Haider and } \\
\text { Husain [1993a], Haider and Husain [1993b] }\end{array}$ \\
\hline $\mathrm{C}+\mathrm{C}_{2} \mathrm{H}_{4}$ & $\rightarrow \mathrm{C}_{2} \mathrm{H}_{2}+{ }^{3} \mathrm{CH}_{2}$ & $2.0 \times 10^{-11} \times(T / 300)^{-0.11}$ & 2 & 0 & $\begin{array}{l}\text { Chastaing et al. [1999], Chastaing et al. } \\
\text { [2001], Bergeat and Loison [2001], Haider and } \\
\text { Husain [1993a], Haider and Husain [1993b] }\end{array}$ \\
\hline $\mathrm{C}+\mathrm{c}-\mathrm{C}_{3} \mathrm{H}_{2}$ & $\rightarrow \mathrm{C}_{4} \mathrm{H}+\mathrm{H}$ & $2.0 \times 10^{-10}$ & 3 & 0 & $\begin{array}{l}\text { Georgievskii and Klippenstein }[2005] \\
\text { considering no barrier }\end{array}$ \\
\hline $\mathrm{C}+\mathrm{t}-\mathrm{C}_{3} \mathrm{H}_{2}$ & $\rightarrow \mathrm{C}_{4} \mathrm{H}+\mathrm{H}$ & $2.0 \times 10^{-11} \times(T / 300)^{-0.54}$ & 3 & 0 & $\begin{array}{r}\text { Georgievskii and Klippenstein [2005] } \\
\text { considering no barrier }\end{array}$ \\
\hline $\mathrm{C}+1-\mathrm{C}_{3} \mathrm{H}_{2}$ & $\rightarrow \mathrm{C}_{4} \mathrm{H}+\mathrm{H}$ & $2.0 \times 10^{-10}$ & 3 & 0 & $\begin{array}{r}\text { Georgievskii and Klippenstein }[2005] \\
\text { considering no barrier }\end{array}$ \\
\hline $\mathrm{C}+\mathrm{CH}_{3} \mathrm{C}_{2} \mathrm{H}$ & $\rightarrow \mathrm{C}_{4} \mathrm{H}_{3}+\mathrm{H}$ & $2.67 \times 10^{-10} \times(T / 300)^{-0.11}$ & 1.4 & 0 & Chastaing et al. [2000], Loison et al. [2004] \\
\hline $\mathrm{C}+\mathrm{CH}_{2} \mathrm{CCH}_{2}$ & $\rightarrow \mathrm{C}_{4} \mathrm{H}_{3}+\mathrm{H}$ & $3.5 \times 10^{-10} \times(T / 300)^{-0.01}$ & 1.4 & 0 & Chastaing et al. [2000], Loison et al. [2004] \\
\hline $\mathrm{C}+\mathrm{C}_{3} \mathrm{H}_{6}$ & $\rightarrow \mathrm{C}_{4} \mathrm{H}_{5}+\mathrm{H}$ & $1.4 \times 10^{-10} \times(T / 300)^{-0.08}$ & 1.6 & 0 & $\begin{array}{r}\text { Chastaing et al. [1999], Loison and Bergeat } \\
\text { [2004] }\end{array}$ \\
\hline $\mathrm{C}+\mathrm{C}_{3} \mathrm{H}_{6}$ & $\rightarrow \mathrm{C}_{3} \mathrm{H}_{3}+\mathrm{CH}_{3}$ & $1.4 \times 10^{-10} \times(T / 300)^{-0.08}$ & 1.6 & 0 & Chastaing et al. [1999], Loison and Bergeat \\
\hline $\mathrm{C}+\mathrm{C}_{4} \mathrm{H}_{2}$ & $\rightarrow \mathrm{C}_{5} \mathrm{H}+\mathrm{H}$ & $3.0 \times 10^{-10}$ & 2 & 0 & Loison et al. [2014] \\
\hline $\mathrm{C}+\mathrm{C}_{4} \mathrm{H}_{4}$ & $\rightarrow \mathrm{C}_{5} \mathrm{H}_{3}+\mathrm{H}$ & $3.0 \times 10^{-10}$ & 2 & 0 & Loison et al. [2014] \\
\hline $\mathrm{C}+\mathrm{C}_{4} \mathrm{H}_{6}$ & $\rightarrow \mathrm{C}_{5} \mathrm{H}_{5}+\mathrm{H}$ & $3.0 \times 10^{-10}$ & 1.4 & 21 & $\begin{array}{l}\text { Husain and Ioannou [1997], Chastaing et al. } \\
\text { [2001] }\end{array}$ \\
\hline $\mathrm{C}+\mathrm{C}_{4} \mathrm{H}_{8}$ & $\rightarrow \mathrm{C}_{5} \mathrm{H}_{7}+\mathrm{H}$ & $3.0 \times 10^{-10}$ & 1.4 & 21 & Loison et al. [2014] \\
\hline $\mathrm{C}+\mathrm{C}_{6} \mathrm{H}_{4}$ & $\rightarrow \mathrm{C}_{7} \mathrm{H}_{3}+\mathrm{H}$ & $3.0 \times 10^{-10}$ & 3 & 0 & Loison et al. [2014] \\
\hline $\mathrm{C}+\mathrm{C}_{6} \mathrm{H}_{6}$ & $\rightarrow \mathrm{C}_{7} \mathrm{H}_{5}+\mathrm{H}$ & $3.0 \times 10^{-10}$ & 3 & 0 & $\begin{array}{l}\text { Bergeat and Loison [2001], Bettinger et al. } \\
\text { [2000] }\end{array}$ \\
\hline $\mathrm{CH}+\mathrm{H}_{2}$ & $\rightarrow{ }^{3} \mathrm{CH}_{2}+\mathrm{H}$ & $3.1 \times 10^{-10} \times \exp (-1650 / T)$ & 1.3 & 100 & Brownsword et al. [1997] \\
\hline $\mathrm{CH}+\mathrm{H}_{2}^{2}$ & $\rightarrow \mathrm{CH}_{3}$ & $k_{0}=6.2 \times 10^{-30} \times(T / 300)^{-1.6}$ & 1.4 & 100 & \\
\hline & & $\begin{array}{l}k_{\infty}=1.6 \times 10^{-10} \times(T / 300)^{-0.08} \\
k_{r}=0\end{array}$ & $\begin{array}{r}1.4 \\
30\end{array}$ & $\begin{array}{r}21 \\
0\end{array}$ & $\begin{array}{l}\text { Brownsword et al. [1997], Fulle and Hippler } \\
\text { [1997] }\end{array}$ \\
\hline
\end{tabular}




\begin{tabular}{|c|c|c|c|c|c|}
\hline Reactions & & Rate coefficients & $F(300 K)$ & $g$ & References \\
\hline $\mathrm{CH}+\mathrm{CH}$ & $\rightarrow \mathrm{C}_{2} \mathrm{H}+\mathrm{H}$ & $2.0 \times 10^{-10}$ & 2 & 0 & $\begin{array}{r}\text { Shen and Pritchard [1991], Dean and Hanson } \\
{[1992], \text { Bergeat et al. [1999] }}\end{array}$ \\
\hline $\mathrm{CH}+\mathrm{CH}$ & $\rightarrow{ }^{3} \mathrm{CH}_{2}+\mathrm{C}$ & $2.0 \times 10^{-11}$ & 3 & 0 & $\begin{array}{r}\text { Shen and Pritchard [1991], Dean and Hanson } \\
{[1992], \text { Bergeat et al. [1999] }}\end{array}$ \\
\hline $\mathrm{CH}+{ }^{3} \mathrm{CH}_{2}$ & $\rightarrow \mathrm{C}_{2} \mathrm{H}_{2}+\mathrm{H}$ & $2.0 \times 10^{-10}$ & 3 & 0 & $\begin{array}{r}\text { Georgievskii and Klippenstein }[2005] \\
\text { considering no barrier }\end{array}$ \\
\hline $\mathrm{CH}+\mathrm{CH}_{3}$ & $\rightarrow \mathrm{C}_{2} \mathrm{H}_{3}+\mathrm{H}$ & $1.0 \times 10^{-11}$ & 3 & 0 & $\begin{array}{l}\text { Satyapal et al. [1990], Chang et al. [1998b], } \\
\text { Georgievskii and Klippenstein [2005] }\end{array}$ \\
\hline $\mathrm{CH}+\mathrm{CH}_{3}$ & $\rightarrow \mathrm{C}_{2} \mathrm{H}_{2}+\mathrm{H}+\mathrm{H}$ & $1.0 \times 10^{-10}$ & 3 & 0 & $\begin{array}{r}\text { Satyapal et al. [1990], Chang et al. [1998b], } \\
\text { Georgievskii and Klippenstein [2005] }\end{array}$ \\
\hline $\mathrm{CH}+\mathrm{CH}_{4}$ & $\rightarrow \mathrm{C}_{2} \mathrm{H}_{4}+\mathrm{H}$ & $1.05 \times 10^{-10} \times(T / 300)^{-1.04} \times \exp (-36.1 / T)$ & 1.3 & 4.45 & KIDA \\
\hline $\mathrm{CH}+\mathrm{C}_{2} \mathrm{H}_{2}$ & $\rightarrow \mathrm{c}-\mathrm{C}_{3} \mathrm{H}_{2}+\mathrm{H}$ & $1.3 \times 10^{-10} \times(T / 300)^{-0.233} \times \exp (-16 / T)$ & 1.6 & 7 & $\begin{array}{r}\text { Butler et al. [1981], Berman et al. [1982], } \\
\text { Canosa et al. [1997], Thiesemann et al. [1997], } \\
\text { Boullart et al. [1996], McKee et al. [2003], } \\
\text { Loison and Bergeat }[2009], \text { Maksyutenko et al. } \\
\text { [2010], Goulay et al. [2009] }\end{array}$ \\
\hline $\mathrm{CH}+\mathrm{C}_{2} \mathrm{H}_{2}$ & $\rightarrow \mathrm{t}-\mathrm{C}_{3} \mathrm{H}_{2}+\mathrm{H}$ & $2.5 \times 10^{-10} \times(T / 300)^{-0.233} \times \exp (-16 / T)$ & 1.6 & 7 & $\begin{array}{r}\text { Butler et al. [1981], Berman et al. [1982], } \\
\text { Canosa et al. [1997], Thiesemann et al. [1997], } \\
\text { Boullart et al. [1996], McKee et al. [2003], } \\
\text { Loison and Bergeat [2009], Maksyutenko et al. } \\
\text { [2010], Goulay et al. [2009] }\end{array}$ \\
\hline $\mathrm{CH}+\mathrm{C}_{2} \mathrm{H}_{2}$ & $\rightarrow 1-\mathrm{C}_{3} \mathrm{H}+\mathrm{H}_{2}$ & $3.71 \times 10^{-11} \times(T / 300)^{-0.233} \times \exp (-16 / T)$ & 1.6 & 7 & $\begin{array}{r}\text { Butler et al. [1981], Berman et al. [1982], } \\
\text { Canosa et al. [1997], Thiesemann et al. [1997], } \\
\text { Boullart et al. [1996], McKee et al. [2003], } \\
\text { Loison and Bergeat }[2009], \text { Maksyutenko et al. } \\
\text { [2010], Goulay et al. [2009] }\end{array}$ \\
\hline $\mathrm{CH}+\mathrm{C}_{2} \mathrm{H}_{4}$ & $\rightarrow \mathrm{CH}_{3} \mathrm{C}_{2} \mathrm{H}+\mathrm{H}$ & $1.0 \times 10^{-10} \times(T / 300)^{-0.546} \times \exp (-29.6 / T)$ & 1.6 & 7 & $\begin{array}{r}\text { Butler et al. [1981], Berman et al. [1982], } \\
\text { Thiesemann et al. [1997], Thiesemann et al. } \\
\text { [2001], Canosa et al. [1997], McKee et al. } \\
\text { [2003], Loison and Bergeat [2009], Goulay et } \\
\text { al. [2009], Gosavi et al. [1985], Wang and } \\
\text { Huang [1998], Davis et al. [1999], Stranges et } \\
\text { al. [2008] }\end{array}$ \\
\hline $\mathrm{CH}+\mathrm{C}_{2} \mathrm{H}_{4}$ & $\rightarrow \mathrm{CH}_{2} \mathrm{CCH}_{2}+\mathrm{H}$ & $2.4 \times 10^{-10} \times(T / 300)^{-0.546} \times \exp (-29.6 / T)$ & 1.6 & 7 & $\begin{array}{r}\text { Butler et al. [1981], Berman et al. [1982], } \\
\text { Thiesemann et al. [1997], Thiesemann et al. } \\
\text { [2001], Canosa et al. [1997], McKee et al. } \\
\text { [2003], Loison and Bergeat [2009], Goulay et } \\
\text { al. [2009], Gosavi et al. [1985], Wang and } \\
\text { Huang [1998], Davis et al. [1999], Stranges et } \\
\text { al. [2008] }\end{array}$ \\
\hline $\mathrm{CH}+\mathrm{C}_{2} \mathrm{H}_{6}$ & $\rightarrow \mathrm{C}_{3} \mathrm{H}_{6}+\mathrm{H}$ & $5.0 \times 10^{-12} \times(T / 300)^{-0.648} \times \exp (-43.6 / T)$ & 1.6 & 7 & $\begin{array}{l}\text { Butler et al. [1980], Butler et al. [1981], } \\
\text { Berman and Lin [1983], Canosa et al. [1997], } \\
\text { McKee et al. [2003], Galland et al. [2003] }\end{array}$ \\
\hline $\mathrm{CH}+\mathrm{C}_{2} \mathrm{H}_{6}$ & $\rightarrow \mathrm{C}_{2} \mathrm{H}_{4}+\mathrm{CH}_{3}$ & $2.8 \times 10^{-11} \times(T / 300)^{-0.648} \times \exp (-43.6 / T)$ & 1.6 & 7 & $\begin{array}{l}\text { Butler et al. [1980], Butler et al. [1981], } \\
\text { Berman and Lin [1983], Canosa et al. [1997], } \\
\text { McKee et al. [2003], Galland et al. [2003] }\end{array}$ \\
\hline $\mathrm{CH}+\mathrm{C}_{3}$ & $\rightarrow \mathrm{C}_{4}+\mathrm{H}$ & $2.0 \times 10^{-10}$ & 3 & 0 & $\begin{array}{r}\text { Estimated by comparison with CH }+ \\
\text { unsaturated hydrocarbons (Butler et al. } \\
\text { [1980], Berman et al. [1982], Thiesemann et al. } \\
{[1997] \text {, Canosa et al. [1997], Thiesemann et al. }} \\
\text { [2001], Daugey et al. [2005]) }\end{array}$ \\
\hline $\mathrm{CH}+\mathrm{c}-\mathrm{C}_{3} \mathrm{H}_{2}$ & $\rightarrow \mathrm{C}_{4} \mathrm{H}_{2}+\mathrm{H}$ & $2.0 \times 10^{-10}$ & 3 & 0 & Hébrard et al. [2013] \\
\hline $\mathrm{CH}+\mathrm{t}-\mathrm{C}_{3} \mathrm{H}_{2}$ & $\rightarrow \mathrm{C}_{4} \mathrm{H}_{2}+\mathrm{H}$ & $2.0 \times 10^{-10}$ & 3 & 0 & Hébrard et al. [2013] \\
\hline $\mathrm{CH}+1-\mathrm{C}_{3} \mathrm{H}_{2}$ & $\rightarrow \mathrm{C}_{4} \mathrm{H}_{2}+\mathrm{H}$ & $2.0 \times 10^{-10}$ & 3 & 0 & Hébrard et al. [2013] \\
\hline $\mathrm{CH}+\mathrm{CH}_{3} \mathrm{C}_{2} \mathrm{H}$ & $\rightarrow \mathrm{C}_{4} \mathrm{H}_{4}+\mathrm{H}$ & $4.0 \times 10^{-10}$ & 2 & 14 & $\begin{array}{r}\text { Fleming et al. }[1980], \text { Butler et al. [1981], } \\
\text { Daugey et al. }[2005], \text { Loison and Bergeat } \\
{[2009], \text { Goulay et al. }[2009]}\end{array}$ \\
\hline $\mathrm{CH}+\mathrm{CH}_{2} \mathrm{CCH}_{2}$ & $\rightarrow \mathrm{C}_{4} \mathrm{H}_{4}+\mathrm{H}$ & $4.2 \times 10^{-10}$ & 2 & 14 & $\begin{array}{r}\text { Daugey et al. [2005], Loison and Bergeat } \\
{[2009], \text { Goulay et al. [2009] }}\end{array}$ \\
\hline $\mathrm{CH}+\mathrm{C}_{3} \mathrm{H}_{6}$ & $\rightarrow \mathrm{C}_{4} \mathrm{H}_{6}+\mathrm{H}$ & $3.3 \times 10^{-10}$ & 1.4 & 7 & Daugey et al. [2005], Loison and Bergeat [2009] \\
\hline $\mathrm{CH}+\mathrm{C}_{3} \mathrm{H}_{6}$ & $\rightarrow \mathrm{CH}_{2} \mathrm{CCH}_{2}+\mathrm{CH}_{3}$ & $9 \times 10^{-11}$ & 1.4 & 7 & Daugey et al. [2005], Loison and Bergeat [2009] \\
\hline $\mathrm{CH}+\mathrm{C}_{3} \mathrm{H}_{8}$ & $\rightarrow \mathrm{C}_{4} \mathrm{H}_{8}+\mathrm{H}$ & $5.0 \times 10^{-11}$ & 1.8 & 7 & Loison et al. [2006] \\
\hline $\mathrm{CH}+\mathrm{C}_{3} \mathrm{H}_{8}$ & $\rightarrow \mathrm{C}_{3} \mathrm{H}_{6}+\mathrm{CH}_{3}$ & $1.4 \times 10^{-10}$ & 1.8 & 7 & Loison et al. [2006] \\
\hline $\mathrm{CH}+\mathrm{C}_{3} \mathrm{H}_{8}$ & $\rightarrow \mathrm{C}_{2} \mathrm{H}_{5}+\mathrm{C}_{2} \mathrm{H}_{4}$ & $8.0 \times 10^{-11}$ & 1.8 & 7 & Loison et al. [2006] \\
\hline $\mathrm{CH}+\mathrm{C}_{4} \mathrm{H}_{2}$ & $\rightarrow \mathrm{C}_{5} \mathrm{H}_{2}+\mathrm{H}$ & $4.21 \times 10^{-10} \times(T / 300)^{-0.233} \times \exp (-16 / T)$ & 10 & 100 & By comparison with $\mathrm{CH}+\mathrm{C}_{2} \mathrm{H}_{2}$ \\
\hline $\mathrm{CH}+\mathrm{C}_{4} \mathrm{H}_{4}$ & $\rightarrow \mathrm{C}_{5} \mathrm{H}_{4}+\mathrm{H}$ & $2.0 \times 10^{-10}$ & 2 & 0 & $\begin{array}{r}\text { By comparison with } \mathrm{CH}+\text { alkenes and alkynes } \\
\text { (Butler et al. [1980], Berman et al. [1982], } \\
\text { Thiesemann et al. [1997], Canosa et al. [1997], } \\
\text { Thiesemann et al. [2001], Daugey et al. [2005], } \\
\text { Loison and Bergeat [2009]) }\end{array}$ \\
\hline $\mathrm{CH}+\mathrm{C}_{4} \mathrm{H}_{6}$ & $\rightarrow \mathrm{C}_{5} \mathrm{H}_{6}+\mathrm{H}$ & $1.0 \times 10^{-10}$ & 2 & 100 & $\begin{array}{r}\text { By comparison with CH }+ \text { alkenes and alkynes } \\
\text { (Butler et al. [1980], Berman et al. [1982], } \\
\text { Thiesemann et al. [1997], Canosa et al. [1997], } \\
\text { Thiesemann et al. [2001], Daugey et al. [2005], } \\
\text { Loison and Bergeat [2009]) }\end{array}$ \\
\hline $\mathrm{CH}+\mathrm{C}_{4} \mathrm{H}_{6}$ & $\rightarrow \mathrm{C}_{4} \mathrm{H}_{4}+\mathrm{CH}_{3}$ & $1.0 \times 10^{-10}$ & 2 & 100 & $\begin{array}{r}\text { By comparison with CH }+ \text { alkenes and alkynes } \\
\text { (Butler et al. [1980], Berman et al. [1982], } \\
\text { Thiesemann et al. [1997], Canosa et al. [1997], } \\
\text { Thiesemann et al. [2001], Daugey et al. [2005], } \\
\text { Loison and Bergeat [2009]) }\end{array}$ \\
\hline
\end{tabular}




\begin{tabular}{|c|c|c|c|c|c|}
\hline Reactions & & Rate coefficients & $F(300 K)$ & $g$ & References \\
\hline $\mathrm{CH}+\mathrm{C}_{4} \mathrm{H}_{8}$ & $\rightarrow \mathrm{C}_{5} \mathrm{H}_{8}+\mathrm{H}$ & $2.6 \times 10^{-10}$ & 1.8 & 7 & Canosa et al. [1997], Loison and Bergeat [2009] \\
\hline $\mathrm{CH}+\mathrm{C}_{4} \mathrm{H}_{8}$ & $\rightarrow \mathrm{C}_{4} \mathrm{H}_{6}+\mathrm{CH}_{3}$ & $1.1 \times 10^{-10}$ & 1.8 & 7 & Canosa et al. [1997], Loison and Bergeat [2009] \\
\hline $\mathrm{CH}+\mathrm{C}_{4} \mathrm{H}_{10}$ & $\rightarrow \mathrm{C}_{5} \mathrm{H}_{10}+\mathrm{H}^{3}$ & $5.0 \times 10^{-11}$ & 1.8 & 7 & Loison et al. [2006] \\
\hline $\mathrm{CH}+\mathrm{C}_{4} \mathrm{H}_{10}$ & $\rightarrow \mathrm{C}_{4} \mathrm{H}_{8}+\mathrm{CH}_{3}$ & $3.0 \times 10^{-10}$ & 1.8 & 7 & Loison et al. [2006] \\
\hline $\mathrm{CH}+\mathrm{C}_{6} \mathrm{H}_{6}$ & $\rightarrow \mathrm{C}_{7} \mathrm{H}_{6}+\mathrm{H}$ & $4.3 \times 10^{-10}$ & 3 & 0 & Berman et al. [1982] \\
\hline${ }^{1} \mathrm{CH}_{2}+\mathrm{H}_{2}$ & $\rightarrow{ }^{3} \mathrm{CH}_{2}+\mathrm{H}_{2}$ & $1.6 \times 10^{-11} \times(T / 300)^{-0.9}$ & 1.6 & 7 & Gannon et al. [2008] \\
\hline${ }^{1} \mathrm{CH}_{2}^{2}+\mathrm{H}_{2}^{2}$ & $\rightarrow \mathrm{CH}_{3}{ }^{2}+\mathrm{H}$ & $8.8 \times 10^{-11} \times(T / 300)^{0.35}$ & 1.4 & 7 & Gannon et al. [2008] \\
\hline${ }^{1} \mathrm{CH}_{2}+{ }^{3} \mathrm{CH}_{2}$ & $\rightarrow \mathrm{C}_{2} \mathrm{H}_{2}+\mathrm{H}+\mathrm{H}$ & $3.0 \times 10^{-11}$ & 2 & 100 & Tsang and Hampson [1986] \\
\hline${ }^{1} \mathrm{CH}_{2}{ }^{2}+{ }^{1} \mathrm{CH}_{2}{ }^{2}$ & $\rightarrow \mathrm{C}_{2} \mathrm{H}_{2}+\mathrm{H}+\mathrm{H}$ & $5.0 \times 10^{-11}$ & 2 & 100 & Tsang and Hampson [1986] \\
\hline${ }^{1} \mathrm{CH}_{2}+\mathrm{CH}_{3}{ }^{2}$ & $\rightarrow \mathrm{C}_{2} \mathrm{H}_{4}+\mathrm{H}$ & $3.0 \times 10^{-11}$ & 2 & 100 & Tsang and Hampson [1986] \\
\hline${ }^{1} \mathrm{CH}_{2}^{2}+\mathrm{CH}_{4}^{3}$ & $\rightarrow{ }^{3} \mathrm{CH}_{2}^{2}+\mathrm{CH}_{4}$ & $3.1 \times 10^{-12} \times \exp (250 / T)$ & 1.4 & 100 & Böhland et al. [1985] \\
\hline${ }^{1} \mathrm{CH}_{2}^{2}+\mathrm{CH}_{4}$ & $\rightarrow \mathrm{CH}_{3}+\mathrm{CH}_{3}$ & $2.79 \times 10^{-11} \times \exp (250 / T)$ & 1.4 & 100 & $\begin{array}{r}\text { Ashfold et al. [1981], Langford et al. [1983], } \\
\text { Irle and Morokuma [2000] }\end{array}$ \\
\hline${ }^{1} \mathrm{CH}_{2}+\mathrm{C}_{2} \mathrm{H}$ & $\rightarrow \mathrm{c}-\mathrm{C}_{3} \mathrm{H}_{2}+\mathrm{H}$ & $1.0 \times 10^{-10}$ & 3 & 0 & $\begin{array}{r}\text { Deduced from } \mathrm{C}_{3} \mathrm{H}_{3} \text { dissociation, Nguyen } \\
\text { [2001] }\end{array}$ \\
\hline${ }^{1} \mathrm{CH}_{2}+\mathrm{C}_{2} \mathrm{H}$ & $\rightarrow \mathrm{t}-\mathrm{C}_{3} \mathrm{H}_{2}+\mathrm{H}$ & $2.0 \times 10^{-10}$ & 3 & 0 & Deduced from $\mathrm{C}_{3} \mathrm{H}_{3}$ dissociation, Nguyen \\
\hline${ }^{1} \mathrm{CH}_{2}+\mathrm{C}_{2} \mathrm{H}$ & $\rightarrow 1-\mathrm{C}_{3} \mathrm{H}_{2}+\mathrm{H}$ & $5.0 \times 10^{-11}$ & 3 & 0 & 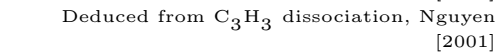 \\
\hline${ }^{1} \mathrm{CH}_{2}+\mathrm{C}_{2} \mathrm{H}_{2}$ & $\rightarrow{ }^{3} \mathrm{CH}_{2}+\mathrm{C}_{2} \mathrm{H}_{2}$ & $2.3 \times 10^{-10}$ & 1.8 & 21 & $\begin{array}{r}\text { Gannon et al. [2010b], Gannon et al. [2010c], } \\
\text { Hébrard et al. [2013] }\end{array}$ \\
\hline${ }^{1} \mathrm{CH}_{2}+\mathrm{C}_{2} \mathrm{H}_{2}$ & $\rightarrow \mathrm{C}_{3} \mathrm{H}_{3}+\mathrm{H}$ & $7.6 \times 10^{-11} \times(T / 300)^{-0.3}$ & 1.8 & 21 & $\begin{array}{r}\text { Gannon et al. [2010b], Gannon et al. [2010c], } \\
\text { Hébrard et al. [2013] }\end{array}$ \\
\hline${ }^{1} \mathrm{CH}_{2}+\mathrm{C}_{2} \mathrm{H}_{3}$ & $\rightarrow \mathrm{C}_{2} \mathrm{H}_{2}+\mathrm{CH}_{3}$ & $3.0 \times 10^{-11}$ & 3 & 100 & Tsang and Hampson [1986] \\
\hline${ }^{1} \mathrm{CH}_{2}+\mathrm{C}_{2} \mathrm{H}_{4}$ & $\rightarrow{ }^{3} \mathrm{CH}_{2}+\mathrm{C}_{2} \mathrm{H}_{4}$ & $1.4 \times 10^{-10}$ & 1.8 & 21 & $\begin{array}{r}\text { Gannon et al. [2010b], Gannon et al. [2010c], } \\
\text { Hébrard et al. [2013] }\end{array}$ \\
\hline${ }^{1} \mathrm{CH}_{2}+\mathrm{C}_{2} \mathrm{H}_{4}$ & $\rightarrow \mathrm{C}_{3} \mathrm{H}_{5}+\mathrm{H}$ & $6.3 \times 10^{-11}$ & 1.8 & 21 & $\begin{array}{r}\text { Gannon et al. [2010b], Gannon et al. [2010c], } \\
\text { Hébrard et al. [2013] }\end{array}$ \\
\hline${ }^{1} \mathrm{CH}_{2}+\mathrm{C}_{2} \mathrm{H}_{5}$ & $\rightarrow \mathrm{C}_{2} \mathrm{H}_{4}+\mathrm{CH}_{3}$ & $1.5 \times 10^{-11}$ & 3 & 100 & Tsang and Hampson [1986] \\
\hline${ }^{1} \mathrm{CH}_{2}+\mathrm{C}_{2} \mathrm{H}_{5}$ & $\rightarrow \mathrm{C}_{3} \mathrm{H}_{6}+\mathrm{H}$ & $1.5 \times 10^{-11}$ & 3 & 100 & Tsang and Hampson [1986] \\
\hline${ }^{1} \mathrm{CH}_{2}+\mathrm{C}_{2} \mathrm{H}_{6}$ & $\rightarrow{ }^{3} \mathrm{CH}_{2}+\mathrm{C}_{2} \mathrm{H}_{6}$ & $3.6 \times 10^{-11}$ & 2 & 100 & Baulch et al. [1992] \\
\hline${ }^{1} \mathrm{CH}_{2}+\mathrm{C}_{2} \mathrm{H}_{6}{ }^{\circ}$ & $\rightarrow \mathrm{C}_{2} \mathrm{H}_{5}+\mathrm{CH}_{3}$ & $1.9 \times 10^{-10}$ & 2 & 100 & Tsang and Hampson [1986] \\
\hline${ }^{1} \mathrm{CH}_{2}+\mathrm{C}_{3}$ & $\rightarrow \mathrm{C}_{4} \mathrm{H}+\mathrm{H}$ & $2.0 \times 10^{-10}$ & 3 & 0 & 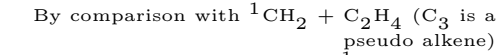 \\
\hline${ }^{1} \mathrm{CH}_{2}+\mathrm{CH}_{3} \mathrm{C}_{2} \mathrm{H}$ & $\rightarrow \mathrm{C}_{4} \mathrm{H}_{5}+\mathrm{H}$ & $9.62 \times 10^{-11}$ & 10 & 100 & By comparison with ${ }^{1} \mathrm{CH}_{2}+\mathrm{C}_{2} \mathrm{H}_{2}$ \\
\hline${ }^{1} \mathrm{CH}_{2}+\mathrm{CH}_{2} \mathrm{CCH}_{2}$ & $\rightarrow \mathrm{C}_{4} \mathrm{H}_{5}+\mathrm{H}$ & $9.62 \times 10^{-11}$ & 10 & 100 & By comparison with ${ }^{1} \mathrm{CH}_{2}+\mathrm{C}_{2} \mathrm{H}_{4}$ \\
\hline${ }^{1} \mathrm{CH}_{2}+\mathrm{C}_{3} \mathrm{H}_{5}$ & $\rightarrow \mathrm{C}_{4} \mathrm{H}_{6}+\mathrm{H}$ & $3.33 \times 10^{-10}$ & 2.5 & 100 & Tsang [1991] \\
\hline${ }^{1} \mathrm{CH}_{2}+\mathrm{C}_{3} \mathrm{H}_{5}$ & $\rightarrow \mathrm{C}_{2} \mathrm{H}_{4}+\mathrm{C}_{2} \mathrm{H}_{3}$ & $6.7 \times 10^{-11}$ & 2 & 100 & Tsang [1991] \\
\hline${ }^{1} \mathrm{CH}_{2}+\mathrm{C}_{3} \mathrm{H}_{7}$ & $\rightarrow \mathrm{C}_{2} \mathrm{H}_{5}+\mathrm{C}_{2} \mathrm{H}_{4}$ & $3.0 \times 10^{-11}$ & 3 & 100 & Tsang [1988] \\
\hline${ }^{1} \mathrm{CH}_{2}+\mathrm{C}_{3} \mathrm{H}_{7}$ & $\rightarrow \mathrm{C}_{3} \mathrm{H}_{6}+\mathrm{CH}_{3}$ & $3.0 \times 10^{-12}$ & 3 & 100 & Tsang [1988] \\
\hline${ }^{1} \mathrm{CH}_{2}+\mathrm{C}_{3} \mathrm{H}_{8}$ & $\rightarrow \mathrm{C}_{2} \mathrm{H}_{5}+\mathrm{C}_{2} \mathrm{H}_{5}$ & $1.6 \times 10^{-10}$ & 2 & 100 & Tsang [1988] \\
\hline${ }^{1} \mathrm{CH}_{2}+\mathrm{C}_{4} \mathrm{H}$ & $\rightarrow \mathrm{C}_{4} \mathrm{H}_{2}+\mathrm{CH}$ & $3.0 \times 10^{-11}$ & 10 & 100 & By comparison with ${ }^{1} \mathrm{CH}_{2}+\mathrm{C}_{2} \mathrm{H}$ from Tsang \\
\hline${ }^{1} \mathrm{CH}_{2}+\mathrm{C}_{4} \mathrm{H}_{2}$ & $\rightarrow \mathrm{C}_{5} \mathrm{H}_{3}+\mathrm{H}$ & $9.62 \times 10^{-11}$ & 10 & 100 & By comparison with ${ }^{1} \mathrm{CH}_{2}+\mathrm{C}_{2} \mathrm{H}_{2}$ \\
\hline${ }^{1} \mathrm{CH}_{2}+\mathrm{N}_{2}$ & $\rightarrow{ }^{3} \mathrm{CH}_{2}+\mathrm{N}_{2}$ & $1.1 \times 10^{-11} \times(T / 300)^{0.81}$ & 1.6 & 0 & Gannon et al. [2010a] \\
\hline${ }^{1} \mathrm{CH}_{2}+\mathrm{c}-\mathrm{C}_{3} \mathrm{H}_{2}$ & $\rightarrow \mathrm{C}_{4} \mathrm{H}_{3}+\mathrm{H}^{2}$ & $3.0 \times 10^{-10}$ & 3 & 0 & $\begin{array}{r}\text { Capture rate constant considering no barrier in } \\
\text { the entrance valley }\end{array}$ \\
\hline${ }^{1} \mathrm{CH}_{2}+\mathrm{t}-\mathrm{C}_{3} \mathrm{H}_{2}$ & $\rightarrow \mathrm{C}_{4} \mathrm{H}_{3}+\mathrm{H}$ & $3.0 \times 10^{-10}$ & 3 & 0 & $\begin{array}{r}\text { Capture rate constant considering no barrier in } \\
\text { the entrance valley }\end{array}$ \\
\hline${ }^{1} \mathrm{CH}_{2}+1-\mathrm{C}_{3} \mathrm{H}_{2}$ & $\rightarrow \mathrm{C}_{4} \mathrm{H}_{3}+\mathrm{H}$ & $3.0 \times 10^{-10}$ & 3 & 0 & $\begin{array}{r}\text { Capture rate constant considering no barrier in } \\
\text { the entrance valley }\end{array}$ \\
\hline${ }^{3} \mathrm{CH}_{2}+\mathrm{H}_{2}$ & $\rightarrow \mathrm{CH}_{3}+\mathrm{H}$ & $8.0 \times 10^{-12} \times \exp (-4500 / T)$ & 10 & 1000 & Tsang and Hampson [1986] - Upper limit \\
\hline${ }^{3} \mathrm{CH}_{2}+{ }^{3} \mathrm{CH}_{2}$ & $\rightarrow \mathrm{C}_{2} \mathrm{H}_{2}+\mathrm{H}+\mathrm{H}$ & $7.0 \times 10^{-11}$ & 3 & 0 & $\begin{array}{r}\text { Estimated by comparison with the } \\
\text { photodissociation of } \mathrm{C}_{2} \mathrm{H}_{4} \text { (Satyapal et al. } \\
\text { [1990], Chang et al. [1998a], Chang et al. } \\
{[1998 \mathrm{~b}], \text { Lee et al. [2004]) }}\end{array}$ \\
\hline${ }^{3} \mathrm{CH}_{2}+{ }^{3} \mathrm{CH}_{2}$ & $\rightarrow \mathrm{C}_{2} \mathrm{H}_{2}+\mathrm{H}_{2}$ & $3.0 \times 10^{-11}$ & 3 & 0 & $\begin{array}{r}\text { Estimated by comparison with the } \\
\text { photodissociation of } \mathrm{C}_{2} \mathrm{H}_{4} \text { (Satyapal et al. } \\
\text { [1990], Chang et al. [1998a], Chang et al. } \\
{[1998 \mathrm{~b}], \text { Lee et al. [2004]) }}\end{array}$ \\
\hline${ }^{3} \mathrm{CH}_{2}+{ }^{3} \mathrm{CH}_{2}$ & $\rightarrow \mathrm{C}_{2} \mathrm{H}_{3}+\mathrm{H}$ & $5.0 \times 10^{-12}$ & 4 & 0 & $\begin{array}{r}\text { Estimated by comparison with the } \\
\text { photodissociation of } \mathrm{C}_{2} \mathrm{H}_{4} \text { (Satyapal et al. } \\
\text { [1990], Chang et al. [1998a], Chang et al. } \\
{[1998 \mathrm{~b}], \text { Lee et al. [2004]) }}\end{array}$ \\
\hline${ }^{3} \mathrm{CH}_{2}+\mathrm{CH}_{3}$ & $\rightarrow \mathrm{C}_{2} \mathrm{H}_{4}+\mathrm{H}$ & $1.0 \times 10^{-10}$ & 2 & 0 & $\begin{array}{r}\text { Wang and Fockenberg [2001], Georgievskii and } \\
\text { Klippenstein [2005] }\end{array}$ \\
\hline${ }^{3} \mathrm{CH}_{2}+\mathrm{CH}_{4}$ & $\rightarrow \mathrm{CH}_{3}+\mathrm{CH}_{3}$ & $7.13 \times 10^{-12} \times \exp (-5050 / T)$ & 3 & 100 & Böhland et al. [1985a] - Upper limit \\
\hline${ }^{3} \mathrm{CH}_{2}^{2}+\mathrm{C}_{2} \mathrm{H}$ & $\rightarrow \mathrm{c}-\stackrel{\mathrm{C}}{\mathrm{C}}_{3} \mathrm{H}_{2}+\mathrm{H}$ & $4.0 \times 10^{-11}$ & 3 & 0 & $\begin{array}{l}\text { Estimated by comparison with the } \\
\text { photodissociation of } \mathrm{C}_{3} \mathrm{H}_{3} \text { (Crider et al. } \\
{[2009], \text { Nguyen et al. [2001b]) }}\end{array}$ \\
\hline${ }^{3} \mathrm{CH}_{2}+\mathrm{C}_{2} \mathrm{H}$ & $\rightarrow \mathrm{t}-\mathrm{C}_{3} \mathrm{H}_{2}+\mathrm{H}$ & $2.0 \times 10^{-11}$ & 3 & 0 & $\begin{array}{r}\text { Estimated by comparison with the } \\
\text { photodissociation of } \mathrm{C}_{3} \mathrm{H}_{3} \text { (Crider et al. } \\
{[2009], \text { Nguyen et al. [2001b]) }}\end{array}$ \\
\hline
\end{tabular}




\begin{tabular}{|c|c|c|c|c|c|}
\hline Reactions & & Rate coefficients & $F(300 K)$ & $g$ & References \\
\hline${ }^{3} \mathrm{CH}_{2}+\mathrm{C}_{2} \mathrm{H}$ & $\rightarrow \mathrm{l}-\mathrm{C}_{3} \mathrm{H}_{2}+\mathrm{H}$ & $3.0 \times 10^{-11}$ & 3 & 0 & $\begin{array}{r}\text { Estimated by comparison with the } \\
\text { photodissociation of } \mathrm{C}_{3} \mathrm{H}_{3} \text { (Crider et al. } \\
\left.[2009], \mathrm{Nguyen}^{2} \text { et al. }[2001 \mathrm{~b}]\right)\end{array}$ \\
\hline${ }^{3} \mathrm{CH}_{2}+\mathrm{C}_{2} \mathrm{H}$ & $\rightarrow \mathrm{c}-\mathrm{C}_{3} \mathrm{H}+\mathrm{H}_{2}$ & $1.0 \times 10^{-11}$ & 3 & 0 & $\begin{array}{r}\text { Estimated by comparison with the } \\
\text { photodissociation of } \mathrm{C}_{3} \mathrm{H}_{3} \text { (Crider et al } \\
[2009], \text { Nguyen et al. }[2001 \mathrm{~b}])\end{array}$ \\
\hline${ }^{3} \mathrm{CH}_{2}+\mathrm{C}_{2} \mathrm{H}$ & $\rightarrow 1-\mathrm{C}_{3} \mathrm{H}+\mathrm{H}_{2}$ & $1.0 \times 10^{-11}$ & 3 & 0 & $\begin{array}{r}\text { Estimated by comparison with the } \\
\text { photodissociation of } \mathrm{C}_{3} \mathrm{H}_{3} \text { (Crider et al } \\
{[2009], \text { Nguyen et al. [2001b]) }}\end{array}$ \\
\hline${ }^{3} \mathrm{CH}_{2}+\mathrm{C}_{2} \mathrm{H}_{3}$ & $\rightarrow \mathrm{C}_{2} \mathrm{H}_{2}+\mathrm{CH}_{3}$ & $3.0 \times 10^{-11}$ & 3 & 100 & Tsang and Hampson [1986] \\
\hline${ }^{3} \mathrm{CH}_{2}+\mathrm{C}_{2} \mathrm{H}_{5}$ & $\rightarrow \mathrm{C}_{2} \mathrm{H}_{4}+\mathrm{CH}_{3}$ & $3.0 \times 10^{-11}$ & 3 & 100 & Tsang and Hampson [1986] \\
\hline${ }^{3} \mathrm{CH}_{2}+\mathrm{c}-\mathrm{C}_{3} \mathrm{H}$ & $\rightarrow \mathrm{C}_{4} \mathrm{H}_{2}+\mathrm{H}$ & $1.0 \times 10^{-10}$ & 3 & 0 & $\begin{array}{r}\text { by comparison with } \mathrm{CH}_{2}+\mathrm{CH}_{3} \text { (Wang and } \\
\text { Fockenberg [2001], Georgievskii and } \\
\text { Klippenstein }[2005])\end{array}$ \\
\hline${ }^{3} \mathrm{CH}_{2}+1-\mathrm{C}_{3} \mathrm{H}$ & $\rightarrow \mathrm{C}_{4} \mathrm{H}_{2}+\mathrm{H}$ & $1.0 \times 10^{-10}$ & 3 & 0 & $\begin{array}{r}\text { by comparison with } \mathrm{CH}_{2}+\mathrm{CH}_{3} \text { (Wang and } \\
\text { Fockenberg [2001], Georgievskii and } \\
\text { Klippenstein }[2005])\end{array}$ \\
\hline${ }^{3} \mathrm{CH}_{2}+\mathrm{c}-\mathrm{C}_{3} \mathrm{H}_{2}$ & $\rightarrow \mathrm{C}_{4} \mathrm{H}_{3}+\mathrm{H}$ & $1.0 \times 10^{-13}$ & 10 & 100 & value at $150-190 \mathrm{~K}$ considering a small barrier \\
\hline${ }^{3} \mathrm{CH}_{2}^{2}+\mathrm{c}-\mathrm{C}_{3} \mathrm{H}_{2}^{2}$ & $\rightarrow \mathrm{C}_{2} \mathrm{H}_{2}+\mathrm{C}_{2} \mathrm{H}_{2}$ & $1.0 \times 10^{-13}$ & 10 & 100 & value at $150-190 \mathrm{~K}$ considering a small barrier \\
\hline${ }^{3} \mathrm{CH}_{2}+\mathrm{C}_{3} \mathrm{H}_{3}$ & $\rightarrow \mathrm{C}_{4} \mathrm{H}_{4}+\mathrm{H}$ & $1.0 \times 10^{-10}$ & 3 & 0 & $\begin{array}{r}\text { Estimated by comparison with }{ }^{3} \mathrm{CH}_{2}+\mathrm{CH}_{3}+ \\
\mathrm{CH}_{3} \text { (Wang and Fockenberg [2001], } \\
\text { Georgievskii and Klippenstein [2005]) }\end{array}$ \\
\hline${ }^{3} \mathrm{CH}_{2}+\mathrm{C}_{3} \mathrm{H}_{5}$ & $\rightarrow \mathrm{C}_{4} \mathrm{H}_{6}+\mathrm{H}$ & $5.0 \times 10^{-11}$ & 2 & 100 & Tsang [1991], Miller [2004] \\
\hline${ }^{3} \mathrm{CH}_{2}+\mathrm{C}_{3} \mathrm{H}_{5}$ & $\rightarrow \mathrm{C}_{2} \mathrm{H}_{3}+\mathrm{C}_{2} \mathrm{H}_{4}$ & $1.2 \times 10^{-11}$ & 2 & 100 & Tsang [1991], Miller [2004] \\
\hline${ }^{3} \mathrm{CH}_{2}+\mathrm{C}_{3} \mathrm{H}_{7}$ & $\rightarrow \mathrm{C}_{2} \mathrm{H}_{4}+\mathrm{C}_{2} \mathrm{H}_{5}$ & $3.01 \times 10^{-11}$ & 3 & 100 & Tsang $[1988]$ \\
\hline${ }^{3} \mathrm{CH}_{2}^{2}+\mathrm{C}_{3} \mathrm{H}_{7}$ & $\rightarrow \mathrm{C}_{3} \mathrm{H}_{6}+\mathrm{CH}_{3}$ & $3.0 \times 10^{-12}$ & 3 & 100 & Tsang $[1988]$ \\
\hline${ }^{3} \mathrm{CH}_{2}^{2}+\mathrm{C}_{4}^{3} \mathrm{H}^{7}$ & $\rightarrow \mathrm{C}_{4}^{3} \mathrm{H}_{2}^{6}+\mathrm{CH}^{3}$ & $3.0 \times 10^{-11}$ & 10 & 100 & By comparison with ${ }^{1} \mathrm{CH}_{2}+\mathrm{C}_{2} \mathrm{H}$ from Tsang \\
\hline${ }^{3} \mathrm{CH}_{2}+\mathrm{C}_{4} \mathrm{H}_{2}$ & $\rightarrow \mathrm{C}_{4} \mathrm{H}+\mathrm{CH}_{3}$ & $2.16 \times 10^{-11} \times \exp (-2160 / T)$ & 1.25 & 100 & Böhland et al. [1988] \\
\hline${ }^{3} \mathrm{CH}_{2}+\mathrm{C}_{4} \mathrm{H}_{3}$ & $\rightarrow \mathrm{C}_{4} \mathrm{H}_{2}+\mathrm{CH}_{3}$ & $3.0 \times 10^{-11}$ & 10 & 100 & By comparison with $\mathrm{CH}_{2}+\mathrm{C}_{2} \mathrm{H}_{3}$ \\
\hline $\mathrm{CH}_{3}+\mathrm{H}_{2}$ & $\rightarrow \mathrm{CH}_{4}+\mathrm{H}$ & $2.45 \times 10^{-14} \times(T / 300)^{2.88} \times \exp (-4600 / T)$ & 1.12 & 0 & Baulch et al. [2005] \\
\hline $\mathrm{CH}_{3}+\mathrm{CH}_{3}$ & $\rightarrow \mathrm{C}_{2} \mathrm{H}_{5}+\mathrm{H}$ & $1.46 \times 10^{-11} \times(T / 300)^{0.1} \times \exp (-5340 / T)$ & 2 & 100 & Stewart et al. [1989] \\
\hline $\mathrm{CH}_{3}+\mathrm{CH}_{3}$ & $\rightarrow \mathrm{C}_{2} \mathrm{H}_{6}$ & $\begin{array}{l}k_{0}=1.8 \times 10^{-26} \times(T / 300)^{-3.77} \times \\
\exp (-61.6 / T) \\
k_{\infty}=6.8 \times 10^{-11} \times(T / 300)^{-0.359} \times \\
\exp (-30.2 / T) \\
k_{r}=0\end{array}$ & $\begin{array}{r}1.4 \\
100\end{array}$ & $\begin{array}{l}0 \\
0\end{array}$ & $\begin{array}{l}\text { Vuitton et al. [2012] with some modifications } \\
\text { to fit the experimental data from Slagle et al } \\
\text { [1988], Cody et al. [2002], Cody et al. [2003] } \\
\text { Very similar to Moses et al. [2005] but with } \\
\qquad F_{C}=0.64\end{array}$ \\
\hline $\mathrm{CH}_{3}+\mathrm{C}_{2} \mathrm{H}$ & $\rightarrow \mathrm{C}_{3} \mathrm{H}_{3}+\mathrm{H}$ & $1.0 \times 10^{-10}$ & 3 & 0 & $\begin{array}{r}\text { Tsang [1986], Georgievskii and Klippenstein } \\
{[2005]}\end{array}$ \\
\hline $\mathrm{CH}_{3}+\mathrm{C}_{2} \mathrm{H}_{2}$ & $\rightarrow \mathrm{C}_{3} \mathrm{H}_{5}$ & $\begin{array}{l}k_{0}=3.3 \times 10^{-30} \times \exp (-740 / T) \\
k_{\infty}=1.0 \times 10^{-12} \times \exp (-3900 / T) \\
k_{r}=0\end{array}$ & $\begin{array}{r}10 \\
3.16 \\
30\end{array}$ & $\begin{array}{r}100 \\
100 \\
0\end{array}$ & $\begin{array}{r}k_{0} \text { by comparison with } \mathrm{H}+\mathrm{C}_{2} \mathrm{H}_{2}, k_{\infty} \text { from } \\
\text { Baulch }[2005]\end{array}$ \\
\hline $\begin{array}{l}\mathrm{CH}_{3}+\mathrm{C}_{2} \mathrm{H}_{3} \\
\mathrm{CH}_{3}+\mathrm{C}_{2} \mathrm{H}_{3}\end{array}$ & $\begin{array}{l}\rightarrow \mathrm{C}_{2} \mathrm{H}_{2}+\mathrm{CH}_{4} \\
\rightarrow \mathrm{C}_{3} \mathrm{H}_{6}\end{array}$ & $\begin{array}{l}3.3 \times 10^{-11} \\
k_{0}=2.4 \times 10^{-27} \times(T / 300)^{-3.77} \times \\
\exp (-61.6 / T)\end{array}$ & $\begin{array}{r}1.4 \\
10\end{array}$ & $\begin{array}{l}0 \\
0\end{array}$ & $\begin{array}{r}\text { Hébrard et al. [2013] } \\
\text { Fahr et al. [1999], Thorn et al. [2000], } \\
\text { Stoliarov et al. [2000] }\end{array}$ \\
\hline & & $\begin{array}{l}k_{\infty}=1.0 \times 10^{-10} \\
k_{r}=0\end{array}$ & $\begin{array}{r}1.4 \\
1\end{array}$ & $\begin{array}{l}0 \\
0\end{array}$ & $\begin{array}{r}k_{0}=0.1 \times k_{0}\left(\mathrm{CH}_{3}+\mathrm{CH}_{3}\right) \text { considering the } \\
\text { bimolecular exit channel }\end{array}$ \\
\hline $\mathrm{CH}_{3}+\mathrm{C}_{2} \mathrm{H}_{3}$ & $\rightarrow \mathrm{C}_{3} \mathrm{H}_{5}+\mathrm{H}$ & $k=k_{\infty}-k_{\text {adduct }}$ & 0 & 0 & \\
\hline $\mathrm{CH}_{3}+\mathrm{C}_{2} \mathrm{H}_{4}$ & $\rightarrow \mathrm{C}_{2} \mathrm{H}_{3}+\mathrm{CH}_{4}$ & $1.61 \times 10^{-14} \times(T / 300)^{3.7} \times \exp (-4780 / T)$ & 2 & 100 & Tsang and Hampson [1986] \\
\hline $\mathrm{CH}_{3}+\mathrm{C}_{2} \mathrm{H}_{4}$ & $\rightarrow \mathrm{C}_{3} \mathrm{H}_{7}^{3}$ & $k_{0}=1.39 \times 10^{-29} \times \exp (-562 / T)$ & 10 & 100 & $k_{0}$ by comparison with $\mathrm{H}+\mathrm{C}_{2} \mathrm{H}_{4}, k_{\infty}$ from \\
\hline & & $\begin{array}{l}k_{\infty}=3.5 \times 10^{-13} \times \exp (-3700 / T) \\
k_{r}=0\end{array}$ & $\begin{array}{r}2 \\
30\end{array}$ & $\begin{array}{r}100 \\
0\end{array}$ & Baulch [2005] \\
\hline $\mathrm{CH}_{3}+\mathrm{C}_{2} \mathrm{H}_{5}$ & $\rightarrow \mathrm{C}_{2} \mathrm{H}_{4}+\mathrm{CH}_{4}$ & $1.91 \times 10^{-12}$ & 2.5 & 100 & Hébrard et al. [2013] \\
\hline $\mathrm{CH}_{3}^{3}+\mathrm{C}_{2}^{2} \mathrm{H}_{5}^{5}$ & $\rightarrow \mathrm{C}_{3}^{2} \mathrm{H}_{8}^{4}$ & $k_{0}=1.0 \times 10^{-24} \times(T / 300)^{-4.47} \times \exp (-95 / T)$ & 4 & 0 & Vuitton et al. [2012], Hébrard et al. [2013] \\
\hline & & $\begin{array}{l}k_{\infty}=8.8 \times 10^{-11} \times(T / 300)^{-0.61} \times \\
\exp (-44.8 / T) \\
k_{r}=0\end{array}$ & 2 & $\begin{array}{l}0 \\
0\end{array}$ & \\
\hline $\mathrm{CH}_{3}+\mathrm{C}_{2} \mathrm{H}_{6}$ & $\rightarrow \mathrm{C}_{2} \mathrm{H}_{5}+\mathrm{CH}_{4}$ & $1.82 \times 10^{-16} \times(T / 300)^{6} \times \exp (-3040 / T)$ & 1.58 & 100 & Baulch et al. [1992] \\
\hline $\mathrm{CH}_{3}+\mathrm{c}-\mathrm{C}_{3} \mathrm{H}$ & $\rightarrow \mathrm{C}_{4} \mathrm{H}_{3}+\mathrm{H}$ & $1.0 \times 10^{-10}$ & 3 & 0 & By comparison with $\mathrm{CH}_{3}+\mathrm{C}_{2} \mathrm{H}_{3}$ \\
\hline $\mathrm{CH}_{3}+1-\mathrm{C}_{3} \mathrm{H}$ & $\rightarrow \mathrm{C}_{4} \mathrm{H}_{3}+\mathrm{H}$ & $1.0 \times 10^{-10}$ & 3 & 0 & By comparison with $\mathrm{CH}_{3}+\mathrm{C}_{2} \mathrm{H}_{3}$ \\
\hline $\mathrm{CH}_{3}+\mathrm{c}-\mathrm{C}_{3} \mathrm{H}_{2}$ & $\rightarrow \mathrm{C}_{4} \mathrm{H}_{4}+\mathrm{H}$ & $1.0 \times 10^{-11} \times \exp (-700 / T)$ & 4 & 0 & $\begin{array}{r}\text { Estimated considering a small barrier in the } \\
\text { entrance valley }\end{array}$ \\
\hline $\mathrm{CH}_{3}+\mathrm{c}-\mathrm{C}_{3} \mathrm{H}_{2}$ & $\rightarrow \mathrm{C}_{2} \mathrm{H}_{3}+\mathrm{C}_{2} \mathrm{H}_{2}$ & $1.0 \times 10^{-11} \times \exp (-700 / T)$ & 4 & 0 & $\begin{array}{c}\text { Estimated considering a small barrier in the } \\
\text { entrance valley }\end{array}$ \\
\hline $\mathrm{CH}_{3}+\mathrm{t}-\mathrm{C}_{3} \mathrm{H}_{2}$ & $\rightarrow \mathrm{C}_{4} \mathrm{H}_{4}+\mathrm{H}$ & $4.0 \times 10^{-11}$ & 10 & 0 & By comparison with $\mathrm{CH}_{3}+{ }^{3} \mathrm{CH}_{2}$ \\
\hline $\mathrm{CH}_{3}+\mathrm{t}-\mathrm{C}_{3} \mathrm{H}_{2}$ & $\rightarrow \mathrm{C}_{2} \mathrm{H}_{3}+\mathrm{C}_{2} \mathrm{H}_{2}$ & $4.0 \times 10^{-11}$ & 10 & 0 & By comparison with $\mathrm{CH}_{3}+{ }^{3} \mathrm{CH}_{2}$ \\
\hline $\mathrm{CH}_{3}+\mathrm{l}-\mathrm{C}_{3} \mathrm{H}_{2}$ & $\rightarrow \mathrm{C}_{4} \mathrm{H}_{4}+\mathrm{H}$ & $4.0 \times 10^{-11}$ & 10 & 0 & $\begin{array}{c}\text { Estimated considering no barrier in the } \\
\text { entrance valley }\end{array}$ \\
\hline $\mathrm{CH}_{3}+\mathrm{l}-\mathrm{C}_{3} \mathrm{H}_{2}$ & $\rightarrow \mathrm{C}_{2} \mathrm{H}_{3}+\mathrm{C}_{2} \mathrm{H}_{2}$ & $4.0 \times 10^{-11}$ & 10 & 0 & $\begin{array}{r}\text { Estimated considering no barrier in the } \\
\text { entrance valley }\end{array}$ \\
\hline
\end{tabular}




\begin{tabular}{|c|c|c|c|c|c|}
\hline Reactions & & Rate coefficients & $F(300 K)$ & $g$ & References \\
\hline \multirow{2}{*}{$\begin{array}{l}\mathrm{CH}_{3}+\mathrm{C}_{3} \mathrm{H}_{3} \\
+\end{array}$} & \multirow[t]{2}{*}{$\rightarrow \mathrm{C}_{4} \mathrm{H}_{6}$} & \multirow{2}{*}{$\begin{array}{l}k_{0}=8.0 \times 10^{-26} \times(T / 300)^{-3.5} \\
k_{\infty}=6.8 \times 10^{-11} \times \exp (130 / T) \\
k_{r}=1.0 \times 10^{-12} \times(T / 300)^{-1.5}\end{array}$} & 10 & 0 & $k_{0}$ from our semi empirical model \\
\hline & & & $\begin{array}{r}1.6 \\
30\end{array}$ & $\begin{array}{r}21 \\
0\end{array}$ & $\begin{array}{l}\text { Hébrard et al. [2013] taking into account the } \\
\text { bimolecular exit channel, } k_{\infty} \text { from Knyazev }\end{array}$ \\
\hline $\mathrm{CH}_{3}+\mathrm{C}_{3} \mathrm{H}_{3}$ & $\rightarrow \mathrm{C}_{2} \mathrm{H}_{2}+\mathrm{C}_{2} \mathrm{H}_{4}$ & $=k_{\infty}-k_{\text {adduct }}$ & 0 & 0 & \\
\hline $\mathrm{CH}_{3}+\mathrm{CH}_{3} \mathrm{C}_{2} \mathrm{H}$ & $\rightarrow \mathrm{C}_{2} \mathrm{H}_{6}+\mathrm{C}_{2} \mathrm{H}$ & $8.32 \times 10^{-13} \times \exp (-4430 / T)$ & 2 & 100 & Kerr and Parsonage [1972] \\
\hline $\mathrm{CH}_{3}+\mathrm{CH}_{2} \mathrm{CCH}_{2}$ & $\rightarrow \mathrm{C}_{2} \mathrm{H}_{5}+\mathrm{C}_{2} \mathrm{H}_{2}$ & $3.32 \times 10^{-13} \times \exp (-4080 / T)$ & 2 & 100 & Kerr and Parsonage [1972] \\
\hline $\mathrm{CH}_{3}+\mathrm{C}_{3} \mathrm{H}_{5}$ & $\rightarrow \mathrm{CH}_{3} \mathrm{C}_{2} \mathrm{H}+\mathrm{CH}_{4}$ & $4.03 \times 10^{-13} \times(T / 300)^{-0.32} \times \exp (66 / T)$ & 3 & 100 & Tsang [1991] \\
\hline $\mathrm{CH}_{3}+\mathrm{C}_{3} \mathrm{H}_{5}$ & $\rightarrow \mathrm{CH}_{2} \mathrm{CCH}_{2}+\mathrm{CH}_{4}$ & $4.03 \times 10^{-13} \times(T / 300)^{-0.32} \times \exp (66 / T)$ & 3 & 100 & Tsang [1991] \\
\hline $\mathrm{CH}_{3}+\mathrm{C}_{3} \mathrm{H}_{5}$ & $\rightarrow \mathrm{C}_{4} \mathrm{H}_{8}$ & $k_{0}=1.1 \times 10^{-22} \times(T / 300)^{-3.5}$ & 10 & 0 & Hébrard et al. [2013], Knyazev and Slagle \\
\hline & & $\begin{array}{l}k_{\infty}=7.1 \times 10^{-11} \times(T / 300)^{-0.54} \times \exp (117 / T) \\
k_{r}=3.4 \times 10^{-11} \times(T / 300)^{-1.5}\end{array}$ & $\begin{array}{r}1.6 \\
30\end{array}$ & $\begin{array}{r}21 \\
0\end{array}$ & [2001], Hébrard et al. [2013] \\
\hline $\mathrm{CH}_{3}+\mathrm{C}_{3} \mathrm{H}_{6}$ & $\rightarrow \mathrm{C}_{3} \mathrm{H}_{5}+\mathrm{CH}_{4}$ & $2.32 \times 10^{-13} \times \exp (-4390 / T)$ & 2 & 100 & Kinsman and Roscoe [1994] \\
\hline $\mathrm{CH}_{3}+\mathrm{C}_{3} \mathrm{H}_{6}$ & $\rightarrow \mathrm{C}_{4} \mathrm{H}_{9}$ & $k_{0}=1.39 \times 10^{-29} \times \exp (-562 / T)$ & 10 & 100 & $k_{0}$ by comparison with $\mathrm{H}+\mathrm{C}_{2} \mathrm{H}_{4}, k_{\infty}$ from \\
\hline & & $\begin{array}{l}k_{\infty}=1.34 \times 10^{-13} \times \exp (-3330 / T) \\
k_{r}=0\end{array}$ & $\begin{array}{r}2 \\
30\end{array}$ & $\begin{array}{r}100 \\
0\end{array}$ & Tsang [1991] \\
\hline \multirow{4}{*}{$\begin{array}{l}\mathrm{CH}_{3}+\mathrm{C}_{3} \mathrm{H}_{7} \\
\mathrm{CH}_{3}+\mathrm{C}_{3} \mathrm{H}_{7}\end{array}$} & $\rightarrow \mathrm{C}_{3} \mathrm{H}_{6}+\mathrm{CH}_{4}$ & $7.52 \times 10^{-12} \times(T / 300)^{0.68}$ & 3 & 0 & Tsang [1991] \\
\hline & $\rightarrow \mathrm{C}_{4} \mathrm{H}_{10}$ & $k_{0}=2.7 \times 10^{-21} \times(T / 300)^{-3.5}$ & 10 & 0 & By comparison with $\mathrm{CH}_{3}+\mathrm{C}_{2} \mathrm{H}_{5}$ \\
\hline & & 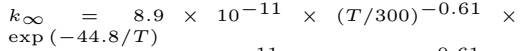 & 3 & 0 & \\
\hline & & $\begin{array}{l}k_{r}=\begin{array}{r}8.9 \\
\exp (-44.8 / T)\end{array} \\
\end{array}$ & 3 & 0 & \\
\hline \multirow{4}{*}{$\begin{array}{l}\mathrm{CH}_{3}+\mathrm{C}_{3} \mathrm{H}_{8} \\
\mathrm{CH}_{3}+\mathrm{C}_{4} \mathrm{H} \\
\mathrm{CH}_{3}+\mathrm{C}_{4} \mathrm{H}_{2}\end{array}$} & $\rightarrow \mathrm{C}_{3} \mathrm{H}_{7}+\mathrm{CH}_{4}$ & $1.65 \times 10^{-15} \times(T / 300)^{3.65} \times \exp (-3600 / T)$ & 1.5 & 100 & Tsang [1988] \\
\hline & $\rightarrow \mathrm{C}_{5} \mathrm{H}_{3}+\mathrm{H}$ & $4.0 \times 10^{-11}$ & 10 & 100 & By comparison with $\mathrm{CH}_{3}+\mathrm{C}_{2} \mathrm{H}$ \\
\hline & $\rightarrow \mathrm{C}_{5} \mathrm{H}_{5}$ & $k_{0}=3.3 \times 10^{-30} \times \exp (-740 / T)$ & 10 & 100 & $k_{0}$ by comparison with $\mathrm{H}+\mathrm{C}_{2} \mathrm{H}_{2}$ \\
\hline & & $\begin{array}{l}k_{\infty}=1.0 \times 10^{-12} \times \exp (-3900 / T) \\
k_{r}=0\end{array}$ & $\begin{array}{l}10 \\
30\end{array}$ & $\begin{array}{r}100 \\
0\end{array}$ & \\
\hline $\mathrm{CH}_{3}+\mathrm{C}_{4} \mathrm{H}_{3}$ & $\rightarrow \mathrm{C}_{4} \mathrm{H}_{2}+\mathrm{CH}_{4}$ & $1.0 \times 10^{-11}$ & 3 & 0 & By comparison with $\mathrm{CH}_{3}+\mathrm{C}_{2} \mathrm{H}_{3}$ \\
\hline $\mathrm{CH}_{3}+\mathrm{C}_{4} \mathrm{H}_{3}$ & $\rightarrow \mathrm{C}_{5} \mathrm{H}_{6}$ & $k_{0}=2.2 \times 10^{-21} \times(T / 300)^{-3.5}$ & 10 & 0 & Using our semi empirical model Hébrard [2012] \\
\hline & & $\begin{array}{l}k_{\infty}=8 \times 10^{-11} \\
k_{r}=0\end{array}$ & $\begin{array}{r}2 \\
30\end{array}$ & $\begin{array}{l}0 \\
0\end{array}$ & \\
\hline $\mathrm{CH}_{3}+\mathrm{C}_{4} \mathrm{H}_{4}$ & $\rightarrow \mathrm{C}_{4} \mathrm{H}_{3}+\mathrm{CH}_{4}$ & $6.61 \times 10^{-13} \times \exp (-2500 / T)$ & 2 & 100 & Scherzer et al. [1985] \\
\hline $\mathrm{CH}_{3}+\mathrm{C}_{4} \mathrm{H}_{5}$ & $\rightarrow \mathrm{C}_{4} \mathrm{H}_{4}+\mathrm{CH}_{4}$ & $3.0 \times 10^{-11}$ & 10 & 100 & By comparison with $\mathrm{CH}_{3}+\mathrm{C}_{2} \mathrm{H}_{3}$ \\
\hline $\mathrm{CH}_{3}+\mathrm{C}_{6} \mathrm{H}_{5}$ & $\rightarrow$ SOOTC & $6.0 \times 10^{-11}$ & 3 & 0 & $\begin{array}{r}\text { Vuitton et al [2012] leads to } \\
k_{\infty}=k\left(\mathrm{CH}_{3}+\mathrm{C}_{6} \mathrm{H}_{5}->\text { toluene }\right)\end{array}$ \\
\hline $\mathrm{CH}_{3}+\mathrm{C}_{6} \mathrm{H}_{5}$ & $\rightarrow \mathrm{C}_{6} \mathrm{H}_{4}+\mathrm{CH}_{4}$ & $2.0 \times 10^{-12}$ & 5 & 0 & By comparison with $\mathrm{CH}_{3}+\mathrm{C}_{2} \mathrm{H}_{3}$ \\
\hline $\mathrm{C}_{2}+\mathrm{H}_{2}$ & $\rightarrow \mathrm{C}_{2} \mathrm{H}+\mathrm{H}$ & $1.77 \times 10^{-10} \times \exp (-1470 / T)$ & 1.6 & 0.2 & Reisler et al. [1980], Pitts et al. [1982] \\
\hline $\mathrm{C}_{2}+\mathrm{CH}_{4}$ & $\rightarrow \mathrm{C}_{3} \mathrm{H}_{3}+\mathrm{H}$ & $1.2 \times 10^{-11}$ & 1.8 & 7 & $\begin{array}{l}\text { Richardson and Francisco [1994], Canosa et al. } \\
{[2007], \text { Paramo et al. [2008], Matsugi et al. }} \\
{[2010], \text { Hornet et al. [1995] }}\end{array}$ \\
\hline $\mathrm{C}_{2}+\mathrm{C}_{2} \mathrm{H}_{2}$ & $\rightarrow \mathrm{C}_{4} \mathrm{H}+\mathrm{H}$ & $4.0 \times 10^{-10}$ & 1.6 & 0 & $\begin{array}{r}\text { Canosa et al. [2007], Daugey et al. [2008], } \\
\text { Paramo et al. [2008] }\end{array}$ \\
\hline $\mathrm{C}_{2}+\mathrm{C}_{2} \mathrm{H}_{4}$ & $\rightarrow \mathrm{C}_{4} \mathrm{H}_{3}+\mathrm{H}$ & $3.0 \times 10^{-10}$ & 1.8 & 0 & $\begin{array}{r}\text { Gu et al. [2006], Mebel et al. [2006], Canosa et } \\
\text { al. [2007], Paramo et al. [2008] }\end{array}$ \\
\hline $\mathrm{C}_{2}+\mathrm{C}_{2} \mathrm{H}_{4}$ & $\rightarrow \mathrm{C}_{2} \mathrm{H}_{2}+\mathrm{C}_{2} \mathrm{H}_{2}$ & $1.0 \times 10^{-10}$ & 2 & 0 & $\begin{array}{r}\text { Gu et al. [2006], Mebel et al. [2006], Canosa et } \\
\text { al. [2007], Paramo et al. }[2008]\end{array}$ \\
\hline $\mathrm{C}_{2}+\mathrm{C}_{2} \mathrm{H}_{6}$ & $\rightarrow \mathrm{C}_{3} \mathrm{H}_{3}+\mathrm{CH}_{3}$ & $1.3 \times 10^{-10} \times(T / 300)^{-0.94} \times \exp (-44 / T)$ & 1.4 & 0 & Paramo et al. [2008], Canosa et al. [2007] \\
\hline $\mathrm{C}_{2}+\mathrm{C}_{3} \mathrm{H}_{8}$ & $\rightarrow \mathrm{C}_{3} \mathrm{H}_{3}+\mathrm{C}_{2} \mathrm{H}_{5}$ & $2.2 \times 10^{-10} \times(T / 300)^{-1.31} \times \exp (-94 / T)$ & 1.4 & 0 & Paramo et al. [2008], Canosa et al. [2007] \\
\hline $\mathrm{C}_{2}+\mathrm{C}_{4} \mathrm{H}_{10}$ & $\rightarrow \mathrm{C}_{3} \mathrm{H}_{3}+\mathrm{C}_{3} \mathrm{H}_{7}$ & $2.2 \times 10^{-10} \times(T / 300)^{-1.31} \times \exp (-94 / T)$ & 1.4 & 0 & By comparison with $\mathrm{C}_{2}+\mathrm{C}_{3} \mathrm{H}_{8}$ \\
\hline $\mathrm{C}_{2}+\mathrm{C}_{6} \mathrm{H}_{6}$ & $\rightarrow \mathrm{C}_{8} \mathrm{H}_{5}+\mathrm{H}$ & $5.2 \times 10^{-10}$ & 1.6 & 0 & Reisler et al. [1980] \\
\hline $\mathrm{C}_{2} \mathrm{H}+\mathrm{H}_{2}$ & $\rightarrow \mathrm{C}_{2} \mathrm{H}_{2}+\mathrm{H}$ & $1.2 \times 10^{-11} \times \exp (-998 / T)$ & 1.6 & 57 & Opansky and Leone [1996] \\
\hline $\mathrm{C}_{2} \mathrm{H}+\mathrm{CH}_{4}$ & $\rightarrow \mathrm{C}_{2} \mathrm{H}_{2}+\mathrm{CH}_{3}$ & $1.2 \times 10^{-11} \times \exp (-491 / T)$ & 1.2 & 12 & $\begin{array}{r}\text { Opansky and Leone [1996a], Murphy et al. } \\
\text { [2003] }\end{array}$ \\
\hline $\mathrm{C}_{2} \mathrm{H}+\mathrm{C}_{2} \mathrm{H}$ & $\rightarrow \mathrm{C}_{2} \mathrm{H}_{2}+\mathrm{C}_{2}$ & $3.0 \times 10^{-12}$ & 3 & 100 & Tsang and Hampson [1986] \\
\hline $\mathrm{C}_{2} \mathrm{H}+\mathrm{C}_{2} \mathrm{H}_{2}$ & $\rightarrow \mathrm{C}_{4} \mathrm{H}_{2}+\mathrm{H}$ & $1.3 \times 10^{-10}$ & 2 & 0 & Vakhtin et al. [2001], Chastaing et al. [1998] \\
\hline $\mathrm{C}_{2} \mathrm{H}+\mathrm{C}_{2} \mathrm{H}_{3}$ & $\rightarrow \mathrm{C}_{2} \mathrm{H}_{2}+\mathrm{C}_{2} \mathrm{H}_{2}$ & $1.6 \times 10^{-12}$ & 3 & 100 & Tsang and Hampson [1986] \\
\hline $\mathrm{C}_{2} \mathrm{H}+\mathrm{C}_{2} \mathrm{H}_{3}$ & $\rightarrow \mathrm{C}_{4} \mathrm{H}_{3}+\mathrm{H}$ & $3.0 \times 10^{-11}$ & 3 & 100 & Tsang and Hampson [1986] \\
\hline $\mathrm{C}_{2} \mathrm{H}+\mathrm{C}_{2} \mathrm{H}_{4}$ & $\rightarrow \mathrm{C}_{4} \mathrm{H}_{4}+\mathrm{H}$ & $1.4 \times 10^{-10}$ & 1.7 & 0 & Vakhtin et al. [2001], Chastaing et al. [1998] \\
\hline $\mathrm{C}_{2} \mathrm{H}+\mathrm{C}_{2} \mathrm{H}_{5}$ & $\rightarrow \mathrm{C}_{2} \mathrm{H}_{4}+\mathrm{C}_{2} \mathrm{H}_{2}$ & $3.0 \times 10^{-12}$ & 3 & 100 & Tsang and Hampson [1986] \\
\hline $\mathrm{C}_{2} \mathrm{H}+\mathrm{C}_{2} \mathrm{H}_{5}$ & $\rightarrow \mathrm{C}_{3} \mathrm{H}_{3}+\mathrm{CH}_{3}$ & $3.0 \times 10^{-11}$ & 3 & 100 & Tsang and Hampson [1986] \\
\hline $\mathrm{C}_{2} \mathrm{H}+\mathrm{C}_{2} \mathrm{H}_{6}$ & $\rightarrow \mathrm{C}_{2} \mathrm{H}_{5}+\mathrm{C}_{2} \mathrm{H}_{2}$ & $5.1 \times 10^{-11} \times \exp (-76 / T)$ & 1.5 & 20 & Murphy et al. [2003] \\
\hline $\mathrm{C}_{2} \mathrm{H}+\mathrm{C}_{3}$ & $\rightarrow \mathrm{C}_{5}+\mathrm{H}$ & $3.0 \times 10^{-10}$ & 3 & 0 & Considering no barrier for this reaction \\
\hline $\mathrm{C}_{2} \mathrm{H}+\mathrm{c}-\mathrm{C}_{3} \mathrm{H}_{2}$ & $\rightarrow \mathrm{C}_{5} \mathrm{H}_{2}+\mathrm{H}$ & $3.0 \times 10^{-10}$ & 3 & 0 & Considering no barrier for this reaction \\
\hline $\mathrm{C}_{2} \mathrm{H}+\mathrm{t}-\mathrm{C}_{3} \mathrm{H}_{2}$ & $\rightarrow \mathrm{C}_{5} \mathrm{H}_{2}+\mathrm{H}$ & $3.0 \times 10^{-10}$ & 3 & 0 & Considering no barrier for this reaction \\
\hline $\mathrm{C}_{2} \mathrm{H}+\mathrm{l}-\mathrm{C}_{3} \mathrm{H}_{2}$ & $\rightarrow \mathrm{C}_{5} \mathrm{H}_{2}+\mathrm{H}$ & $3.0 \times 10^{-10}$ & 3 & 0 & Considering no barrier for this reaction \\
\hline $\mathrm{C}_{2} \mathrm{H}+\mathrm{CH}_{3} \mathrm{C}_{2} \mathrm{H}$ & $\rightarrow \mathrm{C}_{5} \mathrm{H}_{4}+\mathrm{H}$ & $2.1 \times 10^{-10} \times(T / 300)^{-0.3}$ & 1.6 & 0 & Carty et al. [2001] \\
\hline $\mathrm{C}_{2} \mathrm{H}+\mathrm{CH}_{2} \mathrm{CCH}_{2}$ & $\rightarrow \mathrm{C}_{5} \mathrm{H}_{4}+\mathrm{H}$ & $2.04 \times 10^{-10} \times(T / 300)^{-0.4}$ & 1.8 & 0 & Carty et al. [2001] \\
\hline $\mathrm{C}_{2} \mathrm{H}+\mathrm{C}_{3} \mathrm{H}_{5}$ & $\rightarrow \mathrm{CH}_{2} \mathrm{CCH}_{2}+\mathrm{C}_{2} \mathrm{H}_{2}$ & $1.2 \times 10^{-11}$ & 3 & 100 & Tsang [1991] \\
\hline $\mathrm{C}_{2} \mathrm{H}+\mathrm{C}_{3} \mathrm{H}_{6}$ & $\rightarrow \mathrm{C}_{4} \mathrm{H}_{4}+\mathrm{CH}_{3}$ & $2.0 \times 10^{-10}$ & 1.3 & 0 & $\begin{array}{r}\text { Vakhtin et al. [2001], Chastaing et al. [1998], } \\
\text { Woon and Park [2009] }\end{array}$ \\
\hline $\mathrm{C}_{2} \mathrm{H}+\mathrm{C}_{3} \mathrm{H}_{7}$ & $\rightarrow \mathrm{C}_{2} \mathrm{H}_{5}+\mathrm{C}_{3} \mathrm{H}_{3}$ & $2.0 \times 10^{-11}$ & 2 & 100 & Tsang [1988] \\
\hline
\end{tabular}




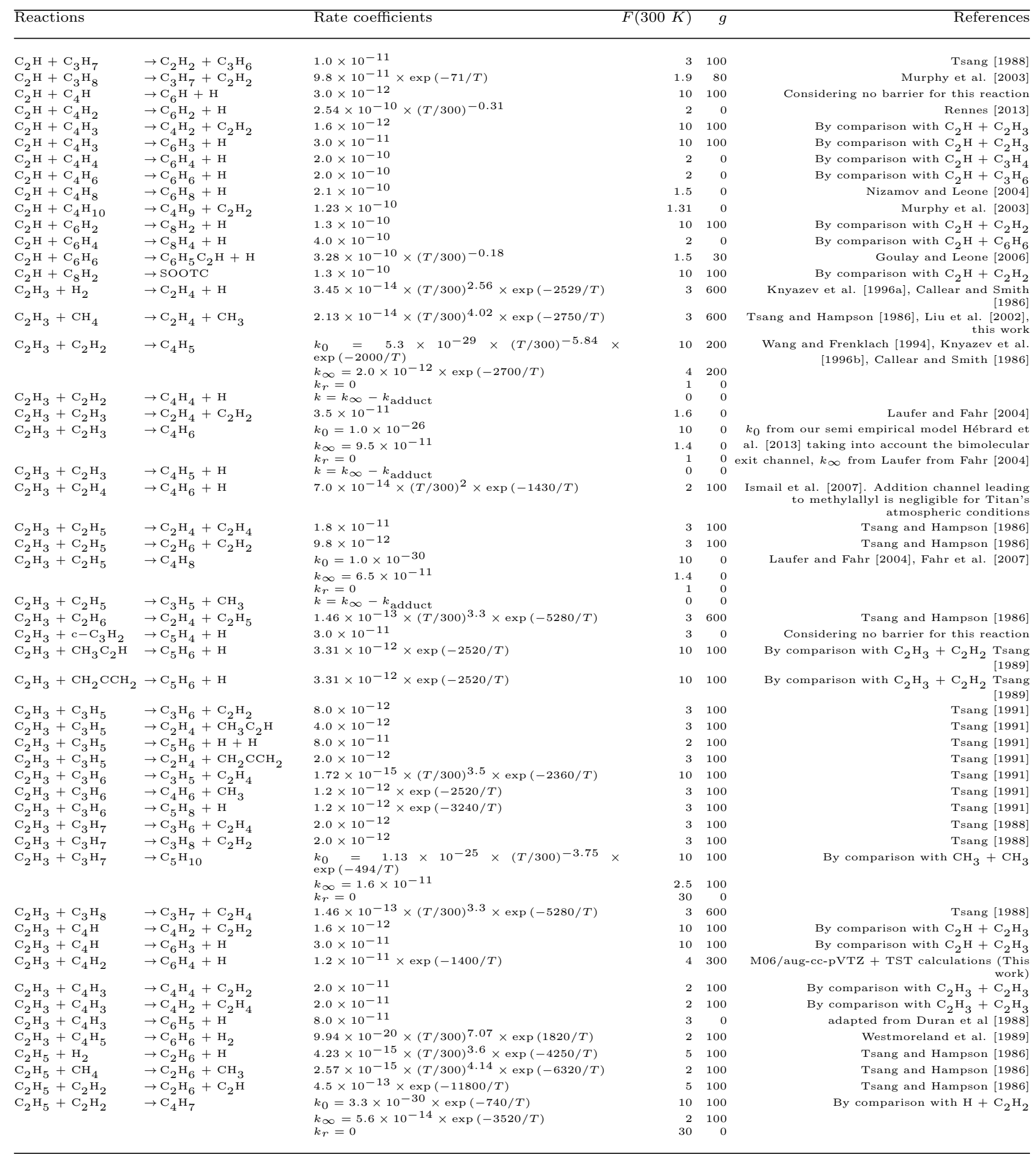




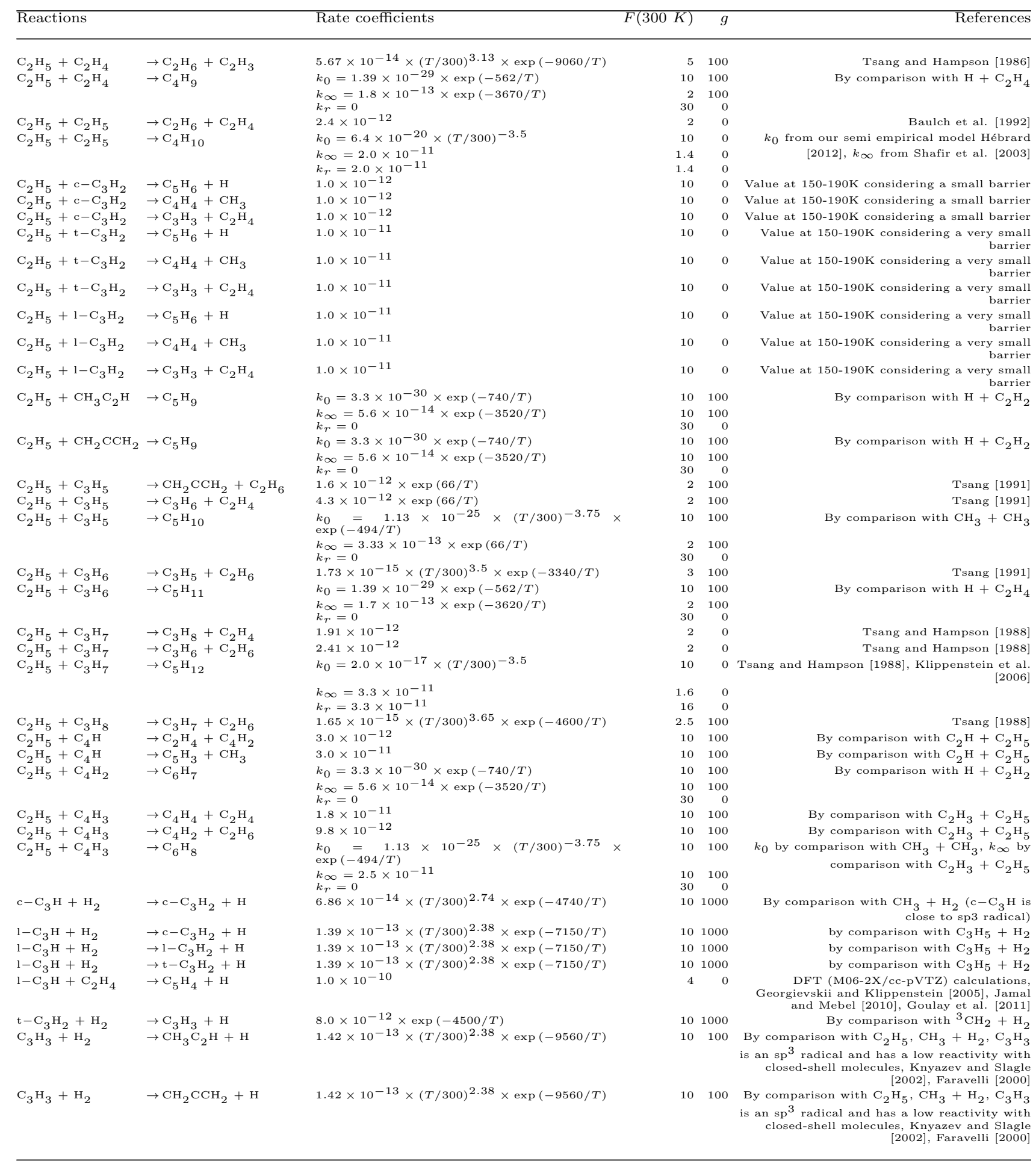




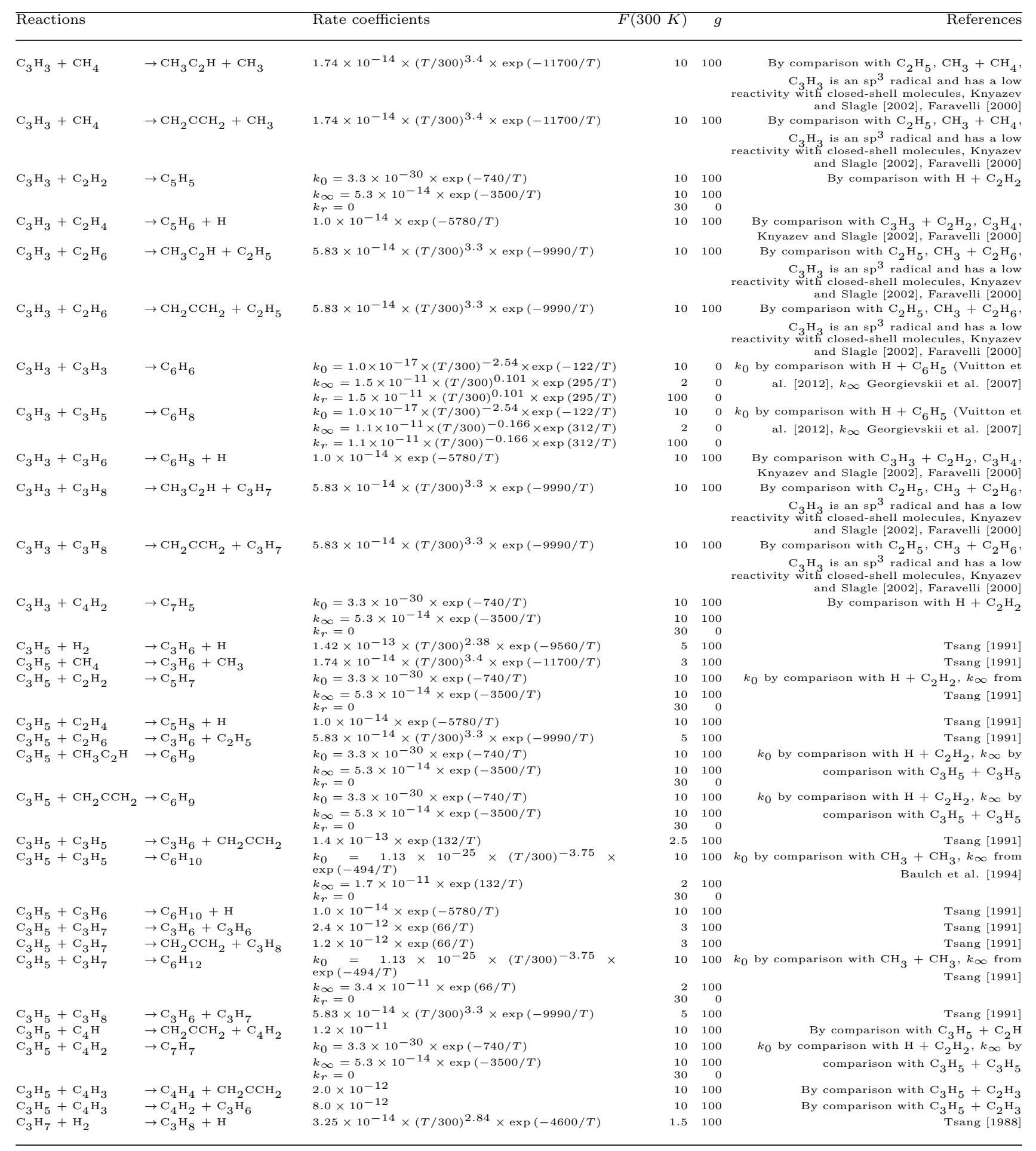




\begin{tabular}{|c|c|c|c|c|c|}
\hline \multicolumn{2}{|l|}{ Reactions } & Rate coefficients & $F(300 K)$ & $g$ & References \\
\hline $\mathrm{C}_{3} \mathrm{H}_{7}+\mathrm{CH}_{4}$ & $\rightarrow \mathrm{C}_{3} \mathrm{H}_{8}+\mathrm{CH}_{3}$ & $3.63 \times 10^{-16} \times(T / 300)^{4.02} \times \exp (-5470 / T)$ & 2 & 100 & Tsang [1988] \\
\hline $\mathrm{C}_{3}^{3} \mathrm{H}_{7}+\mathrm{C}_{2} \mathrm{H}_{2}$ & $\rightarrow \mathrm{C}_{2} \mathrm{H}_{4}+\mathrm{C}_{3} \mathrm{H}_{5}$ & $1.2 \times 10^{-12} \times \exp (-4530 / T)$ & 3 & 100 & Tsang [1988] \\
\hline $\mathrm{C}_{3} \mathrm{H}_{7}+\mathrm{C}_{2} \mathrm{H}_{4}$ & $\rightarrow \mathrm{C}_{3} \mathrm{H}_{8}+\mathrm{C}_{2} \mathrm{H}_{3}$ & $5.67 \times 10^{-14} \times(T / 300)^{3.13} \times \exp (-9060 / T)$ & 10 & 100 & By comparison with $\mathrm{C}_{2} \mathrm{H}_{5}+\mathrm{C}_{2} \mathrm{H}_{4}$ \\
\hline $\mathrm{C}_{3} \mathrm{H}_{7}+\mathrm{C}_{2} \mathrm{H}_{4}$ & $\rightarrow \mathrm{C}_{5} \mathrm{H}_{11}$ & $k_{0}=1.39 \times 10^{-29} \times \exp (-562 / T)$ & 10 & 100 & $k_{0}$ by comparison with $\mathrm{H}+\mathrm{C}_{2} \mathrm{H}_{4}, k_{\infty}$ from \\
\hline & & $\begin{array}{l}k_{\infty}=7.5 \times 10^{-14} \times \exp (-3470 / T) \\
k_{r}=0\end{array}$ & $\begin{array}{r}2 \\
30\end{array}$ & $\begin{array}{r}100 \\
0\end{array}$ & Baulch et al. [1994] \\
\hline $\mathrm{C}_{3} \mathrm{H}_{7}+\mathrm{C}_{2} \mathrm{H}_{6}$ & $\rightarrow \mathrm{C}_{3} \mathrm{H}_{8}+\mathrm{C}_{2} \mathrm{H}_{5}$ & $1.22 \times 10^{-15} \times(T / 300)^{3.82} \times \exp (-4550 / T)$ & 3 & 100 & Tsang [1988] \\
\hline $\mathrm{C}_{3} \mathrm{H}_{7}+\mathrm{CH}_{3} \mathrm{C}_{2} \mathrm{H}$ & $\rightarrow \mathrm{C}_{6} \mathrm{H}_{11}^{\circ}$ & $k_{0}=3.3 \times 10^{-30} \times \exp (-740 / T)$ & 10 & 100 & $k_{0}$ by comparison with $\mathrm{H}+\mathrm{C}_{2} \mathrm{H}_{2}, k_{\infty}$ by \\
\hline & & $\begin{array}{l}k_{\infty}=1.2 \times 10^{-12} \times \exp (-4530 / T) \\
k_{r}=0\end{array}$ & $\begin{array}{l}10 \\
30\end{array}$ & $\begin{array}{r}100 \\
0\end{array}$ & comparison with $\mathrm{C}_{3} \mathrm{H}_{7}+\mathrm{CH}_{4}$ \\
\hline $\mathrm{C}_{3} \mathrm{H}_{7}+\mathrm{CH}_{2} \mathrm{CCH}_{2}$ & $\rightarrow \mathrm{C}_{6} \mathrm{H}_{11}$ & $k_{0}=3.3 \times 10^{-30} \times \exp (-740 / T)$ & 10 & 100 & $k_{0}$ by comparison with $\mathrm{H}+\mathrm{C}_{2} \mathrm{H}_{2}, k_{\infty}$ by \\
\hline $\begin{array}{lll}3 & 7 & 2 \\
2\end{array}$ & $\begin{array}{llll}0 & 11\end{array}$ & $\begin{array}{l}k_{\infty}=1.2 \times 10^{-12} \times \exp (-4530 / T) \\
k_{r}=0\end{array}$ & $\begin{array}{l}10 \\
30\end{array}$ & $\begin{array}{r}100 \\
0\end{array}$ & comparison with $\mathrm{C}_{3} \mathrm{H}_{7}+\mathrm{CH}_{4}$ \\
\hline $\mathrm{C}_{3} \mathrm{H}_{7}+\mathrm{C}_{3} \mathrm{H}_{6}$ & $\rightarrow \mathrm{C}_{3} \mathrm{H}_{8}+\mathrm{C}_{3} \mathrm{H}_{5}$ & $1.73 \times 10^{-15} \times(T / 300)^{3.5} \times \exp (-3340 / T)$ & 3 & 100 & Tsang [1991] \\
\hline $\mathrm{C}_{3} \mathrm{H}_{7}+\mathrm{C}_{3} \mathrm{H}_{6}$ & $\rightarrow \mathrm{C}_{6} \mathrm{H}_{13}$ & $k_{0}=1.39 \times 10^{-29} \times \exp (-562 / T)$ & 10 & 100 & $k_{0}$ by comparison with $\mathrm{H}+\mathrm{C}_{2} \mathrm{H}_{4}, k_{\infty}$ from \\
\hline & & $\begin{array}{l}k_{\infty}=7.5 \times 10^{-14} \times \exp (-3470 / T) \\
k_{r}=0\end{array}$ & $\begin{array}{r}2 \\
30\end{array}$ & $\begin{array}{r}100 \\
0\end{array}$ & Baulch et al. [1994] \\
\hline $\mathrm{C}_{3} \mathrm{H}_{7}+\mathrm{C}_{3} \mathrm{H}_{7}$ & $\rightarrow \mathrm{C}_{3} \mathrm{H}_{8}+\mathrm{C}_{3} \mathrm{H}_{6}$ & $2.8 \times 10^{-12}$ & 1.5 & 100 & Tsang $[1988]$ \\
\hline $\mathrm{C}_{3} \mathrm{H}_{7}+\mathrm{C}_{3} \mathrm{H}_{7}$ & $\rightarrow \mathrm{C}_{6} \mathrm{H}_{14}$ & $\begin{array}{l}k_{0}=9.77 \times 10^{-22} \times(T / 300)^{-6.39} \times \\
\exp (-301 / T)\end{array}$ & 10 & 100 & $\begin{array}{r}k_{0} \text { by comparison with } \mathrm{C}_{2} \mathrm{H}_{5}+\mathrm{C}_{2} \mathrm{H}_{5}, k_{\infty} \\
\text { from Tsang [1988] }\end{array}$ \\
\hline & & $\begin{array}{l}k_{\infty}=1.7 \times 10^{-11} \\
k_{r}=0\end{array}$ & $\begin{array}{r}1.5 \\
30\end{array}$ & $\begin{array}{r}100 \\
0\end{array}$ & \\
\hline $\mathrm{C}_{3} \mathrm{H}_{7}+\mathrm{C}_{4} \mathrm{H}$ & $\rightarrow \mathrm{C}_{2} \mathrm{H}_{5}+\mathrm{C}_{5} \mathrm{H}_{3}$ & $2.0 \times 10^{-11}$ & 10 & 100 & By comparison with $\mathrm{C}_{3} \mathrm{H}_{7}+\mathrm{C}_{2} \mathrm{H}$ \\
\hline $\mathrm{C}_{3} \mathrm{H}_{7}+\mathrm{C}_{4} \mathrm{H}$ & $\rightarrow \mathrm{C}_{4} \mathrm{H}_{2}+\mathrm{C}_{3} \mathrm{H}_{6}$ & $1.0 \times 10^{-11}$ & 10 & 100 & By comparison with $\mathrm{C}_{3} \mathrm{H}_{7}+\mathrm{C}_{2} \mathrm{H}$ \\
\hline $\mathrm{C}_{3}^{3} \mathrm{H}_{7}+\mathrm{C}_{4}^{4} \mathrm{H}_{2}$ & $\rightarrow \mathrm{C}_{7} \mathrm{H}_{9}$ & $k_{0}=3.3 \times 10^{-30} \times \exp (-740 / T)$ & 10 & 100 & $k_{0}$ by comparison with $\mathrm{H}+\mathrm{C}_{2} \mathrm{H}_{2} \cdot k_{\infty}$ by \\
\hline & & $\begin{array}{l}k_{\infty}=5.3 \times 10^{-14} \times \exp (-3500 / T) \\
k_{r}=0\end{array}$ & $\begin{array}{l}10 \\
30\end{array}$ & $\begin{array}{r}100 \\
0\end{array}$ & comparison with $\mathrm{C}_{3} \mathrm{H}_{5}+\mathrm{C}_{2} \mathrm{H}_{2}$ \\
\hline $\mathrm{C}_{3} \mathrm{H}_{7}+\mathrm{C}_{4} \mathrm{H}_{3}$ & $\rightarrow \mathrm{C}_{4} \mathrm{H}_{4}+\mathrm{C}_{3} \mathrm{H}_{6}$ & $2.0 \times 10^{-12}$ & 10 & 100 & By comparison with $\mathrm{C}_{3} \mathrm{H}_{7}+\mathrm{C}_{2} \mathrm{H}_{3}$ \\
\hline $\mathrm{C}_{3} \mathrm{H}_{7}+\mathrm{C}_{4} \mathrm{H}_{3}$ & $\rightarrow \mathrm{C}_{4} \mathrm{H}_{2}+\mathrm{C}_{3} \mathrm{H}_{8}$ & $2.0 \times 10^{-12}$ & 10 & 100 & By comparison with $\mathrm{C}_{3} \mathrm{H}_{7}+\mathrm{C}_{2} \mathrm{H}_{3}$ \\
\hline $\mathrm{C}_{3} \mathrm{H}_{7}+\mathrm{C}_{4} \mathrm{H}_{3}$ & $\rightarrow \mathrm{C}_{7} \mathrm{H}_{10}$ & $\begin{array}{l}k_{0}=1.13 \times 10^{-25} \times(T / 300)^{-3.75} \times \\
\exp (-494 / T)\end{array}$ & 10 & 100 & $k_{0}$ by comparison with $\mathrm{CH}_{3}+\mathrm{CH}_{3}, k_{\infty}$ by \\
\hline & & $\begin{array}{l}k_{\infty}=1.6 \times 10^{-11} \\
k_{r}=0\end{array}$ & $\begin{array}{l}10 \\
30\end{array}$ & $\begin{array}{r}100 \\
0\end{array}$ & comparison with $\mathrm{C}_{2} \mathrm{H}_{3}+\mathrm{C}_{3} \mathrm{H}_{7}$ \\
\hline $\mathrm{C}_{4}+\mathrm{C}_{2} \mathrm{H}_{2}$ & $\rightarrow \mathrm{C}_{6} \mathrm{H}+\mathrm{H}$ & $9 \times 10^{-11}$ & 2 & 0 & $\begin{array}{l}\text { By comparison with }{ }^{3} \mathrm{C}_{2}+\mathrm{C}_{2} \mathrm{H}_{2} \text {, Loison } \\
{[2014]}\end{array}$ \\
\hline $\mathrm{C}_{4}+\mathrm{C}_{2} \mathrm{H}_{4}$ & $\rightarrow \mathrm{C}_{4} \mathrm{H}_{2}+\mathrm{C}_{2} \mathrm{H}_{2}$ & $2.0 \times 10^{-11}$ & 2 & 0 & By comparison with ${ }^{3} \mathrm{C}_{2}+\mathrm{C}_{2} \mathrm{H}_{4}$, Loison \\
\hline $\mathrm{C}_{4}+\mathrm{C}_{2} \mathrm{H}_{4}$ & $\rightarrow \mathrm{C}_{6} \mathrm{H}_{3}+\mathrm{H}$ & $8.0 \times 10^{-11}$ & 2 & 0 & By comparison with ${ }^{3} \mathrm{C}_{2}+\mathrm{C}_{2} \mathrm{H}_{4}$, Loison \\
\hline $\mathrm{C}_{4} \mathrm{H}+\mathrm{H}_{2}$ & $\rightarrow \mathrm{C}_{4} \mathrm{H}_{2}+\mathrm{H}$ & $1.2 \times 10^{-11} \times \exp (-998 / T)$ & 10 & 100 & By comparison with $\mathrm{C}_{2} \mathrm{H}+\mathrm{H}_{2}$ \\
\hline $\mathrm{C}_{4} \mathrm{H}+\mathrm{CH}_{4}$ & $\rightarrow \mathrm{C}_{4} \mathrm{H}_{2}+\mathrm{CH}_{3}$ & $1.6 \times 10^{-11} \times \exp (-610 / T)$ & 1.1 & 0 & Berteloite et al. [2010a] \\
\hline $\mathrm{C}_{4} \mathrm{H}+\mathrm{C}_{2} \mathrm{H}_{2}$ & $\rightarrow \mathrm{C}_{6} \mathrm{H}_{2}+\mathrm{H}$ & $1.82 \times 10^{-10} \times(T / 300)^{-1.06} \times \exp (-65.8 / T)$ & 1.21 & 0 & Berteloite et al. [2010b] \\
\hline $\mathrm{C}_{4} \mathrm{H}+\mathrm{C}_{2} \mathrm{H}_{4}$ & $\rightarrow \mathrm{C}_{6} \mathrm{H}_{4}+\mathrm{H}$ & $1.95 \times 10^{-10} \times(T / 300)^{-0.4} \times \exp (9.4 / T)$ & 1.21 & 0 & Berteloite et al. [2008] \\
\hline $\mathrm{C}_{4} \mathrm{H}+\mathrm{C}_{2} \mathrm{H}_{6}$ & $\rightarrow \mathrm{C}_{4} \mathrm{H}_{2}+\mathrm{C}_{2} \mathrm{H}_{5}$ & $2.87 \times 10^{-11} \times(T / 300)^{-1.24} \times \exp (-25.6 / T)$ & 1.2 & 0 & Berteloite et al. [2010a] \\
\hline $\mathrm{C}_{4} \mathrm{H}+\mathrm{CH}_{3} \mathrm{C}_{2} \mathrm{H}$ & $\rightarrow \mathrm{C}_{6} \mathrm{H}_{2}+\mathrm{CH}_{3}$ & $3.2 \times 10^{-10} \times(T / 300)^{-0.82} \times \exp (-47.5 / T)$ & 1.12 & 0 & Berteloite et al. [2010b] \\
\hline $\mathrm{C}_{4} \mathrm{H}+\mathrm{CH}_{2} \mathrm{CCH}_{2}$ & $\rightarrow \mathrm{C}_{7} \mathrm{H}_{4}+\mathrm{H}$ & $1.3 \times 10^{-10}$ & 10 & 100 & Berteloite et al. [2010b] \\
\hline $\mathrm{C}_{4} \mathrm{H}+\mathrm{C}_{3} \mathrm{H}_{6}$ & $\rightarrow \mathrm{C}_{4} \mathrm{H}_{3}+\mathrm{CH}_{3} \mathrm{C}_{2} \mathrm{H}$ & $2.0 \times 10^{-11}$ & 10 & 100 & $\begin{array}{r}\text { By comparison with } \mathrm{C}_{2} \mathrm{H}+\mathrm{C}_{3} \mathrm{H}_{6} \text {, see also } \\
\text { Berteloite et al. [2010b] }\end{array}$ \\
\hline $\mathrm{C}_{4} \mathrm{H}+\mathrm{C}_{3} \mathrm{H}_{6}$ & $\rightarrow \mathrm{C}_{6} \mathrm{H}_{6}+\mathrm{CH}$ & $2.0 \times 10^{-11}$ & 10 & 100 & $\begin{array}{r}\text { By comparison with } \mathrm{C}_{2} \mathrm{H}+\mathrm{C}_{3} \mathrm{H}_{6} \text {, see also } \\
\text { Berteloite et al. [2010b] }\end{array}$ \\
\hline $\mathrm{C}_{4} \mathrm{H}+\mathrm{C}_{3} \mathrm{H}_{6}$ & $\rightarrow \mathrm{C}_{7} \mathrm{H}_{6}+\mathrm{H}$ & $1.6 \times 10^{-11} \times \exp (-4.04 / T)$ & 10 & 100 & $\begin{array}{r}\text { By comparison with } \mathrm{C}_{2} \mathrm{H}+\mathrm{C}_{3} \mathrm{H}_{6} \text {, see also } \\
\text { Berteloite et al. [2010b] }\end{array}$ \\
\hline $\mathrm{C}_{4} \mathrm{H}+\mathrm{C}_{3} \mathrm{H}_{8}$ & $\rightarrow \mathrm{C}_{4} \mathrm{H}_{2}+\mathrm{C}_{3} \mathrm{H}_{7}$ & $1.05 \times 10^{-10} \times(T / 300)^{-1.35} \times \exp (-56.3 / T)$ & 1.22 & 0 & Berteloite et al. [2008] \\
\hline $\mathrm{C}_{4} \mathrm{H}+\mathrm{C}_{4} \mathrm{H}$ & $\rightarrow \mathrm{C}_{8} \mathrm{H}+\mathrm{H}$ & $3.0 \times 10^{-12}$ & 10 & 100 & By comparison with $\mathrm{C}_{2} \mathrm{H}+\mathrm{C}_{2} \mathrm{H}$ \\
\hline $\mathrm{C}_{4} \mathrm{H}+\mathrm{C}_{4} \mathrm{H}_{2}$ & $\rightarrow \mathrm{C}_{8}^{\circ} \mathrm{H}_{2}+\mathrm{H}$ & $1.3 \times 10^{-10}$ & 10 & 100 & By comparison with $\mathrm{C}_{4} \mathrm{H}+\mathrm{C}_{2} \mathrm{H}_{2}$ \\
\hline $\mathrm{C}_{4} \mathrm{H}+\mathrm{C}_{4} \mathrm{H}_{3}$ & $\rightarrow \mathrm{C}_{4} \mathrm{H}_{2}+\mathrm{C}_{4} \mathrm{H}_{2}$ & $1.6 \times 10^{-12}$ & 10 & 100 & By comparison with $\mathrm{C}_{2} \mathrm{H}+\mathrm{C}_{2} \mathrm{H}_{3}$ \\
\hline $\mathrm{C}_{4} \mathrm{H}+\mathrm{C}_{4} \mathrm{H}_{3}$ & $\rightarrow \mathrm{C}_{8} \mathrm{H}_{3}+\mathrm{H}$ & $3.0 \times 10^{-11}$ & 10 & 100 & By comparison with $\mathrm{C}_{2} \mathrm{H}+\mathrm{C}_{2} \mathrm{H}_{3}$ \\
\hline $\mathrm{C}_{4} \mathrm{H}+\mathrm{C}_{6} \mathrm{H}_{2}$ & $\rightarrow$ SOOTC & $1.3 \times 10^{-10}$ & 10 & 100 & By comparison with $\mathrm{C}_{4} \mathrm{H}+\mathrm{C}_{2} \mathrm{H}_{2}$ \\
\hline $\mathrm{C}_{4} \mathrm{H}+\mathrm{C}_{8} \mathrm{H}_{2}$ & $\rightarrow$ SOOTC & $1.3 \times 10^{-10}$ & 10 & 100 & By comparison with $\mathrm{C}_{4} \mathrm{H}+\mathrm{C}_{2} \mathrm{H}_{2}$ \\
\hline $\mathrm{C}_{4} \mathrm{H}_{2} \mathrm{X}$ & $\rightarrow \mathrm{C}_{4} \mathrm{H}_{2}$ & $1.0 \times 10^{+01}$ & 10 & 100 & Vuitton et al. [2003] \\
\hline $\mathrm{C}_{4} \mathrm{H}_{2} \mathrm{X}+\mathrm{H}_{2}$ & $\rightarrow \mathrm{C}_{4} \mathrm{H}_{2}^{2}+\mathrm{H}_{2}$ & $1.4 \times 10^{-15}$ & 3 & 100 & Zwier and Allen [1996] \\
\hline $\mathrm{C}_{4} \mathrm{H}_{2} \mathrm{X}+\mathrm{CH}_{4}$ & $\rightarrow \mathrm{C}_{4} \mathrm{H}_{2}+\mathrm{CH}_{4}$ & $1.4 \times 10^{-15}$ & 3 & 100 & Zwier and Allen [1996] \\
\hline $\mathrm{C}_{4} \mathrm{H}_{2} \mathrm{X}+\mathrm{C}_{2} \mathrm{H}_{2}$ & $\rightarrow \mathrm{C}_{6} \mathrm{H}_{2}+\mathrm{H}_{2}$ & $1.75 \times 10^{-13}$ & 3 & 100 & Zwier and Allen [1996] \\
\hline $\mathrm{C}_{4} \mathrm{H}_{2} \mathrm{X}+\mathrm{C}_{2} \mathrm{H}_{2}$ & $\rightarrow \mathrm{C}_{6} \mathrm{H}_{2}+\mathrm{H}+\mathrm{H}$ & $1.75 \times 10^{-13}$ & 3 & 100 & Zwier and Allen [1996] \\
\hline $\mathrm{C}_{4}^{4} \mathrm{H}_{2}^{2} \mathrm{X}+\mathrm{C}_{2}^{2} \mathrm{H}_{4}^{2}$ & $\rightarrow \mathrm{C}_{6}^{6} \mathrm{H}_{5}^{2}+\mathrm{H}$ & $9.8 \times 10^{-14}$ & 3 & 100 & Zwier and Allen [1996] \\
\hline $\mathrm{C}_{4}^{4} \mathrm{H}_{2}^{2} \mathrm{X}+\mathrm{C}_{2} \mathrm{H}_{4}^{4}$ & $\rightarrow \mathrm{C}_{6}^{6} \mathrm{H}_{4}^{5}+\mathrm{H}_{2}$ & $3.69 \times 10^{-13}$ & 3 & 100 & Zwier and Allen [1996] \\
\hline $\mathrm{C}_{4} \mathrm{H}_{2}^{2} \mathrm{X}+\mathrm{CH}_{3} \mathrm{C}_{2} \mathrm{H}$ & $\rightarrow \mathrm{C}_{7}^{6} \mathrm{H}_{4}^{4}+\mathrm{H}_{2}^{2}$ & $1.59 \times 10^{-13}$ & 3 & 100 & Zwier and Allen [1996] \\
\hline $\mathrm{C}_{4} \mathrm{H}_{2}^{2} \mathrm{X}+\mathrm{CH}_{3}^{3} \mathrm{C}_{2} \mathrm{H}$ & $\rightarrow \mathrm{C}_{6} \mathrm{H}_{2}^{4}+\mathrm{CH}_{3}^{2}+\mathrm{H}$ & $2.31 \times 10^{-13}$ & 3 & 100 & Zwier and Allen [1996] \\
\hline $\mathrm{C}_{4} \mathrm{H}_{2} \mathrm{X}+\mathrm{CH}_{3} \mathrm{C}_{2} \mathrm{H}$ & $\rightarrow \mathrm{C}_{5} \mathrm{H}_{4}+\mathrm{C}_{2} \mathrm{H}_{2}$ & $2.46 \times 10^{-13}$ & 3 & 100 & Zwier and Allen [1996] \\
\hline $\mathrm{C}_{4} \mathrm{H}_{2} \mathrm{X}+\mathrm{CH}_{3} \mathrm{C}_{2} \mathrm{H}$ & $\rightarrow \mathrm{C}_{5} \mathrm{H}_{3}+\mathrm{C}_{2} \mathrm{H}_{3}$ & $8.68 \times 10^{-13}$ & 3 & 100 & Zwier and Allen [1996] \\
\hline
\end{tabular}




\begin{tabular}{|c|c|c|c|c|c|}
\hline \multicolumn{2}{|l|}{ Reactions } & Rate coefficients & $F(300 K)$ & $g$ & References \\
\hline $\mathrm{C}_{4} \mathrm{H}_{2} \mathrm{X}+\mathrm{C}_{3} \mathrm{H}_{6}$ & $\rightarrow \mathrm{C}_{7} \mathrm{H}_{6}+\mathrm{H}_{2}$ & $1.63 \times 10^{-13}$ & 3 & 100 & Zwier and Allen [1996] \\
\hline $\mathrm{C}_{4} \mathrm{H}_{2} \mathrm{X}+\mathrm{C}_{3} \mathrm{H}_{6}$ & $\rightarrow \mathrm{C}_{6} \mathrm{H}_{4}+\mathrm{CH}_{3}+\mathrm{H}$ & $3.76 \times 10^{-13}$ & 3 & 100 & Zwier and Allen [1996] \\
\hline $\mathrm{C}_{4} \mathrm{H}_{2} \mathrm{X}+\mathrm{C}_{3} \mathrm{H}_{6}$ & $\rightarrow \mathrm{C}_{5} \mathrm{H}_{6}+\mathrm{C}_{2} \mathrm{H}_{2}$ & $2.29 \times 10^{-13}$ & 3 & 100 & Zwier and Allen [1996] \\
\hline $\mathrm{C}_{4} \mathrm{H}_{2} \mathrm{X}+\mathrm{C}_{3} \mathrm{H}_{6}$ & $\rightarrow \mathrm{C}_{5} \mathrm{H}_{5}+\mathrm{C}_{2} \mathrm{H}_{3}$ & $4.9 \times 10^{-13}$ & 3 & 100 & Zwier and Allen [1996] \\
\hline $\mathrm{C}_{4} \mathrm{H}_{2} \mathrm{X}+\mathrm{C}_{4} \mathrm{H}_{2}$ & $\rightarrow \mathrm{C}_{8} \mathrm{H}_{2}+\mathrm{H}+\mathrm{H}$ & $2.57 \times 10^{-13}$ & 3 & 100 & Zwier and Allen [1996] \\
\hline $\mathrm{C}_{4} \mathrm{H}_{2} \mathrm{X}+\mathrm{C}_{4} \mathrm{H}_{2}$ & $\rightarrow \mathrm{C}_{8} \mathrm{H}_{2}+\mathrm{H}_{2}$ & $2.57 \times 10^{-13}$ & 3 & 100 & Zwier and Allen [1996] \\
\hline $\mathrm{C}_{4} \mathrm{H}_{2} \mathrm{X}+\mathrm{C}_{4} \mathrm{H}_{2}$ & $\rightarrow \mathrm{C}_{6} \mathrm{H}_{2}+\mathrm{C}_{2} \mathrm{H}_{2}$ & $8.17 \times 10^{-13}$ & 3 & 100 & Zwier and Allen [1996] \\
\hline $\mathrm{C}_{4} \mathrm{H}_{2} \mathrm{X}+\mathrm{C}_{4} \mathrm{H}_{2}$ & $\rightarrow \mathrm{C}_{8} \mathrm{H}_{3}+\mathrm{H}$ & $1.0 \times 10^{-12}$ & 3 & 100 & Zwier and Allen [1996] \\
\hline $\mathrm{C}_{4} \mathrm{H}_{2} \mathrm{X}+\mathrm{C}_{4} \mathrm{H}_{6}$ & $\rightarrow \mathrm{C}_{6} \mathrm{H}_{6}+\mathrm{C}_{2} \mathrm{H}_{2}$ & $8.8 \times 10^{-13}$ & 3 & 100 & Zwier and Allen [1996] \\
\hline $\mathrm{C}_{4} \mathrm{H}_{2} \mathrm{X}+\mathrm{N}_{2}$ & $\rightarrow \mathrm{C}_{4} \mathrm{H}_{2}+\mathrm{N}_{2}$ & $1.4 \times 10^{-15}$ & 3 & 100 & Zwier and Allen [1996] \\
\hline $\mathrm{C}_{4} \mathrm{H}_{3}^{2}+\mathrm{H}_{2}^{2}$ & $\rightarrow \mathrm{C}_{4}^{4} \mathrm{H}_{4}^{2}+\mathrm{H}^{2}$ & $3.31 \times 10^{-14} \times(T / 300)^{2.56} \times \exp (-2562 / T)$ & 10 & 1000 & By comparison with $\mathrm{C}_{2} \mathrm{H}_{3}+\mathrm{H}_{2}$ \\
\hline $\mathrm{C}_{4} \mathrm{H}_{3}+\mathrm{CH}_{4}$ & $\rightarrow \mathrm{C}_{4}^{4} \mathrm{H}_{4}^{4}+\mathrm{CH}_{3}$ & $2.13 \times 10^{-14} \times(T / 300)^{4.02} \times \exp (-2750 / T)$ & 10 & 1000 & By comparison with $\mathrm{C}_{2} \mathrm{H}_{3}+\mathrm{CH}_{4}^{2}$ \\
\hline $\mathrm{C}_{4} \mathrm{H}_{3}+\mathrm{C}_{2} \mathrm{H}_{2}$ & $\rightarrow \mathrm{C}_{6} \mathrm{H}_{5}$ & $\begin{array}{l}k_{0}=2.55 \times 10^{-22} \times(T / 300)^{-12.8} \times \\
\exp (-5890 / T)\end{array}$ & 2 & 100 & $\begin{array}{l}\text { Wang and Frenklach [1994], Wang and } \\
\text { Frenklach [1997], Westmoreland et al. [1989] }\end{array}$ \\
\hline & & $\begin{array}{l}k_{\infty}=4.09 \times 10^{-16} \times(T / 300)^{0.47} \times \\
\exp (-3020 / T) \\
k_{r}=0\end{array}$ & $\begin{array}{r}2 \\
30\end{array}$ & $\begin{array}{r}100 \\
0\end{array}$ & \\
\hline $\mathrm{C}_{4} \mathrm{H}_{3}+\mathrm{C}_{4} \mathrm{H}_{3}$ & $\rightarrow \mathrm{C}_{4} \mathrm{H}_{4}+\mathrm{C}_{4} \mathrm{H}_{2}$ & $3.5 \times 10^{-11}$ & 10 & 100 & $\begin{array}{r}\text { By comparison with } \mathrm{C}_{2} \mathrm{H}_{3}+\mathrm{C}_{2} \mathrm{H}_{3} \text { (Fahr et } \\
\text { al. [1991], Laufer and Fahr [2004]) }\end{array}$ \\
\hline $\mathrm{C}_{4} \mathrm{H}_{3}+\mathrm{C}_{4} \mathrm{H}_{3}$ & $\rightarrow \mathrm{C}_{6} \mathrm{H}_{5} \mathrm{C}_{2} \mathrm{H}$ & $\begin{array}{l}k_{0}=1.13 \times 10^{-25} \times(T / 300)^{-3.75} \times \\
\exp (-494 / T)\end{array}$ & 10 & 100 & $\begin{array}{r}k_{0} \text { by comparison with } \mathrm{CH}_{3}+\mathrm{CH}_{3}, k_{\infty} \text { by } \\
\text { comparison with } \mathrm{C}_{0} \mathrm{H}_{3}+\mathrm{C}_{0} \mathrm{H}_{0}\end{array}$ \\
\hline & & $\begin{array}{l}k_{\infty}=1.2 \times 10^{-10} \\
k_{r}=0\end{array}$ & $\begin{array}{l}10 \\
30\end{array}$ & $\begin{array}{r}100 \\
0\end{array}$ & \\
\hline $\mathrm{C}_{4} \mathrm{H}_{5}+\mathrm{H}_{2}$ & $\rightarrow \mathrm{C}_{4} \mathrm{H}_{6}+\mathrm{H}$ & $4.0 \times 10^{-14} \times(T / 300)^{2} \times \exp (-2000 / T)$ & 4 & 600 & $\begin{array}{r}6 \times k\left(\mathrm{C}_{2} \mathrm{H}_{3}+\mathrm{H}_{2}\right) \text { from Knyazev et al. [1996a] } \\
\text { Callear and Smith [1986], Weismann and } \\
\text { Benson [1988] }\end{array}$ \\
\hline $\mathrm{C}_{4} \mathrm{H}_{5}+\mathrm{CH}_{4}$ & $\rightarrow \mathrm{C}_{4} \mathrm{H}_{6}+\mathrm{CH}_{3}$ & $4.0 \times 10^{-14} \times(T / 300)^{2} \times \exp (-1600 / T)$ & 4 & 600 & By comparison with $\mathrm{C}_{2} \mathrm{H}_{3}+\mathrm{CH}_{4}$ and $\mathrm{C}_{4} \mathrm{H}_{5}$ \\
\hline $\mathrm{C}_{4} \mathrm{H}_{5}+\mathrm{C}_{2} \mathrm{H}_{2}$ & $\rightarrow \mathrm{C}_{6} \mathrm{H}_{6}+\mathrm{H}$ & $1.38 \times 10^{-12} \times(T / 300)^{1.47} \times \exp (-2470 / T)$ & 2 & 100 & Westmoreland et al. [1989] \\
\hline $\mathrm{C}_{6} \mathrm{H}+\mathrm{H}_{2}$ & $\rightarrow \mathrm{C}_{6} \mathrm{H}_{2}+\mathrm{H}$ & $2.18 \times 10^{-12} \times(T / 300)^{2.17} \times \exp (-478 / T)$ & 2 & 100 & By comparison with $\mathrm{C}_{2} \mathrm{H}+\mathrm{H}_{2}$ \\
\hline $\mathrm{C}_{6}^{0} \mathrm{H}+\mathrm{CH}_{4}$ & $\rightarrow \mathrm{C}_{6}^{0} \mathrm{H}_{2}^{2}+\mathrm{CH}_{3}$ & $1.2 \times 10^{-11} \times \exp (-491 / T)$ & 10 & 100 & By comparison with $\mathrm{C}_{2} \mathrm{H}, \mathrm{C}_{4} \mathrm{H}+\mathrm{CH}_{4}^{2}$ \\
\hline $\mathrm{C}_{6} \mathrm{H}+\mathrm{C}_{2} \mathrm{H}_{2}$ & $\rightarrow \mathrm{C}_{8} \mathrm{H}_{2}+\mathrm{H}$ & $1.3 \times 10^{-10}$ & 10 & 100 & By comparison with $\mathrm{C}_{2} \mathrm{H}, \mathrm{C}_{4} \mathrm{H}+\mathrm{C}_{2} \mathrm{H}_{2}$ \\
\hline $\mathrm{C}_{6} \mathrm{H}+\mathrm{C}_{2}^{2} \mathrm{H}_{6}^{2}$ & $\rightarrow \mathrm{C}_{6} \mathrm{H}_{2}^{2}+\mathrm{C}_{2} \mathrm{H}_{5}$ & $5.1 \times 10^{-11} \times \exp (-76 / T)$ & 10 & 100 & By comparison with $\mathrm{C}_{2}^{2} \mathrm{H}, \mathrm{C}_{4}^{4} \mathrm{H}+\mathrm{C}_{2}^{2} \mathrm{H}_{6}^{2}$ \\
\hline $\mathrm{C}_{6} \mathrm{H}+\mathrm{C}_{4} \mathrm{H}_{2}^{\circ}$ & $\rightarrow$ SOOTC & $1.3 \times 10^{-10}$ & 10 & 100 & By comparison with $\mathrm{C}_{4}^{4} \mathrm{H}+\mathrm{C}_{4} \mathrm{H}_{2}^{\circ}$ \\
\hline $\mathrm{C}_{6} \mathrm{H}+\mathrm{C}_{6} \mathrm{H}_{2}$ & $\rightarrow \mathrm{SOOTC}$ & $1.3 \times 10^{-10}$ & 10 & 100 & By comparison with $\mathrm{C}_{4}^{4} \mathrm{H}+\mathrm{C}_{4} \mathrm{H}_{2}^{2}$ \\
\hline $\mathrm{C}_{6} \mathrm{H}+\mathrm{C}_{8} \mathrm{H}_{2}$ & $\rightarrow \mathrm{SOOTC}$ & $1.3 \times 10^{-10}$ & 10 & 100 & By comparison with $\mathrm{C}_{4}^{4} \mathrm{H}+\mathrm{C}_{4}^{4} \mathrm{H}_{2}^{2}$ \\
\hline $\mathrm{C}_{6}^{\circ} \mathrm{H}_{5}+\stackrel{\circ}{\mathrm{H}}_{2}^{2}$ & $\rightarrow \mathrm{C}_{6} \mathrm{H}_{6}+\mathrm{H}$ & $9.91 \times 10^{-14} \times(T / 300)^{2.43} \times \exp (-3160 / T)$ & 2 & 100 & Mebel et al. [1997] \\
\hline $\mathrm{C}_{6} \mathrm{H}_{5}+\mathrm{C}_{2} \mathrm{H}_{2}$ & $\rightarrow \mathrm{SOOTC}+\mathrm{H}$ & $3.25 \times 10^{-12} \times(T / 300)^{0.21} \times \exp (-2520 / T)$ & 2 & 100 & Wang and Frenklach [1994] \\
\hline $\mathrm{C}_{6} \mathrm{H}_{5}+\mathrm{C}_{2} \mathrm{H}_{2}$ & $\rightarrow$ SOOTC & $k_{0}=3.89 \times 10^{-29} \times(T / 300)^{-4.08} \times \exp (403 / T)$ & 2 & 100 & Wang and Frenklach [1994] \\
\hline & & $\begin{array}{l}k_{\infty}=4.86 \times 10^{-13} \times(T / 300)^{1.56} \times \\
\exp (-1910 / T)\end{array}$ & 2 & 100 & \\
\hline & & $k_{r}=0$ & 30 & 0 & \\
\hline $\mathrm{C}_{6} \mathrm{H}_{5}+\mathrm{C}_{6} \mathrm{H}_{6}$ & $\rightarrow \mathrm{SOOTC}+\mathrm{H}$ & $1.35 \times 10^{-12} \times \exp (-2100 / T)$ & 2 & 150 & Park et al. [1999] \\
\hline $\mathrm{N}\left({ }^{4} \mathrm{~S}\right)+\mathrm{CH}$ & $\rightarrow \mathrm{CN}+\mathrm{H}$ & $1.4 \times 10^{-10} \times(T / 300)^{4.1}$ & 3 & 0 & Daranlot et al. [2013] \\
\hline $\mathrm{N}\left({ }^{4} \mathrm{~S}\right)+{ }^{3} \mathrm{CH}_{2}$ & $\rightarrow \mathrm{HCN}+\mathrm{H}$ & $5.0 \times 10^{-11} \times(T / 300)^{0.17}$ & 3 & 0 & Hébrard et al. [2012] \\
\hline $\mathrm{N}\left({ }^{4} \mathrm{~S}\right)+{ }^{3} \mathrm{CH}_{2}$ & $\rightarrow \mathrm{HNC}+\mathrm{H}$ & $3.0 \times 10^{-11} \times(T / 300)^{0.17}$ & 3 & 0 & Hébrard et al. [2012] \\
\hline $\mathrm{N}\left({ }^{4} \mathrm{~S}\right)+\mathrm{CH}_{3}{ }^{2}$ & $\rightarrow \mathrm{H}_{2} \mathrm{CN}+\mathrm{H}$ & $5.6 \times 10^{-11}$ & 1.6 & 7 & Hébrard et al. [2012] \\
\hline $\mathrm{N}\left({ }^{4} \mathrm{~S}\right)+\mathrm{CH}_{3}$ & $\rightarrow \mathrm{HCN}+\mathrm{H}+\mathrm{H}$ & $6.0 \times 10^{-12}$ & 2 & 7 & Hébrard et al. [2012] \\
\hline $\mathrm{N}\left({ }^{4} \mathrm{~S}\right)+\mathrm{C}_{2}$ & $\rightarrow \mathrm{CN}+\mathrm{C}$ & $2.0 \times 10^{-10}$ & 3 & 0 & $\begin{array}{l}\text { Capture rate constant Georgievskii and } \\
\text { Klippenstein [2005] considering no barrier }\end{array}$ \\
\hline $\mathrm{N}\left({ }^{4} \mathrm{~S}\right)+\mathrm{C}_{2} \mathrm{H}$ & $\rightarrow \mathrm{C}_{2} \mathrm{~N}+\mathrm{H}$ & $2.0 \times 10^{-10} \times(T / 300)^{0.17}$ & 3 & 0 & Hébrard et al. [2012] \\
\hline $\mathrm{N}\left({ }^{4} \mathrm{~S}\right)+\mathrm{C}_{2} \mathrm{H}$ & $\rightarrow \stackrel{\mathrm{HCN}}{2}+\mathrm{C}$ & $8.0 \times 10^{-12} \times(T / 300)^{0.17}$ & 3 & 0 & Hébrard et al. [2012] \\
\hline $\mathrm{N}\left({ }^{4} \mathrm{~S}\right)+\mathrm{C}_{2}^{2} \mathrm{H}$ & $\rightarrow \mathrm{HNC}+\mathrm{C}$ & $4.0 \times 10^{-12} \times(T / 300)^{0.17}$ & 3 & 0 & Hébrard et al. [2012] \\
\hline $\mathrm{N}\left({ }^{4} \mathrm{~S}\right)+\mathrm{C}_{2} \mathrm{H}_{3}$ & $\rightarrow \mathrm{CH}_{2} \mathrm{CN}+\mathrm{H}$ & $6.4 \times 10^{-11} \times(T / 300)^{0.17}$ & 2 & 7 & Payne et al. [1996] \\
\hline $\mathrm{N}\left({ }^{4} \mathrm{~S}\right)+\mathrm{C}_{2} \mathrm{H}_{3}$ & $\rightarrow \mathrm{NH}+\mathrm{C}_{2} \mathrm{H}_{2}$ & $1.3 \times 10^{-11} \times(T / 300)^{0.17}$ & 2 & 7 & Payne et al. [1996] \\
\hline $\mathrm{N}\left({ }^{4} \mathrm{~S}\right)+\mathrm{C}_{2} \mathrm{H}_{5}^{3}$ & $\rightarrow \mathrm{H}_{2} \mathrm{CN}+\mathrm{CH}_{3}$ & $6.0 \times 10^{-11} \times(T / 300)^{0.17}$ & 2 & 7 & Stief et al. [1995], Yang et al. [2005] \\
\hline $\mathrm{N}\left({ }^{4} \mathrm{~S}\right)+\mathrm{C}_{2} \mathrm{H}_{5}$ & $\rightarrow \mathrm{NH}+\mathrm{C}_{2} \mathrm{H}_{4}$ & $4.0 \times 10^{-11} \times(T / 300)^{0.17}$ & 3 & 21 & Stief et al. [1995], Yang et al. [2005] \\
\hline $\mathrm{N}\left({ }^{4} \mathrm{~S}\right)+\mathrm{C}_{3}$ & $\rightarrow \mathrm{CN}+\mathrm{C}_{2}$ & $1.0 \times 10^{-11} \times \exp (-1000 / T)$ & 4 & 100 & KIDA datasheet \\
\hline $\mathrm{N}\left({ }^{4} \mathrm{~S}\right)+\mathrm{l}-\mathrm{C}_{3} \mathrm{H}$ & $\rightarrow \mathrm{CN}+\mathrm{C}_{2} \mathrm{H}$ & $1.0 \times 10^{-10} \times(T / 300)^{0.17}$ & 3 & 0 & $\begin{array}{l}\text { Calculs DFT (M06-2X/cc-pVTZ) }+ \\
\text { Georgievskii and Klippenstein [2005] }\end{array}$ \\
\hline $\mathrm{N}\left({ }^{4} \mathrm{~S}\right)+\mathrm{l}-\mathrm{C}_{3} \mathrm{H}$ & $\rightarrow \mathrm{C}_{3} \mathrm{~N}+\mathrm{H}$ & $1.0 \times 10^{-10} \times(T / 300)^{0.17}$ & 3 & 0 & $\begin{array}{r}\text { Calculs DFT (M06-2X/cc-pVTZ) } \\
\text { Georgievskii and Klippenstein }[2005]\end{array}$ \\
\hline $\mathrm{N}\left({ }^{4} \mathrm{~S}\right)+\mathrm{c}-\mathrm{C}_{3} \mathrm{H}$ & $\rightarrow \mathrm{CN}+\mathrm{C}_{2} \mathrm{H}$ & $1.0 \times 10^{-10} \times(T / 300)^{0.17}$ & 3 & 0 & $\begin{array}{l}\text { Calculs DFT (M06-2X/cc-pVTZ) } \\
\text { Georgievskii and Klippenstein }[2005]\end{array}$ \\
\hline $\mathrm{N}\left({ }^{4} \mathrm{~S}\right)+\mathrm{c}-\mathrm{C}_{3} \mathrm{H}$ & $\rightarrow \mathrm{C}_{3} \mathrm{~N}+\mathrm{H}$ & $1.0 \times 10^{-10} \times(T / 300)^{0.17}$ & 3 & 0 & $\begin{array}{l}\text { Calculs DFT (M06-2X/cc-pVTZ) } \\
\text { Georgievskii and Klippenstein }[2005]\end{array}$ \\
\hline $\mathrm{N}\left({ }^{4} \mathrm{~S}\right)+\mathrm{t}-\mathrm{C}_{3} \mathrm{H}_{2}$ & $\rightarrow \mathrm{HC}_{3} \mathrm{~N}+\mathrm{H}$ & $4.0 \times 10^{-11}$ & 3 & 0 & By comparison with $\mathrm{N}+{ }^{3} \mathrm{CH}_{2}$ \\
\hline $\mathrm{N}\left({ }^{4} \mathrm{~S}\right)+\mathrm{C}_{3} \mathrm{H}_{3}$ & $\rightarrow \mathrm{H}_{2} \mathrm{C}_{3} \mathrm{~N}+\mathrm{H}$ & $5.0 \times 10^{-11}$ & 4 & 0 & $\begin{array}{c}\text { Calculs DFT (M06-2X/cc-pVTZ) } \\
\text { Georgievskii and Klippenstein }[2005]\end{array}$ \\
\hline $\mathrm{N}\left({ }^{4} \mathrm{~S}\right)+\mathrm{C}_{3} \mathrm{H}_{5}$ & $\rightarrow \mathrm{C}_{2} \mathrm{H}_{3} \mathrm{CN}+\mathrm{H}_{2}$ & $3.2 \times 10^{-11} \times(T / 300)^{0.17}$ & 3 & 0 & By comparison with $\mathrm{N}+\mathrm{C}_{2} \mathrm{H}_{3}$ \\
\hline $\mathrm{N}\left({ }^{4} \mathrm{~S}\right)+\mathrm{C}_{3} \mathrm{H}_{5}^{5}$ & $\rightarrow \mathrm{HCN}^{3}+\mathrm{C}_{2} \mathrm{H}_{4}$ & $3.2 \times 10^{-11} \times(T / 300)^{0.17}$ & 3 & 0 & By comparison with $\mathrm{N}+\mathrm{C}_{2} \mathrm{H}_{3}$ \\
\hline
\end{tabular}




\begin{tabular}{|c|c|c|c|c|c|}
\hline \multicolumn{2}{|l|}{ Reactions } & \multirow{2}{*}{$\begin{array}{l}\text { Rate coefficients } \\
1.3 \times 10^{-11} \times(T / 300)^{0.17}\end{array}$} & \multirow{2}{*}{$\begin{array}{r}F(300 K) \\
2\end{array}$} & \multirow{2}{*}{$\begin{array}{l}g \\
7\end{array}$} & \multirow{2}{*}{$\begin{array}{r}\text { References } \\
\text { By comparison with } \mathrm{N}+\mathrm{C}_{2} \mathrm{H}_{3}\end{array}$} \\
\hline $\mathrm{N}\left({ }^{4} \mathrm{~S}\right)+\mathrm{C}_{3} \mathrm{H}_{5}$ & $\rightarrow \mathrm{NH}+\mathrm{CH}_{2} \mathrm{CCH}_{2}$ & & & & \\
\hline $\mathrm{N}\left({ }^{4} \mathrm{~S}\right)+\mathrm{C}_{3}^{3} \mathrm{H}_{7}^{5}$ & $\rightarrow \mathrm{H}_{2} \mathrm{CN}+\mathrm{C}_{2} \mathrm{H}_{5}$ & $1.0 \times 10^{-10}$ & 4 & 0 & By comparison with $\mathrm{N}+\mathrm{C}_{2} \mathrm{H}_{5}^{3}$ \\
\hline $\mathrm{N}\left({ }^{4} \mathrm{~S}\right)+\mathrm{C}_{4} \mathrm{H}$ & $\rightarrow \mathrm{C}_{4} \mathrm{~N}+\mathrm{H}$ & $7.0 \times 10^{-11} \times(T / 300)^{0.17}$ & 3 & 0 & By comparison with $\mathrm{N}+\mathrm{C}_{2} \mathrm{H}$ \\
\hline $\mathrm{N}\left({ }^{4} \mathrm{~S}\right)+\mathrm{C}_{4} \mathrm{H}$ & $\rightarrow \mathrm{CN}+1-\mathrm{C}_{3} \mathrm{H}$ & $1.0 \times 10^{-11} \times(T / 300)^{0.17}$ & 3 & 0 & By comparison with $\mathrm{N}+\mathrm{C}_{2} \mathrm{H}$ \\
\hline $\mathrm{N}\left({ }^{4} \mathrm{~S}\right)+\mathrm{C}_{4}^{4} \mathrm{H}$ & $\rightarrow \mathrm{HC}_{3} \mathrm{~N}+\mathrm{C}$ & $7.0 \times 10^{-11} \times(T / 300)^{0.17}$ & 3 & 0 & By comparison with $\mathrm{N}+\mathrm{C}_{2} \mathrm{H}$ \\
\hline $\mathrm{N}\left({ }^{4} \mathrm{~S}\right)+\mathrm{C}_{4} \mathrm{H}_{3}$ & $\rightarrow \mathrm{CH}_{2} \mathrm{C}_{3} \mathrm{~N}+\mathrm{H}$ & $6.0 \times 10^{-11}$ & 4 & 0 & By comparison with $\mathrm{N}+\mathrm{C}_{2} \mathrm{H}_{3}$ \\
\hline $\mathrm{N}\left({ }^{4} \mathrm{~S}\right)+\mathrm{C}_{4} \mathrm{H}_{3}$ & $\rightarrow \mathrm{NH}+\mathrm{C}_{4} \mathrm{H}_{2}$ & $1.0 \times 10^{-11}$ & 4 & 0 & By comparison with $\mathrm{N}+\mathrm{C}_{2} \mathrm{H}_{3}$ \\
\hline $\mathrm{N}\left({ }^{4} \mathrm{~S}\right)+\mathrm{C}_{4} \mathrm{H}_{9}$ & $\rightarrow \mathrm{H}_{2} \mathrm{CN}+\mathrm{C}_{3} \mathrm{H}_{7}$ & $6.0 \times 10^{-11} \times(T / 300)^{0.17}$ & 2 & 7 & By comparison with $\mathrm{N}+\mathrm{C}_{2} \mathrm{H}_{5}$ \\
\hline $\mathrm{N}\left({ }^{4} \mathrm{~S}\right)+\mathrm{C}_{4} \mathrm{H}_{9}$ & $\rightarrow \mathrm{NH}+\mathrm{C}_{4} \mathrm{H}_{8}$ & $4.0 \times 10^{-11} \times(T / 300)^{0.17}$ & 3 & 21 & By comparison with $\mathrm{N}+\mathrm{C}_{2} \mathrm{H}_{5}$ \\
\hline $\mathrm{N}\left({ }^{4} \mathrm{~S}\right)+\mathrm{N}\left({ }^{4} \mathrm{~S}\right)$ & $\rightarrow \mathrm{N}_{2}$ & $k_{0}=4.1 \times 10^{-34}$ & 2.5 & 100 & $k_{0}$ from Pravilov et al. $[2001], k_{\infty}$ from \\
\hline & & $\begin{array}{l}k_{\infty}=1.0 \times 10^{-10} \\
k_{r}=0\end{array}$ & $\begin{array}{r}2 \\
30\end{array}$ & $\begin{array}{r}100 \\
0\end{array}$ & capture rate theory \\
\hline $\mathrm{N}\left({ }^{4} \mathrm{~S}\right)+\mathrm{NH}$ & $\rightarrow \mathrm{N}_{2}+\mathrm{H}$ & $2.5 \times 10^{-11} \times(T / 300)^{0.17}$ & 1.6 & 0 & $\begin{array}{r}\text { Hack et al. [1994], Caridade et al. [2005], } \\
\text { Franckcombe and Nyman [2007], Georgievski } \\
\text { and Klippenstein }[2005]\end{array}$ \\
\hline $\mathrm{N}\left({ }^{4} \mathrm{~S}\right)+\mathrm{NH}_{2}$ & $\rightarrow \mathrm{N}_{2}+\mathrm{H}+\mathrm{H}$ & $1.2 \times 10^{-10} \times(T / 300)^{0.17}$ & 3 & 21 & $\begin{array}{l}\text { Whyte and Phillips [1983], Whyte and Phillips } \\
{[1984], \text { Dransfled and Wagner [1987] }}\end{array}$ \\
\hline $\mathrm{N}\left({ }^{4} \mathrm{~S}\right)+\mathrm{CN}$ & $\rightarrow \mathrm{C}+\mathrm{N}_{2}$ & $9 \times 10^{-11} \times(T / 300)^{0.42}$ & 1.4 & 0 & Daranlot et al. [2012] \\
\hline $\mathrm{N}\left({ }^{4} \mathrm{~S}\right)+\mathrm{H}_{2} \mathrm{CN}$ & $\rightarrow \mathrm{N}_{2}+{ }^{2} \mathrm{CH}_{2}$ & $4.0 \times 10^{-11}$ & 2 & 0 & Hébrard et al. [2012] \\
\hline $\mathrm{N}\left({ }^{4} \mathrm{~S}\right)+\mathrm{H}_{2} \mathrm{CN}$ & $\rightarrow \mathrm{HCN}+\mathrm{NH}$ & $5.0 \times 10^{-12}$ & 2 & 0 & Hébrard et al. [2012] \\
\hline $\mathrm{N}\left({ }^{4} \mathrm{~S}\right)+\mathrm{C}_{2} \mathrm{~N}$ & $\rightarrow \mathrm{CN}+\mathrm{CN}$ & $1.0 \times 10^{-10}$ & 3 & 0 & $\begin{array}{l}\text { Whyte and Phillips [1983], Daranlot et al. } \\
\text { [2012] }\end{array}$ \\
\hline $\mathrm{N}\left({ }^{4} \mathrm{~S}\right)+\mathrm{CHCN}$ & $\rightarrow \mathrm{HCN}+\mathrm{CN}$ & $1.4 \times 10^{-11} \times(T / 300)^{0.17}$ & 4 & 21 & By comparison with $\mathrm{N}+{ }^{3} \mathrm{CH}_{2}$ \\
\hline $\mathrm{N}\left({ }^{4} \mathrm{~S}\right)+\mathrm{CHCN}$ & $\rightarrow \mathrm{HNC}+\mathrm{CN}$ & $6.0 \times 10^{-12} \times(T / 300)^{0.17}$ & 4 & 21 & By comparison with $\mathrm{N}+{ }^{3} \mathrm{CH}_{2}$ \\
\hline $\mathrm{N}\left({ }^{4} \mathrm{~S}\right)+\mathrm{CHCN}$ & $\rightarrow \mathrm{C}_{2} \mathrm{~N}_{2}+\mathrm{H}$ & $4.0 \times 10^{-11} \times(T / 300)^{0.17}$ & 4 & 21 & By comparison with $\mathrm{N}+{ }^{3} \mathrm{CH}_{2}$ \\
\hline $\mathrm{N}\left({ }^{4} \mathrm{~S}\right)+\mathrm{CH}_{2} \mathrm{CN}$ & $\rightarrow \mathrm{H}_{2} \mathrm{CN}+\mathrm{CN}$ & $2.0 \times 10^{-11}$ & 3 & 0 & By comparison with $\mathrm{N}+\mathrm{CH}_{3}, \mathrm{C}_{2} \mathrm{H}_{5}^{2}$ \\
\hline $\mathrm{N}\left({ }^{4} \mathrm{~S}\right)+\mathrm{CH}_{2} \mathrm{CN}$ & $\rightarrow \mathrm{HC}_{2} \mathrm{~N}_{2}+\mathrm{H}$ & $2.0 \times 10^{-11}$ & 3 & 0 & By comparison with $\mathrm{N}+\mathrm{CH}_{3}, \mathrm{C}_{2} \mathrm{H}_{5}$ \\
\hline $\mathrm{N}\left({ }^{4} \mathrm{~S}\right)+\mathrm{C}_{4}{ }^{\mathrm{N}}$ & $\rightarrow \mathrm{C}_{3} \mathrm{~N}+\mathrm{CN}$ & $9 \times 10^{-11}$ & 3 & 0 & $\begin{array}{l}\text { Capture rate constant, Georgievskii and } \\
\text { Klippenstein }[2005] \text { considering no barrier }\end{array}$ \\
\hline $\mathrm{N}\left({ }^{4} \mathrm{~S}\right)+\mathrm{HC}_{4} \mathrm{~N}$ & $\rightarrow \mathrm{C}_{4} \mathrm{~N}_{2}+\mathrm{H}$ & $4.0 \times 10^{-11}$ & 3 & 0 & By comparison with $\mathrm{N}+{ }^{3} \mathrm{CH}_{2}$ \\
\hline $\mathrm{N}\left({ }^{4} \mathrm{~S}\right)+\mathrm{HC}_{4} \mathrm{~N}$ & $\rightarrow \mathrm{C}_{3} \mathrm{~N}+\mathrm{HCN}$ & $2.0 \times 10^{-11}$ & 3 & 0 & By comparison with $\mathrm{N}+{ }^{3} \mathrm{CH}_{2}$ \\
\hline $\mathrm{N}\left({ }^{4} \mathrm{~S}\right)+\mathrm{CH}_{2} \mathrm{C}_{3} \mathrm{~N}$ & $\rightarrow \mathrm{HC}_{3} \mathrm{~N}+\mathrm{HCN}$ & $4.0 \times 10^{-11}$ & 3 & 0 & By comparison with $\mathrm{N}+\mathrm{CH}_{3}$ \\
\hline $\mathrm{N}\left({ }^{4} \mathrm{~S}\right)+\mathrm{CN}_{2}$ & $\rightarrow \mathrm{CN}+\mathrm{N}_{2}$ & $6.0 \times 10^{-11} \times(T / 300)^{0.17}$ & 3 & 21 & $\begin{array}{l}\text { Capture rate constant, Georgievskii and } \\
\text { Klippenstein }[2005] \text { considering no barrier }\end{array}$ \\
\hline $\mathrm{N}\left({ }^{2} \mathrm{D}\right)$ & $\rightarrow \mathrm{N}\left({ }^{4} \mathrm{~S}\right)$ & $2.3 \times 10^{-05}$ & 2 & 100 & Okabe et al. [1978] \\
\hline $\mathrm{N}\left({ }^{2} \mathrm{D}\right)+\mathrm{H}_{2}$ & $\rightarrow \mathrm{NH}+\mathrm{H}$ & $4.2 \times 10^{-11} \times \exp (-880 / T)$ & 1.6 & 7 & Herron [1999] \\
\hline $\mathrm{N}\left({ }^{2} \mathrm{D}\right)+\mathrm{CH}_{4}$ & $\rightarrow \mathrm{NH}+\mathrm{CH}_{3}$ & $1.3 \times 10^{-11} \times \exp (-755 / T)$ & 1.6 & 7 & $\begin{array}{l}\text { Herron [1999], Takayanagi and Kurosaki [1999], } \\
\text { Takayanagi et al. [1999], Balucani et al. } \\
\text { [2009], Ouk et al. [2011] }\end{array}$ \\
\hline $\mathrm{N}\left({ }^{2} \mathrm{D}\right)+\mathrm{CH}_{4}$ & $\rightarrow \mathrm{CH}_{2} \mathrm{NH}+\mathrm{H}$ & $3.5 \times 10^{-11} \times \exp (-755 / T)$ & 1.6 & 7 & $\begin{array}{l}\text { Herron [1999], Takayanagi and Kurosaki [1999], } \\
\text { Takayanagi et al. [1999], Balucani et al. } \\
\text { [2009], Ouk et al. [2011] }\end{array}$ \\
\hline $\mathrm{N}\left({ }^{2} \mathrm{D}\right)+\mathrm{C}_{2} \mathrm{H}_{2}$ & $\rightarrow \mathrm{CHCN}+\mathrm{H}$ & $1.6 \times 10^{-10} \times \exp (-270 / T)$ & 1.4 & 0 & Takayanagi et al. [1998], Herron [1999] \\
\hline $\mathrm{N}\left({ }^{2} \mathrm{D}\right)+\mathrm{C}_{2} \mathrm{H}_{4}$ & $\rightarrow \mathrm{CH}_{2} \mathrm{NCH}+\mathrm{H}$ & $1.7 \times 10^{-10} \times \exp (-503 / T)$ & 2 & 200 & $\begin{array}{r}\text { Takayanagi et al. [1998], Sato et al. [1999], } \\
\text { Balucani et al. [2000a], Balucani et al. }[2000 \mathrm{~b}] \\
\text { Lee et al. [2011], Balucani et al. }[2012]\end{array}$ \\
\hline $\mathrm{N}\left({ }^{2} \mathrm{D}\right)+\mathrm{C}_{2} \mathrm{H}_{4}$ & $\rightarrow \mathrm{cCH}_{2} \mathrm{NCH}+\mathrm{H}$ & $6.0 \times 10^{-11} \times \exp (-503 / T)$ & 2 & 200 & $\begin{array}{l}\text { Takayanagi et al. [1998], Sato et al. [1999], } \\
\text { Balucani et al. [2000a], Balucani et al. }[2000 \mathrm{~b}] \\
\text { Lee et al. }[2011] \text {, Balucani et al. }[2012]\end{array}$ \\
\hline $\mathrm{N}\left({ }^{2} \mathrm{D}\right)+\mathrm{C}_{2} \mathrm{H}_{6}$ & $\rightarrow \mathrm{CH}_{2} \mathrm{NH}+\mathrm{CH}_{3}$ & $1.9 \times 10^{-11}$ & 1.6 & 7 & Herron [1999], Balucani et al. [2010] \\
\hline $\mathrm{N}\left({ }^{2} \mathrm{D}\right)+\mathrm{C}_{3}$ & $\rightarrow \mathrm{CN}+\mathrm{C}_{2}$ & $2.3 \times 10^{-10} \times \exp (-503 / T)$ & 3 & 0 & By comparison with $\mathrm{N}\left({ }^{4} \mathrm{~S}\right)+\mathrm{C}_{2} \mathrm{H}_{4}$ \\
\hline $\mathrm{N}\left({ }^{2} \mathrm{D}\right)+\mathrm{c}-\mathrm{C}_{3} \mathrm{H}_{2}$ & $\rightarrow \mathrm{HC}_{3} \mathrm{~N}+\mathrm{H}$ & $1.6 \times 10^{-10} \times \exp (-270 / T)$ & 3 & 0 & By comparison with $\mathrm{N}\left({ }^{4} \mathrm{~S}\right)+\mathrm{C}_{2} \mathrm{H}_{2}$ \\
\hline $\mathrm{N}\left({ }^{2} \mathrm{D}\right)+1-\mathrm{C}_{3}^{3} \mathrm{H}_{2}^{2}$ & $\rightarrow \mathrm{HC}_{3}^{3} \mathrm{~N}+\mathrm{H}$ & $1.6 \times 10^{-10} \times \exp (-270 / T)$ & 3 & 0 & By comparison with $\mathrm{N}\left({ }^{4} \mathrm{~S}\right)+\mathrm{C}_{2} \mathrm{H}_{2}^{2}$ \\
\hline $\mathrm{N}\left({ }^{2} \mathrm{D}\right)+\mathrm{t}-\mathrm{C}_{3} \mathrm{H}_{2}$ & $\rightarrow \mathrm{HC}_{3}^{3} \mathrm{~N}+\mathrm{H}$ & $1.6 \times 10^{-10} \times \exp (-270 / T)$ & 3 & 0 & By comparison with $\mathrm{N}\left({ }^{4} \mathrm{~S}\right)+\mathrm{C}_{2} \mathrm{H}_{2}^{2}$ \\
\hline $\mathrm{N}\left({ }^{2} \mathrm{D}\right)+\mathrm{CH}_{3} \mathrm{C}_{2} \mathrm{H}$ & $\rightarrow \mathrm{CHCN}+\mathrm{CH}_{3}$ & $8.0 \times 10^{-11} \times \exp (-270 / T)$ & 3 & 0 & By comparison with $\mathrm{N}\left({ }^{4} \mathrm{~S}\right)+\mathrm{C}_{2} \mathrm{H}_{2}$ \\
\hline $\mathrm{N}\left({ }^{2} \mathrm{D}\right)+\mathrm{CH}_{3} \mathrm{C}_{2} \mathrm{H}$ & $\rightarrow \mathrm{C}_{2} \mathrm{H}_{3} \mathrm{CN}+\mathrm{H}$ & $8.0 \times 10^{-11} \times \exp (-270 / T)$ & 3 & 0 & By comparison with $\mathrm{N}\left({ }^{4} \mathrm{~S}\right)+\mathrm{C}_{2} \mathrm{H}_{2}$ \\
\hline $\mathrm{N}\left({ }^{2} \mathrm{D}\right)+\mathrm{CH}_{2} \mathrm{CCH}_{2}$ & $\rightarrow \mathrm{C}_{2} \mathrm{H}_{3} \mathrm{CN}+\mathrm{H}$ & $2.3 \times 10^{-10} \times \exp (-503 / T)$ & 1.4 & 0 & By comparison with $\mathrm{N}\left({ }^{4} \mathrm{~S}\right)+\mathrm{C}_{2} \mathrm{H}_{4}$ \\
\hline $\mathrm{N}\left({ }^{2} \mathrm{D}\right)+\mathrm{C}_{3} \mathrm{H}_{6}$ & $\rightarrow$ SOOTN & $2.3 \times 10^{-10} \times \exp (-503 / T)$ & 3 & 0 & By comparison with $\mathrm{N}\left({ }^{4} \mathrm{~S}\right)+\mathrm{C}_{2} \mathrm{H}_{4}$ \\
\hline $\mathrm{N}\left({ }^{2} \mathrm{D}\right)+\mathrm{C}_{3} \mathrm{H}_{8}$ & $\rightarrow \mathrm{CH}_{2} \mathrm{NH}+\mathrm{C}_{2} \mathrm{H}_{5}$ & $3.0 \times 10^{-11}$ & 3 & 0 & By comparison with $\mathrm{N}\left({ }^{4} \mathrm{~S}\right)+\mathrm{C}_{2} \mathrm{H}_{6}$ \\
\hline $\mathrm{N}\left({ }^{2} \mathrm{D}\right)+\mathrm{C}_{4} \mathrm{H}_{2}$ & $\rightarrow \mathrm{HCN}+\mathrm{c}-\mathrm{C}_{3} \mathrm{H}$ & $4.0 \times 10^{-11} \times \exp (-270 / T)$ & 3 & 0 & By comparison with $\mathrm{N}\left({ }^{4} \mathrm{~S}\right)+\mathrm{C}_{2} \mathrm{H}_{2}$ \\
\hline $\mathrm{N}\left({ }^{2} \mathrm{D}\right)+\mathrm{C}_{4} \mathrm{H}_{2}$ & $\rightarrow \mathrm{HCN}+1-\mathrm{C}_{3} \mathrm{H}$ & $4.0 \times 10^{-11} \times \exp (-270 / T)$ & 3 & 0 & By comparison with $\mathrm{N}\left({ }^{4} \mathrm{~S}\right)+\mathrm{C}_{2} \mathrm{H}_{2}$ \\
\hline $\mathrm{N}\left({ }^{2} \mathrm{D}\right)+\mathrm{C}_{4} \mathrm{H}_{2}$ & $\rightarrow \mathrm{HC}_{4} \mathrm{~N}+\mathrm{H}^{3}$ & $8.0 \times 10^{-11} \times \exp (-270 / T)$ & 3 & 0 & By comparison with $\mathrm{N}\left({ }^{4} \mathrm{~S}\right)+\mathrm{C}_{2} \mathrm{H}_{2}$ \\
\hline $\mathrm{N}\left({ }^{2} \mathrm{D}\right)+\mathrm{C}_{4} \mathrm{H}_{4}$ & $\rightarrow$ SOOTN & $1.6 \times 10^{-10} \times \exp (-270 / T)$ & 3 & 0 & By comparison with $\mathrm{N}\left({ }^{4} \mathrm{~S}\right)+\mathrm{C}_{2} \mathrm{H}_{2}$ \\
\hline $\mathrm{N}\left({ }^{2} \mathrm{D}\right)+\mathrm{C}_{4} \mathrm{H}_{6}$ & $\rightarrow \mathrm{C}_{4} \mathrm{H}_{4} \mathrm{NH}+\mathrm{H}$ & $1.6 \times 10^{-10} \times \exp (-270 / T)$ & 3 & 0 & By comparison with $\mathrm{N}\left({ }^{4} \mathrm{~S}\right)+\mathrm{C}_{2} \mathrm{H}_{2}$ \\
\hline $\mathrm{N}\left({ }^{2} \mathrm{D}\right)+\mathrm{C}_{4} \mathrm{H}_{8}$ & $\rightarrow \mathrm{C}_{4} \mathrm{H}_{6} \mathrm{NH}+\mathrm{H}$ & $2.3 \times 10^{-10} \times \exp (-503 / T)$ & 3 & 0 & By comparison with $\mathrm{N}\left({ }^{4} \mathrm{~S}\right)+\mathrm{C}_{2} \mathrm{H}_{4}$ \\
\hline $\mathrm{N}\left({ }^{2} \mathrm{D}\right)+\mathrm{C}_{4}^{4} \mathrm{H}_{10}^{8}$ & $\rightarrow \mathrm{CH}_{2} \stackrel{6}{\mathrm{NH}}+\mathrm{C}_{3} \mathrm{H}_{7}$ & $3.0 \times 10^{-11}$ & 3 & 0 & By comparison with $\mathrm{N}\left({ }^{4} \mathrm{~S}\right)+\mathrm{C}_{2}^{2} \mathrm{H}_{6}^{4}$ \\
\hline $\mathrm{N}\left({ }^{2} \mathrm{D}\right)+\mathrm{C}_{6}^{4} \mathrm{H}_{4}^{10}$ & $\rightarrow \mathrm{C}_{5} \mathrm{H}_{3} \mathrm{CN}+\mathrm{H}$ & $2.3 \times 10^{-10} \times \exp (-503 / T)$ & 1.4 & 0 & By comparison with $\mathrm{N}\left({ }^{4} \mathrm{~S}\right)+\mathrm{C}_{2} \mathrm{H}_{4}^{6}$ \\
\hline $\mathrm{N}\left({ }^{2} \mathrm{D}\right)+\mathrm{Ar}$ & $\rightarrow \mathrm{N}^{5}\left({ }^{4} \mathrm{~S}^{3}\right)+\mathrm{Ar}$ & $1.0 \times 10^{-16}$ & 2 & 100 & Lin and Kaufman $[1971]$ \\
\hline $\mathrm{N}\left({ }^{2} \mathrm{D}\right)+\mathrm{N}_{2}$ & $\rightarrow \mathrm{N}\left({ }^{4} \mathrm{~S}\right)+\mathrm{N}_{2}$ & $1.0 \times 10^{-13} \times \exp (-520 / T)$ & 2 & 42 & Herron [1999] \\
\hline $\mathrm{N}\left({ }^{2} \mathrm{D}\right)+\mathrm{NH}_{3}$ & $\rightarrow \mathrm{N}_{2} \mathrm{H}_{2}+\mathrm{H}^{2}$ & $5.0 \times 10^{-11}$ & 2 & 21 & Herron [1999] \\
\hline $\mathrm{N}\left({ }^{2} \mathrm{D}\right)+\mathrm{HCN}$ & $\rightarrow \mathrm{CH}+\mathrm{N}_{2}$ & $5.0 \times 10^{-11}$ & 3 & 0 & Hébrard et al. [2012] \\
\hline
\end{tabular}




\begin{tabular}{|c|c|c|c|c|c|}
\hline Reactions & & Rate coefficients & $F(300 K)$ & $g$ & References \\
\hline $\mathrm{N}\left({ }^{2} \mathrm{D}\right)+\mathrm{HNC}$ & $\rightarrow \mathrm{CN}_{2}+\mathrm{H}$ & $2.0 \times 10^{-11}$ & 3 & 0 & Hébrard et al. [2012] \\
\hline $\mathrm{N}\left({ }^{2} \mathrm{D}\right)+\mathrm{HNC}$ & $\rightarrow \mathrm{CH}^{2}+\mathrm{N}_{2}$ & $2.0 \times 10^{-11}$ & 3 & 0 & Hébrard et al. [2012] \\
\hline $\mathrm{N}\left({ }^{2} \mathrm{D}\right)+\mathrm{CH}_{2} \mathrm{NH}$ & $\rightarrow \mathrm{H}_{2} \mathrm{CNN}+\mathrm{H}$ & $1.0 \times 10^{-10} \times \exp (-503 / T)$ & 2 & 100 & $\begin{array}{r}\text { Estimated by comparison with } \mathrm{N}\left({ }^{2} \mathrm{D}\right)+\mathrm{C}_{2} \mathrm{H}_{4} \\
\text { et } \mathrm{N}\left({ }^{2} \mathrm{D}\right)+\mathrm{NH}_{3} \text { (Takayanagi et al. [1998], } \\
\text { Sato et al. [1999], Balucani et al. [2000a], } \\
\text { Balucani et al. [2000b], Lee et al. [2011]) }\end{array}$ \\
\hline $\mathrm{N}\left({ }^{2} \mathrm{D}\right)+\mathrm{CH}_{2} \mathrm{NH}$ & $\rightarrow \mathrm{HNCNH}+\mathrm{H}$ & $1.0 \times 10^{-10} \times \exp (-503 / T)$ & 2 & 100 & $\begin{array}{l}\text { Estimated by comparison with } \mathrm{N}\left({ }^{2} \mathrm{D}\right)+\mathrm{C}_{2} \mathrm{H}_{4} \\
\text { et } \mathrm{N}\left({ }^{2} \mathrm{D}\right)+\mathrm{NH}_{3} \text { (Takayanagi et al. [1998], } \\
\text { Sato et al. [1999], Balucani et al. [2000a], } \\
\text { Balucani et al. [2000b], Lee et al. [2011]) }\end{array}$ \\
\hline $\mathrm{N}\left({ }^{2} \mathrm{D}\right)+\mathrm{CH}_{3} \mathrm{NH}_{2}$ & $\rightarrow \mathrm{CH}_{3} \mathrm{NNH}+\mathrm{H}$ & $2.0 \times 10^{-11}$ & 4 & 0 & By comparison with $\mathrm{N}\left({ }^{2} \mathrm{D}\right)+\mathrm{C}_{2} \mathrm{H}_{6}$ \\
\hline $\mathrm{N}\left({ }^{2} \mathrm{D}\right)+\mathrm{CH}_{3} \mathrm{NH}_{2}$ & $\rightarrow \mathrm{HNCHNH}_{2}+\mathrm{H}$ & $3.0 \times 10^{-11}$ & 4 & 0 & By comparison with $\mathrm{N}\left({ }^{2} \mathrm{D}\right)+\mathrm{NH}_{3}$ \\
\hline $\mathrm{N}\left({ }^{2} \mathrm{D}\right)+\mathrm{CH}_{3} \mathrm{CN}$ & $\rightarrow \mathrm{CH}_{2} \mathrm{CN}+\mathrm{NH}$ & $1.3 \times 10^{-11} \times \exp (-755 / T)$ & 4 & 100 & By comparison with $\mathrm{N}\left({ }^{2} \mathrm{D}\right)+\mathrm{CH}_{4}$ \\
\hline $\mathrm{N}\left({ }^{2} \mathrm{D}\right)+\mathrm{CH}_{3} \mathrm{CN}$ & $\rightarrow \mathrm{HNCHCN}+\mathrm{H}$ & $3.5 \times 10^{-11} \times \exp (-755 / T)$ & 4 & 100 & By comparison with $\mathrm{N}\left({ }^{2} \mathrm{D}\right)+\mathrm{CH}_{4}$ \\
\hline $\mathrm{N}\left({ }^{2} \mathrm{D}\right)+\mathrm{CH}_{3}^{3} \mathrm{CN}$ & $\rightarrow \mathrm{N}_{2}+\mathrm{C}_{2} \mathrm{H}_{3}$ & $5.0 \times 10^{-11}$ & 4 & 0 & By comparison with $\mathrm{N}\left({ }^{2} \mathrm{D}\right)+\mathrm{HCN}$ \\
\hline $\mathrm{N}\left({ }^{2} \mathrm{D}\right)+\mathrm{cCH}_{2} \mathrm{NCH}$ & $\rightarrow \mathrm{N}_{2}^{2}+\mathrm{C}_{2} \mathrm{H}_{3}$ & $2.3 \times 10^{-10} \times \exp (-503 / T)$ & 3 & 100 & By comparison with $\mathrm{N}\left({ }^{2} \mathrm{D}\right)+\mathrm{C}_{2} \mathrm{H}_{4}$ \\
\hline $\mathrm{N}\left({ }^{2} \mathrm{D}\right)+\mathrm{HC}_{3} \mathrm{~N}$ & $\rightarrow \mathrm{N}_{2}+\mathrm{c}-\mathrm{C}_{3} \mathrm{H}$ & $1.5 \times 10^{-11}$ & 4 & 100 & By comparison with $\mathrm{N}\left({ }^{2} \mathrm{D}\right)+\mathrm{HCN}, \mathrm{C}_{2} \mathrm{H}_{2}$ \\
\hline $\mathrm{N}\left({ }^{2} \mathrm{D}\right)+\mathrm{HC}_{3} \mathrm{~N}$ & $\rightarrow \mathrm{N}_{2}^{2}+1-\mathrm{C}_{3} \mathrm{H}$ & $1.5 \times 10^{-11}$ & 4 & 100 & By comparison with $\mathrm{N}\left({ }^{2} \mathrm{D}\right)+\mathrm{HCN}, \mathrm{C}_{2} \mathrm{H}_{2}^{2}$ \\
\hline $\mathrm{N}\left({ }^{2} \mathrm{D}\right)+\mathrm{HC}_{3} \mathrm{~N}$ & $\rightarrow \mathrm{C}_{2} \mathrm{~N}+\mathrm{HCN}$ & $3.0 \times 10^{-11}$ & 4 & 100 & By comparison with $\mathrm{N}\left({ }^{2} \mathrm{D}\right)+\mathrm{HCN}, \mathrm{C}_{2} \mathrm{H}_{2}^{2}$ \\
\hline $\mathrm{N}\left({ }^{2} \mathrm{D}\right)+\mathrm{HC}_{5} \mathrm{~N}$ & $\rightarrow \mathrm{N}_{2}+\mathrm{C}_{5} \mathrm{H}$ & $3.0 \times 10^{-11}$ & 4 & 100 & By comparison with $\mathrm{N}\left({ }^{2} \mathrm{D}\right)+\mathrm{HCN}, \mathrm{C}_{2} \mathrm{H}_{2}^{2}$ \\
\hline $\mathrm{N}\left({ }^{2} \mathrm{D}\right)+\mathrm{HC}_{5} \mathrm{~N}$ & $\rightarrow \mathrm{C}_{4} \mathrm{~N}+\mathrm{HCN}$ & $3.0 \times 10^{-11}$ & 4 & 100 & By comparison with $\mathrm{N}\left({ }^{2} \mathrm{D}\right)+\mathrm{HCN}, \mathrm{C}_{2}^{2} \mathrm{H}_{2}^{2}$ \\
\hline $\mathrm{N}\left({ }^{2} \mathrm{D}\right)+\mathrm{C}_{2} \mathrm{H}_{3} \mathrm{CN}$ & $\rightarrow \mathrm{HNCCHCN}+\mathrm{H}$ & $2.3 \times 10^{-10} \times \exp (-503 / T)$ & 3 & 0 & By comparison with $\mathrm{N}\left({ }^{2} \mathrm{D}\right)+\mathrm{C}_{2} \mathrm{H}_{4}$ \\
\hline $\mathrm{N}\left({ }^{2} \mathrm{D}\right)+\mathrm{C}_{2} \mathrm{H}_{3} \mathrm{CN}$ & $\rightarrow \mathrm{N}_{2}+\mathrm{C}_{3} \mathrm{H}_{3}$ & $4.0 \times 10^{-11}$ & 4 & 0 & By comparison with $\mathrm{N}\left({ }^{2} \mathrm{D}\right)+{ }_{\mathrm{HCN}}^{4}$ \\
\hline $\mathrm{N}\left({ }^{2} \mathrm{D}\right)+\mathrm{C}_{2} \mathrm{H}_{5} \mathrm{CN}$ & $\rightarrow \mathrm{CH}_{2} \mathrm{NH}+\mathrm{CH}_{2} \mathrm{CN}$ & $1.9 \times 10^{-11}$ & 4 & 100 & By comparison with $\mathrm{N}\left({ }^{2} \mathrm{D}\right)+\mathrm{C}_{2} \mathrm{H}_{6}$ \\
\hline $\mathrm{N}\left({ }^{2} \mathrm{D}\right)+\mathrm{C}_{2} \mathrm{H}_{5} \mathrm{CN}$ & $\rightarrow \mathrm{C}_{3} \mathrm{H}_{5}+\mathrm{N}_{2}$ & $4.0 \times 10^{-11}$ & 4 & 100 & By comparison with $\mathrm{N}\left({ }^{2} \mathrm{D}\right)+\mathrm{HCN}$ \\
\hline $\mathrm{N}\left({ }^{2} \mathrm{D}\right)+\mathrm{CH}_{3} \mathrm{C}_{3} \mathrm{~N}$ & $\rightarrow$ SOOTN & $3.0 \times 10^{-11}$ & 4 & 100 & By comparison with $\mathrm{N}\left({ }^{2} \mathrm{D}\right)+\mathrm{HCN}, \mathrm{C}_{2} \mathrm{H}_{2}$ \\
\hline $\mathrm{N}\left({ }^{2} \mathrm{D}\right)+\mathrm{C}_{2} \mathrm{~N}_{2}$ & $\rightarrow \mathrm{C}_{2} \mathrm{~N}+\mathrm{N}_{2}$ & $3.0 \times 10^{-11}$ & 4 & 100 & By comparison with $\mathrm{N}\left({ }^{2} \mathrm{D}\right)+\mathrm{HCN}, \mathrm{C}_{2} \mathrm{H}_{4}^{2}$ \\
\hline $\mathrm{N}\left({ }^{2} \mathrm{D}\right)+\mathrm{C}_{4} \mathrm{~N}_{2}^{2}$ & $\rightarrow \mathrm{C}_{4} \mathrm{~N}+\mathrm{N}_{2}^{2}$ & $3.0 \times 10^{-11}$ & 4 & 100 & By comparison with $\mathrm{N}\left({ }^{2} \mathrm{D}\right)+\mathrm{HCN}, \mathrm{C}_{2} \mathrm{H}_{4}$ \\
\hline $\mathrm{NH}+\mathrm{H}$ & $\rightarrow \mathrm{N}\left({ }^{4} \mathrm{~S}\right)+\mathrm{H}_{2}$ & $2.2 \times 10^{-12} \times(T / 300)^{1.55} \times \exp (-103 / T)$ & 2 & 7 & Adam et al. [2005] \\
\hline $\mathrm{NH}+\mathrm{CH}$ & $\rightarrow \mathrm{HCN}+\mathrm{H}^{2}$ & $5.0 \times 10^{-11}$ & 3 & 0 & $\begin{array}{r}\text { Takahashi and Takayanagi [2007], Georgievskii } \\
\text { and Klippenstein [2005] }\end{array}$ \\
\hline $\mathrm{NH}+\mathrm{CH}$ & $\rightarrow \mathrm{HNC}+\mathrm{H}$ & $5.0 \times 10^{-11}$ & 3 & 0 & $\begin{array}{l}\text { Takahashi and Takayanagi [2007], Georgievskii } \\
\text { and Klippenstein [2005] }\end{array}$ \\
\hline $\mathrm{NH}+{ }^{3} \mathrm{CH}_{2}$ & $\rightarrow \mathrm{H}_{2} \mathrm{CN}+\mathrm{H}$ & $3.0 \times 10^{-11}$ & 3 & 21 & $\begin{array}{r}\text { Capture rate constant, Georgievskii and } \\
\text { Klippenstein [2005] considering no barrier and } \\
\text { branching ratio deduced from } \mathrm{H}_{2} \mathrm{CNH} \\
\text { decomposition, Nguyen et al. [1996], Zhou and } \\
\text { Schlegel [2009], Georgievskii and Klippenstein } \\
\text { [2005] }\end{array}$ \\
\hline $\mathrm{NH}+{ }^{3} \mathrm{CH}_{2}$ & $\rightarrow \mathrm{HCN}+\mathrm{H}+\mathrm{H}$ & $3.0 \times 10^{-11}$ & 3 & 21 & $\begin{array}{r}\text { Capture rate constant, Georgievskii and } \\
\text { Klippenstein [2005] considering no barrier and } \\
\text { branching ratio deduced from } \mathrm{H}_{2} \text { CNH } \\
\text { decomposition, Nguyen et al. [1996], Zhou and } \\
\text { Schlegel [2009], Georgievskii and Klippenstein } \\
\text { [2005] }\end{array}$ \\
\hline $\mathrm{NH}+{ }^{3} \mathrm{CH}_{2}$ & $\rightarrow \mathrm{HNC}+\mathrm{H}_{2}$ & $5.0 \times 10^{-12}$ & 4 & 21 & $\begin{array}{r}\text { Capture rate constant, Georgievskii and } \\
\text { Klippenstein [2005] considering no barrier and } \\
\text { branching ratio deduced from } \mathrm{H}_{2} \mathrm{CNH} \\
\text { decomposition, Nguyen et al. [1996], Zhou and } \\
\text { Schlegel [2009], Georgievskii and Klippenstein } \\
\text { [2005] }\end{array}$ \\
\hline $\mathrm{NH}+\mathrm{CH}_{3}$ & $\rightarrow \mathrm{CH}_{2} \mathrm{NH}+\mathrm{H}$ & $1.3 \times 10^{-10} \times(T / 300)^{0.17}$ & 2 & 100 & $\begin{array}{r}\text { Redondo et al. [2006], Georgievskii and } \\
\text { Klippenstein [2005] }\end{array}$ \\
\hline $\mathrm{NH}+\mathrm{C}_{2}$ & $\rightarrow \mathrm{HNC}+\mathrm{C}$ & $1.0 \times 10^{-10}$ & 3 & 0 & $\begin{array}{l}\text { Takahashi and Takayanagi [2007], Georgievskii } \\
\text { and Klippenstein [2005] }\end{array}$ \\
\hline $\mathrm{NH}+\mathrm{C}_{2} \mathrm{H}$ & $\rightarrow \mathrm{CHCN}+\mathrm{H}$ & $1.0 \times 10^{-10}$ & 3 & 7 & $\begin{array}{r}\text { Takahashi et al. [1998], Georgievskii and } \\
\text { Klippenstein [2005] }\end{array}$ \\
\hline $\mathrm{NH}+\mathrm{C}_{2} \mathrm{H}_{2}$ & $\rightarrow \mathrm{CH}_{2} \mathrm{CN}+\mathrm{H}$ & $8.3 \times 10^{-10} \times \exp (-7096 / T)$ & 3 & 100 & $\begin{array}{r}\text { Rohrig and Wagner [1994a], Rohrig and } \\
\text { Wagner }[1994 \mathrm{~b}], \text { Feng et al. [2007]. Likely } \\
\text { experimental artefact in Mullen and Smith } \\
{[2005]}\end{array}$ \\
\hline $\mathrm{NH}+\mathrm{C}_{2} \mathrm{H}_{3}$ & $\rightarrow \mathrm{CH}_{3} \mathrm{CN}+\mathrm{H}$ & $1.0 \times 10^{-10}$ & 4 & 21 & $\begin{array}{r}\text { Lee et al. [2011], Georgievskii and } \\
\text { Klippenstein [2005] }\end{array}$ \\
\hline $\mathrm{NH}+\mathrm{C}_{2} \mathrm{H}_{3}$ & $\rightarrow \mathrm{HNC}+\mathrm{CH}_{3}$ & $1.0 \times 10^{-11}$ & 6 & 21 & $\begin{array}{r}\text { Lee et al. [2011], Georgievskii and } \\
\text { Klippenstein [2005] }\end{array}$ \\
\hline $\mathrm{NH}+\mathrm{C}_{2} \mathrm{H}_{3}$ & $\rightarrow \mathrm{NH}_{2}+\mathrm{C}_{2} \mathrm{H}_{2}$ & $1.0 \times 10^{-11}$ & 4 & 100 & $\begin{array}{r}\text { Lee et al. [2011], Georgievskii and } \\
\text { Klippenstein [2005] }\end{array}$ \\
\hline $\mathrm{NH}+\mathrm{C}_{2} \mathrm{H}_{4}$ & $\rightarrow \mathrm{H}_{2} \mathrm{CN}+\mathrm{CH}_{3}$ & $3.0 \times 10^{-12} \times \exp (-6735 / T)$ & 3 & 100 & $\begin{array}{l}\text { Yang et al. [2005]. Likely experimental } \\
\text { artefact in Mullen and Smith [2005] }\end{array}$ \\
\hline $\mathrm{NH}+\mathrm{C}_{2} \mathrm{H}_{5}$ & $\rightarrow \mathrm{NH}_{2}+\mathrm{C}_{2} \mathrm{H}_{4}$ & $1.0 \times 10^{-11}$ & 4 & 100 & By comparison with $\mathrm{NH}+\mathrm{CH}_{3}$ \\
\hline $\mathrm{NH}+\mathrm{C}_{2} \mathrm{H}_{5}$ & $\rightarrow \mathrm{CH}_{3} \mathrm{CHNH}+\mathrm{H}$ & $6.0 \times 10^{-11} \times(T / 300)^{0.17}$ & 3 & 21 & By comparison with $\mathrm{NH}+\mathrm{CH}_{3}$ \\
\hline $\mathrm{NH}+\mathrm{c}-\mathrm{C}_{3} \mathrm{H}_{2}$ & $\rightarrow \mathrm{H}_{2} \stackrel{3}{\mathrm{C}}_{3} \mathrm{~N}+\mathrm{H}$ & $1.0 \times 10^{-11}$ & 10 & 100 & Value in the $150-190 \mathrm{~K}$ range \\
\hline
\end{tabular}




\begin{tabular}{|c|c|c|c|c|c|}
\hline Reactions & & Rate coefficients & $F(300 K)$ & $g$ & References \\
\hline $\mathrm{NH}+\mathrm{C}_{3} \mathrm{H}_{3}$ & $\rightarrow \mathrm{C}_{2} \mathrm{H}_{3} \mathrm{CN}+\mathrm{H}$ & $1.0 \times 10^{-10}$ & 4 & 0 & $\begin{array}{r}\text { Capture rate constant, Georgievskii and } \\
\text { Klippenstein [2005] as there is no barrier at } \\
\text { DFT (M06-2X/cc-pVTZ) and MP2/cc-pVTZ } \\
\text { level. }\end{array}$ \\
\hline $\mathrm{NH}+\mathrm{NH}$ & $\rightarrow \mathrm{N}_{2}+\mathrm{H}+\mathrm{H}$ & $2.0 \times 10^{-10}$ & 3 & 7 & Mertens et al. [1989], Xu et al. [1997] \\
\hline $\mathrm{NH}+\mathrm{NH}_{2}$ & $\rightarrow \mathrm{N}_{2} \mathrm{H}_{2}+\mathrm{H}$ & $1.0 \times 10^{-10} \times(T / 300)^{0.17}$ & 3 & 21 & $\begin{array}{r}\text { Dransfeld et al. [1984], Bahng and Macdonald } \\
{[2009]}\end{array}$ \\
\hline $\mathrm{NH}+\mathrm{CN}$ & $\rightarrow \mathrm{CN}_{2}+\mathrm{H}$ & $1.0 \times 10^{-10}$ & 2 & 100 & $\begin{array}{r}\text { Georgievskii and Klippenstein [2005], Berman } \\
\text { et al. [2005] }\end{array}$ \\
\hline $\mathrm{NH}+\mathrm{CN}$ & $\rightarrow \mathrm{N}_{2}+\mathrm{CH}$ & $1.0 \times 10^{-10}$ & 2 & 100 & $\begin{array}{r}\text { Georgievskii and Klippenstein [2005], Berman } \\
\text { et al. [2005] }\end{array}$ \\
\hline $\mathrm{NH}+\mathrm{H}_{2} \mathrm{CN}$ & $\rightarrow \mathrm{NH}_{2}+\mathrm{HCN}$ & $2.0 \times 10^{-11}$ & 4 & 21 & $\begin{array}{r}\text { Capture rate constant, Georgievskii and } \\
\text { Klippenstein [2005] as there is no barrier at } \\
\text { DFT (M06-2X/cc-pVTZ) level. }\end{array}$ \\
\hline $\mathrm{NH}+\mathrm{H}_{2} \mathrm{CN}$ & $\rightarrow \mathrm{H}_{2} \mathrm{CNN}+\mathrm{H}$ & $2.0 \times 10^{-11}$ & 4 & 0 & $\begin{array}{r}\text { Capture rate constant, Georgievskii and } \\
\text { Klippenstein }[2005] \text { as there is no barrier at } \\
\text { DFT (M06-2X/cc-pVTZ) level. }\end{array}$ \\
\hline $\mathrm{NH}_{2}+\mathrm{H}$ & $\rightarrow \mathrm{NH}_{3}$ & $\begin{array}{l}k_{0}=1.0 \times 10^{-33} \\
k_{\infty}=3.5 \times 10^{-12} \\
k_{r}=0\end{array}$ & $\begin{array}{r}10 \\
2 \\
30\end{array}$ & $\begin{array}{r}100 \\
100 \\
0\end{array}$ & $\begin{array}{r}\mathrm{k}_{0} \text { from Schofield et al. [1973], } k_{\infty} \text { from } \\
\text { Pagsberg et al. [1979] }\end{array}$ \\
\hline $\begin{array}{l}\mathrm{NH}_{2}+\mathrm{H}_{2} \\
\mathrm{NH}_{2}+\mathrm{H}\end{array}$ & $\begin{array}{l}\rightarrow \mathrm{NH}_{3}+\mathrm{H} \\
\rightarrow \mathrm{NH}+\mathrm{H}_{2}\end{array}$ & $\begin{array}{l}2.09 \times 10^{-12} \times \exp (-4280 / T) \\
2.0 \times 10^{-11} \times \exp (-2400 / T)\end{array}$ & $\begin{array}{r}12 \\
2\end{array}$ & $\begin{array}{l}100 \\
100\end{array}$ & $\begin{array}{r}\text { Demissy and Lesclaux [1980] } \\
\text { Linder et al. [1995], Bahng and Macdonald } \\
\text { [2009] }\end{array}$ \\
\hline $\mathrm{NH}_{2}+\mathrm{C}$ & $\rightarrow \mathrm{HCN}+\mathrm{H}$ & $3.0 \times 10^{-11} \times(T / 300)^{-0.2} \times \exp (6 / T)$ & 3 & 0 & Talbi [1999], Herbst et al. [2000] \\
\hline $\mathrm{NH}_{2}+\mathrm{C}$ & $\rightarrow \mathrm{HNC}+\mathrm{H}$ & $3.0 \times 10^{-11} \times(T / 300)^{-0.2} \times \exp (6 / T)$ & 3 & 0 & Talbi [1999], Herbst et al. [2000] \\
\hline $\mathrm{NH}_{2}+\mathrm{CH}_{3}$ & $\rightarrow \mathrm{CH}_{3} \mathrm{NH}_{2}$ & $\begin{array}{l}k_{0}=1.8 \times 10^{-27} \times(T / 300)^{-3.85} \\
k_{\infty}=1.3 \times 10^{-10} \times(T / 300)^{0.42} \\
k_{r}=0\end{array}$ & $\begin{array}{r}2 \\
2 \\
30\end{array}$ & $\begin{array}{l}7 \\
7 \\
0\end{array}$ & Jodkowski et al. [1995], Xu et al. [1999] \\
\hline $\begin{array}{l}\mathrm{NH}_{2}+\mathrm{CH}_{4} \\
\mathrm{NH}_{2}+\mathrm{C}_{2} \mathrm{H}_{2}\end{array}$ & $\begin{array}{l}\rightarrow \mathrm{NH}_{3}+\mathrm{CH}_{3} \\
\rightarrow \mathrm{NH}_{3}+\mathrm{C}_{2} \mathrm{H}\end{array}$ & $\begin{array}{l}3.99 \times 10^{-14} \times(T / 300)^{3.59} \times \exp (-4540 / T) \\
1.11 \times 10^{-13} \times \exp (-1850 / T)\end{array}$ & $\begin{array}{l}5 \\
5\end{array}$ & $\begin{array}{l}200 \\
250\end{array}$ & $\begin{array}{l}\text { Mebel and Lin [1999] } \\
\text { Bosco et al. [1984] }\end{array}$ \\
\hline $\mathrm{NH}_{2}+\mathrm{C}_{2} \mathrm{H}_{3}$ & $\rightarrow \mathrm{NH}_{3}+\mathrm{C}_{2} \mathrm{H}_{2}$ & $2.0 \times 10^{-11}$ & 10 & 21 & By comparison with $\mathrm{NH}_{2}+\mathrm{H}_{2} \mathrm{CN}$ and $\mathrm{CH}_{2} \mathrm{CH}_{3}+$ \\
\hline $\mathrm{NH}_{2}+\mathrm{C}_{2} \mathrm{H}_{3}$ & $\rightarrow \mathrm{C}_{2} \mathrm{H}_{3} \mathrm{NH}+\mathrm{H}$ & $8.0 \times 10^{-11}$ & 3 & 0 & By comparison with $\mathrm{NH}_{2}+\mathrm{H}_{2} \mathrm{CN}$ and $\mathrm{CH}_{3} \mathrm{CH}_{3}+$ \\
\hline $\begin{array}{l}\mathrm{NH}_{2}+\mathrm{C}_{2} \mathrm{H}_{4} \\
\mathrm{NH}_{2}+\mathrm{C}_{2} \mathrm{H}_{5}\end{array}$ & $\begin{array}{l}\rightarrow \mathrm{NH}_{3}+\mathrm{C}_{2} \mathrm{H}_{3} \\
\rightarrow \mathrm{NH}_{3}+\mathrm{C}_{2} \mathrm{H}_{4}\end{array}$ & $\begin{array}{l}3.42 \times 10^{-14} \times \exp (-1320 / T) \\
1.0 \times 10^{-11}\end{array}$ & $\begin{array}{r}1.1 \\
10\end{array}$ & $\begin{array}{r}100 \\
21\end{array}$ & By comparison with $\mathrm{NH}_{2}+\mathrm{H}_{2} \mathrm{CN}$ and $\mathrm{NH}_{2}^{+}+$ \\
\hline $\mathrm{NH}_{2}+\mathrm{C}_{2} \mathrm{H}_{5}$ & $\rightarrow \mathrm{CH}_{3} \mathrm{NH}+\mathrm{CH}_{3}$ & $6.0 \times 10^{-11}$ & 3 & 0 & By comparison with $\mathrm{NH}_{2}+\mathrm{H}_{2} \mathrm{CN}$ and $\underset{\mathrm{CH}_{3}}{\mathrm{NH}_{2}}+$ \\
\hline $\begin{array}{l}\mathrm{NH}_{2}+\mathrm{C}_{2} \mathrm{H}_{6} \\
\mathrm{NH}_{2}+\mathrm{NH}_{2}\end{array}$ & $\begin{array}{l}\rightarrow \mathrm{NH}_{3}+\mathrm{C}_{2} \mathrm{H}_{5} \\
\rightarrow \mathrm{N}_{2} \mathrm{H}_{4}\end{array}$ & $\begin{array}{l}6.14 \times 10^{-13} \times \exp (-3600 / T) \\
k_{0}=5.7 \times 10^{-29} \\
k_{\infty}=8.0 \times 10^{-11} \\
k_{r}=0\end{array}$ & $\begin{array}{r}2 \\
2 \\
1.6 \\
30\end{array}$ & $\begin{array}{r}100 \\
100 \\
100 \\
0\end{array}$ & $\begin{array}{r}\text { Lesclaux and Demissy [1978] } \\
\text { Fagerström et al. [1995], Bahnd and } \\
\text { Macdonald [2008], Stothard et al. [1995], } \\
\text { Klippenstein et al. [2009], Altiney and } \\
\text { Macdonald [2012], Asatryan et al. [2012] }\end{array}$ \\
\hline $\begin{array}{l}\mathrm{NH}_{2}+\mathrm{N}_{2} \mathrm{H}_{2} \\
\mathrm{NH}_{2}+\mathrm{N}_{2} \mathrm{H}_{4} \\
\mathrm{NH}_{2}+\mathrm{H}_{2} \mathrm{CN} \\
\mathrm{NH}_{2}+\mathrm{H}_{2} \mathrm{CN}\end{array}$ & $\begin{array}{l}\rightarrow \mathrm{NH}_{3}+\mathrm{N}_{2} \mathrm{H} \\
\rightarrow \mathrm{N}_{2} \mathrm{H}_{3}+\mathrm{NH}_{3} \\
\rightarrow \mathrm{HCN}+\mathrm{NH}_{3} \\
\rightarrow \mathrm{H}_{2} \mathrm{CNNH}_{2}\end{array}$ & $\begin{array}{l}1.62 \times 10^{-15} \times(T / 300)^{4.05} \times \exp (-810 / T) \\
2.0 \times 10^{-11} \times \exp (-1100 / T) \\
5.4 \times 10^{-11} \times(T / 300)^{-1.1} \times \exp (-60 / T) \\
k_{0}=1.0 \times 10^{-28} \times(T / 300)^{-3.5} \\
k_{\infty}=1.0 \times 10^{-10} \\
k_{r}=0\end{array}$ & $\begin{array}{r}2 \\
2 \\
3 \\
10 \\
3 \\
30\end{array}$ & $\begin{array}{r}100 \\
100 \\
0 \\
0 \\
0 \\
0\end{array}$ & $\begin{array}{r}\text { Linder et al. [1996] } \\
\text { von Gehring at al [1971], Li and Zhang [2006] } \\
\text { Yelle et al. }[2010] \\
\text { Yelle et al. }[2010]\end{array}$ \\
\hline $\begin{array}{l}\mathrm{NH}_{3}+\mathrm{H} \\
\mathrm{NH}_{3}+\mathrm{CH}\end{array}$ & $\begin{array}{l}\rightarrow \mathrm{NH}_{2}+\mathrm{H}_{2} \\
\rightarrow \mathrm{CH}_{2} \mathrm{NH}+\mathrm{H}\end{array}$ & $\begin{array}{l}4.23 \times 10^{-14} \times(T / 300)^{3.93} \times \exp (-4060 / T) \\
1.69 \times 10^{-10} \times(T / 300)^{-0.56} \times \exp (-28 / T)\end{array}$ & $\begin{array}{r}5 \\
1.6\end{array}$ & $\begin{array}{r}100 \\
0\end{array}$ & $\begin{array}{r}\text { Espinosa-Garcia et al. [1994] } \\
\text { Zabarnick et al. [1989a], Bocherel et al. [1996], } \\
\text { Blitz et al. }[2012]\end{array}$ \\
\hline $\begin{array}{l}\mathrm{NH}_{3}+\mathrm{CH}_{3} \\
\mathrm{NH}_{3}+\mathrm{C}_{2} \mathrm{H} \\
\mathrm{N}_{2} \mathrm{H}+\mathrm{H}\end{array}$ & $\begin{array}{l}\rightarrow \mathrm{NH}_{2}+\mathrm{CH}_{4} \\
\rightarrow \mathrm{NH}_{2}+\mathrm{C}_{2} \mathrm{H}_{2} \\
\rightarrow \mathrm{N}_{2}+\mathrm{H}_{2}\end{array}$ & $\begin{array}{l}5.1 \times 10^{-14} \times(T / 300)^{2.86} \times \exp (-7340 / T) \\
2.9 \times 10^{-11} \times(T / 300)^{-0.9} \\
1.0 \times 10^{-10} \times(T / 300)^{0.17}\end{array}$ & $\begin{array}{r}2 \\
1.4 \\
2\end{array}$ & $\begin{array}{r}100 \\
0 \\
100\end{array}$ & $\begin{array}{r}\text { Yu et al. [1998] } \\
\text { Nizamov et al. [2004] } \\
\text { Glarborg et al. [1995], Georgievskii and } \\
\text { Klippenstein [2005] }\end{array}$ \\
\hline $\begin{array}{l}\mathrm{N}_{2} \mathrm{H}_{2}+\mathrm{H} \\
\mathrm{N}_{2} \mathrm{H}_{3}+\mathrm{H}\end{array}$ & $\begin{array}{l}\rightarrow \mathrm{N}_{2} \mathrm{H}+\mathrm{H}_{2} \\
\rightarrow \mathrm{NH}_{2}+\mathrm{NH}_{2}\end{array}$ & $\begin{array}{l}4.58 \times 10^{-13} \times(T / 300)^{2.63} \times \exp (-115 / T) \\
8.0 \times 10^{-11} \times \exp (-1000 / T)\end{array}$ & $\begin{array}{l}2 \\
2\end{array}$ & $\begin{array}{l}100 \\
100\end{array}$ & $\begin{array}{r}\text { Linder et al. }[1996] \\
\text { Gehring et al. [1971], Konnov and de Ruyck } \\
{[2001]}\end{array}$ \\
\hline $\mathrm{N}_{2} \mathrm{H}_{3}+\mathrm{H}$ & $\rightarrow \mathrm{N}_{2} \mathrm{H}_{2}+\mathrm{H}_{2}$ & $1.7 \times 10^{-11}$ & 3 & 21 & $\begin{array}{l}\text { Gehring et al. [1971], Konnov and de Ruyck } \\
\text { [2001] }\end{array}$ \\
\hline $\mathrm{N}_{2} \mathrm{H}_{3}+\mathrm{N}_{2} \mathrm{H}_{3}$ & $\rightarrow \mathrm{N}_{2} \mathrm{H}_{4}+\mathrm{N}_{2}+\mathrm{H}_{2}$ & $6.0 \times 10^{-11}$ & 2 & 100 & Atreya et al. [1986] \\
\hline $\mathrm{N}_{2} \mathrm{H}_{4}+\mathrm{H}$ & $\rightarrow \mathrm{N}_{2} \mathrm{H}_{3}+\mathrm{H}_{2}$ & $9.86 \times 10^{-12} \times \exp (-1200 / T)$ & 1.2 & 100 & Stief and Payne [1976] \\
\hline $\mathrm{N}_{2} \mathrm{H}_{4}+\mathrm{CH}_{3}$ & $\rightarrow \mathrm{N}_{2} \mathrm{H}_{3}+\mathrm{CH}_{4}$ & $1.66 \times 10^{-13} \times \exp (-2520 / T)$ & 2 & 100 & Gray and Thynne [1965] \\
\hline $\mathrm{CN}+\mathrm{H}$ & $\rightarrow \mathrm{HCN}$ & $\begin{array}{l}k_{0}=8.52 \times 10^{-30} \times(T / 300)^{-2.2} \times \exp (-567 / T) \\
k_{\infty}=1.73 \times 10^{-10} \times(T / 300)^{-0.5} \\
k_{r}=0\end{array}$ & $\begin{array}{l}10 \\
10 \\
30\end{array}$ & $\begin{array}{r}100 \\
100 \\
0\end{array}$ & Tsang et al. [1992] \\
\hline $\mathrm{CN}+\mathrm{H}_{2}$ & $\rightarrow \mathrm{HCN}+\mathrm{H}$ & $4.12 \times 10^{-13} \times(T / 300)^{2.87} \times \exp (-820 / T)$ & 1.6 & 50 & Sun et al. [1990] \\
\hline $\mathrm{CN}+\mathrm{CH}$ & $\rightarrow \mathrm{C}_{2} \mathrm{~N}+\mathrm{H}$ & $1.0 \times 10^{-10} \times(T / 300)^{-0.17}$ & 3 & 0 & $\begin{array}{r}\text { Mebel and Kaiser [2002], Takahashi and } \\
\text { Takayanagi [2006], Georgievskii and } \\
\text { Klippenstein [2005] }\end{array}$ \\
\hline
\end{tabular}




\begin{tabular}{|c|c|c|c|c|c|}
\hline \multicolumn{2}{|l|}{ Reactions } & \multirow{2}{*}{$\begin{array}{l}\text { Rate coefficients } \\
1.0 \times 10^{-10} \times(T / 300)-0.17\end{array}$} & \multirow{2}{*}{$\begin{array}{r}F(300 K) \\
3\end{array}$} & \multirow{2}{*}{$\begin{array}{l}g \\
0\end{array}$} & \multirow{2}{*}{$\begin{array}{r}\text { References } \\
\text { Mebel and Kaiser }[2002], \text { Takahashi and } \\
\text { Takayanagi }[2006], \text { Georgievski and } \\
\text { Klippenstein }[2005]\end{array}$} \\
\hline $\mathrm{CN}+\mathrm{CH}$ & $\rightarrow \mathrm{HCN}+\mathrm{C}$ & & & & \\
\hline $\mathrm{CN}+{ }^{3} \mathrm{CH}_{2}$ & $\rightarrow \mathrm{HCN}+\mathrm{CH}$ & $5.0 \times 10^{-11}$ & 3 & 0 & $\begin{array}{r}\text { Takahashi et al. [1998], Du et al. [2005], } \\
\text { Osamura and Petrie [2004], Georgievskii and } \\
\text { Klippenstein [2005] }\end{array}$ \\
\hline $\mathrm{CN}+{ }^{3} \mathrm{CH}_{2}$ & $\rightarrow \mathrm{CHCN}+\mathrm{H}$ & $5.0 \times 10^{-11}$ & 3 & 0 & $\begin{array}{r}\text { Takahashi et al. [1998], Du et al. [2005], } \\
\text { Osamura and Petrie [2004], Georgievskii and } \\
\text { Klippenstein [2005] }\end{array}$ \\
\hline $\mathrm{CN}+{ }^{3} \mathrm{CH}_{2}$ & $\rightarrow \mathrm{C}_{2} \mathrm{~N}+\mathrm{H}_{2}$ & $5.0 \times 10^{-11}$ & 3 & 0 & $\begin{array}{r}\text { Takahashi et al. [1998], Du et al. [2005], } \\
\text { Osamura and Petrie [2004], Georgievskii and } \\
\text { Klippenstein [2005] }\end{array}$ \\
\hline $\mathrm{CN}+\mathrm{CH}_{3}$ & $\rightarrow \mathrm{CH}_{2} \mathrm{CN}+\mathrm{H}$ & $1.0 \times 10^{-10}$ & 3 & 21 & $\begin{array}{r}\text { Yang et al. [2005], Georgievskii and } \\
\text { Klippenstein [2005] }\end{array}$ \\
\hline $\mathrm{CN}+\mathrm{CH}_{4}$ & $\rightarrow \mathrm{HCN}+\mathrm{CH}_{3}$ & $6.2 \times 10^{-12} \times \exp (-721 / T)$ & 1.6 & 0 & $\begin{array}{r}\text { Sims et al. [1993], Yang et al. [1993], Huang et } \\
\text { al. [2008] }\end{array}$ \\
\hline $\mathrm{CN}+\mathrm{C}_{2} \mathrm{H}_{2}$ & $\rightarrow \mathrm{HC}_{3} \mathrm{~N}+\mathrm{H}$ & $2.72 \times 10^{-10} \times(T / 300)^{-0.52} \times \exp (-19 / T)$ & 1.4 & 0 & Sims et al. [1993], Gannon et al. [2007] \\
\hline $\mathrm{CN}+\mathrm{C}_{2} \mathrm{H}_{4}$ & $\rightarrow \mathrm{C}_{2} \mathrm{H}_{3} \mathrm{CN}+\mathrm{H}$ & $2.67 \times 10^{-10} \times(T / 300)^{-0.69} \times \exp (-31 / T)$ & 1.4 & 0 & Sims et al. [1993], Gannon et al. [2007] \\
\hline $\mathrm{CN}+\mathrm{C}_{2} \mathrm{H}_{6}$ & $\rightarrow \mathrm{HCN}+\mathrm{C}_{2} \mathrm{H}_{5}$ & $2.08 \times 10^{-11} \times(T / 300)^{0.22} \times \exp (58 / T)$ & 1.4 & 0 & Sims et al. [1993] \\
\hline $\mathrm{CN}+\mathrm{c}-\mathrm{C}_{3} \mathrm{H}_{2}$ & $\rightarrow \mathrm{HC}_{4} \mathrm{~N}+\mathrm{H}$ & $2.0 \times 10^{-10}$ & 4 & 0 & $\begin{array}{r}\text { Wang et al. [2006], Georgievskii and } \\
\text { Klippenstein [2005] }\end{array}$ \\
\hline $\mathrm{CN}+1-\mathrm{C}_{3} \mathrm{H}_{2}$ & $\rightarrow \mathrm{HC}_{4} \mathrm{~N}+\mathrm{H}$ & $2.0 \times 10^{-10}$ & 4 & 0 & $\begin{array}{r}\text { Wang et al. [2006], Georgievskii and } \\
\text { Klippenstein [2005] }\end{array}$ \\
\hline $\mathrm{CN}+\mathrm{t}-\mathrm{C}_{3} \mathrm{H}_{2}$ & $\rightarrow \mathrm{HC}_{4} \mathrm{~N}+\mathrm{H}$ & $2.0 \times 10^{-10}$ & 4 & 0 & $\begin{array}{r}\text { Wang et al. [2006], Georgievskii and } \\
\text { Klippenstein [2005] }\end{array}$ \\
\hline $\mathrm{CN}+\mathrm{CH}_{3} \mathrm{C}_{2} \mathrm{H}$ & $\rightarrow \mathrm{HC}_{3} \mathrm{~N}+\mathrm{CH}_{3}$ & $1.0 \times 10^{-10}$ & 1.6 & 7 & By comparison with $\mathrm{CN}+\mathrm{C}_{2} \mathrm{H}_{2}$ \\
\hline $\mathrm{CN}+\mathrm{CH}_{3} \mathrm{C}_{2} \mathrm{H}$ & $\rightarrow \mathrm{CH}_{3} \mathrm{C}_{3} \mathrm{~N}+\stackrel{\mathrm{H}}{\mathrm{H}}$ & $1.0 \times 10^{-10}$ & 1.6 & 7 & By comparison with $\mathrm{CN}+\mathrm{C}_{2} \mathrm{H}_{2}$ \\
\hline $\mathrm{CN}+\mathrm{CH}_{2} \mathrm{CCH}_{2}$ & $\rightarrow \mathrm{HC}_{3} \mathrm{~N}+\mathrm{CH}_{3}$ & $1.0 \times 10^{-10}$ & 1.6 & 7 & By comparison with $\mathrm{CN}+\mathrm{C}_{2} \mathrm{H}_{2}$ and $\mathrm{C}_{2} \mathrm{H}_{4}$ \\
\hline $\mathrm{CN}+\mathrm{CH}_{2} \mathrm{CCH}_{2}$ & $\rightarrow \mathrm{CH}_{3} \mathrm{C}_{3} \mathrm{~N}+\stackrel{\mathrm{H}}{\mathrm{H}}$ & $1.0 \times 10^{-10}$ & 1.6 & 7 & By comparison with $\mathrm{CN}+\mathrm{C}_{2} \mathrm{H}_{2}$ and $\mathrm{C}_{2} \mathrm{H}_{4}$ \\
\hline $\mathrm{CN}+\mathrm{C}_{3} \mathrm{H}_{6}$ & $\rightarrow \mathrm{C}_{3} \mathrm{H}_{5} \mathrm{CN}+\mathrm{H}$ & $1.5 \times 10^{-10}$ & 1.6 & 7 & Sims et al. [1993] \\
\hline $\mathrm{CN}+\mathrm{C}_{3} \mathrm{H}_{6}$ & $\rightarrow \mathrm{C}_{2} \mathrm{H}_{3} \mathrm{CN}+\mathrm{CH}_{3}$ & $1.5 \times 10^{-10}$ & 1.6 & 7 & Sims et al. [1993] \\
\hline $\mathrm{CN}+\mathrm{C}_{3} \mathrm{H}_{8}$ & $\rightarrow \mathrm{HCN}+\mathrm{C}_{3} \mathrm{H}_{7}$ & $2.14 \times 10^{-11} \times(T / 300)^{1.19} \times \exp (378 / T)$ & 1.4 & 0 & Yang et al. [1992] \\
\hline $\mathrm{CN}+\mathrm{C}_{4} \mathrm{H}_{2}$ & $\rightarrow \mathrm{HC}_{5} \mathrm{~N}+\mathrm{H}$ & $4.0 \times 10^{-10}$ & 1.6 & 0 & Seki [1996] \\
\hline $\mathrm{CN}+\mathrm{C}_{4} \mathrm{H}_{4}$ & $\rightarrow \mathrm{C}_{4} \mathrm{H}_{3} \mathrm{CN}+\mathrm{H}$ & $2.0 \times 10^{-10}$ & 2 & 0 & By comparison with $\mathrm{CN}+\mathrm{C}_{2} \mathrm{H}_{4}$ \\
\hline $\mathrm{CN}+\mathrm{C}_{4} \mathrm{H}_{6}$ & $\rightarrow$ SOOTN & $2.57 \times 10^{-10} \times \exp (169 / T)$ & 1.6 & 40 & Butterfield et al. [1993] \\
\hline $\mathrm{CN}+\mathrm{C}_{4} \mathrm{H}_{8}$ & $\rightarrow \mathrm{C}_{2} \mathrm{H}_{3} \mathrm{CN}+\mathrm{C}_{2} \mathrm{H}_{5}$ & $1.5 \times 10^{-10}$ & 2 & 0 & By comparison with $\mathrm{CN}+\mathrm{C} 3 \mathrm{H} 6$ \\
\hline $\mathrm{CN}+\mathrm{C}_{4} \mathrm{H}_{10}$ & $\rightarrow \mathrm{HCN}+\mathrm{C}_{4} \mathrm{H}_{9}$ & $2.14 \times 10^{-11} \times(T / 300)^{1.19} \times \exp (378 / T)$ & 1.4 & 0 & By comparison with $\mathrm{CN}+\mathrm{C}_{3} \mathrm{H}_{8}$ \\
\hline $\mathrm{CN}+\mathrm{C}_{6} \mathrm{H}_{6}$ & $\rightarrow \mathrm{C}_{6} \mathrm{H}_{5} \mathrm{CN}+\mathrm{H}$ & $2.8 \times 10^{-10}$ & 1.6 & 0 & Bullock and Cooper [1971] \\
\hline $\mathrm{CN}+\mathrm{NH}_{3}$ & $\rightarrow \mathrm{HCN}+\mathrm{NH}_{2}$ & $2.77 \times 10^{-11} \times(T / 300)^{-1.14}$ & 1.4 & 0 & $\begin{array}{r}\text { Meads et al. }[1993], \text { Sims et al. [1994], Blitz et } \\
\text { al. [2009], Talbi and Smith [2009] }\end{array}$ \\
\hline $\mathrm{CN}+\mathrm{CN}$ & $\rightarrow \mathrm{C}_{2} \mathrm{~N}_{2}$ & $k_{0}=3.22 \times 10^{-29} \times(T / 300)^{-2.61}$ & 3 & 100 & Tsang et al. [1992] \\
\hline & & $\begin{array}{l}k_{\infty}=9.4 \times 10^{-12} \\
k_{r}=0\end{array}$ & $\begin{array}{r}3 \\
30\end{array}$ & $\begin{array}{r}100 \\
0\end{array}$ & \\
\hline $\mathrm{CN}+\mathrm{HCN}$ & $\rightarrow \mathrm{C}_{2} \mathrm{~N}_{2}+\mathrm{H}$ & $4.3 \times 10^{-13} \times(T / 300)^{1.71} \times \exp (-770 / T)$ & 1.4 & 60 & Yang et al. [1992a] \\
\hline $\mathrm{CN}+\mathrm{HNC}$ & $\rightarrow \mathrm{C}_{2} \mathrm{~N}_{2}+\mathrm{H}$ & $2.0 \times 10^{-10}$ & 4 & 0 & $\begin{array}{r}\text { Petrie and Osamura [2004], Georgievskii and } \\
\text { Klippenstein [2005] }\end{array}$ \\
\hline $\mathrm{CN}+\mathrm{CH}_{2} \mathrm{NH}$ & $\rightarrow \mathrm{NCCHNH}+\mathrm{H}$ & $5.0 \times 10^{-11}$ & 4 & 0 & By comparison with $\mathrm{CN}+\mathrm{C}_{2} \mathrm{H}_{4}$ \\
\hline $\mathrm{CN}+\mathrm{CH}_{2} \mathrm{NH}$ & $\rightarrow \mathrm{H}_{2} \mathrm{CNCN}+\mathrm{H}$ & $5.0 \times 10^{-11}$ & 4 & 0 & By comparison with $\mathrm{CN}+\mathrm{C}_{2} \mathrm{H}_{4}$ \\
\hline $\mathrm{CN}+\mathrm{CH}_{3} \mathrm{NH}_{2}$ & $\rightarrow \mathrm{CH}_{3} \mathrm{NH}+\mathrm{HCN}$ & $8.0 \times 10^{-11}$ & 3 & 0 & By comparison with $\mathrm{CN}+\mathrm{NH}_{3}, \mathrm{C}_{2} \mathrm{H}_{6}$ \\
\hline $\mathrm{CN}+\mathrm{CH}_{3} \mathrm{CN}$ & $\rightarrow \mathrm{C}_{2} \stackrel{\mathrm{N}}{2}_{2}+\mathrm{CH}_{3}$ & $4.0 \times 10^{-11} \times \exp (-1190 / T)$ & 1.6 & 71 & Zabarnick [1989] \\
\hline $\mathrm{CN}+\mathrm{CH}_{3} \mathrm{CN}$ & $\rightarrow \mathrm{CH}_{2} \mathrm{CN}+\mathrm{HCN}$ & $2.46 \times 10^{-11} \times \exp (-1190 / T)$ & 1.6 & 71 & Zabarnick [1989] \\
\hline $\mathrm{CN}+\mathrm{cCH}_{2} \mathrm{NCH}$ & $\rightarrow$ SOOTN & $3.0 \times 10^{-11}$ & 10 & 100 & By comparison with $\mathrm{CN}+\mathrm{C}_{2} \mathrm{H}_{4}$ \\
\hline $\mathrm{CN}+\mathrm{C}_{2} \mathrm{H}_{3} \mathrm{CN}$ & $\rightarrow \mathrm{C}_{4} \mathrm{~N}_{2} \mathrm{H}_{2}+\mathrm{H}$ & $3.02 \times 10^{-11} \times \exp (103 / T)$ & 1.6 & 50 & Butterfield et al. [1993] \\
\hline $\mathrm{CN}+\mathrm{C}_{2} \mathrm{H}_{5} \mathrm{CN}$ & $\rightarrow \mathrm{C}_{2} \mathrm{H}_{4} \mathrm{CN}+\mathrm{HCN}$ & $2.08 \times 10^{-11} \times(T / 300)^{0.22} \times \exp (58 / T)$ & 3 & 100 & By comparison with $\mathrm{CN}+\mathrm{C}_{2} \mathrm{H}_{6}$ \\
\hline $\mathrm{CN}+\mathrm{C}_{3} \mathrm{~N}$ & $\rightarrow \mathrm{C}_{4} \mathrm{~N}_{2}$ & $k_{0}=3.22 \times 10^{-29} \times(T / 300)^{-2.61}$ & 10 & 100 & By comparison with $\mathrm{CN}+\mathrm{CN}$ \\
\hline & & $\begin{array}{l}k_{\infty}=9.4 \times 10^{-12} \\
k_{r}=0\end{array}$ & $\begin{array}{l}10 \\
30\end{array}$ & $\begin{array}{r}100 \\
0\end{array}$ & \\
\hline $\mathrm{CN}+\mathrm{HC}_{3} \mathrm{~N}$ & $\rightarrow \mathrm{C}_{4} \mathrm{~N}_{2}+\mathrm{H}$ & $1.79 \times 10^{-11} \times(T / 300)^{-0.67}$ & 1.6 & 0 & Cheikh Sid Ely [2013] \\
\hline $\mathrm{CN}+\mathrm{HC}_{5} \mathrm{~N}$ & $\rightarrow \mathrm{C}_{6} \mathrm{~N}_{2}+\mathrm{H}$ & $3.0 \times 10^{-11} \times(T / 300)^{-0.7}$ & 2 & 0 & By comparison with $\mathrm{CN}+\mathrm{HC}_{3} \mathrm{~N}$ \\
\hline $\mathrm{CN}+\mathrm{C}_{4} \mathrm{~N}_{2}$ & $\rightarrow$ SOOTN & $k_{0}=1.0 \times 10^{-26}$ & 10 & 0 & $k_{0}$ by comparison with $\mathrm{CH}_{3}+\mathrm{CH}_{3}, k_{\infty}$ from \\
\hline & & $\begin{array}{l}k_{\infty}=3.0 \times 10^{-11} \\
k_{r}=0\end{array}$ & $\begin{array}{r}3 \\
30\end{array}$ & $\begin{array}{l}0 \\
0\end{array}$ & $\mathrm{CN}+\mathrm{HC}_{3} \mathrm{~N}$ \\
\hline $\mathrm{HCN}+\mathrm{H}$ & $\rightarrow \mathrm{H}_{2} \mathrm{CN}$ & $k_{0}=1.0 \times 10^{-34}$ & 30 & 100 & DFT (M06-2X/cc-pVTZ)/RRKM calculations \\
\hline & & $\begin{array}{l}k_{\infty}=9.8 \times 10^{-12} \times \exp (-2076 / T) \\
k_{r}=0\end{array}$ & $\begin{array}{r}4 \\
30\end{array}$ & $\begin{array}{r}100 \\
0\end{array}$ & $\begin{array}{r}\text { (this work), see also Sumathi and Nguyen } \\
\text { [1998], Jiang and Guo [2013] }\end{array}$ \\
\hline $\mathrm{HCN}+\mathrm{CH}$ & $\rightarrow \mathrm{CHCN}+\mathrm{H}$ & $1.4 \times 10^{-10} \times(T / 300)^{-0.17}$ & 2 & 21 & $\begin{array}{c}\text { Zabarnick et al. [1991], Du and Zhang [2006], } \\
\text { Osamura and Petrie [2004] }\end{array}$ \\
\hline $\mathrm{HCN}+\mathrm{CH}$ & $\rightarrow \mathrm{C}_{2} \mathrm{~N}+\mathrm{H}_{2}$ & $1.4 \times 10^{-10} \times(T / 300)^{-0.17}$ & 2 & 21 & $\begin{array}{r}\text { Zabarnick et al. [1991], Du and Zhang [2006], } \\
\text { Osamura and Petrie [2004] }\end{array}$ \\
\hline $\mathrm{HCN}+{ }^{3} \mathrm{CH}_{2}$ & $\rightarrow \mathrm{CH}_{2} \mathrm{CN}+\mathrm{H}$ & $1.5 \times 10^{-12} \times \exp (-3330 / T)$ & 2 & 100 & By comparison with ${ }^{3} \mathrm{CH}_{2}+$ alkynes \\
\hline $\mathrm{HCN}+\mathrm{C}_{2}$ & $\rightarrow \mathrm{C}_{3} \mathrm{~N}+\mathrm{H}$ & $2.0 \times 10^{-10} \times(T / 300)^{0.17}$ & 3 & 0 & Silva et al. [2009], Georgievskii and \\
\hline
\end{tabular}




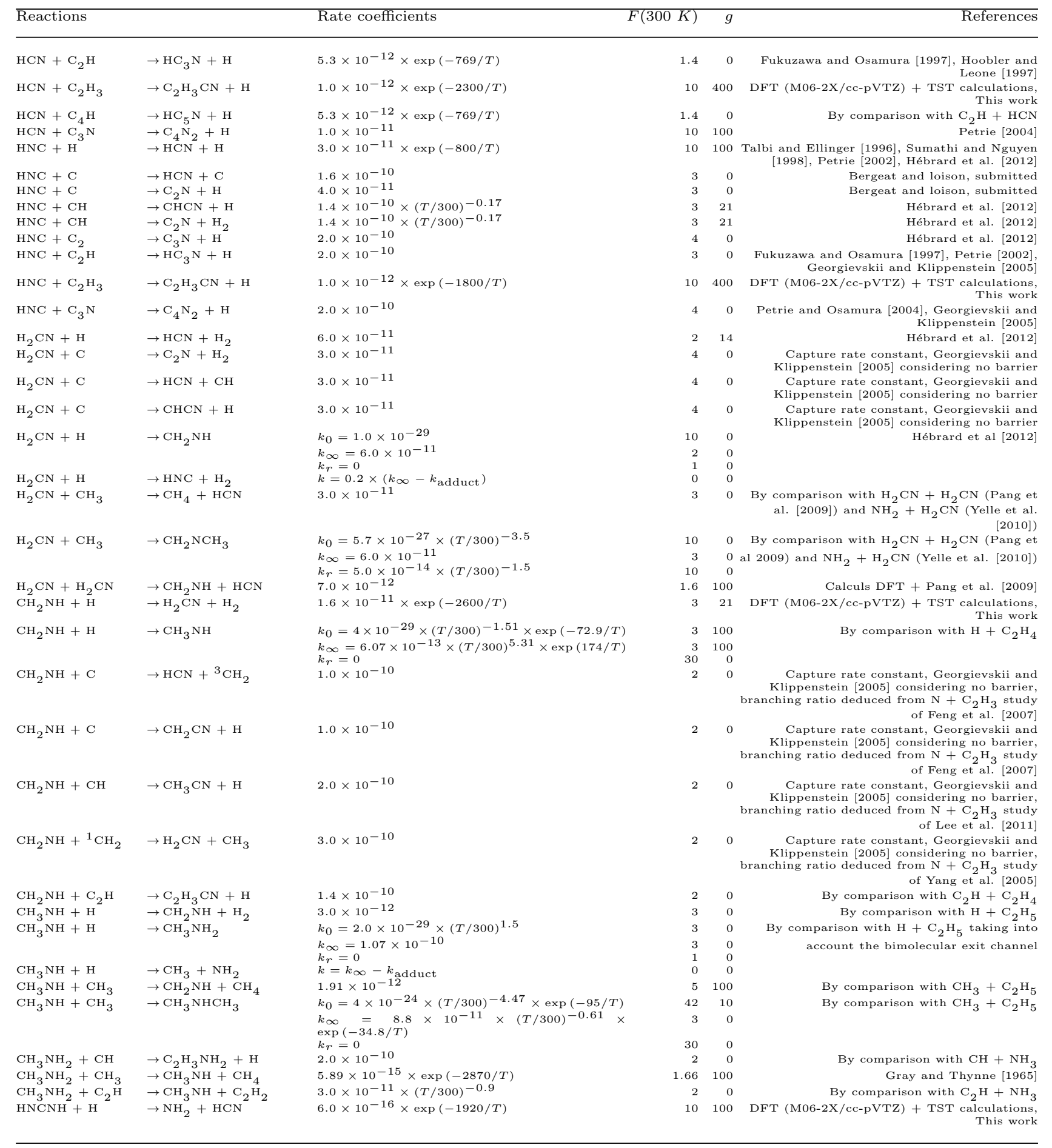




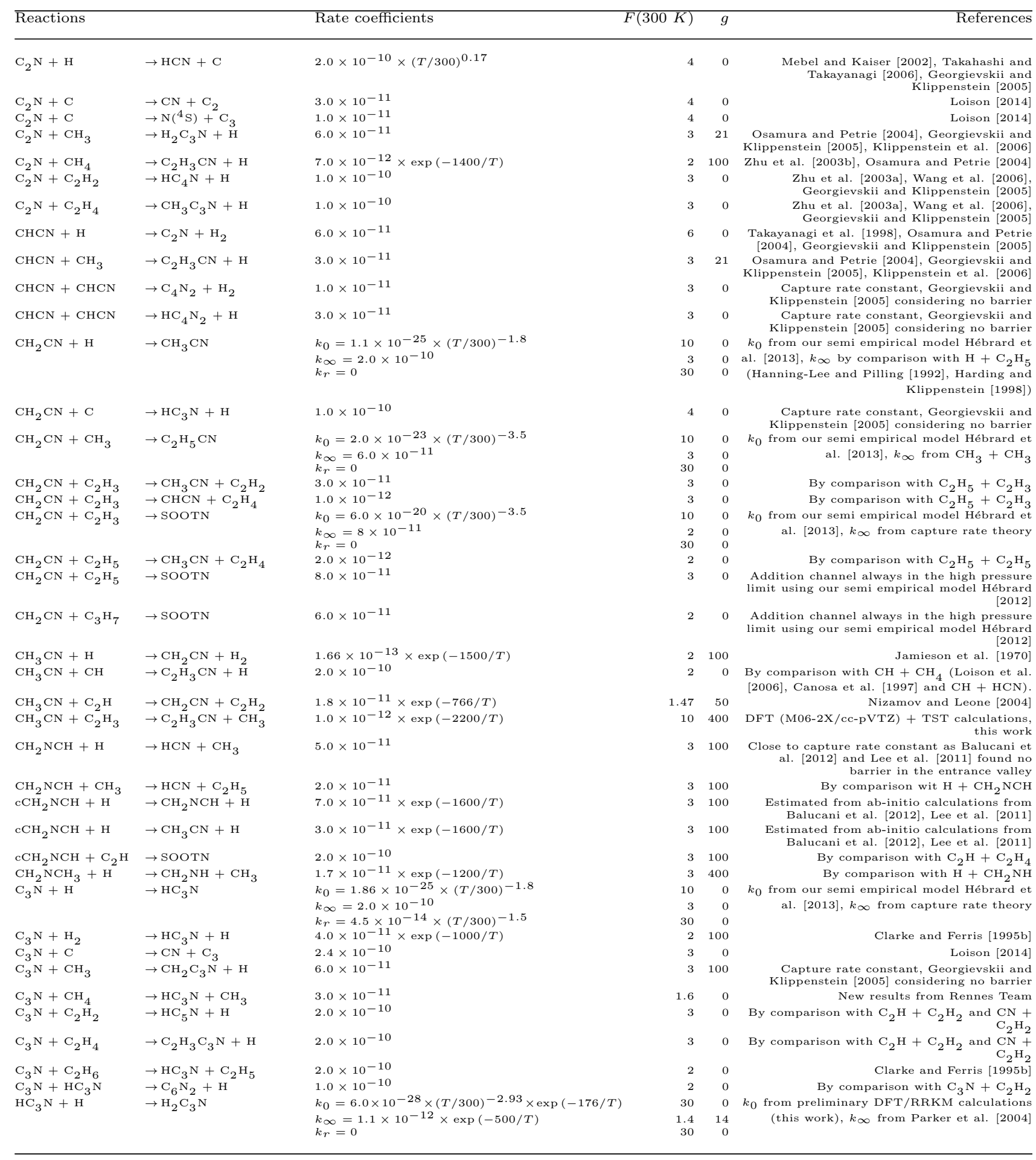




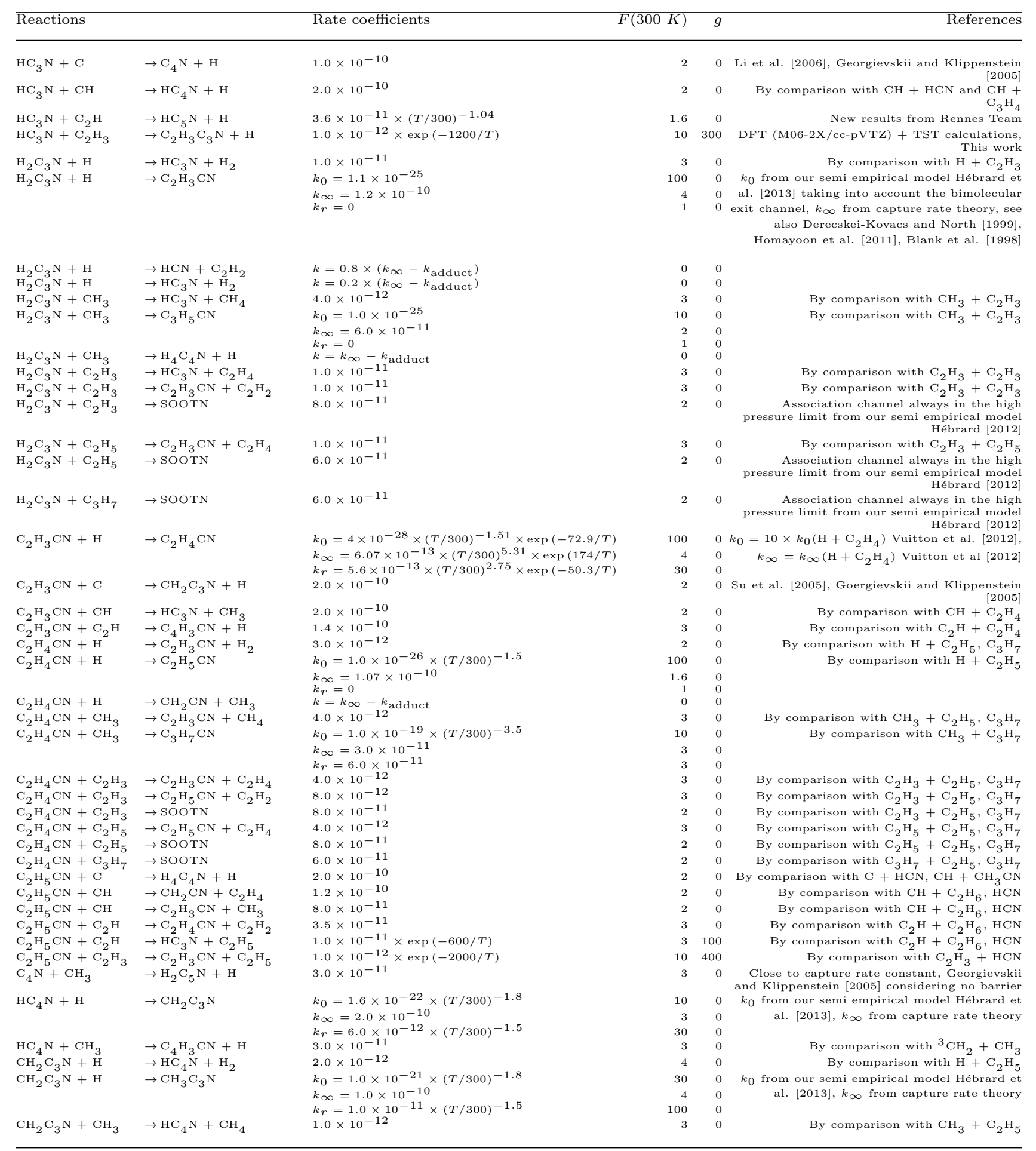




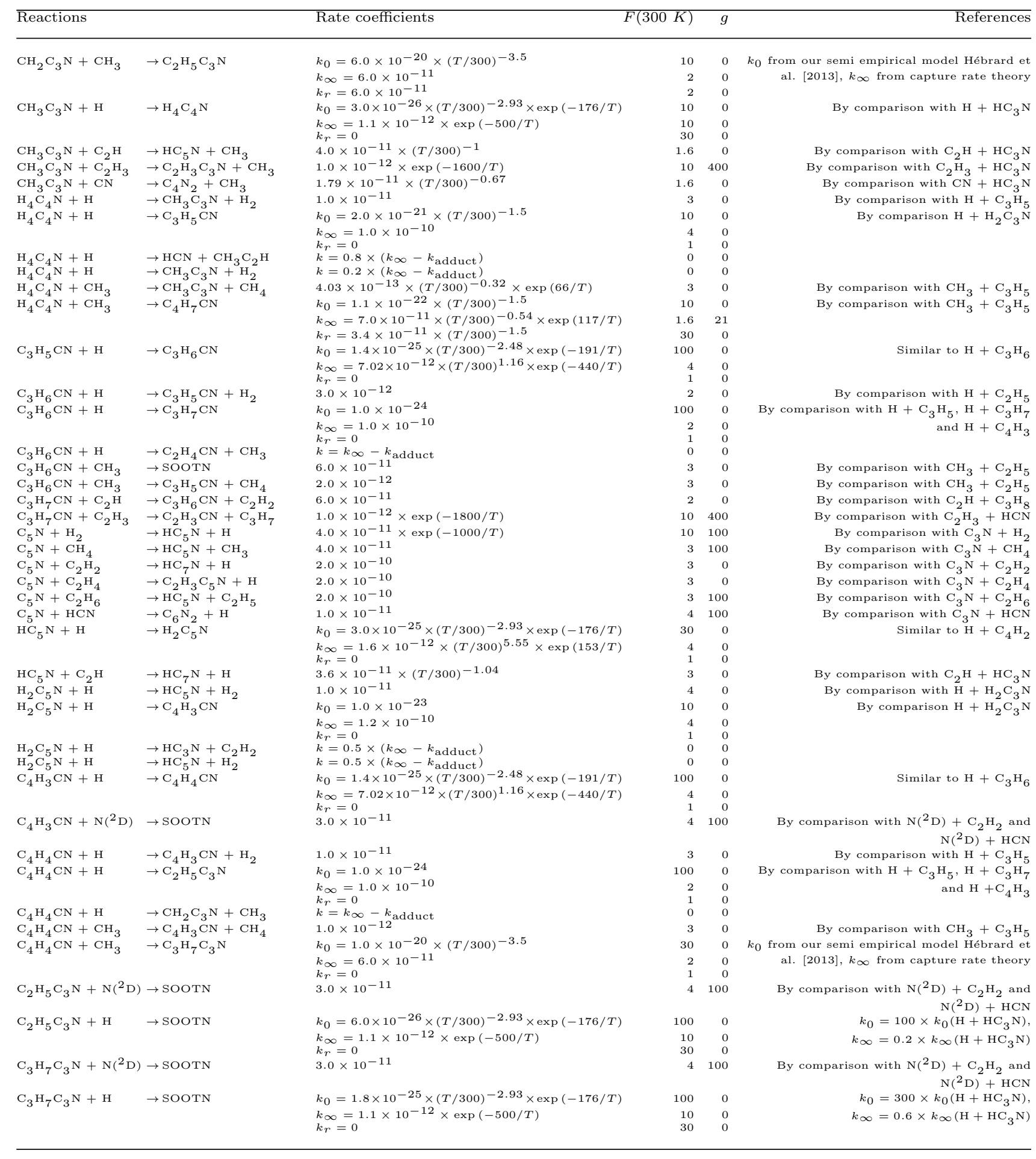




\begin{tabular}{|c|c|c|c|c|c|}
\hline Reactions & & Rate coefficients & $F(300 K)$ & $g$ & References \\
\hline \multirow[t]{2}{*}{$\mathrm{N}_{2}+\mathrm{C}$} & \multirow[t]{2}{*}{$\rightarrow \mathrm{CN}_{2}$} & $k_{0}=3.1 \times 10^{-33} \times(T / 300)^{-1.5}$ & 1.8 & 10 & \multirow[t]{2}{*}{ Husain and Kirsch [1971] } \\
\hline & & $\begin{array}{l}k_{\infty}=1.0 \times 10^{-11} \\
k_{r}=0\end{array}$ & $\begin{array}{l}10 \\
30\end{array}$ & $\begin{array}{l}0 \\
0\end{array}$ & \\
\hline \multirow{2}{*}{$\mathrm{N}_{2}+\mathrm{CH}$} & \multirow[t]{2}{*}{$\rightarrow \mathrm{HCNN}$} & $k_{0}=1.9 \times 10^{-31} \times(T / 300)^{-2.2}$ & 1.4 & 0 & \multirow{2}{*}{$\begin{array}{r}\text { Brownsword et al. [1996], Le Picard and } \\
\text { Canosa [1998] }\end{array}$} \\
\hline & & $\begin{array}{l}k_{\infty}=1.8 \times 10^{-12} \times(T / 300)^{-1.5} \\
k_{r}=0\end{array}$ & $\begin{array}{r}3 \\
30\end{array}$ & $\begin{array}{r}100 \\
0\end{array}$ & \\
\hline $\mathrm{CN}_{2}+\mathrm{H}$ & $\rightarrow \mathrm{CH}+\mathrm{N}_{2}$ & $2.0 \times 10^{-10}$ & 3 & 7 & $\begin{array}{r}\text { Moskaleva et al. [2000], Georgievskii and } \\
\text { Klippenstein [2005] }\end{array}$ \\
\hline \multirow{4}{*}{$\begin{array}{l}\mathrm{HCNN}+\mathrm{H} \\
\mathrm{H}_{2} \mathrm{CNN}+\mathrm{H} \\
\mathrm{C}_{2} \mathrm{~N}_{2}+\mathrm{H}\end{array}$} & \multirow{4}{*}{$\begin{array}{l}\rightarrow{ }^{1} \mathrm{CH}_{2}+\mathrm{N}_{2} \\
\rightarrow \mathrm{CH}_{3}+\mathrm{N}_{2} \\
\rightarrow \mathrm{HC}_{2} \mathrm{~N}_{2}\end{array}$} & $2.0 \times 10^{-10}$ & 3 & 0 & Tomeczek [2003] \\
\hline & & $1.6 \times 10^{-11}$ & 4 & 100 & \multirow{3}{*}{$\begin{array}{r}\text { Morris and Niki }[1973] \\
k_{0}=0.1 \times k_{0}\left(\mathrm{H}+\mathrm{C}_{2} \mathrm{H}_{2}\right) \\
k_{\infty}=0.1 \times k_{\infty}\left(\mathrm{H}+\mathrm{C}_{2} \mathrm{H}_{2}\right) \text { considering the } \\
\text { entrance TS value calculated at the } \\
\text { M06- } 2 \mathrm{X} / \text { cc-pVTZ level }\end{array}$} \\
\hline & & $\begin{array}{l}k_{0}=2.0 \times 10^{-31} \times(T / 300)^{-1.07} \times \\
\exp (-83.8 / T)\end{array}$ & 10 & 0 & \\
\hline & & $\begin{array}{l}k_{\infty}=1.17 \times 10^{-14} \times(T / 300)^{8.41} \times \exp (359 / T) \\
k_{r}=0\end{array}$ & $\begin{array}{r}3 \\
30\end{array}$ & $\begin{array}{l}0 \\
0\end{array}$ & \\
\hline $\mathrm{C}_{2} \mathrm{~N}_{2}+\mathrm{C}$ & $\rightarrow \mathrm{C}_{3}+\mathrm{N}_{2}$ & $6.0 \times 10^{-11}$ & 4 & 0 & Whyte and Phillips [1983] \\
\hline $\mathrm{C}_{2} \mathrm{~N}_{2}+\mathrm{CH}$ & $\rightarrow \mathrm{C}_{2} \mathrm{~N}+\mathrm{HCN}$ & $2.0 \times 10^{-10}$ & 3 & 0 & By comparison with $\mathrm{CH}+\mathrm{HCN}$ \\
\hline $\mathrm{C}_{2} \mathrm{~N}_{2}+\mathrm{C}_{2} \mathrm{H}$ & $\rightarrow \mathrm{HC}_{3} \mathrm{~N}+\mathrm{CN}$ & $5.3 \times 10^{-12} \times \exp (-769 / T)$ & 1.4 & 0 & By comparison with $\mathrm{C}_{2} \mathrm{H}+\mathrm{HCN}$ \\
\hline \multirow{3}{*}{$\mathrm{C}_{4} \mathrm{~N}_{2}+\mathrm{H}$} & \multirow{3}{*}{$\rightarrow \mathrm{HC}_{4} \mathrm{~N}_{2}$} & $k_{0}=4.3 \times 10^{-28} \times(T / 300)^{-1.51} \times$ & 100 & 0 & \multirow{3}{*}{$\begin{array}{r}k_{0}=10 \times k_{0}\left(\mathrm{H}+\mathrm{C}_{2} \mathrm{H}_{4}\right) \\
k_{\infty}=0.2 \times k_{\infty}\left(\mathrm{H}+\mathrm{C}_{2} \mathrm{H}_{2}\right) \text { considering the } \\
\text { entrance TS value calculated at the } \\
\text { M06-2X/cc-pVTZ level and the size of the } \\
\text { system }\end{array}$} \\
\hline & & $\begin{array}{l}\exp (-72.9 / T) \\
k_{\infty}=2.2 \times 10^{-14} \times(T / 300)^{8.41} \times \exp (359 / T)\end{array}$ & 10 & 0 & \\
\hline & & $k_{r}=0$ & 30 & 0 & \\
\hline $\mathrm{C}_{4} \mathrm{~N}_{2}+\mathrm{C}$ & $\rightarrow \mathrm{C}_{5}+\mathrm{N}_{2}$ & $6.0 \times 10^{-11}$ & 4 & 0 & By comparison with $\mathrm{C}+\mathrm{C}_{2} \mathrm{~N}_{2}$ \\
\hline $\mathrm{C}_{4} \mathrm{~N}_{2}^{2}+\mathrm{CH}$ & $\rightarrow \mathrm{C}_{4} \mathrm{~N}+\mathrm{HCN}$ & $2.0 \times 10^{-10}$ & 3 & 0 & By comparison with $\mathrm{CH}+\mathrm{HC}_{3} \mathrm{~N}, \mathrm{HCN}$ \\
\hline $\mathrm{C}_{4} \mathrm{~N}_{2}+\mathrm{C}_{2} \mathrm{H}$ & $\rightarrow \mathrm{HC}_{5} \mathrm{~N}+\mathrm{CN}$ & $2.1 \times 10^{-10} \times(T / 300)^{-0.3}$ & 1.6 & 0 & By comparison with $\mathrm{C}_{2} \mathrm{H}^{3}+\mathrm{HC}_{3} \mathrm{~N}$ \\
\hline $\mathrm{HC}_{2} \mathrm{~N}_{2}+\mathrm{H}$ & $\rightarrow \mathrm{C}_{2} \mathrm{~N}_{2}+\mathrm{H}_{2}$ & $1.0 \times 10^{-11}$ & 3 & 0 & $\begin{array}{l}\text { Evans et al. [1991], Smith et al. [2001], } \\
\text { Phillips [1978], Basiuk and Kobayashi }[2004]\end{array}$ \\
\hline $\mathrm{HC}_{2} \mathrm{~N}_{2}+\mathrm{H}$ & $\rightarrow \mathrm{HCN}+\mathrm{HNC}$ & $6.0 \times 10^{-11}$ & 3 & 0 & $\begin{array}{l}\text { Evans et al. [1991], Smith et al. [2001], } \\
\text { Phillips [1978], Basiuk and Kobayashi }[2004]\end{array}$ \\
\hline $\mathrm{HC}_{4} \mathrm{~N}_{2}+\mathrm{H}$ & $\rightarrow \mathrm{C}_{4} \mathrm{~N}_{2}+\mathrm{H}_{2}$ & $1.0 \times 10^{-11}$ & 3 & 0 & By comparison with $\mathrm{H}+\mathrm{C}_{2} \mathrm{~N}_{2}$ \\
\hline $\mathrm{HC}_{4} \mathrm{~N}_{2}+\mathrm{H}$ & $\rightarrow \mathrm{HC}_{3} \mathrm{~N}+\mathrm{HNC}$ & $6.0 \times 10^{-11}$ & 3 & 0 & By comparison with $\mathrm{H}+\mathrm{C}_{2} \mathrm{~N}_{2}$ \\
\hline $\mathrm{O}\left({ }^{3} \mathrm{P}\right)+{ }^{1} \mathrm{CH}_{2}$ & $\rightarrow \mathrm{HCO}+\mathrm{H}$ & $1.0 \times 10^{-11}$ & 2 & 0 & $\begin{array}{r}\text { Bohland et al. [1984], Vinckier [1979], Tsuboi } \\
\text { and Hashimoto [1981] and HCO dissociation } \\
\text { Shepler et al. [2007], Wang et al. [1973], } \\
\text { Baulch et al. [2005], Zhang et al. [2004b] }\end{array}$ \\
\hline $\mathrm{O}\left({ }^{3} \mathrm{P}\right)+{ }^{1} \mathrm{CH}_{2}$ & $\rightarrow \mathrm{CO}+\mathrm{H}+\mathrm{H}$ & $5.0 \times 10^{-11}$ & 1.6 & 0 & \\
\hline $\mathrm{O}\left({ }^{3} \mathrm{P}\right)+{ }^{1} \mathrm{CH}_{2}$ & $\rightarrow \mathrm{CO}+\mathrm{H}_{2}$ & $6.0 \times 10^{-11}$ & 1.6 & 0 & \\
\hline $\mathrm{O}\left({ }^{3} \mathrm{P}\right)+{ }^{3} \mathrm{CH}_{2}$ & $\rightarrow \mathrm{HCO}+\mathrm{H}$ & $1.0 \times 10^{-11}$ & 2 & 0 & \\
\hline $\mathrm{O}\left({ }^{3} \mathrm{P}\right)+{ }^{3} \mathrm{CH}_{2}^{2}$ & $\rightarrow \mathrm{CO}+\mathrm{H}+\mathrm{H}$ & $5.0 \times 10^{-11}$ & 1.6 & 0 & \\
\hline $\mathrm{O}\left({ }^{3} \mathrm{P}\right)+{ }^{3} \mathrm{CH}_{2}^{2}$ & $\rightarrow \mathrm{CO}+\mathrm{H}_{2}$ & $6.0 \times 10^{-11}$ & 1.6 & 0 & \\
\hline $\mathrm{O}\left({ }^{3} \mathrm{P}\right)+\mathrm{CH}_{3}{ }^{2}$ & $\rightarrow \mathrm{CO}+\mathrm{H}_{2}^{2}+\mathrm{H}$ & $2.9 \times 10^{-11}$ & 1.4 & 0 & Baulch et al. [2005] \\
\hline $\mathrm{O}\left({ }^{3} \mathrm{P}\right)+\mathrm{CH}_{3}$ & $\rightarrow \mathrm{H}_{2} \mathrm{CO}+\mathrm{H}$ & $1.1 \times 10^{-10}$ & 1.4 & 0 & \\
\hline $\mathrm{O}\left({ }^{3} \mathrm{P}\right)+\mathrm{C}_{2} \mathrm{H}_{2}$ & $\rightarrow \mathrm{CO}+{ }^{3} \mathrm{CH}_{2}$ & $6.6 \times 10^{-12} \times \exp (-1600 / T)$ & 1.4 & 250 & Sander et al. [2011], Baulch et al. [2005] \\
\hline $\mathrm{O}\left({ }^{3} \mathrm{P}\right)+\mathrm{C}_{2} \mathrm{H}_{2}$ & $\rightarrow \mathrm{HCCO}+\mathrm{H}^{2}$ & $2.6 \times 10^{-11} \times \exp (-1600 / T)$ & 1.4 & 250 & \\
\hline $\mathrm{O}\left({ }^{3} \mathrm{P}\right)+\mathrm{C}_{2} \mathrm{H}_{3}$ & $\rightarrow \mathrm{CH}_{3}+\mathrm{CO}$ & $6.0 \times 10^{-11}$ & 2 & 0 & Heinemann et al. [1988], Harding et al. [2005] \\
\hline $\mathrm{O}\left({ }^{3} \mathrm{P}\right)+\mathrm{C}_{2} \mathrm{H}_{3}$ & $\rightarrow \mathrm{OH}^{3}+\mathrm{C}_{2} \mathrm{H}_{2}$ & $1.0 \times 10^{-11}$ & 3 & 0 & Heinemann et al. [1988], Harding et al. [2005] \\
\hline $\mathrm{O}\left({ }^{3} \mathrm{P}\right)+\mathrm{C}_{2} \mathrm{H}_{4}^{3}$ & $\rightarrow \mathrm{CH}_{3} \mathrm{CO}+\mathrm{H}$ & $3.0 \times 10^{-14} \times(T / 300)^{1.88} \times \exp (-92 / T)$ & 1.6 & 100 & $\begin{array}{l}\text { Baulch et al. [2005], Fu et al. [2012a], Fu et al. } \\
\text { [2012b], Balucani et al. [2012]. Branching ratio } \\
\text { values are for } 298 \mathrm{~K} \text {. This reaction has a very } \\
\text { small flux in Titan's atmosphere. Second } \\
\text { reaction: } \mathrm{CH}_{2} \mathrm{CHO} .\end{array}$ \\
\hline $\mathrm{O}\left({ }^{3} \mathrm{P}\right)+\mathrm{C}_{2} \mathrm{H}_{4}$ & $\rightarrow \mathrm{CH}_{3} \mathrm{CO}+\mathrm{H}$ & $4.8 \times 10^{-13} \times(T / 300)^{1.88} \times \exp (-92 / T)$ & 1.6 & 100 & \\
\hline $\mathrm{O}\left({ }^{3} \mathrm{P}\right)+\mathrm{C}_{2} \mathrm{H}_{4}$ & $\rightarrow \mathrm{HCO}+\mathrm{CH}_{3}$ & $5.0 \times 10^{-13} \times(T / 300)^{1.88} \times \exp (-92 / T)$ & 1.6 & 100 & \\
\hline $\mathrm{O}\left({ }^{3} \mathrm{P}\right)+\mathrm{C}_{2} \mathrm{H}_{4}^{4}$ & $\rightarrow \mathrm{H}_{2} \mathrm{CO}+{ }^{3} \mathrm{CH}_{2}$ & $1.0 \times 10^{-13} \times(T / 300)^{1.88} \times \exp (-92 / T)$ & 1.6 & 100 & \\
\hline $\mathrm{O}\left({ }^{3} \mathrm{P}\right)+\mathrm{C}_{2} \mathrm{H}_{4}$ & $\rightarrow \mathrm{CH}_{2} \mathrm{CO}+\mathrm{H}_{2}$ & $3.0 \times 10^{-14} \times(T / 300)^{1.88} \times \exp (-92 / T)$ & 1.6 & 100 & \\
\hline $\mathrm{O}\left({ }^{3} \mathrm{P}\right)+\mathrm{C}_{2} \mathrm{H}_{5}$ & $\rightarrow \mathrm{H}_{2} \mathrm{CO}+\mathrm{CH}_{3}$ & $5.0 \times 10^{-11}$ & 2 & 0 & Heinemann et al. [1988], Harding et al. [2005] \\
\hline $\mathrm{O}\left({ }^{3} \mathrm{P}\right)+\mathrm{C}_{2} \mathrm{H}_{5}$ & $\rightarrow \mathrm{CH}_{3} \mathrm{CHO}+\mathrm{H}$ & $6.0 \times 10^{-11}$ & 2 & 0 & Heinemann et al. [1988], Harding et al. [2005] \\
\hline $\mathrm{O}\left({ }^{3} \mathrm{P}\right)+\mathrm{C}_{2} \mathrm{H}_{5}$ & $\rightarrow \mathrm{OH}+\mathrm{C}_{2} \mathrm{H}_{4}$ & $3.0 \times 10^{-11}$ & 2 & 0 & Heinemann et al. [1988], Harding et al. [2005] \\
\hline $\mathrm{O}\left({ }^{3} \mathrm{P}\right)+\mathrm{C}_{3}$ & $\rightarrow \mathrm{CO}+\mathrm{C}_{2}$ & $3.0 \times 10^{-11}$ & 4 & 500 & $\begin{array}{r}\text { Deduced from ab-initio calculations, Woon } \\
{[1996], T=150-200 \mathrm{~K}}\end{array}$ \\
\hline $\mathrm{O}\left({ }^{3} \mathrm{P}\right)+\mathrm{C}_{3} \mathrm{H}_{6}$ & $\rightarrow \mathrm{HCO}+\mathrm{C}_{2} \mathrm{H}_{5}$ & $1.0 \times 10^{-12}$ & 2 & 0 & Sabbah et al. [2007], Savee et al. [2012] \\
\hline $\mathrm{O}\left({ }^{3} \mathrm{P}\right)+\mathrm{C}_{3} \mathrm{H}_{6}$ & $\rightarrow \mathrm{CH}_{3} \mathrm{CO}+\mathrm{CH}_{3}$ & $1.1 \times 10^{-12}$ & 2 & 0 & \\
\hline $\mathrm{O}\left({ }^{3} \mathrm{P}\right)+\mathrm{C}_{3} \mathrm{H}_{6}$ & $\rightarrow \mathrm{SOOTC}+\mathrm{H}$ & $1.8 \times 10^{-12}$ & 2 & 0 & \\
\hline $\mathrm{O}\left({ }^{3} \mathrm{P}\right)+\mathrm{C}_{3}^{3} \mathrm{H}_{6}^{6}$ & $\rightarrow \mathrm{SOOTC}+\mathrm{H}_{2}$ & $6.0 \times 10^{-14}$ & 2 & 0 & \\
\hline $\mathrm{O}\left({ }^{3} \mathrm{P}\right)+\mathrm{C}_{4} \mathrm{H}_{2}$ & $\rightarrow \mathrm{CO}+\mathrm{t}-\mathrm{C}_{3} \mathrm{H}_{2}$ & $1.31 \times 10^{-11} \times \exp (-678 / T)$ & 1.4 & 60 & Mitchell [1986] \\
\hline $\mathrm{O}\left({ }^{3} \mathrm{P}\right)+\mathrm{NH}$ & $\rightarrow \mathrm{NO}+\mathrm{H}$ & $6.6 \times 10^{-11}$ & 1.4 & 100 & $\begin{array}{r}\text { Adamson et al. [1994], Dransfeld et al. 1985, } \\
\text { Li et al. [2013] }\end{array}$ \\
\hline
\end{tabular}




\begin{tabular}{|c|c|c|c|c|c|}
\hline Reactions & & Rate coefficients & $F(300 K)$ & $g$ & References \\
\hline $\mathrm{O}\left({ }^{3} \mathrm{P}\right)+\mathrm{H}_{2} \mathrm{CN}$ & $\rightarrow \mathrm{OH}+\mathrm{HCN}$ & $4.0 \times 10^{-11}$ & 3 & & $\begin{array}{l}\text { rate constant from capture theory, Georgievskii } \\
\text { and Klippenstein [2005] considering no barrier } \\
\text { in the entrance valley and branching ratio } \\
\text { deduced from Fikri et al. [2001], Zhang et al. } \\
\text { [2004] }\end{array}$ \\
\hline $\mathrm{O}\left({ }^{3} \mathrm{P}\right)+\mathrm{H}_{2} \mathrm{CN}$ & $\rightarrow \mathrm{OH}+\mathrm{HNC}$ & $1.0 \times 10^{-11}$ & 3 & 0 & \\
\hline $\mathrm{O}\left({ }^{3} \mathrm{P}\right)+\mathrm{H}_{2}^{2} \mathrm{CN}$ & $\rightarrow \mathrm{HNCO}+\mathrm{H}$ & $5.0 \times 10^{-11}$ & 3 & 0 & \\
\hline $\mathrm{O}\left({ }^{3} \mathrm{P}\right)+\mathrm{HCCO}$ & $\rightarrow \mathrm{H}+\mathrm{CO}+\mathrm{CO}$ & $1.6 \times 10^{-10}$ & 1.6 & 0 & Baulch et al. [2005] \\
\hline $\mathrm{O}\left({ }^{3} \mathrm{P}\right)+\mathrm{HCCO}$ & $\rightarrow \mathrm{CH}+\mathrm{CO}_{2}$ & $4.9 \times 10^{-11} \times \exp (-560 / T)$ & 2 & 100 & \\
\hline $\mathrm{O}\left({ }^{3} \mathrm{P}\right)+\mathrm{HNO}$ & $\rightarrow \mathrm{OH}+\mathrm{NO}^{2}$ & $3.8 \times 10^{-11}$ & 1.6 & 0 & Inomata and Washida [1999] \\
\hline $\mathrm{O}\left({ }^{1} \mathrm{D}\right)+\mathrm{H}_{2}$ & $\rightarrow \mathrm{OH}+\mathrm{H}$ & $1.1 \times 10^{-10}$ & 1.1 & 100 & Sander et al. [2011] \\
\hline $\mathrm{O}\left({ }^{1} \mathrm{D}\right)+\mathrm{CH}_{4}$ & $\rightarrow \mathrm{OH}+\mathrm{CH}_{3}$ & $1.05 \times 10^{-10}$ & 1.4 & 100 & Atkinson et al. [2006] \\
\hline $\mathrm{O}\left({ }^{1} \mathrm{D}\right)+\mathrm{CH}_{4}$ & $\rightarrow \mathrm{CH}_{3} \mathrm{O}+\stackrel{\mathrm{H}}{ }$ & $3.5 \times 10^{-11}$ & 1.3 & 100 & \\
\hline $\mathrm{O}\left({ }^{1} \mathrm{D}\right)+\mathrm{CH}_{4}^{4}$ & $\rightarrow \mathrm{H}_{2} \mathrm{CO}+\mathrm{H}_{2}$ & $7.5 \times 10^{-12}$ & 1.3 & 100 & \\
\hline $\mathrm{O}\left({ }^{1} \mathrm{D}\right)+\mathrm{N}_{2}$ & $\rightarrow \mathrm{O}\left({ }^{3} \mathrm{P}\right)+\mathrm{N}_{2}$ & $2.15 \times 10^{-11} \times \exp (110 / T)$ & 1.1 & 30 & Sander et al. [2011] \\
\hline $\mathrm{OH}+\mathrm{H}_{2}$ & $\rightarrow \mathrm{H}_{2} \mathrm{O}+\mathrm{H}^{2}$ & $2.8 \times 10^{-12} \times \exp (-1800 / T)$ & 1.05 & 100 & Sander et al. [2011] \\
\hline $\mathrm{OH}+\mathrm{CH}_{3}$ & $\rightarrow \mathrm{H}_{2} \mathrm{O}+{ }^{1} \mathrm{CH}_{2}$ & $3.2 \times 10^{-11}$ & 1.4 & 100 & $\begin{array}{r}\text { De Avillez Pereira et al. [1997], Jasper et al. } \\
{[2007], \text { Sangwan et al. }[2012]}\end{array}$ \\
\hline $\mathrm{OH}+\mathrm{CH}_{3}$ & $\rightarrow \mathrm{H}_{2} \mathrm{CO}+\mathrm{H}_{2}$ & $8.0 \times 10^{-12}$ & 2 & 100 & $\begin{array}{r}\text { De Avillez Pereira et al. [1997], Jasper et al. } \\
{[2007], \text { Sangwan et al. }[2012]}\end{array}$ \\
\hline $\mathrm{OH}+\mathrm{CH}_{3}$ & $\rightarrow \mathrm{CH}_{3} \mathrm{OH}$ & $\begin{array}{l}k_{0}=2.0 \times 10^{-26} \times(T / 300)^{-6} \times \exp (-1000 / T) \\
k_{\infty}=1.2 \times 10^{-10} \times(T / 300)-0.49 \\
k_{r}=0\end{array}$ & $\begin{array}{r}2 \\
1.2 \\
30\end{array}$ & $\begin{array}{r}100 \\
100 \\
0\end{array}$ & $\begin{array}{r}\text { De Avillez Pereira et al. [1997], Jasper et al. } \\
{[2007 \mathrm{~b}], \text { Sangwan et al. [2012] }}\end{array}$ \\
\hline $\mathrm{OH}+\mathrm{CH}_{4}$ & $\rightarrow \mathrm{H}_{2} \mathrm{O}+\mathrm{CH}_{3}$ & $1.85 \times 10^{-12} \times \exp (-1690 / T)$ & 1.2 & 100 & Atkinson et al. [2006] \\
\hline $\mathrm{OH}+\mathrm{C}_{2} \mathrm{H}_{2}$ & $\rightarrow \mathrm{C}_{2} \mathrm{H}_{2} \mathrm{OH}$ & $\begin{array}{l}k_{0}=5.5 \times 10^{-30} \\
k_{\infty}=8.3 \times 10^{-13} \times(T / 300)^{2} \\
k_{r}=0\end{array}$ & $\begin{array}{r}1.6 \\
1.2 \\
30\end{array}$ & $\begin{array}{r}100 \\
50 \\
0\end{array}$ & Sander et al. [2011] \\
\hline $\mathrm{OH}+\mathrm{C}_{2} \mathrm{H}_{4}$ & $\rightarrow \mathrm{C}_{2} \mathrm{H}_{4} \mathrm{OH}$ & $\begin{array}{l}k_{0}=1.0 \times 10^{-28} \times(T / 300)^{-4.5} \\
k_{\infty}=7.5 \times 10^{-12} \times(T / 300)^{-0.85} \\
k_{r}=0\end{array}$ & $\begin{array}{r}2 \\
1.2 \\
30\end{array}$ & $\begin{array}{r}100 \\
50 \\
0\end{array}$ & Sander et al. [2011] \\
\hline $\mathrm{OH}+\mathrm{N}\left({ }^{4} \mathrm{~S}\right)$ & $\rightarrow \mathrm{NO}+\mathrm{H}$ & $4.5 \times 10^{-11}$ & 1.3 & 0 & Daranlot et al. [2011] \\
\hline $\mathrm{OH}+\mathrm{N}\left({ }^{2} \mathrm{D}\right)$ & $\rightarrow \mathrm{NO}+\mathrm{H}$ & $4.5 \times 10^{-11}$ & 2 & 0 & Daranlot et al. [2011] \\
\hline $\mathrm{OH}+\mathrm{CO}$ & $\rightarrow \mathrm{CO}_{2}+\mathrm{H}$ & $1.3 \times 10^{-13}$ & 1.4 & 0 & Atkinson et al. [2006] \\
\hline $\mathrm{OH}+\mathrm{CO}$ & $\rightarrow \mathrm{CO}_{2}+\mathrm{H}$ & $\begin{array}{l}k_{0}=3.23 \times 10^{-33} \times(T / 300)^{1} \\
k_{\infty}=1.0 \times 10^{+90} \\
k_{r}=0\end{array}$ & $\begin{array}{r}1.4 \\
1 \\
30\end{array}$ & $\begin{array}{r}21 \\
0 \\
0\end{array}$ & Atkinson et al. [2006] \\
\hline $\mathrm{H}_{2} \mathrm{O}+\mathrm{CH}$ & $\rightarrow \mathrm{H}_{2} \mathrm{CO}+\mathrm{H}$ & $2.8 \times 10^{-11} \times(T / 300)^{-1.22} \times \exp (-12 / T)$ & 1.2 & 21 & Blitz et al. [1999], Bergeat et al. [2009] \\
\hline $\mathrm{H}_{2} \mathrm{O}+\mathrm{C}_{2} \mathrm{H}$ & $\rightarrow \mathrm{OH}+\mathrm{C}_{2} \mathrm{H}_{2}$ & $7.9 \times 10^{-14} \times(T / 300)^{3.05} \times \exp (-376 / T)$ & 1.2 & 100 & Carl et al. [2005] \\
\hline $\mathrm{H}_{2}^{2} \mathrm{O}+\mathrm{N}\left({ }^{2} \mathrm{D}\right)$ & $\rightarrow \mathrm{OH}+\mathrm{NH}$ & $4.5 \times 10^{-11}$ & 2 & 100 & $\begin{array}{r}\text { Umemoto et al. [1998], Herron [1999], } \\
\text { Kurosaki and Takayanagi [1999], Umemoto et } \\
\text { al. [1999], Casavecchia et al. [2001] }\end{array}$ \\
\hline $\mathrm{H}_{2} \mathrm{O}+\mathrm{N}\left({ }^{2} \mathrm{D}\right)$ & $\rightarrow \mathrm{HNO}+\mathrm{H}$ & $5.0 \times 10^{-12}$ & 2 & 100 & \\
\hline $\mathrm{CO}+\mathrm{H}$ & $\rightarrow \mathrm{HCO}$ & $\begin{array}{l}k_{0}=7.5 \times 10^{-35} \times(T / 300)^{0.2} \\
k_{\infty}=1.0 \times 10^{-10} \times \exp (-1000 / T) \\
k_{r}=0\end{array}$ & $\begin{array}{r}1.6 \\
3 \\
30\end{array}$ & $\begin{array}{r}100 \\
300 \\
0\end{array}$ & $\begin{array}{l}k_{0} \text { from Baulch et al. [2005], } k_{\infty} \text { from Wagner } \\
\text { and Bowman [1987], Wang et al. [1973] }\end{array}$ \\
\hline $\mathrm{HCO}+\mathrm{H}$ & $\rightarrow \mathrm{CO}+\mathrm{H}_{2}$ & $1.5 \times 10^{-10}$ & 1.4 & 0 & Baulch et al. [2005] \\
\hline $\mathrm{HCO}+\mathrm{CH}_{3}$ & $\rightarrow \mathrm{CO}+\mathrm{CH}_{4}$ & $9.3 \times 10^{-11}$ & 1.4 & 0 & Krasnoperov et al. [2005] \\
\hline $\mathrm{HCO}+\mathrm{CH}_{3}$ & $\rightarrow \mathrm{CH}_{3} \mathrm{CHO}$ & $\begin{array}{l}k_{0}=7.0 \times 10^{-26} \times(T / 300)^{-3.5} \\
k_{\infty}=3.01 \times 10^{-11} \\
k_{r}=0\end{array}$ & $\begin{array}{r}10 \\
2 \\
30\end{array}$ & $\begin{array}{r}100 \\
100 \\
0\end{array}$ & $\begin{array}{l}k_{0} \text { from our semi empirical model Hébrard et } \\
\text { al. [2013], } k_{\infty} \text { from Tsang and Herron [1991] }\end{array}$ \\
\hline $\mathrm{HCO}+\mathrm{N}\left({ }^{4} \mathrm{~S}\right)$ & $\rightarrow \mathrm{CO}+\mathrm{NH}$ & $1.0 \times 10^{-10}$ & 3 & 0 & $\begin{array}{r}\text { Catpure rate constant considering no barrier in } \\
\text { the entrance valley }\end{array}$ \\
\hline $\mathrm{H}_{2} \mathrm{CO}+\mathrm{H}$ & $\rightarrow \mathrm{HCO}+\mathrm{H}_{2}$ & $3.3 \times 10^{-11} \times \exp (-1850 / T)$ & 1.4 & 200 & Klemm [1979] \\
\hline $\mathrm{H}_{2} \mathrm{CO}+\mathrm{C}$ & $\rightarrow \mathrm{CO}+{ }^{3} \mathrm{CH}_{2}$ & $4.0 \times 10^{-10}$ & 1.8 & 0 & Husain and Ioannou [1999] \\
\hline $\mathrm{H}_{2} \mathrm{CO}+\mathrm{CH}$ & $\rightarrow \mathrm{CO}+\mathrm{CH}_{3}$ & $5.0 \times 10^{-11} \times \exp (-260 / T)$ & 2 & 0 & Zabarnick et al. [1988] \\
\hline $\mathrm{H}_{2} \mathrm{CO}+\mathrm{CH}$ & $\rightarrow \mathrm{CH}_{2} \mathrm{CO}+\mathrm{H}$ & $1.0 \times 10^{-10} \times \exp (-260 / T)$ & 2 & 0 & Zabarnick et al. [1988] \\
\hline $\mathrm{H}_{2} \mathrm{CO}+\mathrm{N}\left({ }^{2} \mathrm{D}\right)$ & $\rightarrow \mathrm{HNCO}+\mathrm{H}$ & $4.0 \times 10^{-11}$ & 4 & 0 & $\begin{array}{l}\text { Umemoto et al. [1998], Herron [1999], Kurosaki } \\
\text { and Takayanagi [1999], Umemoto et al. [1999], } \\
\text { Casavecchia et al. [2001], Homayoon [2014] }\end{array}$ \\
\hline $\mathrm{H}_{2} \mathrm{CO}+\mathrm{CN}$ & $\rightarrow \mathrm{HCO}+\mathrm{HCN}$ & $6.7 \times 10^{-11} \times \exp (-412 / T)$ & 1.6 & 20 & Yu et al. [1993], Chang and Wang [1995] \\
\hline $\mathrm{CH}_{3} \mathrm{O}+\mathrm{H}$ & $\rightarrow \mathrm{H}_{2} \mathrm{CO}+\mathrm{H}_{2}$ & $3.0 \times 10^{-11}$ & 1.6 & 100 & $\begin{array}{r}\text { Hoyermann et al. [1981], Dobe et al. [1991], } \\
\text { Jasper et al [2007] }\end{array}$ \\
\hline $\mathrm{CH}_{3} \mathrm{O}+\mathrm{H}$ & $\rightarrow \mathrm{OH}+\mathrm{CH}_{3}$ & $3.0 \times 10^{-12}$ & 1.6 & 100 & $\begin{array}{r}\text { Hoyermann et al. [1981], Dobe et al. [1991], } \\
\text { Jasper et al [2007] }\end{array}$ \\
\hline $\mathrm{CH}_{3} \mathrm{O}+\mathrm{CH}_{3}$ & $\rightarrow \mathrm{H}_{2} \mathrm{CO}+\mathrm{CH}_{4}$ & $4.0 \times 10^{-11}$ & 1.6 & 0 & Tsang and Hampson [1986] \\
\hline $\mathrm{CH}_{3} \mathrm{O}+\mathrm{N}\left({ }^{4} \mathrm{~S}\right)$ & $\rightarrow \mathrm{NO}+\mathrm{CH}_{3}$ & $6.0 \times 10^{-11}$ & 3 & 100 & By comparison with $\mathrm{N}+\mathrm{OH}$ \\
\hline $\mathrm{CH}_{3} \mathrm{OH}+\mathrm{H}$ & $\rightarrow \mathrm{CH}_{3} \mathrm{O}+\mathrm{H}_{2}$ & $2.16 \times 10^{-11} \times \exp (-2650 / T)$ & 2 & 100 & Hoyermann et al. [1981] \\
\hline $\mathrm{CH}_{3} \mathrm{OH}+\mathrm{CH}$ & $\rightarrow \mathrm{H}_{2} \mathrm{CO}+\mathrm{CH}_{3}$ & $1.3 \times 10^{-10}$ & 1.8 & 100 & Johnson et al. [2000] \\
\hline $\mathrm{CH}_{3} \mathrm{OH}+\mathrm{CH}$ & $\rightarrow \mathrm{OH}+\mathrm{C}_{2} \mathrm{H}_{4}$ & $1.3 \times 10^{-10}$ & 1.8 & 100 & Johnson et al. [2000] \\
\hline $\mathrm{CH}_{3} \mathrm{OH}+\mathrm{C}_{2} \mathrm{H}$ & $\rightarrow \mathrm{CH}_{3} \mathrm{O}+\mathrm{C}_{2} \mathrm{H}_{2}$ & $5.0 \times 10^{-12}$ & 3 & 100 & $\begin{array}{l}\text { Tsang 1987, Carl et al. [2005], Murphy et al. } \\
\text { [2003] }\end{array}$ \\
\hline $\mathrm{CH}_{3} \mathrm{OH}+\mathrm{N}\left({ }^{2} \mathrm{D}\right)$ & $\rightarrow \mathrm{OH}+\mathrm{CH}_{2} \mathrm{NH}$ & $1.0 \times 10^{-11}$ & 4 & 0 & $\begin{array}{r}\text { By comparison with } \mathrm{N}\left({ }^{2} \mathrm{D}\right)+\mathrm{C}_{2} \mathrm{H}_{6} \text { and } \\
\mathrm{N}\left({ }^{2} \mathrm{D}\right)+\mathrm{H}_{2} \mathrm{O}\end{array}$ \\
\hline
\end{tabular}




\begin{tabular}{|c|c|c|c|c|c|}
\hline Reactions & & Rate coefficients & $F(300 K)$ & $g$ & References \\
\hline $\mathrm{CH}_{3} \mathrm{OH}+\mathrm{N}\left({ }^{2} \mathrm{D}\right)$ & $\rightarrow \mathrm{HNO}+\mathrm{CH}_{3}$ & $1.0 \times 10^{-11}$ & 4 & 0 & $\begin{array}{r}\text { By comparison with } \mathrm{N}\left({ }^{2} \mathrm{D}\right)+\mathrm{C}_{2} \mathrm{H}_{6} \text { and } \\
\mathrm{N}\left({ }^{2} \mathrm{D}\right)+\mathrm{H}_{2} \mathrm{O}\end{array}$ \\
\hline $\mathrm{CH}_{3} \mathrm{OH}+\mathrm{CN}$ & $\rightarrow \mathrm{CH}_{3} \mathrm{O}+\mathrm{HCN}$ & $1.2 \times 10^{-10}$ & 1.4 & 100 & Sayah et al. [1988] \\
\hline $\mathrm{CH}_{3} \mathrm{CO}+\mathrm{H}$ & $\rightarrow \mathrm{HCO}+\mathrm{CH}_{3}$ & $4.0 \times 10^{-11}$ & 2 & 100 & Bartels et al. [1991], Ohmori et al. [1990] \\
\hline $\mathrm{CH}_{3} \mathrm{CO}+\mathrm{H}$ & $\rightarrow \mathrm{CH}_{2} \mathrm{CO}+\stackrel{\mathrm{H}}{\mathrm{H}}_{2}$ & $2.0 \times 10^{-11}$ & 2 & 100 & Bartels et al. [1991], Ohmori et al. [1990] \\
\hline $\mathrm{HCCO}+\mathrm{H}$ & $\rightarrow{ }^{3} \mathrm{CH}_{2}+\mathrm{CO}$ & $1.7 \times 10^{-10}$ & 1.6 & 0 & Glass et al. [2000], Baulch et al. [2005] \\
\hline $\mathrm{HCCO}+\mathrm{CH}_{3}$ & $\rightarrow \mathrm{C}_{2} \mathrm{H}_{4}^{2}+\mathrm{CO}$ & $1.0 \times 10^{-10}$ & 3 & 0 & By comparison with $\mathrm{H}+\mathrm{HCCO}$ \\
\hline $\mathrm{HCCO}+\mathrm{N}\left({ }^{4} \mathrm{~S}\right)$ & $\rightarrow \mathrm{HCN}+\mathrm{CO}$ & $1.0 \times 10^{-10}$ & 3 & 0 & By comparison with $\mathrm{N}+{ }^{3} \mathrm{CH}_{2}$ \\
\hline $\mathrm{CH}_{3} \mathrm{CHO}+\mathrm{H}$ & $\rightarrow \mathrm{CH}_{3} \mathrm{CO}+\mathrm{H}_{2}$ & $2.23 \times 10^{-11} \times \exp (-1660 / T)$ & 1.4 & 200 & Baulch et al. [2005] \\
\hline $\mathrm{CH}_{3} \mathrm{CHO}+\mathrm{C}$ & $\rightarrow \mathrm{C}_{2} \mathrm{H}_{2}+\mathrm{H}_{2}+\mathrm{CO}$ & $3.0 \times 10^{-10}$ & 1.8 & 0 & $\begin{array}{r}\text { Husain and Ioannou [1999]. Various products } \\
\text { possible. }\end{array}$ \\
\hline $\mathrm{CH}_{3} \mathrm{CHO}+\mathrm{CH}$ & $\rightarrow \mathrm{C}_{2} \mathrm{H}_{2}+\mathrm{H}_{2}+\mathrm{CO}+\mathrm{H}$ & $2.0 \times 10^{-10}$ & 3 & 0 & $\begin{array}{l}\text { Capture rate constant considering no barrier. } \\
\mathrm{CH}_{2} \mathrm{CHCHO} \text { likely to be produced but giving } \\
\text { finally } \mathrm{CO} .\end{array}$ \\
\hline $\mathrm{CH}_{3} \mathrm{CHO}+\mathrm{N}\left({ }^{2} \mathrm{D}\right)$ & $\rightarrow \mathrm{HNCO}+\mathrm{CH}_{3}$ & $4.0 \times 10^{-11}$ & 4 & 0 & By comparison with $\mathrm{N}\left({ }^{2} \mathrm{D}\right)+\mathrm{C}_{2} \mathrm{H}_{4}$ \\
\hline $\mathrm{C}_{2} \mathrm{H}_{2} \mathrm{OH}+\mathrm{H}$ & $\rightarrow \mathrm{HCO}+\mathrm{CH}_{3}$ & $6.0 \times 10^{-11}$ & 3 & 100 & $\begin{array}{r}\text { Nguyen et al. [2005], Horowitz and Calvert } \\
{[1982], \text { Bartels et al. [1982] }}\end{array}$ \\
\hline $\mathrm{C}_{2} \mathrm{H}_{2} \mathrm{OH}+\mathrm{H}$ & $\rightarrow \mathrm{CH}_{3} \mathrm{CO}+\mathrm{H}$ & $1.0 \times 10^{-11}$ & 3 & 100 & $\begin{array}{r}\text { Nguyen et al. [2005], Horowitz and Calvert } \\
{[1982], \text { Bartels et al. [1982] }}\end{array}$ \\
\hline $\mathrm{C}_{2} \mathrm{H}_{2} \mathrm{OH}+\mathrm{H}$ & $\rightarrow \mathrm{CO}+\mathrm{CH}_{4}$ & $1.0 \times 10^{-11}$ & 3 & 100 & $\begin{array}{r}\text { Nguyen et al. [2005], Horowitz and Calvert } \\
{[1982], \text { Bartels et al. [1982] }}\end{array}$ \\
\hline $\mathrm{C}_{2} \mathrm{H}_{4} \mathrm{OH}+\mathrm{H}$ & $\rightarrow \mathrm{H}_{2} \mathrm{O}+\mathrm{C}_{2} \mathrm{H}_{4}$ & $2.0 \times 10^{-11}$ & 3 & 100 & Bartels et al. [1982], Park et al. [2002] \\
\hline $\mathrm{C}_{2} \mathrm{H}_{4} \mathrm{OH}+\mathrm{H}$ & $\rightarrow \mathrm{CH}_{3} \mathrm{O}+\mathrm{CH}_{3}$ & $5.0 \times 10^{-11}$ & 3 & 100 & Bartels et al. [1982], Park et al. [2002] \\
\hline $\mathrm{C}_{2} \mathrm{H}_{4} \mathrm{OH}+\mathrm{H}$ & $\rightarrow \mathrm{OH}+\mathrm{C}_{2} \mathrm{H}_{5}$ & $1.0 \times 10^{-11}$ & 3 & 100 & Bartels et al. [1982], Park et al. [2002] \\
\hline $\mathrm{CO}_{2}+\mathrm{CH}$ & $\rightarrow \mathrm{CO}+\mathrm{CO}+\mathrm{H}$ & $5.71 \times 10^{-12} \times \exp (-345 / T)$ & 1.4 & 50 & Berman et al. [1982] \\
\hline $\mathrm{CO}_{2}+\mathrm{N}\left({ }^{2} \mathrm{D}\right)$ & $\rightarrow \mathrm{CO}+\mathrm{NO}$ & $1.0 \times 10^{-11} \times \exp (-1000 / T)$ & 1.6 & 300 & Herron [1999] \\
\hline \multirow[t]{2}{*}{$\mathrm{NO}+\mathrm{H}$} & $\rightarrow \mathrm{HNO}$ & $\begin{array}{l}k_{0}=1.34 \times 10^{-31} \times(T / 300)^{-1.32} \times \\
\exp (-370 / T)\end{array}$ & 2 & 0 & Tsang and Herron [1991] \\
\hline & & $\begin{array}{l}k_{\infty}=2.44 \times 10^{-10} \times(T / 300)^{-0.41} \\
k_{r}=0\end{array}$ & $\begin{array}{r}1.6 \\
30\end{array}$ & $\begin{array}{l}0 \\
0\end{array}$ & \\
\hline $\mathrm{NO}+\mathrm{C}$ & $\rightarrow \mathrm{CN}+\mathrm{O}\left({ }^{3} \mathrm{P}\right)$ & $7.0 \times 10^{-11} \times(T / 300)^{-0.16}$ & 1.4 & 0 & $\begin{array}{r}\text { Geppert et al. [2000], Bergeat et al. [1999], } \\
\text { Andersson et al. [2003] }\end{array}$ \\
\hline $\mathrm{NO}+\mathrm{C}$ & $\rightarrow \mathrm{CO}+\mathrm{N}\left({ }^{4} \mathrm{~S}\right)$ & $8.0 \times 10^{-11} \times(T / 300)^{-0.16}$ & 1.4 & 0 & $\begin{array}{r}\text { Geppert et al. [2000], Bergeat et al. [1999], } \\
\text { Andersson et al. [2003] }\end{array}$ \\
\hline $\mathrm{NO}+\mathrm{CH}$ & $\rightarrow \mathrm{HCN}+\mathrm{O}\left({ }^{3} \mathrm{P}\right)$ & $1.0 \times 10^{-10} \times(T / 300)^{-0.13}$ & 2 & 7 & $\begin{array}{r}\text { Bocherel et al. [1996], Bergeat et al. [1998], } \\
\text { Marchand et al. [1997] }\end{array}$ \\
\hline $\mathrm{NO}+\mathrm{CH}$ & $\rightarrow \mathrm{NCO}+\mathrm{H}$ & $3.0 \times 10^{-11} \times(T / 300)^{-0.13}$ & 2 & 7 & $\begin{array}{r}\text { Bocherel et al. [1996], Bergeat et al. [1998], } \\
\text { Marchand et al. [1997] }\end{array}$ \\
\hline $\mathrm{NO}+\mathrm{CH}$ & $\rightarrow \mathrm{CO}+\mathrm{NH}$ & $3.0 \times 10^{-11} \times(T / 300)^{-0.13}$ & 2 & 7 & $\begin{array}{r}\text { Bocherel et al. [1996], Bergeat et al. [1998], } \\
\text { Marchand et al. [1997] }\end{array}$ \\
\hline $\mathrm{NO}+\mathrm{CH}$ & $\rightarrow \mathrm{OH}+\mathrm{CN}$ & $1.0 \times 10^{-11} \times(T / 300)^{-0.13}$ & 2 & 7 & $\begin{array}{r}\text { Bocherel et al. [1996], Bergeat et al. [1998], } \\
\text { Marchand et al. [1997] }\end{array}$ \\
\hline $\mathrm{NO}+{ }^{3} \mathrm{CH}_{2}$ & $\rightarrow \mathrm{HNCO}+\mathrm{H}$ & $2.1 \times 10^{-12} \times \exp (554 / T)$ & 1.2 & 0 & $\begin{array}{r}\text { Vinckier and Debruyn [1979], Seidler et al. } \\
{[1989], \text { Darwin et al. [1989] + Fikri et al. }} \\
{[2001], \text { Zhang et al. }[2004 \text { a }]}\end{array}$ \\
\hline $\mathrm{NO}+{ }^{3} \mathrm{CH}_{2}$ & $\rightarrow \mathrm{CO}+\mathrm{NH}_{2}$ & $3.0 \times 10^{-13} \times \exp (554 / T)$ & 2 & 0 & $\begin{array}{r}\text { Vinckier and Debruyn [1979], Seidler et al. } \\
\text { [1989], Darwin et al. [1989] + Fikri et al. } \\
{[2001], \text { Zhang et al. [2004a] }}\end{array}$ \\
\hline \multirow[t]{2}{*}{$\mathrm{NO}+\mathrm{CH}_{3}$} & $\rightarrow \mathrm{CH}_{3} \mathrm{NO}$ & $k_{0}=1.1 \times 10^{-29} \times(T / 300)^{-3.5}$ & 2 & 0 & Kaiser [1993], Jodkowski et al. [1993], Baulch \\
\hline & & $\begin{array}{l}k_{\infty}=1.1 \times 10^{-11} \times(T / 300)^{0.6} \\
k_{r}=0\end{array}$ & $\begin{array}{r}1.6 \\
30\end{array}$ & $\begin{array}{l}0 \\
0\end{array}$ & et al. [2005] \\
\hline $\mathrm{NO}+\mathrm{N}\left({ }^{4} \mathrm{~S}\right)$ & $\rightarrow \mathrm{O}\left({ }^{3} \mathrm{P}\right)+\mathrm{N}_{2}$ & $4.0 \times 10^{-11}$ & 1.3 & 0 & Bergeat et al. [2009a] \\
\hline $\mathrm{NO}+\mathrm{N}\left({ }^{2} \mathrm{D}\right)$ & $\rightarrow \mathrm{O}\left({ }^{3} \mathrm{P}\right)+\mathrm{N}_{2}$ & $6.0 \times 10^{-11}$ & 1.6 & 100 & Herron [1999] \\
\hline $\mathrm{NO}+\mathrm{NH}$ & $\rightarrow \mathrm{N}_{2} \mathrm{O}+\mathrm{H}$ & $2.9 \times 10^{-11} \times(T / 300)^{-0.3} \times \exp (77 / T)$ & 1.6 & 0 & $\begin{array}{r}\text { Mullen and Smith [2005], Baulch et al. [2005], } \\
\text { Okada et al. [1994], Durant [1994] }\end{array}$ \\
\hline $\mathrm{NO}+\mathrm{NH}$ & $\rightarrow \mathrm{OH}+\mathrm{N}_{2}$ & $1.2 \times 10^{-11} \times(T / 300)^{-0.3} \times \exp (77 / T)$ & 1.6 & 0 & $\begin{array}{r}\text { Mullen and Smith [2005], Baulch et al. [2005], } \\
\text { Okada et al. [1994], Durant [1994] }\end{array}$ \\
\hline $\mathrm{HNO}+\mathrm{H}$ & $\rightarrow \mathrm{NO}+\mathrm{H}_{2}$ & $3.1 \times 10^{-11} \times \exp (-500 / T)$ & 2 & 200 & Tsang and Herron [1991], Nguyen et al. [2004] \\
\hline $\mathrm{HNO}+\mathrm{C}$ & $\rightarrow \mathrm{NO}+\mathrm{CH}$ & $3.8 \times 10^{-11}$ & 3 & 0 & By comparison with $\mathrm{O}+\mathrm{HNO}$ \\
\hline $\mathrm{HNO}+\mathrm{C}$ & $\rightarrow \mathrm{NCO}+\mathrm{H}$ & $3.0 \times 10^{-11}$ & 3 & 0 & \\
\hline $\mathrm{HNO}+\mathrm{C}$ & $\rightarrow \mathrm{HNC}+\mathrm{O}\left({ }^{3} \mathrm{P}\right)$ & $3.0 \times 10^{-11}$ & 3 & 0 & \\
\hline $\mathrm{HNO}+\mathrm{C}$ & $\rightarrow \mathrm{CO}+\mathrm{NH}$ & $3.0 \times 10^{-11}$ & 3 & 0 & \\
\hline $\mathrm{HNO}+\mathrm{CH}$ & $\rightarrow \mathrm{NO}+{ }^{3} \mathrm{CH}_{2}$ & $3.8 \times 10^{-11}$ & 3 & 100 & Capture rate constant considering no barrier \\
\hline $\mathrm{HNO}+\mathrm{CH}$ & $\rightarrow \mathrm{HNCO}+\mathrm{H}^{2}$ & $1.0 \times 10^{-10}$ & 3 & 100 & Capture rate constant considering no barrier \\
\hline $\mathrm{HNO}+\mathrm{N}\left({ }^{2} \mathrm{D}\right)$ & $\rightarrow \mathrm{NO}+\mathrm{NH}$ & $5.0 \times 10^{-11}$ & 2 & 100 & By comparison with $\mathrm{N}\left({ }^{2} \mathrm{D}\right)+\mathrm{H}_{2} \mathrm{O}, \mathrm{NH}_{3}$ \\
\hline $\mathrm{NCO}+\mathrm{H}$ & $\rightarrow \mathrm{CO}+\mathrm{NH}$ & $3.0 \times 10^{-11}$ & 2 & 100 & 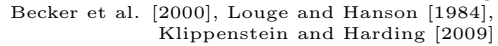 \\
\hline $\mathrm{NCO}+\mathrm{N}\left({ }^{4} \mathrm{~S}\right)$ & $\rightarrow \mathrm{CO}+\mathrm{N}_{2}$ & $5.5 \times 10^{-11}$ & 2 & 100 & Brownsword [1997] \\
\hline $\mathrm{HNCO}+\mathrm{C}$ & $\rightarrow \mathrm{HCN}+\mathrm{CO}$ & $1.0 \times 10^{-10}$ & 3 & 100 & $\begin{array}{r}\text { By comparison with } \mathrm{C}+\text { alkynes and } \mathrm{C}+ \\
\text { alkenes }\end{array}$ \\
\hline $\mathrm{HNCO}+\mathrm{C}$ & $\rightarrow \mathrm{HNC}+\mathrm{CO}$ & $1.0 \times 10^{-10}$ & 3 & 100 & $\begin{array}{r}\text { By comparison with } \mathrm{C}+\text { alkynes and } \mathrm{C}+ \\
\text { alkenes }\end{array}$ \\
\hline $\mathrm{HNCO}+\mathrm{CH}$ & $\rightarrow \mathrm{CO}+\mathrm{H}_{2} \mathrm{CN}$ & $1.0 \times 10^{-10}$ & 3 & 100 & $\begin{array}{r}\text { By comparison with } \mathrm{CH}+\text { alkynes and } \mathrm{CH}+ \\
\text { alkenes }\end{array}$ \\
\hline
\end{tabular}




\begin{tabular}{|c|c|c|c|c|c|}
\hline Reactions & & Rate coefficients & $F(300 K)$ & $g$ & References \\
\hline $\mathrm{HNCO}+\mathrm{CH}$ & $\rightarrow \mathrm{CO}+\mathrm{HCN}+\mathrm{H}$ & $1.0 \times 10^{-10}$ & 3 & 100 & By comparison with $\mathrm{CH}+$ alkynes and $\mathrm{CH}+$ \\
\hline $\mathrm{HNCO}+\mathrm{N}\left({ }^{2} \mathrm{D}\right)$ & $\rightarrow \mathrm{CO}+\mathrm{N}_{2}+\mathrm{H}$ & $5.0 \times 10^{-11}$ & 3 & 100 & By comparison with $\mathrm{N}\left({ }^{2} \mathrm{D}\right)+\mathrm{NH}_{3}$ \\
\hline $\mathrm{HNCO}+\mathrm{CN}$ & $\rightarrow \mathrm{NCO}+\mathrm{HCN}$ & $3.0 \times 10^{-11}$ & 3 & 100 & By comparison with $\mathrm{CN}+\mathrm{C}_{2} \mathrm{H}_{6}$ and ${ }_{\mathrm{NH}_{3}}^{\mathrm{CN}}+$ \\
\hline $\mathrm{CH}_{3} \mathrm{NO}+\mathrm{H}$ & $\rightarrow \mathrm{HNO}+\mathrm{CH}_{3}$ & $1.39 \times 10^{-11} \times(T / 300)^{0.84} \times \exp (120 / T)$ & 2 & 100 & Choi and Lin [2005] \\
\hline $\mathrm{N}_{2} \mathrm{O}+\mathrm{C}$ & $\rightarrow \mathrm{CO}+\mathrm{N}_{2}$ & $1.5 \times 10^{-11} \times \exp (-300 / T)$ & 1.4 & 100 & Husain and Young [1975], Dorthe et al. [1991] \\
\hline $\mathrm{N}_{2} \mathrm{O}+\mathrm{C}$ & $\rightarrow \mathrm{NO}+\mathrm{CN}$ & $1.5 \times 10^{-11} \times \exp (-300 / T)$ & 1.4 & 100 & Husain and Young [1975], Dorthe et al. [1991] \\
\hline $\mathrm{N}_{2}^{2} \mathrm{O}+\mathrm{CH}$ & $\rightarrow \mathrm{CO}+\mathrm{N}_{2}+\mathrm{H}$ & $1.5 \times 10^{-11} \times \exp (257 / T)$ & 1.2 & 10 & Becker et al. [1993], Zabarnick et al. [1989b] \\
\hline $\mathrm{N}_{2} \mathrm{O}+\mathrm{CH}$ & $\rightarrow \mathrm{NO}+\mathrm{HCN}$ & $1.5 \times 10^{-11} \times \exp (257 / T)$ & 1.2 & 10 & Becker et al. [1993], Zabarnick et al. [1989b] \\
\hline $\mathrm{N}_{2} \mathrm{O}+\mathrm{N}\left({ }^{2} \mathrm{D}\right)$ & $\rightarrow \mathrm{N}_{2}+\mathrm{NO}$ & $1.5 \times 10^{-11} \times \exp (-570 / T)$ & 1.6 & 70 & Herron [1999] \\
\hline
\end{tabular}

\section{References}

Adam, L., Hack, W., McBane, G. C., Zhu, H., Qu, Z.-W., Schinke, R., 2007. Exploring Renner-Teller induced quenching in the reaction H( $\left.{ }^{2} \mathrm{~S}\right)+\mathrm{NH}\left(\mathrm{a}^{1} \Delta\right)$ : A combined experimental and theoretical study. J. Chem. Phys. 126 (3), 034304.

Adamson, J., DeSain, J., Curl, R., Glass, G., 1997. Reaction of cyanomethylene with nitric oxide and oxygen at $298 \mathrm{~K}:$ HCCN + NO, O 2. J. Phys. Chem. A 101 (5),
$864-870$. Adamson, J. D., Farhat, S. K., Morter, C. L., Glass, G. P., Curl, R. F., Phillips, L. F., 1994. The reaction of NH 2 with O. J. Phys. Chem. 98 (22), 5665-5669.

Adriani, A., Dinelli, B. M., López-Puertas, M., García-Comas, M., Moriconi, M. L., D'Aversa, E., Funke, B., Coradini, A., Aug. 2011. Distribution of HCN in Titan's upper atmosphere from Cassini/VIMS observations at $3 \mu \mathrm{m}$. Icarus $214,584-595$.

Altinay, G., Macdonald, R. G., 2012. Determination of the rate constant for the $\mathrm{NH}_{2}\left(\mathrm{X}^{2} \mathrm{~B}_{1}\right)+\mathrm{NH}_{2}\left(\mathrm{X}^{2} \mathrm{~B}_{1}\right)$ recombination reaction with collision partners He, Ne, Ar, and $\mathrm{N}_{2}$ at low pressures and $296 \mathrm{~K}$. Part 1. J. Phys. Chem. A 116 (5), 1353-1367.

Andersson, S., Markovic, N., Nyman, G., 2003. Computational Studies of the Kinetics of the C + NO and O + CN Reactions. J. Phys. Chem. A 107 (28), 5439-5447.

Anicich, V. G., 2003. An index of the literature for bimolecular gas phase cation-molecule reaction kinetics. JPL Publication 03-19, 1-1194.

Asatryan, R., Bozzelli, J. W., Silva, G. d., Swinnen, S., Nguyen, M. T., 2010. Formation and decomposition of chemically activated and stabilized hydrazine. J. PHys. Chem. A $114(21), 6235-6249$.

Ashfold, M. N. R., Fullstone, M. A., Hancock, G., Ketley, G. W., 1981. Singlet methylene kinetics: Direct measurements of removal rates of $\tilde{a}^{1} \mathrm{~A}_{1}$ and $\tilde{b}^{1} \mathrm{~B}_{1} \mathrm{CH}_{2}$ and $\mathrm{CD}_{2}$. Chem. Phys. 55 (2), 245-257.

Atkinson, R., Baulch, D. L., Cox, R. A., Crowley, J. N., Hampson, R. F., Haynes, R. G., Jenkin, M. E., Rossi, M. J., Troe, J., 2004. Evaluated kinetic and photochemical data for atmospheric chemistry: Volume I - Gas phase reactions of $\mathrm{O}_{\mathrm{x}}, \mathrm{HO}_{\mathrm{x}}, \mathrm{NO}_{\mathrm{x}}$ and $\mathrm{SO}_{\mathrm{x}}$ species. Atmos. Chem. Phys. $4(6), 1461-1738$.

Atkinson, R., Baulch, D. L., Cox, R. A., Hampson, R. F., Kerr, J. A., Rossi, M. J., Troe, J., 2006. Evaluated kinetic and photochemical data for atmospheric chemistry: Volume II - Gaz phase reactions of organic species. Atmos. Chem. Phys. 6 (11), 3625-4055.

Atreya, S., 1986. Atmospheres and ionospheres of the outer planets and their satellites. Springer-Verlag.

Bahng, M.-K., Macdonald, R. G., 2008. Determination of the rate constant for the $\mathrm{NH}_{2}\left(\mathrm{X}^{2} \mathrm{~B}_{1}\right)+\mathrm{NH}_{2}\left(\mathrm{X}^{2} \mathrm{~B}_{1}\right)$ reaction at low pressure and $293 \mathrm{~K}$. J. Phys. Chem. A $112(51), 13432-13443$.

Bahng, M.-K., Macdonald, R. G., 2009. Determination of the rate constants for the radicalradical reactions $\mathrm{NH}_{2}\left(\tilde{X}^{2} \mathrm{~B}_{1}\right)+\mathrm{NH}\left(\tilde{X}^{3} \Sigma\right)$ and $\left.\mathrm{NH}_{2}\left(\tilde{X}^{2} \mathrm{~B}_{1}\right)+\mathrm{H}^{2} \mathrm{~S}\right)$ at 293 K. J. Phys. Chem. A $113(11), 2415-2423$

Balucani, N., Alagia, M., Cartechini, L., Casavecchia, P., Volpi, G. G., Sato, K., Takayanagi, T., Kurosaki, Y., 2000a. Cyanomethylene formation from the reaction of excited nitrogen atoms with acetylene: A crossed beam and ab initio study. J. Am. Chem. Soc. 122 (18), 4443-4450.

Balucani, N., Bergeat, A., Cartechini, L., Volpi, G., Casavecchia, P., Skouteris, D., Rosi, M., 2009. Combined crossed molecular beam and theoretical studies of the $\mathrm{N}\left({ }^{2} \mathrm{D}\right)+\mathrm{CH}_{4}$ reaction and implications for atmospheric models of Titan. J. Chem. Phys. A 113 (42), 11138-11152

Balucani, N., Cartechini, L., Alagia, M., Casavecchia, P., Volpi, G. G., 2000b. Observation of nitrogen-bearing organic molecules from reactions of nitrogen atoms with hydrocarbons: A crossed beam Study of $\left(^{2} \mathrm{D}\right)+$ ethylene. J. Phys. Chem. A $104(24), 5655-5659$.

Balucani, N., Leonori, F., Casavecchia, P., 2012. Crossed molecular beam studies of bimolecular reactions of relevance in combustion. Energy 43 (1), $47-54$.

Balucani, N., Leonori, F., Petrucci, R., Stazi, M., Skouteris, D., Rosi, M., Casavecchia, P., 2010. Formation of nitriles and imines in the atmosphere of Titan: Combined crossed-beam and theoretical studies on the reaction dynamics of excited nitrogen atoms $\mathrm{N}\left({ }^{2} \mathrm{D}\right)$ with ethane. Faraday Discuss. $147,189-216$.

Barger, T., Wodtke, A. M., Bowman, J. M., 2003. Radiative relaxation and isomeric branching of highly excited H/C/N: The importance of delocalized vibrational states. Astrophys. J. 587 (2 I), 841-846.

Bartels, M., Edelbuttel-Einhaus, J., Hoyermann, K., 1991. The detection of $\mathrm{CH}_{3} \mathrm{CO}, \mathrm{C}_{2} \mathrm{H}_{5}$, and $\mathrm{CH}_{3} \mathrm{CHO}$ by rempi/mass spectrometry and the application to the study of the reactions $\mathrm{H}+\mathrm{CH}_{3} \mathrm{CO}$ and $\mathrm{O}+\mathrm{CH}_{3} \mathrm{CO}$. Symp. Int. Combust. Proc. 23 (1), 131-138. 
Bartels, M., Hoyermann, K., Sievert, R., 1982. Elementary reactions in the oxidation of ethylene: The reaction of OH radicals with ethylene and the reaction of $\mathrm{C}_{2} \mathrm{H}_{4} \mathrm{OH}$ radicals with $\mathrm{H}$ atoms. Symp. Int. Combust. Proc. 19, 61-72.

Barth, E. L., Toon, O. B., Mar. 2003. Microphysical modeling of ethane ice clouds in titan's atmosphere. Icarus 162, 94-113.

Basiuk, V. A., Kobayashi, K., 2004. DFT study of $\mathrm{HCN}$ and $\mathrm{N} \equiv \mathrm{C}-\mathrm{C}=\mathrm{N}$ reactions with hydrogen species. Int. J. Quantum Chem. 99 (2), $91-101$.

Baulch, D., Cobos, C., Cox, R., Esser, C., Frank, P., Just, T., Kerr, J., Pilling, M., Troe, J., Walker, R., Warnatz, J., 1992. Evaluated kinetic data for combustion modeling. J. Phys. Chem. Ref. Data 21 (3), 411-734.

Baulch, D. L., Bowman, C. T., Cobos, C. J., Cox, R. A., Just, T., Kerr, J. A., Pilling, M. J., Stocker, D., Troe, J., Tsang, W., Walker, R. W., Warnatz, J., 2005. Evaluated kinetic data for combustion modeling: Supplement II. J. Phys. Chem. Ref. Data 34 (3), 757-1397.

Baulch, D. L., Cobos, C. J., Cox, R. A., Frank, P., Hayman, G., Just, T., Kerr, J. A., Murrells, T., Pilling, M. J., Troe, J., Walker, R. W., Warnatz, J., 1994. Evaluated kinetic data for combustion modelling: Supplement I. J. Phys. Chem. Ref. Data 23, $847-1034$ Becker, K., Kurtenbach, R., Schmidt, F., Wiesen, P., 2000. Kinetics of the NCO radical reacting with atoms and selected molecules. Combust. Flame 120 (4),
$570-577$.

Becker, K. H., Engelhardt, B., Geiger, H., Kurtenbach, R., Weisen, P., 1993. Temperature dependence of the reactions of $\mathrm{CH}$ radicals with $\mathrm{NO}$, $\mathrm{NH}_{3}$ and $\mathrm{N}_{2} \mathrm{O}$ in the range 200-1300 K. Chem. Phys. Lett. $210(1-3)$, 135-140.

Bergeat, A., Calvo, T., Daugey, N., Loison, J.-C., Dorthe, G., 1998. Product branching ratios of the CH + NO reaction. J. Phys. Chem. A 102 (42), 8124-8130.

Bergeat, A., Calvo, T., Dorthe, G., Loison, J.-C., 1999. Fast-flow study of the C + NO and C $+\mathrm{O}_{2}$ reactions. Chem. Phys. Lett. 308 (1), 7-12.

Bergeat, A., Hickson, K. M., Daugey, N., Caubet, P., Costes, M., 2009. A low temperature investigation of the N $\left({ }^{4}\right.$ S $)+$ NO reaction. Phys. Chem. Chem. Phys. $11(37), 8149-8155$

Bergeat, A., Loison, J.-C., 2001. Reaction of carbon atoms, $\left.\mathrm{C}_{2} \mathrm{p}^{23} \mathrm{P}\right)$ with $\mathrm{C}_{2} \mathrm{H}_{2}, \mathrm{C}_{2} \mathrm{H}_{4}$ and $\mathrm{C}_{6} \mathrm{H}_{6}$ : Overall rate constant and relative atomic hydrogen production. Phys. Chem. Chem. Phys. 3 (11), 2038-2042.

Berman, M., Fleming, J., Harvey, A., Lin, M., 1982a. Temperature dependence of CH radical reactions with $\mathrm{O}_{2}$, NO, CO and CO 2 . Symp. Int. Combust. Proc. 19 (1), $73-79$.

Berman, M., Fleming, J., Harvey, A., Lin, M., 1982b. Temperature dependence of the reactions of CH radicals with unsaturated hydrocarbons. Chem. Phys. $73(1-2), 27-33$

Berman, M. R., Tsuchiya, T., Gregusova, A., Perera, S. A., Bartlett, R. J., 2007. HNNC radical and its role in the CH $+\mathrm{N}_{2}$ reaction. J. Phys. Chem A. 111 (29), $6894-6899$

Berteloite, C., Le Picard, S. D., Balucani, N., Canosa, A., Sims, I. R., 2010a. Low temperature rate coefficients for reactions of the butadiynyl radical, C 4 H, with various hydrocarbons. Part I: reactions with alkanes $\left(\mathrm{CH}_{4}, \mathrm{C}_{2} \mathrm{H}_{6}, \mathrm{C}_{3} \mathrm{H}_{8}, \mathrm{C}_{4} \mathrm{H}_{10}\right)$. Phys. Chem. Chem. Phys. 12 (15), $3666-3676$.

Berteloite, C., Le Picard, S. D., Balucani, N., Canosa, A., Sims, I. R., 2010b. Low temperature rate coefficients for reactions of the butadiynyl radical, C 4 H, with various hydrocarbons. Part II: reactions with alkenes (ethylene, propene, 1-butene), dienes (allene, 1,3-butadiene) and alkynes (acetylene, propyne and 1-butyne). Phys. Chem. Chem. Phys. $12(15), 3677-3689$

Berteloite, C., Le Picard, S. D., Birza, P., Gazeau, M.-C., Canosa, A., Bnilan, Y., Sims, I. R., 2008. Low temperature (39298 K) kinetics study of the reactions of the $\mathrm{C}_{4} \mathrm{H}$ radical with various hydrocarbons observed in Titan's atmosphere. Icarus $194(2), 746-757$.

Bettinger, H. F., Schleyer, P. V. R., Schaefer Iii, H. F., Schreiner, P. R., Kaiser, R. I., Lee, Y. T., 2000. Reaction of benzene with a ground state carbon atom, C $\left({ }^{3} P_{j}\right)$. J. Chem. Phys. $113(10), 4250-4264$

Blank, D. A., Suits, A. G., Lee, Y. T., North, S. W., Hall, G. E., 1998. Photodissociation of acrylonitrile at 193 nm: A photofragment translational spectroscopy study using synchrotron radiation for product photoionization. J. Chem. Phys. 108 (14), 5784-5794.

Blitz, M. A., Pesa, M., Pilling, M. J., Seakins, P. W., 1999. Reaction of CH with $\mathrm{H}_{2}$ O: Temperature dependence and isotope effect. J. Phys. Chem. A 103 (29), $5699-5704$.

Blitz, M. A., Seakins, P. W., Smith, I. W. M., 2009. An experimental confirmation of the products of the reaction between CN radicals and NH 3 . Phys. Chem. Chem. Phys. 11 (46), 10824-10826.

Blitz, M. A., Talbi, D., Seakins, P. W., Smith, I. W. M., 2012. Rate constants and branching ratios for the reaction of $\mathrm{CH}_{\text {radicals }}$ with $\mathrm{NH}$ : A combined experimental and theoretical study. J. Phys. Chem. A $116(24), 5877-5885$

Bocherel, P., Herbert, L. B., Rowe, B. R., Sims, I. R., Smith, I. W. M., Travers, D., 1996. Ultralow-temperature kinetics of CH(X $\left.{ }^{2} \Pi\right)$ reactions: Rate coefficients for reactions with $\mathrm{O}_{2}$ and $\mathrm{NO}(\mathrm{T}=13-708 \mathrm{~K})$, and with $\mathrm{NH}_{3}(\mathrm{~T}=23-295 \mathrm{~K})$. J. Phys. Chem $100(8), 3063-3069$.

Böhland, T., Temps, F., Wagner, H. G., 1984. Direct investigation of the reaction $\mathrm{CH}_{2}\left(\mathrm{X}^{2} \mathrm{~B}_{1}\right)+\mathrm{O}\left({ }^{3} \mathrm{P}\right)$ with the LMR. Ber. Bunsenges. Phys. Chem. $88(12)$, $1222-1228$

Böhland, T., Temps, F., Wagner, H. G., 1985. The contributions of intersystem crossing and reaction in the removal of $\mathrm{CH}_{2}\left(\tilde{a}^{1} \mathrm{~A}_{1}\right)$ by hydrocarbons studied with the LMR. Ber. Bunsenges. Phys. Chem. 89 (9), 1013-1018.

Böhland, T., Temps, F., Wagner, H. G., 1987. A direct study of the reactions of methylene $\left(\tilde{X}^{3} B_{1}\right)$ radicals with hydrogen and deuterium atoms. J. Phys. Chem. $91(5), 1205-1209$

Bosco, S., Nava, D., Brobst, W., Stief, L., 1984. Temperature and pressure-dependence of the absolute rate-constant for the reactions of NH 2 radicals with acetylene and ethylene. J. Chem. Phys. 81 (8), 3505-3511. 
Boullart, W., Devriendt, T., Borms, R., Peeters, J., 1996. Identification of the sequence CH( $\left.{ }^{2} \Pi\right)+\mathrm{C}_{2} \mathrm{H}_{2} \rightarrow \mathrm{C}_{3} \mathrm{H}_{2}+\mathrm{H}\left(\right.$ and $\mathrm{C}_{3} \mathrm{H}+\mathrm{H}_{2}$ ) followed by $\mathrm{C}_{3} \mathrm{H}_{2}+\mathrm{O}$ $\rightarrow \mathrm{C}_{2} \mathrm{H}+\mathrm{HCO}$ (or $\mathrm{H}+\mathrm{CO}$ ) as $\mathrm{C}_{2} \mathrm{H}$ source in $\mathrm{C}_{2} \mathrm{H}_{2} / \mathrm{O} / \mathrm{H}$ atomic flames. J. Phys. Chem. 100 (3), 998-1007.

Boullart, W., Peeters, J., 1992. Product distributions of the $\mathrm{C}_{2} \mathrm{H}_{2}+\mathrm{H}$ and $\mathrm{HCCO}$ (ketenyl) $+\mathrm{H}$ reactions. Rate constant of CH( $\left.\tilde{X}^{3} \mathrm{~B}_{1}\right)+\mathrm{H}$. J. Phys. Chem. $96(24), 9810-9816$.

Bouwman, J., Goulay, F., Leone, S. R., Wilson, K. R., 2012. Bimolecular rate constant and product branching ratio measurements for the reaction of $\mathrm{C}_{2} \mathrm{H}$ with ethene and propene at $79 \mathrm{~K}$. J. Phys. Chem. A $116(15), 3907-3917$.

Brouard, M., Macpherson, M. T., Pilling, M. J., 1989. Experimental and RRKM modeling study of the methyl + hydrogen atom and deuterium atom reactions. J. Phys. Chem. $93(10), 4047-4059$.

Brownsword, R., Hancock, G., Heard, D., 1997. Kinetics of the N + NCO reaction at 298 K. J. Chem. Soc. Faraday Trans. 93, $2473-2475$.

Brownsword, R. A., Herbert, L. B., Smith, I. W. M., Stewart, D. W. A., 1996. Pressure and temperature dependence of the rate constants for the association reactions of $\mathrm{CH}$ radicals with $\mathrm{CO}$ and $\mathrm{N}_{2}$ between 202 and $584 \mathrm{~K}$. J. Chem. Soc. Faraday Trans. 92, 1087-1094.

Bullock, G., Cooper, R., 1971. Reactions of cyanogen radicals with hydrocarbons. Trans. Faraday Soc. 67, 3258.

Busfield, W., Lee, R., Merigold, D., 1973. Gas phase equilibrium between acetaldehyde and paraldehyde, thermodynamic values for the trimerisation of acetaldehyde and the polymerisability of paraldehyde. Journal of the Chemical Society, Faraday Transactions 1: Physical Chemistry in Condensed Phases 69, 936-940.

Butler, J., Fleming, J., Goss, L., Lin, M., 1981. Kinetics of CH radical reactions with selected molecules at room temperature. Chem. Phys. 56 (3), $355-365$.

Butterfield, M. T., Yu, T., Lin, M. C., 1993. Kinetics of CN reactions with allene, butadiene, propylene and acrylonitrile. Chem. Phys. 169 (1), $129-134$.

Callear, A. B., Smith, G. B., 1986. Recurring chains following addition of atomic hydrogen to acetylene. J. Phys. Chem. 90 (14), $3229-3237$.

Camilleri, P., Marshall, R., Purnell, J., 1974. Reaction of hydrogen atoms with ethane. J. Chem. Soc. Faraday Trans. $170,1434-1444$.

Canosa, A., Paramo, A., Le Picard, S. D., Sims, I. R., 2007. An experimental study of the reaction kinetics of $\mathrm{C}_{2}\left(\mathrm{X}^{1} \Sigma_{g}^{+}\right)$with hydrocarbons $\left(\mathrm{CH}_{4}\right.$, $\mathrm{C}_{2} \mathrm{H}_{2}$, $\mathrm{C}_{2} \mathrm{H}_{4}$, $\mathrm{C}_{2} \mathrm{H}_{6}$ and $\mathrm{C}_{3} \mathrm{H}_{8}$ ) over the temperature range 24-300 K: Implications for the atmospheres of Titan and the Giant Planets. Icarus 187 (2), $558-568$.

Canosa, A., Sims, I., Travers, D., Smith, I., Rowe, B., 1997. Reactions of the methylidine radical with $\mathrm{CH}_{4}, \mathrm{C}_{2} \mathrm{H}_{2}, \mathrm{C}_{2} \mathrm{H}_{4}, \mathrm{C}_{2} \mathrm{H}_{6}$ and but-1-ene studied between 23 and $295 \mathrm{~K}$ with a CRESU apparatus. Astron. Astrophys. 323 (2), 644-651.

Caridade, P. J. S. B., Rodrigues, S. P. J., Sousa, F., Varandas, A. J. C., 2005. Unimolecular and bimolecular calculations for HN 2 . J. Phys. Chem. A 109 (10), $2356-2363$.

Carl, S. A., Nguyen, H. M. T., Elsamra, R. M. I., Nguyen, M. T., Peeters, J., 2005. Pulsed laser photolysis and quantum chemical-statistical rate study of the reaction of the ethynyl radical with water vapor. J. Chem. Phys. 122 (11), 114307.

Carty, D., Le Page, V., Sims, I. R., Smith, I. W. M., 2001. Low temperature rate coefficients for the reactions of $\mathrm{CN}$ and $\mathrm{C}_{2} \mathrm{H}$ radicals with allene $\left(\mathrm{CH}_{2}=\mathrm{C}=\mathrm{CH}_{2}\right)$ and methyl acetylene $\left(\mathrm{CH}_{3} \mathrm{C} \equiv \mathrm{CH}\right)$. Chem. Phys. Lett. $344(3-4), 310-316$.

Casavecchia, P., Balucani, N., Cartechini, L., Capozza, G., Bergeat, A., Volpi, G. G., 2001. Crossed beam studies of elementary reactions of N and C atoms and CN radicals of importance in combustion. Faraday Discuss. 119, 27-49.

Chang, A. H. H., Mebel, A. M., Yang, X. M., Lin, S. H., Lee, Y. T., 1998a. Ab initio calculations of potential energy surface and rate constants for ethylene photodissociation at 193 and $157 \mathrm{~nm}$. Chem. Phys. Lett. 287 (3-4), 301-306.

Chang, A. H. H., Mebel, A. M., Yang, X. M., Lin, S. H., Lee, Y. T., 1998b. Ab initio/RRKM approach toward the understanding of ethylene photodissociation. J. Chem. Phys. $109(7), 2748-2761$.

Chang, Y.-W., Wang, N. S., 1995. Rates of the reactions $\mathrm{CN}+\mathrm{H}_{2} \mathrm{CO}$ and $\mathrm{NCO}+\mathrm{H}_{2} \mathrm{CO}$ in the temperature range 294-769 K. Chem. Phys. 200 (3), $431-437$.

Chastaing, D., James, P., Sims, I., Smith, I., 1998. Neutral-neutral reactions at the temperatures of interstellar clouds: Rate coefficients for reactions of $\mathrm{C}_{2} \mathrm{H}$ radicals with $\mathrm{O}_{2}, \mathrm{C}_{2} \mathrm{H}_{2}, \mathrm{C}_{2} \mathrm{H}_{4}$ and $\mathrm{C}_{3} \mathrm{H}_{6}$ down to $15 \mathrm{~K}$. Faraday Discuss. 109, 169-181.

Chastaing, D., James, P., Sims, I., Smith, I., 1999. Neutral-neutral reactions at the temperatures of interstellar clouds: Rate coefficients for reactions of atomic carbon, $\left.\mathrm{C}^{3} \mathrm{P}\right)$, with $\mathrm{O}_{2}, \mathrm{C}_{2} \mathrm{H}_{2}, \mathrm{C}_{2} \mathrm{H}_{4}$ and $\mathrm{C}_{3} \mathrm{H}_{6}$ down to $15 \mathrm{~K}$. Phys. Chem. Chem. Phys. 1 (9), 2247-2256.

Chastaing, D., Picard, S. D. L., Sims, I. R., Smith, I. W. M., 2001. Rate coefficients for the reactions of $\left.\mathrm{C}^{3} \mathrm{P}_{J}\right)$ atoms with $\mathrm{C}_{2} \mathrm{H}_{2}, \mathrm{C}_{2} \mathrm{H}_{4}, \mathrm{CH}_{3} \mathrm{CCH}$ and $\mathrm{H}_{2} \mathrm{CCCH}_{2}$ at temperatures down to $15 \mathrm{~K}$. Astron. Astrophys. 365 (2), 241-247.

Cheikh Sid Ely, S., Morales, S. B., Guillemin, J.-C., Klippenstein, S. J., Sims, I. R., 2013. Low temperature rate coefficients for the reaction CN + HC 3 N. J. Phys. Chem. A 117 (46), 12155-12164.

Choi, Y. M., Lin, M. C., 2005. Kinetics and mechanisms for reactions of $\mathrm{HNO}$ with $\mathrm{CH}_{3}$ and $\mathrm{C}_{6} \mathrm{H}_{5}$ studied by quantum-chemical and statistical-theory calculations. Int. J. Chem. Kinet. $37(5), 261-274$.

Clarke, D. W., Ferris, J. P., 1995. Photodissociation of cyanoacetylene: Application to the atmospheric chemistry of Titan. Icarus 115 (1), 119-125.

Cody, R. J., Payne, W. A., Thorn, R. P., Nesbitt, F. L., Iannone, M. A., Tardy, D. C., Stief, L. J., 2002. Rate constant for the recombination reaction CH 3 + CH 3 $\rightarrow \mathrm{C}_{2} \mathrm{H}_{6}$ at $\mathrm{T}=298$ and $202 \mathrm{~K}$. J. Phys. Chem. A $106(25), 6060-6067$.

Cody, R. J., Romani, P. N., Nesbitt, F. L., Iannone, M. A., Tardy, D. C., Stief, L. J., 2003. Rate constant for the reaction $\mathrm{CH}_{3}+\mathrm{CH}_{3} \rightarrow \mathrm{C}_{2} \mathrm{H}_{6}$ at $\mathrm{T}=155 \mathrm{~K}$ and model calculation of the $\mathrm{CH}_{3}$ abundance in the atmospheres of Saturn and Neptune. J. Geophys. Res. - Planet. 108 (E11), 5119. 
Costes, M., Halvick, P., Hickson, K. M., Daugey, N., Naulin, C., 2009. Non-threshold, threshold, and nonadiabatic behavior of the key interstellar C $+\mathrm{C}_{2} \mathrm{H}_{2}$ reaction. Astrophys. J. 703 (2), 1179-1187.

Cottini, V., Nixon, C. A., Jennings, D. E., Anderson, C. M., Gorius, N., Bjoraker, G. L., Coustenis, A., Teanby, N. A., Achterberg, R. K., Bézard, B., de Kok, R., Lellouch, E., Irwin, P. G. J., Flasar, F. M., Bampasidis, G., Aug. 2012. Water vapor in Titan's stratosphere from Cassini CIRS far-infrared spectra. Icarus 220, $855-862$.

Cotton, E. C., Francisco, J. S., Klemperer, W., 2013. Computational study of the linear proton bound ion-molecule complexes of HCNH ${ }^{+}$with HCN and HNC. J. Chem. Phys. $139(1), 014304$

Courtin, R., Swinyard, B. M., Moreno, R., Fulton, T., Lellouch, E., Rengel, M., Hartogh, P., Dec. 2011. First results of Herschel-SPIRE observations of Titan. Astronomy and Astrophysics 536, L2.

Coustenis, A., Bezard, B., May 1995. Titan's atmosphere from Voyager infrared observations. 4: Latitudinal variations of temperature and composition. Icarus 115, $126-140$.

Coustenis, A., Bezard, B., Gautier, D., Marten, A., Samuelson, R., Jan. 1991. Titan's atmosphere from Voyager infrared observations. III - Vertical contributions of hydrocarbons and nitriles near Titan's north pole. Icarus $89,152-167$.

Cremer, D., Kraka, E., Joo, H., Stearns, J. A., Zwier, T. S., 2006. Exploration of the potential energy surface of $\mathrm{C}_{4} \mathrm{H}_{4}$ for rearrangement and decomposition reactions of vinylacetylene: A computational study. Part I. Phys. Chem. Chem. Phys. 8 (45), 5304-5316.

Crespin, A., Lebonnois, S., Vinatier, S., Bézard, B., Coustenis, A., Teanby, N. A., Achterberg, R. K., Rannou, P., Hourdin, F., Oct. 2008. Diagnostics of Titan's stratospheric dynamics using Cassini/CIRS data and the 2-dimensional IPSL circulation model. Icarus 197, $556-571$.

Crider, P. E., Castiglioni, L., Kautzman, K. E., Neumark, D. M., 2009. Photodissociation of the propargyl and propynyl (C $\left.3 \mathrm{D}_{3}\right)$ radicals at 248 and 193 nm. J. Chem. Phys. $130(4), 044310$.

Cui, J., Yelle, R. V., Vuitton, V., Waite, J. H., Kasprzak, W. T., Gell, D. A., Niemann, H. B., Müller-Wodarg, I. C. F., Borggren, N., Fletcher, G. G., Patrick, E. L., Raaen, E., Magee, B. A., Apr. 2009. Analysis of Titan's neutral upper atmosphere from Cassini Ion Neutral Mass Spectrometer measurements. Icarus $200,581-615$

Daranlot, J., Hincelin, U., Bergeat, A., Costes, M., Loison, J.-C., Wakelam, V., Hickson, K., 2012. Elemental nitrogen partitioning in dense interstellar clouds. Proc. Natl. Acad. Sci. U. S. A. 109 (26), 1023310238.

Daranlot, J., Hu, X., Xie, C., Loison, J.-C., Caubet, P., Costes, M., Wakelam, V., Xie, D., Guo, H., Hickson, K. M., 2013. Low temperature rate constants for the $\mathrm{N}\left({ }^{4} \mathrm{~S}\right)+\mathrm{CH}\left(\mathrm{X}^{2} \Pi_{r}\right)$ reaction. Implications for $\mathrm{N}_{2}$ formation cycles in dense interstellar clouds. Phys. Chem. Chem. Phys. 15 (33), $13888-13896$.

Daranlot, J., Jorfi, M., Xie, C., Bergeat, A., Costes, M., Caubet, P., Xie, D., Guo, H., Honvault, P., Hickson, K. M., 2011. Revealing atom-radical reactivity at low temperature through the N + OH reaction. Science $334(6062), 1538-1541$.

Darwin, D. C., Young, A. T., Johnston, H. S., Moore, C. B., 1989. Rate constants for triplet methylene $\left(\tilde{\mathrm{X}}^{3} \mathrm{~B}_{1}\right)$ removal by oxygen, nitric oxide and acetylene from infrared diode laser flash kinetic spectroscopy. J. Phys. Chem. 93 (3), 1074-1078.

Daugey, N., Caubet, P., Bergeat, A., Costes, M., Hickson, K. M., 2008. Reaction kinetics to low temperatures. Dicarbon + acetylene, methylacetylene, allene and propene from $77 \leq \mathrm{T} \leq 296 \mathrm{~K}$. Phys. Chem. Chem. Phys. $10(5), 729-737$.

Daugey, N., Caubet, P., Retail, B., Costes, M., Bergeat, A., Dorthe, G., 2005. Kinetic measurements on methylidyne radical reactions with several hydrocarbons at low temperatures. Phys. Chem. Chem. Phys. 7 (15), 2921-2927.

Davis, S. G., Law, C. K., Wang, H., 1999. Propyne pyrolysis in a flow reactor: An experimental, RRKM, and detailed kinetic modeling study. J. Phys. Chem. A $103(30), 5889-5899$.

De Avillez Pereira, R., Baulch, D. L., Pilling, M. J., Robertson, S. H., Zeng, G., 1997. Temperature and pressure dependence of the multichannel rate coefficients for the $\mathrm{CH}_{3}+\mathrm{OH}$ system. J. Phys. Chem. A $101(50), 9681-9693$.

de Kok, R., Irwin, P. G. J., Teanby, N. A., Oct. 2008. Condensation in Titan's stratosphere during polar winter. Icarus 197, 572-578.

de Kok, R., Irwin, P. G. J., Teanby, N. A., Lellouch, E., Bézard, B., Vinatier, S., Nixon, C. A., Fletcher, L., Howett, C., Calcutt, S. B., Bowles, N. E., Flasar, F. M., Taylor, F. W., Feb. 2007. Oxygen compounds in Titan's stratosphere as observed by Cassini CIRS. Icarus 186, $354-363$.

Dean, A. J., Hanson, R. K., 1992. CH and C-atom time histories in dilute hydrocarbon pyrolysis: Measurements and kinetics calculations. Int. J. Chem. Kinet $24(6), 517-532$

Demissy, M., Lesclaux, R., 1980. Kinetics of hydrogen abstraction by $\mathrm{NH}_{2}$ radicals from alkanes in the gas-phase - A flash-photolysis laser resonance-absorption study. J. Am. Chem. Soc. 102 (9), 2897-2902.

Deng, W.-Q., Han, K.-L., Zhan, J.-P., He, G.-Z., 1998. Ab initio and RRKM calculations of o-benzyne pyrolysis. Chem. Phys. Lett. 288 (1), 33-36.

Derecskei-Kovacs, A., North, S. W., 1999. The unimolecular dissociation of vinylcyanide: A theoretical investigation of a complex multichannel reaction. J. Chem. Phys. $110(6), 2862-2871$

Dobe, S., Berces, T., Szilagyi, I., 1991. Kinetics of the reaction between methoxyl radicals and hydrogen atoms. J. Chem. Soc., Faraday Trans. 87, 2331-2336.

Dobrijevic, M., Carrasco, N., Hébrard, E., Pernot, P., Nov. 2008. Epistemic bimodality and kinetic hypersensitivity in photochemical models of Titan's atmosphere. Planetary and Space Science 56, 1630-1643.

Dobrijevic, M., Hébrard, E., Loison, J. C., Hickson, K. M., Jan. 2014. Coupling of oxygen, nitrogen, and hydrocarbon species in the photochemistry of Titan's atmosphere. Icarus $228,324-346$

Dorthe, G., Caubet, P., Vias, T., Barre, B., Marchais, J., 1991. Fast flow studies of atomic carbon kinetics at room temperature. J. Phys. Chem. 95 (13), 5109-5116. 
Dransfeld, P., Hack, W., Kurzke, H., Temps, F., Wagner, H. G., 1985. Direct studies of elementary reactions of $\mathrm{NH}_{2}$-radicals in the gas phase. Symp. Int. Combust. Proc. $20(1), 655-663$.

Dransfeld, P., Wagner, H., 1987. Investigation of the gas phase reaction $\mathrm{N}+\mathrm{NH}_{2} \rightarrow \mathrm{N}_{2}+2 \mathrm{H}$ at room temperature. Z. Phys. Chem. 153 (1-2), 89-97.

Du, B., Zhang, W., 2006. Ab initio MO study of potential energy surface of $\mathrm{NH}_{2}$ with CN reaction. Int. J. Quantum Chem. 106 (8), $1827-1843$.

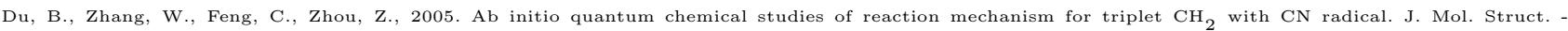
THEOCHEM $713(1-3), 71-78$.

Dunning Jr, T. H., 1989. Gaussian basis sets for use in correlated molecular calculations. I. The atoms boron through neon and hydrogen. J. Chem. Phys. 90 (2), $1007-1023$.

Duran, R. P., Amorebieta, V. T., Colussi, A. J., 1988. Is the homogeneous thermal dimerization of acetylene a free-radical chain reaction? Kinetic and thermochemical analysis. J. Phys. Chem. $92(3), 636-640$.

Durant, J. L., 1994. Product branching fractions in the reaction of NH (ND) $\left({ }^{3} \Sigma_{-}\right)$with nitric oxide. J. Phys. Chem. 98 (2), $518-521$.

Dutuit, O., Carrasco, N., Thissen, R., Vuitton, V., Alcaraz, C., Pernot, P., Balucani, N., Casavecchia, P., Canosa, A., Le Picard, S., Loison, J.-C., Herman, Z., Zabka, J., Ascenzi, D., Tosi, P., Franceschi, P., Price, S. D., Lavvas, P., 2013. Critical review of $\mathrm{N}^{+} \mathrm{N}^{+}, \mathrm{N}_{2}^{+}, \mathrm{N}^{++}$, and $\mathrm{N}_{2}^{++}$main production processes and reactions of relevance to Titan's atmosphere. Astrophys. J. Suppl. Ser. 204 (2), 20.

Eden, S., Limã-Vieira, P., Kendall, P., Mason, N. J., Hoffmann, S. V., Spyrou, S. M., 2003. High resolution photo-absorption studies of acrylonitrile, C ${ }_{2} \mathrm{H}_{3} \mathrm{CN}_{\text {, }}$ and acetonitrile, $\mathrm{CH}_{3} \mathrm{CN}$. Eur. Phys. J. D $26(2), 201-210$

Edvardsson, D., Baltzer, P., Karlsson, L., Wannberg, B., Holland, D. M. P., Shaw, D. A., Rennie, E. E., 1999. A photoabsorption, photodissociation and photoelectron spectroscopy study of $\mathrm{NH}_{3}$ and $\mathrm{ND}_{3}$. J. Phys. B $32(11), 2583$.

Espinosa-Garcia, J., Corchado, J., 1994. Variational transition-state theory calculation using the direct dynamics method $-\mathrm{NH}_{3}+\mathrm{H} \rightarrow \mathrm{NH}_{2}+\mathrm{H}_{2}$ reaction. $\mathrm{J}$ Chem. Phys. 101 (2), 1333-1342.

Evans, R. A., Lorencak, P., Ha, T. K., Wentrup, C., 1991. HCN dimers: iminoacetonitrile and N-cyanomethanimine. J. Am. Chem. Soc. 113 (19), 7261-7276.

Fagerstrom, K., Jodkowski, J. T., Lund, A., Ratajczak, E., 1995. Kinetics of the self-reaction and the reaction with OH of the amidogen radical. Chem. Phys. Lett. $236(1-2), 103-110$.

Fahr, A., Halpern, J. B., Tardy, D. C., 2007. Calculational and experimental investigations of the pressure effects on radical-radical cross combination ceactions: $\mathrm{C}_{2} \mathrm{H}_{5}+\mathrm{C}_{2} \mathrm{H}_{3}$. J. Phys. Chem. A $111(29), 6600-6609$.

Fahr, A., Laufer, A., Klein, R., Braun, W., 1991. Reaction rate determinations of vinyl radical reactions with vinyl, methyl, and hydrogen atoms. J. Phys. Chem. $95(8), 3218-3224$

Fahr, A., Laufer, A., Tardy, D., 1999. Pressure effect on $\mathrm{CH}_{3}$ and $\mathrm{C}_{2} \mathrm{H}_{3}$ cross-radical reactions. J. Phys. Chem. A 103 (42), 8433-8439.

Fahr, A., Laufer, A. H., 1992. The 1,1-elimination of hydrogen cyanide and formation of triplet vinylidene from the photolysis of acrylonitrile. J. Phys. Chem. $96(11), 4217-4219$

Fahr, A., Nayak, A., 2000. Kinetics and products of propargyl $\left(\mathrm{C}_{3} \mathrm{H}_{3}\right)$ radical self-reactions and propargyl-methyl cross-combination reactions. Int. J. Chem. Kinet. $32(2), 118-124$

Faravelli, T., Goldaniga, A., Zappella, L., Ranzi, E., Dagaut, P., Cathonnet, M., 2000. An experimental and kinetic modeling study of propyne and allene oxidation. Proc. Combust. Inst. $28(2), 2601-2608$

Feng, W., Hershberger, J. F., 2007. Kinetics of the O + HCNO Reaction. J. Phys. Chem. A 111 (42), 10654-10659

Fikri, M., Meyer, S., Roggenbuck, J., Temps, F., 2001. An experimental and theoretical study of the product distribution of the reaction $\mathrm{CH}_{2}\left(\tilde{X}^{3} \mathrm{~B}_{1}\right)+\mathrm{NO}$ Faraday Discuss. 119, 223-242 Flasar, F. M., Achterberg, R. K., Conrath, B. J., Gierasch, P. J., Kunde, V. G., Nixon, C. A., Bjoraker, G. L., Jennings, D. E., Romani, P. N., Simon-Miller, A. A.,
Bézard, B., Coustenis, A., Irwin, P. G. J., Teanby, N. A., Brasunas, J., Pearl, J. C., Segura, M. E., Carlson, R. C., Mamoutkine, A., Schinder, P. J., Barucci, A., Courtin, R., Fouchet, T., Gautier, D., Lellouch, E., Marten, A., Prangé, R., Vinatier, S., Strobel, D. F., Calcutt, S. B., Read, P. L., Taylor, F. W., Bowles, Wishnow, E. H., May 2005. Titan's Atmospheric Temperatures, Winds, and Composition. Science 308, 975-978.

Fleming, J., Fujimoto, G., Lin, M., Harvey, A., 1980. Applications of multiphoton dissociation and laser induced fluorescence to combustion: Reactions of CH radicals with unsaturated hydrocarbons. In: Corcoran, V. J. (Ed.), Proc. Int. Conf. Lasers79. STS Press, McLean, VA, pp. 246-250.

Fournier, M., Guillemin, J., Sims, I., 2014. Low temperature kinetics of $\mathrm{C}_{3} \mathrm{~N}$ radical reactions. In preparation.

Frankcombe, T. J., Nyman, G., 2007. Adiabatic capture theory applied to $\mathrm{N}+\mathrm{NH} \rightarrow \mathrm{N}_{2}+\mathrm{H}$ at low temperature. J. Phys. Chem. A 111 (50), 13163-13167.

Fray, N., Schmitt, B., Dec. 2009. Sublimation of ices of astrophysical interest: A bibliographic review. Planetary and Space Science 57, 2053-2080.

Frost, R., Green, D., Osborn, M., Smith, I., 1986. Time-resolved vibrational chemiluminescence: Rate constants for the reactions of $\mathrm{F}$ atoms with $\mathrm{H}_{2} \mathrm{O}$ and $\mathrm{HCN}$ and for the relaxation of $\mathrm{HF}(\mathrm{v}=1)$ by $\mathrm{H}_{2} \mathrm{O}$ and $\mathrm{HCN}$. Int. J. Chem. Kinet. 18 (8), 885-898.

Fu, B., Han, Y.-C., Bowman, J. M., Angelucci, L., Balucani, N., Leonori, F., Casavecchia, P., 2012a. Intersystem crossing and dynamics in O $\left({ }^{3} \mathrm{P}\right)+\mathrm{C}_{2} \mathrm{H}_{4}$ multichannel reaction: Experiment validates theory. P. Natl. A. Sci. 109 (25), 9733-9738. 
Fu, B., Han, Y.-C., Bowman, J. M., Leonori, F., Balucani, N., Angelucci, L., Occhiogrosso, A., Petrucci, R., Casavecchia, P., 2012b. Experimental and theoretical studies of the $\mathrm{O}\left({ }^{3} \mathrm{P}\right)+\mathrm{C}_{2} \mathrm{H}_{4}$ reaction dynamics: Collision energy dependence of branching ratios and extent of intersystem crossing. J. Chem. Phys. 137 (22), $22 \mathrm{~A} 532$. Fukuzawa, K., Osamura, Y., 1997. Molecular orbital study of neutral-neutral reactions concerning $\mathrm{HC}_{3} \mathrm{~N}$ formation in interstellar space. Astrophys. J. 489 (1),
113-121.

Fulle, D., Hippler, H., 1997. The temperature and pressure dependence of the reaction $\mathrm{CH}+\mathrm{H}_{2} \leftrightarrow \mathrm{CH}_{3} \leftrightarrow \mathrm{CH}_{2}+\mathrm{H}$. J. Chem. Phys. 106 (21), 8691-8698.

Galland, N., Caralp, F., Hannachi, Y., Bergeat, A., Loison, J.-C., 2003. Experimental and theoretical studies of the methylidyne CH(X $\left.{ }^{2} \Pi\right)$ radical reaction with ethane $\left(\mathrm{C}_{2} \mathrm{H}_{6}\right)$ : Overall rate constant and product channels. J. Phys. Chem. A $107(28), 5419-5426$.

Gandini, A., Hackett, P. A., 1978. The photochemistry of acrylonitrile vapour at 213.9 nm. Can. J. Chem. 56 (15), $2096-2098$.

Gannon, K., Blitz, M., Kovacs, T., Pilling, M., Seakins, P., 2010a. State resolved measurements of a ${ }^{1} \mathrm{CH}_{2}$ removal confirm predictions of the gateway model for electronic quenching. J. Chem. Phys. 132 (2), 024302.

Gannon, K., Blitz, M., Liang, C., Pilling, M., Seakins, P., Glowacki, D., 2010b. Temperature dependent kinetics and $\mathrm{H}$ atom yields from reactions of ${ }^{1} \mathrm{CH}_{2}$ with acetylene, ethene, and propene. J. Phys. Chem. A 114 (35), 9413-9424.

Gannon, K., Blitz, M., Liang, C.-H., Pilling, M., Seakins, P., Glowacki, D., Harvey, J., 2010c. An experimental and theoretical investigation of the competition between chemical reaction and relaxation for the reactions of ${ }^{1} \mathrm{CH}_{2}$ with acetylene and ethene: implications for the chemistry of the giant planets. Faraday Discuss. $147,1-16$.

Gannon, K., Blitz, M., Pilling, M., Seakins, P., Klippenstein, S., Harding, L., 2008. Kinetics and product branching ratio of the reaction of ${ }^{1} \mathrm{CH}_{2}$ with $\mathrm{H}_{2}$ and $\mathrm{D}_{2}$. J. Phys. Chem A. $112(39), 9575-9583$.

Gannon, K., Glowacki, D., Blitz, M., Hughes, K., Pilling, M., Seakins, P., 2007. H atom yields from the reactions of $\mathrm{CN}$ radicals with $\mathrm{C}_{2} \mathrm{H}_{2}$, $\mathrm{C}_{2} \mathrm{H}_{4}$, $\mathrm{C}_{3} \mathrm{H}_{6}$, trans-2- $\mathrm{C}_{4} \mathrm{H}_{8}$, and iso- $\mathrm{C}_{4} \mathrm{H}_{8}$. J. Phys. Chem. A $111(29), 6679-6692$.

Gans, B., Boy-Pronne, S., Broquier, M., Delsaut, M., Douin, S., Fellows, C. E., Halvick, P., Loison, J. C., Lucchese, R. R., Gauyacq, D., 2011. Photolysis of methane revisited at $121.6 \mathrm{~nm}$ and at $118.2 \mathrm{~nm}$ : Quantum yields of the primary products, measured by mass spectrometry. Phys. Chem. Chem. Phys. 13 (18), $8140-8152$.

Geballe, T. R., Kim, S. J., Noll, K. S., Griffith, C. A., Jan. 2003. High-Resolution 3 Micron Spectroscopy of Molecules in the Mesosphere and Troposphere of Titan. The Astrophysical Journal 583, L39-L42.

Georgievskii, Y., Klippenstein, S. J., 2005. Long-range transition state theory. J. Chem. Phys. 122 (19), $194103-17$.

Georgievskii, Y., Miller, J. A., Klippenstein, S. J., 2007. Association rate constants for reactions between resonance-stabilized radicals: $\mathrm{C}_{3} \mathrm{H}_{3}+\mathrm{C}_{3} \mathrm{H}_{3}$, $\mathrm{C}_{3} \mathrm{H}_{3}+$ $\mathrm{C}_{3} \mathrm{H}_{5}$, and $\mathrm{C}_{3} \mathrm{H}_{5}+\mathrm{C}_{3} \mathrm{H}_{5}$. Phys. Chem. Chem. Phys. 9 (31), 4259-4268.

Geppert, W. D., Reignier, D., Stoecklin, T., Naulin, C., Costes, M., Chastaing, D., Le Picard, S. D., Sims, I. R., Smith, I. W. M., 2000. Comparison of the cross-sections and thermal rate constants for the reactions of $\left.\mathrm{C}^{3}{ }^{3} \mathrm{P}_{J}\right)$ atoms with $\mathrm{O}_{2}$ and NO. Phys. Chem. Chem. Phys. 2 (13), $2873-2881$.

Ghibaudi, E., Colussi, A. J., 1988. Kinetics and thermochemistry of the equilibrium $2 \mathrm{C}_{2} \mathrm{H}_{2} \leftrightarrow \mathrm{C}_{4} \mathrm{H}_{4}$ : direct evidence against a chain mechanism. J. Phys. Chem. $92(20), 5839-5842$.

Gladstone, G. R., Allen, M., Yung, Y. L., 1996. Hydrocarbon photochemistry in the upper atmosphere of Jupiter. Icarus 119 (1), 1-52.

Glarborg, P., Dam-Johansen, K., Miller, J. A., 1995. The reaction of ammonia with nitrogen dioxide in a flow reactor: Implications for the $\mathrm{NH}_{2}+\mathrm{NO}_{2}$ reaction. Int. J. Chem. Kin. 27 (12), 1207-1220.

Glass, G. P., Kumaran, S. S., Michael, J. V., 2000. Photolysis of ketene at $193 \mathrm{~nm}$ and the rate constant for H + HCCO at $297 \mathrm{~K}$. J. Phys. Chem. A 104 (36), $8360-8367$.

Golden, D. M., 2012. The reaction $\mathrm{OH}+\mathrm{C}_{2} \mathrm{H}_{4}$ : An example of rotational channel switching. J. Phys. Chem. A 116 (17), $4259-4266$.

Gosavi, R. K., Safarik, I., Strausz, О. Р., 1985. Molecular orbital studies of carbyne reactions: addition and insertion reaction paths for the CH( $\left.\tilde{X}^{2} \Pi\right)+$ $\mathrm{C}_{2} \mathrm{H}_{4}\left(\tilde{X}^{1} A_{g}\right)$ reaction. Can. J. Chem. $63(7), 1689-1693$.

Goulay, F., Leone, S., 2006. Low-temperature rate coefficients for the reaction of ethynyl radical $\left(\mathrm{C}_{2} \mathrm{H}\right)$ with benzene. J. Phys. Chem. A $110(5)$, 1875-1880.

Goulay, F., Soorkia, S., Meloni, G., Osborn, D. L., Taatjes, C. A., Leone, S. R., 2011. Detection of pentatetraene by reaction of the ethynyl radical (C ${ }_{2}$ H) with allene $\left(\mathrm{CH}_{2}=\mathrm{C}=\mathrm{CH}_{2}\right)$ at room temperature. Phys. Chem. Chem. Phys. 13 (46), 20820-20827.

Goulay, F., Trevitt, A. J., Meloni, G., Selby, T. M., Osborn, D. L., Taatjes, C. A., Vereecken, L., Leone, S. R., 2009. Cyclic versus linear isomers produced by reaction of the methylidyne radical $(\mathrm{CH})$ with small unsaturated hydrocarbons. J. Am. Chem. Soc. 131 (3), 993-1005.

Gray, P., Thynne, J., 1964. Arrhenius parameters for elementary combustion reactions: H-atom abstraction from N-H bonds. Proc. Combust. Inst. 10 (1), 435-44.

Gronoff, G., Mertens, C., Lilensten, J., Desorgher, L., Flückiger, E., Velinov, P., May 2011. Ionization processes in the atmosphere of Titan. III. Ionization by high-Z nuclei cosmic rays. Astronomy and Astrophysics 529, A143.

Gronoff, G., Simon Wedlund, C., Mertens, C. J., Lillis, R. J., Apr. 2012. Computing uncertainties in ionosphere-airglow models: I. Electron flux and species production uncertainties for Mars. Journal of Geophysical Research (Space Physics) 117, 4306. 
Gu, X., Guo, Y., Zhang, F., Mebel, A. M., Kaiser, R. I., 2006. Reaction dynamics of carbon-bearing radicals in circumstellar envelopes of carbon stars. Faraday Disc. $133,245-275$.

Guo, J., Eng, R., Carrington, T., Filseth, S. V., 2000. Photodissociation of HCN at 157 nm: Energy disposal in the CN(A $\Pi$ ) fragment. J. Chem. Phys. 112 (20), $8904-8909$.

Gurwell, M. A., Nov. 2004. Submillimeter Observations of Titan: Global Measures of Stratospheric Temperature, CO, HCN, HC 3 N, and the Isotopic Ratios ${ }^{12} \mathrm{C} /{ }^{13} \mathrm{C}$ and ${ }^{14} \mathrm{~N} /{ }^{15} \mathrm{~N}$. The Astrophysical Journal $616, \mathrm{~L} 7-\mathrm{L} 10$.

Hack, W., Wagner, H., Zaspypkin, A., 1994. Elementary reactions of $\mathrm{NH}\left(\mathrm{a}^{1} \Delta\right)$ and $\mathrm{NH}\left(\mathrm{X}^{3} \Sigma\right)$ with $\mathrm{N}$, O and NO. Ber. Bunsenges. Phys. Chem. $98(2), 156-164$.

Haider, N., Husain, D., 1993a. Absolute rate data for the reactions of ground-state atomic carbon, C $\left[{ }^{2} \mathrm{p}^{2}\left({ }^{3} \mathrm{P}_{J}\right)\right]$, with alkenes investigated by time-resolved atomic resonance absorption spectroscopy in the vacuum ultraviolet. J. Chem. Soc. Faraday Trans. 89, 7-14.

Haider, N., Husain, D., 1993b. The collisional behaviour of ground state atomic carbon, $\left.\mathrm{C}_{2}{ }_{2} \mathrm{p}^{2}\left({ }^{3} \mathrm{P}_{j}\right)\right)$, with ethylene and acetylene investigated by time-resolved atomic resonance absorption spectroscopy in the vacuum ultraviolet. J. Photochem. Photobiol. A 70 (2), 119-124.

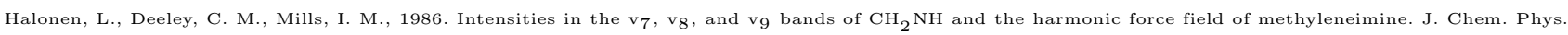
$85(2), 692-696$.

Halpern, J. A., Miller, G. E., Okabe, H., Nottingham, W., 1988. The UV photochemistry of cyanoacetylene. J. Photochem. Photobiol. A 42 (1), 63-72.

Hanning-Lee, M. A., Pilling, M. J., 1992. Kinetics of the reaction between H atoms and allyl radicals. Int. J. Chem. Kinet. 24 (3), $271-278$.

Harding, L., Guadagnini, R., Schatz, G., 1993. Theoretical-studies of the reactions $\mathrm{H}+\mathrm{CH} \rightarrow \mathrm{C}+\mathrm{H}_{2}$ and $\mathrm{C}+\mathrm{H}_{2} \rightarrow \mathrm{CH}_{2}$ using an abinitio global ground-state potential surface for $\mathrm{CH}_{2}$. J. Phys. Chem. $97(21), 5472-5481$.

Harding, L., Klippenstein, S., Georgievskii, Y., 2007. On the combination reactions of hydrogen atoms with resonance-stabilized hydrocarbon radicals. J. Phys. Chem. A $111(19), 3789-3801$.

Harding, L. B., Klippenstein, S. J., 1998. A theoretical analysis of the reaction of $\mathrm{H}$ with $\mathrm{C}_{2} \mathrm{H}_{5}$. Symp. Int. Combust. Proc. 27 (1), $151-157$.

Harding, L. B., Klippenstein, S. J., Georgievskii, Y., 2005. Reactions of oxygen atoms with hydrocarbon radicals: a priori kinetic predictions for the $\mathrm{CH}_{3}+\mathrm{O}_{\text {, }}$ $\mathrm{C}_{2} \mathrm{H}_{5}+\mathrm{O}$, and $\mathrm{C}_{2} \mathrm{H}_{3}+\mathrm{O}$ reactions. P. Combust. Inst. 30 (1), 985-993.

Harris, G. W., Pitts, J. J. N., 1982. Absolute rate constants and temperature dependencies for the gas phase reactions of $\mathrm{H}$ atoms with propene and the butenes in the temperature range 298 to $445 \mathrm{~K}$. J. Chem. Phys. 77 (8), 3994-3997.

Hébrard, E., Dobrijevic, M., Bénilan, Y., Raulin, F., 2006. Photochemical kinetics uncertainties in modeling Titan's atmosphere: a review. J. Photochem. Photobiol. C - Photochem. Rev. 7, 211-230.

Hébrard, E., Dobrijevic, M., Bénilan, Y., Raulin, F., 2007. Photochemical kinetics uncertainties in modeling Titan's atmosphere: First consequences. Planet. Space Sci. $55,1470-1489$.

Hébrard, E., Dobrijevic, M., Loison, J., Bergeat, A., Hickson, K., F., C., 2013. Photochemistry of $\mathrm{C}_{3} \mathrm{H}_{p}$ hydrocarbons in Titan's stratosphere revisited. Astronomy and Astrophysics.

Hébrard, E., Dobrijevic, M., Loison, J. C., Bergeat, A., Hickson, K. M., May 2012. Neutral production of hydrogen isocyanide (HNC) and hydrogen cyanide (HCN) in Titan's upper atmosphere. Astronomy and Astrophysics 541, A21. Hébrard, E., Dobrijevic, M., Pernot, P., Carrasco, N., Bergeat, A., Hickson, K. M., Canosa, A., Le Picard, S. D., Sims, I. R., 2009. How Measurements of Rate
Coefficients at Low Temperature Increase the Predictivity of Photochemical Models of Titan's Atmosphere. Journal of Physical Chemistry 113 (42), $11227-11237$.

Heinemann, P., Hofmann-Sievert, R., Hoyermann, K., 1988. Direct study of the reactions of vinyl radicals with hydrogen and oxygen atoms. Symp. Int. Combust. Proc. $21(1), 865$.

Herbst, E., Terzieva, R., Talbi, D., 2000. Calculations on the rates, mechanisms, and interstellar importance of the reactions between $\mathrm{C}$ and $\mathrm{NH}_{2}$ and between $\mathrm{N}$ and $\mathrm{CH}_{2}$. Mon. Not. Roy. Astron. Soc. $311(4), 869-876$.

Herron, J. T., 1999. Evaluated chemical kinetics data for reactions of $\mathrm{N}\left({ }^{2} \mathrm{D}\right), \mathrm{N}\left({ }^{2} \mathrm{P}\right)$, and $\mathrm{N}_{2}\left(\mathrm{~A}^{3} \Sigma_{u}^{+}\right)$in the gas phase. J. Phys. Chem. Ref. Data 28 (5), $1453-1483$.

Herzberg, G., 1957. Molecular spectra and molecular structures. Vol. III. D. Van Nostrand Company, New York.

Homayoon, Z., Bowman, J. M., 2014. A global potential energy surface describing the $\mathrm{N}\left({ }^{2} \mathrm{D}\right)+\mathrm{H}_{2} \mathrm{O}$ reaction and a quasiclassical trajectory study of the reaction to $\mathrm{NH}+\mathrm{OH}$. J. Phys. Chem. A 118 (3), 545-553.

Homayoon, Z., Vazquez, S. A., Rodriguez-Fernandez, R., Martinez-Nunez, E., 2011. Ab initio and RRKM study of the HCN/HNC elimination channels from vinyl cyanide. J. Phys. Chem. A $115(6), 979-985$.

Hoobler, R., Leone, S., 1997. Rate coefficients for reactions of ethynyl radical $\left(\mathrm{C}_{2} \mathrm{H}\right)$ with $\mathrm{HCN}$ and $\mathrm{CH}_{3} \mathrm{CN}$ : implications for the formation of complex nitriles on titan. J. Geophys. Res. - Planet. 102 (E12), $28717-28723$

Horner, D. A., Curtiss, L. A., Gruen, D. M., 1995. A theoretical study of the energetics of insertion of dicarbon $\left(\mathrm{C}_{2}\right)$ and vinylidene into methane C-H bonds. Chem. Phys. Lett. 233 (3), 243-248.

Horowitz, A., Calvert, J. G., 1982. Wavelength dependence of the primary processes in acetaldehyde photolysis. J. Phys. Chem. 86 (16), 3105-3114.

Hörst, S. M., Vuitton, V., Yelle, R. V., Oct. 2008. Origin of oxygen species in Titan's atmosphere. Journal of Geophysical Research (Planets) 113 , 10006. 
Hourdin, F., Lebonnois, S., Luz, D., Rannou, P., Dec. 2004. Titan's stratospheric composition driven by condensation and dynamics. Journal of Geophysical Research (Planets) 109 (E18), 12005.

Hoyermann, K., Loftfield, N. S., Sievert, R., Wagner, H. G., 1981. Mechanism and rates of the reactions of $\mathrm{CH}_{3} \mathrm{O}$ and $\mathrm{CH}_{2} \mathrm{OH}$ radicals with H atoms. Symp. Int. Combust. Proc. $18(1), 831-842$

Huang, C., Li, W., Estillore, A. D., Suits, A. G., 2008. Dynamics of CN + alkane reactions by crossed-beam DC slice imaging. J. Chem. Phys. 129 (7), 074301.

Hubin-Franskin, M. J., Delwiche, J., Giuliani, A., Ska, M. P., Motte-Tollet, F., Walker, I. C., Mason, N. J., Gingell, J. M., Jones, N. C., 2002. Electronic excitation and optical cross sections of methylamine and ethylamine in the UV-VUV spectral region. J. Chem. Phys. 116 (21), 9261-9268.

Hunter, E. P. L., Lias, S. G., 1998. Evaluated gas phase basicities and proton affinities of molecules: An update. J. Phys. Chem. Ref. Data 27 (3), 413-656.

Husain, D., Ioannou, A. X., 1997. Reactions of atomic carbon, $\mathrm{C}\left[{ }_{2} \mathrm{p}^{2}\left({ }^{3} \mathrm{P} J\right)\right]$, with dienes and diynes investigated by time-resolved atomic resonance absorption spectroscopy in the vacuum ultraviolet. J. Chem. Soc. Faraday Trans. 93, 3625-3629.

Husain, D., Ioannou, A. X., 1999. Collisional removal of atomic carbon, $\mathrm{C}\left[2 \mathrm{p}^{2}\left({ }^{3} \mathrm{P}_{J}\right)\right]$, by aldehydes and ketones, investigated by time-resolved atomic resonance absorption spectroscopy in the vacuum ultra-violet. J. Photochem. Photobiol. A $129(1-2), 1-7$.

Husain, D., Kirsch, L., 1971. Reactions of atomic carbon by kinetic absorption spectroscopy in vacuum ultraviolet. Trans. Faraday Soc. 67 (583), 2025-2035.

Husain, D., Young, A. N., 1975. Kinetic investigation of ground state carbon atoms, $\mathrm{C}\left(2^{3} \mathrm{P}_{J}\right)$. J. Chem. Soc. Faraday Trans. $271,525-531$.

Inomata, S., Washida, N., 1999. Rate constants for the reactions of $\mathrm{NH}_{2}$ and $\mathrm{HNO}$ with atomic oxygen at temperatures between 242 and $473 \mathrm{~K}$. J. Phys. Chem. A $103(26), 5023-5031$.

Irle, S., Morokuma, K., 2000. A molecular orbital study on $\mathrm{H}$ and $\mathrm{H}_{2}$ elimination pathways from methane, ethane, and propan. J. Chem. Phys. 113 (15), 6139-6148.

Ismail, H., Goldsmith, C. F., Abel, P. R., Howe, P.-T., Fahr, A., Halpern, J. B., Jusinski, L. E., Georgievskii, Y., Taatjes, C. A., Green, W. H., 2007. Pressure and temperature dependence of the reaction of vinyl radical with ethylene. J. Phys. Chem. A 111 (29), 6843-6851.

Jamal, A., Mebel, A. M., 2010. An ab initio/RRKM study of the reaction mechanism and product branching ratios of the reactions of ethynyl radical with allene and methylacetylene. Phys. Chem. Chem. Phys. $12(11), 2606-2618$.

Jamieson, J. W. S., Brown, G. R., Tanner, J. S., 1970. The reaction of atomic hydrogen with methyl cyanide. Can. J. Chem. 48 (23), $3619-3622$.

Jasper, A. W., Klippenstein, S. J., Harding, L. B., 2007a. Secondary kinetics of methanol decomposition: Theoretical rate coefficients for ${ }^{3} \mathrm{CH}_{2}+\mathrm{OH}^{3} \mathrm{CH}_{2}+$ ${ }^{3} \mathrm{CH}_{2}$, and ${ }^{3} \mathrm{CH}_{2}+\mathrm{CH}_{3}$. J. Phys. Chem. A $111(35), 8699-8707$.

Jasper, A. W., Klippenstein, S. J., Harding, L. B., Ruscic, B., 2007b. Kinetics of the reaction of methyl radical with hydroxyl radical and methanol decomposition. J. Phys. Chem. A $111(19), 3932-3950$.

Jiang, B., Guo, H., 2013. Competition between abstraction and exchange channels in H + HCN reaction: Full-dimensional quantum dynamics. J. Chem. Phys. $139(22), 224310$

Jodkowski, J. T., Ratajczak, E., E.; Sillesen, A., Pagsberg, P., 1993. Kinetics of the addition reaction of methyl radicals with nitric oxide studied by pulse radiolysis combined with infrared diode laser spectroscopy. Chem. Phys. Lett. 203, 490-496.

Jodkowski, J. T., Ratajczak, E., Fagerstrom, K., Lund, A., Stothard, N. D., Humpfer, R., Grotheer, H.-H., 1995. Kinetics of the cross reaction between amidogen and methyl radicals. Chem. Phys. Lett. $240(1-3), 63-71$

Johnson, D. G., Blitz, M., Seakins, P. W., 2000. The reaction of methylidene (CH) with methanol isotopomers. Phys. Chem. Chem. Phys. 2, 2549-2553.

Kaiser, E. W., 1993. Pressure dependence of the rate constants for the reactions methyl + oxygen and methyl + nitric oxide from 3 to 104 torr. J. Phys. Chem $97(45), 11681-11688$

Kanda, K., Nagata, T., Ibuki, T., 1999. Photodissociation of some simple nitriles in the extreme vacuum ultraviolet region. Chem. Phys. 243 (1-2), 89-96.

Keil, D., Lynch, K., Cowfer, J., Michael, J., 1976. An investigation of nonequilibrium kinetic isotope effects in chemically activated vinyl radicals. Int. J. Chem. Kinet. $8(6), 825-857$.

Kerr, J., Parsonage, M., 1972. Evaluated kinetic data on gas phase addition reactions. Reactions of atoms and radicals with alkenes, alkynes and aromatic compound. Butterworths, London.

Khanna, R. K., Sep. 2005. Condensed species in Titan's atmosphere: Identification of crystalline propionitrile $\left(\mathrm{C}{ }_{2} \mathrm{H}{ }_{5} \mathrm{CN}, \mathrm{CH}{ }_{3} \mathrm{CH}{ }_{2} \mathrm{C}\right.$ tbnd $\left.\mathrm{N}\right)$ based on laboratory infrared data. Icarus $177,116-121$

Khlifi, M., Paillous, P., Bruston, P., Guillemin, J. C., Bnilan, Y., Daoudi, A., Raulin, F., 1997. Gas infrared spectra, assignments, and absolute IR band intensities of $\mathrm{C}_{4} \mathrm{~N}_{2}$ in the $250-3500 \mathrm{~cm}^{-1}$ region: implications for Titan's stratosphere. Spectrochim. Acta A 53 (5), $707-712$

Kiefer, J., von Drasek, W., 1990. The mechanism of the homogeneous pyrolysis of acetylene. Int. J. Chem. Kin. 22 (7), $747-786$.

Kiefer, J. H., Mitchell, K. I., 1988. Molecular dissociation of vinylacetylene and its implications for acetylene pyrolysis. Energ. Fuels 2 (4), 458-461.

Kim, S. J., Geballe, T. R., Noll, K. S., Courtin, R., Feb. 2005. Clouds, haze, and $\mathrm{CH}_{4}, \mathrm{CH}_{3} \mathrm{D}, \mathrm{HCN}$, and $\mathrm{C}_{2} \mathrm{H}_{2}$ in the atmosphere of Titan probed via $3 \mu \mathrm{m}$ spectroscopy. Icarus $173,522-532$.

Kinsman, A., Roscoe, J., 1994. A kinetic-analysis of the photolysis of mixtures of acetone and propylene. Int. J. Chem. Kin. 26 (1), $191-200$. 
Klemm, R. B., 1979. Absolute rate parameters for the reactions of formaldehyde with O atoms and $\mathrm{H}$ atoms over the temperature range $250-500 \mathrm{~K}$. J. Chem. Phys. $71(5), 1987-1993$.

Klippenstein, J., Georgievskii, Y., Harding, L. B., 2006. Predictive theory for the association kinetics of two alkyl radicals. Phys. Chem. Chem. Phys. 8 (10), 1133-1147.

Klippenstein, S. J., Harding, L. B., 1999. A theoretical study of the kinetics of $\mathrm{C}_{2} \mathrm{H}_{3}+$ H. Phys. Chem. Chem. Phys. 1 (6), 989-997.

Klippenstein, S. J., Harding, L. B., 2009. Kinetics of the H + NCO reaction. Proc. Combust. Inst. 32 (1), $149-155$.

Knyazev, V., Slagle, I., 2002. Kinetics of the reaction between propargyl radical and acetylene. J. Phys. Chem. A 106 (23), $5613-5617$.

Knyazev, V. D., Bencsura, A., Stoliarov, S. I., Slagle, I. R., 1996a. Kinetics of the $\mathrm{C}_{2} \mathrm{H}_{3}+\mathrm{H}_{2} \leftrightarrow \mathrm{H}+\mathrm{C}_{2} \mathrm{H}_{4}$ and $\mathrm{CH}_{3}+\mathrm{H}_{2} \leftrightarrow \mathrm{H}+\mathrm{CH} 4$ reactions. J. Phys. Chem. 100 (27), 11346-11354.

Knyazev, V. D., Slagle, I. R., 2001. Kinetics of the reactions of allyl and propargyl radicals with $\mathrm{CH}_{3}$. J. Phys. Chem. A 105 (13), 3196-3204.

Knyazev, V. D., Stoliarov, S. I., Slagle, I. R., 1996b. Kinetics of the reaction of vinyl radicals with acetylene. Symp. (Int.) Comb. 26 (1), 513-519.

Konnov, A. A., De Ruyck, J., 2001. Temperature-dependent rate constant for the reaction NNH + O $\rightarrow$ NH + NO. Combust. Flame 125 (4), 1258-1264.

Koskinen, T. T., Yelle, R. V., Snowden, D. S., Lavvas, P., Sandel, B. R., Capalbo, F. J., Benilan, Y., West, R. A., Dec. 2011. The mesosphere and lower thermosphere of Titan revealed by Cassini/UVIS stellar occultations. Icarus $216,507-534$.

Kovacs, T., Blitz, M. A., Seakins, P. W., 2010. H-atom yields from the photolysis of acetylene and from the reaction of $\mathrm{C}_{2} \mathrm{H}$ with $\mathrm{H}_{2}$, $\mathrm{C}_{2} \mathrm{H}_{2}$, and $\mathrm{C}_{2} \mathrm{H}_{4} . \mathrm{J} . \mathrm{Phys}$ Chem. A $114(14), 4735-4741$

Krasnoperov, L. N., Chesnokov, E. N., Stark, H., Ravishankara, A. R., 2005. Elementary reactions of formyl (HCO) radical studied by laser photolysis transient absorption spectroscopy. Proceedings of the Combustion Institute 30 (1), 935-943

Krasnopolsky, V. A., May 2009. A photochemical model of Titan's atmosphere and ionosphere. Icarus 201, $226-256$.

Krasnopolsky, V. A., Dec. 2012. Titan's photochemical model: Further update, oxygen species, and comparison with Triton and Pluto. Planetary and Space Science $73,318-326$.

Kurosaki, Y., Takayanagi, T., 1999. Ab initio molecular orbital study of the $\mathrm{N}\left({ }^{2} \mathrm{D}\right)+\mathrm{H}_{2} \mathrm{O}$ reaction. J. Phys. Chem. A 103 (3), $436-442$.

Kyogoku, T., Watanabe, T., Tsunashima, S., Sato, S., 1983. Arrhenius parameters for the reactions of hydrogen and deuterium atoms with four butenes. Bull. Chem. Soc. Jpn. $56(1), 19-21$.

Langford, A. O., Petek, H., Moore, C. B., 1983. Collisional removal of ${ }^{1} \mathrm{CH}_{2}$ : Absolute rate constants for atomic and molecular collisional partners at $295 \mathrm{~K}$. J. Chem. Phys. 78 (11), 6650-6659.

Lara, L. M., Lellouch, E., López-Moreno, J. J., Rodrigo, R., Oct. 1996. Vertical distribution of Titan's atmospheric neutral constituents. Journal of Geophysical Research 101, 23261-23283.

Laufer, A. H., 1983. Quenching of triplet vinylidene radicals by helium. Chem. Phys. Lett. 94 (2), 240-242.

Laufer, A. H., Fahr, A., 2004. Reactions and kinetics of unsaturated $\mathrm{C}_{2}$ hydrocarbon radicals. Chem. Rev. 104 (6), $2813-2832$

Läuter, A., Lee, K. S., Jung, K. H., Vatsa, R. K., Mittal, J. P., Volpp, H. R., 2002. Absolute primary H atom quantum yield measurements in the 193.3 and 121.6 $\mathrm{nm}$ photodissociation of acetylene. Chem. Phys. Lett. $358(3-4), 314-319$.

Lavvas, P., Galand, M., Yelle, R. V., Heays, A. N., Lewis, B. R., Lewis, G. R., Coates, A. J., May 2011. Energy deposition and primary chemical products in Titan's upper atmosphere. Icarus $213,233-251$

Lavvas, P. P., Coustenis, A., Vardavas, I. M., 2008. Coupling photochemistry with haze formation in Titan's atmosphere, Part I: Model description. Planet. Space Sci. $56(1), 27-66$

Lavvas, P. P., Coustenis, A., Vardavas, I. M., Jan. 2008a. Coupling photochemistry with haze formation in Titan's atmosphere, Part I: Model description. Planet. Space Sci. 56, 27-66.

Lavvas, P. P., Coustenis, A., Vardavas, I. M., Jan. 2008b. Coupling photochemistry with haze formation in Titan's atmosphere, Part II: Results and validation with Cassini/Huygens data. Planet. Space Sci. 56, 67-99.

Le Picard, S., Canosa, A., 1998. Measurement of the rate constant for the association reaction $\mathrm{CH}+\mathrm{N}_{2}$ at $53 \mathrm{~K}$ and its relevance to Triton's atmosphere. Geophys. Res. Lett. 25 (4), 485-488.

Lebonnois, S., Toublanc, D., Hourdin, F., Rannou, P., Aug. 2001. Seasonal Variations of Titan's Atmospheric Composition. Icarus 152 , 384-406.

Lee, L., 1980. $\mathrm{CN}\left(\mathrm{A}^{2} \Pi_{i} \rightarrow \mathrm{X}^{2} \Sigma^{+}\right)$and $\mathrm{CN}\left(\mathrm{B}^{2} \Sigma^{+} \rightarrow \mathrm{X}^{2} \Sigma^{+}\right)$yields from HCN photodissociation. J. Chem. Phys. 72 (12), $6414-6421$.

Lee, S., Samuels, D. A., Hoobler, R. J., Leone, S. R., 2000. Direct measurements of rate coefficients for the reaction of ethynyl radical $\left(\mathrm{C}_{2} \mathrm{H}\right)$ with $\mathrm{C}_{2} \mathrm{H}_{2}$ at 90 and $120 \mathrm{~K}$ using a pulsed Laval nozzle apparatus. J. Geophys. Res. - Planet. 105 (E6), 15085-15090.

Lee, S.-H., Chin, C.-H., Chen, W.-K., Huang, W.-J., Hsieh, C.-C., 2011. Exploring the dynamics of reactionN $\left({ }^{2} \mathrm{D}\right)+\mathrm{C}_{2} \mathrm{H}_{4}$ with crossed molecular-beam experiments and quantum-chemical calculations. Phys. Chem. Chem. Phys. 13 (18), 8515-8525.

Lee, S.-H., Lee, Y. T., Yang, X., 2004. Dynamics of photodissociation of ethylene and its isotopomers at $157 \mathrm{~nm}$ : Branching ratios and kinetic-energy distributions. J. Chem. Phys. $120(23), 10983-10991$. 
Lee, S.-H., Lee, Y.-Y., Lee, Y. T., Yang, X., 2003. Photodissociation dynamics of propene at 157.6 nm: Kinetic energy distributions and branching ratios. J. Chem. Phys. 119 (2), 827-838.

Lellouch, E., Romani, P. N., Rosenqvist, J., Mar. 1994. The vertical Distribution and Origin of HCN in Neptune's Atmosphere. Icarus 108, 112-136.

Lesclaux, R., Demissy, M., 1978. Kinetics of gas-phase reactions of $\mathrm{NH}_{2}$ radicals with alkane and alkyl radicals. J. Photochem. 9 (2-3), 110-112.

Li, A., Xie, C., Xie, D., Guo, H., 2013. State-to-state quantum dynamics of the $\mathrm{O}\left({ }^{3} \mathrm{P}\right)+\mathrm{NH}\left(\mathrm{X}^{3} \Sigma^{-}\right)$reaction on the three lowest-lying electronic states of HNO/HON. J. Chem. Phys. $138(2), 024308$.

Li, H. Y., Geng, C.-Y., Huang, X. R., Zhan, J.-H., Sun, C. C., 2006a. F/Cl $+\mathrm{C}_{2} \mathrm{H}_{2}$ reactions: Are the addition and hydrogen abstraction direct processes? Chem. Phys. $331(1), 42-54$

Li, J.-L., Geng, C.-Y., Huang, X.-R., Sun, C.-C., 2006b. A barrier-free atomic radical-molecule reaction: F + propene. J. Chem. Theory Comput. 2 (6), 1551-1564.

Li, Q. S., Zhang, X., 2006. Direct dynamics study on the hydrogen abstraction reactions $\mathrm{N}_{2} \mathrm{H}_{4}+\mathrm{R} \rightarrow \mathrm{N}_{2} \mathrm{H}_{3}+\mathrm{RH}\left(\mathrm{R}=\mathrm{NH}_{2}\right.$, CH $\left.\mathrm{H}_{3}\right)$. J. Chem. Phys. $125(6)$,
064304 . 064304 .

Liang, M.-C., Yung, Y. L., Shemansky, D. E., 2007. Photolytically generated aerosols in the mesosphere and thermosphere of Titan. Astrophys. J. Lett. 661 (2),

Lide, D., Kehiaian, H., 1994. CRC Handbook of Thermophysical and Thermochemical Data. CRC Press, Boca Raton, FL.

Lin, C., Kaufman, F., 1971. Reactions of metastable nitrogen atoms. J. Chem. Phys. 55 (8), 3760-3770.

Linder, D. P., Duan, X., Page, M., 1995. Ab initio variational transition state theory calculations for the $\mathrm{H}+\mathrm{NH}_{2} \Leftrightarrow \mathrm{H}_{2}+\mathrm{NH}$ hydrogen abstraction reaction on the triplet potential energy surface. J. Phys. Chem. 99 (29), 11458-11463.

Linder, D. P., Duan, X., Page, M., 1996. Thermal rate constants for $\mathrm{R}+\mathrm{N}_{2} \mathrm{H}_{2} \rightarrow \mathrm{RH}+\mathrm{N}_{2} \mathrm{H}\left(\mathrm{R}=\mathrm{H}, \mathrm{OH}, \mathrm{NH} \mathrm{H}_{2}\right)$ determined from multireference configuration interaction and variational transition state theory calculations. J. Chem. Phys. 104 (16), 6298-6307.

Liu, G.-x., Li, Z.-s., Xiao, J.-f., Liu, J.-y., Fu, Q., Huang, X.-r., Sun, C.-c., Tang, A.-c., 2002. Calculations of the rate constants for the hydrogen abstraction reactions $\mathrm{C}_{2} \mathrm{H}_{3}+\mathrm{CH}_{4} \rightarrow \mathrm{C}_{2} \mathrm{H}_{4}+\mathrm{CH}_{3}$ and $\mathrm{C}_{2} \mathrm{H}_{3}+\mathrm{C}_{2} \mathrm{H}_{6} \rightarrow \mathrm{C}_{2} \mathrm{H}_{4}+\mathrm{C}_{2} \mathrm{H}_{5}$. ChemPhysChem $3(7), 625-629$.

Loison, J.-C., Bergeat, A., 2004. Reaction of carbon atoms, $\mathrm{C}_{2} \mathrm{p}^{23} \mathrm{P}$ ) with $\mathrm{C}_{3} \mathrm{H}_{4}$ (allene and methylacetylene), $\mathrm{C}_{3} \mathrm{H}_{6}(\mathrm{propylene})$ and $\mathrm{C}_{4} \mathrm{H}_{8}($ trans-butene) Overall rate constants and atomic hydrogen branching ratios. Phys. Chem. Chem. Phys. 6 (23), 5396-5401.

Loison, J.-C., Bergeat, A., 2009. Rate constants and the $\mathrm{H}$ atom branching ratio of the reactions of the methylidyne $\mathrm{CH}\left(\mathrm{X}^{2} \Pi\right)$ radical with $\mathrm{C}_{2} \mathrm{H}_{2}$, $\mathrm{C}_{2} \mathrm{H}_{4}$, $\mathrm{C}_{3} \mathrm{H}_{4}$, (methylacetylene and allene), $\mathrm{C}_{3} \mathrm{H}_{6}$, (propene) and $\mathrm{C}_{4} \mathrm{H}_{8}$, (trans-butene). Phys. Chem. Chem. Phys. 11 (4), 655-664.

Loison, J. C., Bergeat, A., Caralp, F., Hannachi, Y., 2006. Rate constants and H atom branching ratios of the gas-phase reactions of methylidyne CH radical with a series of alkanes. J. Phys. Chem. A $110(50), 13500-13506$.

Loison, J.-C., Wakelam, V., Hickson, K. M., Bergeat, A., Mereau, R., 2014. The gas-phase chemistry of carbon chains in dark cloud chemical models. Mon. Not. Roy. Astron. Soc. 437 (1), 930-945.

Louge, M., Hanson, R., 1984. High temperature kinetics of NCO. Combust. Flame 58 (3), 291-300.

Luo, C., Du, W.-N., Duan, X.-M., Li, Z.-S., 2008. A theoretical study of the photodissociation mechanism of cyanoacetylene in its lowest singlet and triplet excited states. Astrophys. J. 687 (1), 726.

Madden, L. K., Moskaleva, L. V., Kristyan, S., Lin, M. C., 1997. Ab initio MO study of the unimolecular decomposition of the phenyl radical. J. Phys. Chem. A $101(36), 6790-6797$.

Magee, B. A., Waite, J. H., Mandt, K. E., Westlake, J., Bell, J., Gell, D. A., Dec. 2009. INMS-derived composition of Titan's upper atmosphere: Analysis methods and model comparison. Planet. Space Sci. 57, 1895-1916.

Maki, A. G., Mellau, G. C., 2001. High-temperature infrared emission measurements on HNC. J. Mol. Spectrosc. 206 (1), 47-52.

Maksyutenko, P., Zhang, F., Gu, X., Kaiser, R. I., 2010. A crossed molecular beam study on the reaction of methylidyne radicals [CH(X $\left.\left.{ }^{2} \Pi\right)\right]$ with acetylene $\left[\mathrm{C}_{2} \mathrm{H}_{2}\left(\mathrm{X}^{1} \Sigma_{g}^{+}\right)\right]$-competing $\mathrm{C}_{3} \mathrm{H}_{2}+\mathrm{H}$ and $\mathrm{C}_{3} \mathrm{H}+\mathrm{H}_{2}$ channels. Phys. Chem. Chem. Phys. 13 (1), 240-252.

Marchand, N., Jimeno, P., Rayez, J.-C., Liotard, D., 1997. Theoretical study of the reaction $\mathrm{CH}\left(\mathrm{X}^{2} \mathrm{P}\right)+\mathrm{NO}\left(\mathrm{X}^{2} \mathrm{P}\right)$. I. Determination of some reaction paths in the lowest triplet potential energy surface. J. Phys. Chem. A 101 (34), 6077-6091

Marten, A., Hidayat, T., Biraud, Y., Moreno, R., Aug. 2002. New Millimeter Heterodyne Observations of Titan: Vertical Distributions of Nitriles HCN, HC ${ }_{3} \mathrm{~N}$ $\mathrm{CH}{ }_{3} \mathrm{CN}$, and the Isotopic Ratio ${ }^{15} \mathrm{~N} /{ }^{14} \mathrm{~N}$ in Its Atmosphere. Icarus $158,532-544$.

Martinotti, F. F., Welch, M. J., Wolf, A. P., 1968. The reactivity of thermal carbon atoms in the gaz phase. Chem. Commun. 3, 115-116.

Matsugi, A., Suma, K., Miyoshi, A., 2010. Rate constants and kinetic isotope effects on the reaction of $\mathrm{C}_{2}\left(\mathrm{X}^{1} \Sigma_{g}^{+}\right)$with $\mathrm{CH}_{4}$ and $\mathrm{CD}_{4} . \mathrm{J}^{\mathrm{P}} \mathrm{Phys}$. Chem. A $114(13)$, $4580-4585$

McElcheran, D. E., Wijnen, M. H. J., Steacie, E. W. R., 1958. The photolysis of methyl cyanide at 184.9 nm. Can. J. Chem. 36 (2), $321-329$.

McKee, K., Blitz, M. A., Hughes, K. J., Pilling, M. J., Qian, H.-B., Taylor, A., Seakins, P. W., 2003. H atoms branching ratio from the reactions of CH with $\mathrm{C}_{2} \mathrm{H}_{2}$, $\mathrm{C}_{2} \mathrm{H}_{4}, \mathrm{C}_{2} \mathrm{H}_{6}$ and neo- $\mathrm{C}_{5} \mathrm{H}_{12}$. J. Phys. Chem. 107 (30), 5710-5716. 
McKee, K. W., Blitz, M. A., Cleary, P. A., Glowacki, D. R., Pilling, M. J., Seakins, P. W., Wang, L., 2007. Experimental and master equation study of the kinetics of $\mathrm{OH}+\mathrm{C}_{2} \mathrm{H}_{2}$ : Temperature dependence of the limiting high pressure and pressure dependent rate coefficients. J. Phys. Chem. A 111 (19), $4043-4055$.

Meads, R., Maclagan, R., Phillips, L., 1993. Kinetics, energetics, and dynamics of the reactions of CN with $\mathrm{NH}_{3}$ and ND $_{3}$. J. Phys. Chem. 97 (13), $3257-3265$.

Mebel, A., Lin, M., 1999. Prediction of absolute rate constants for the reactions of $\mathrm{NH}_{2}$ with alkanes from ab initio G2M/TST calculation. J. Phys. Chem. A $103(13), 2088-2096$.

Mebel, A. M., Kaiser, R. I., 2002. An ab initio study on the formation of interstellar tricarbon isomers $1-\mathrm{C}_{3}\left(\mathrm{X}^{1} \Sigma_{g}^{+}\right)$and c-C $3\left(\mathrm{X}^{3} \mathrm{~A}_{2}^{\prime}\right)$. Chem. Phys. Lett. $360(1-2)$, $139-143$.

Mebel, A. M., Kislov, V. V., Kaiser, R. I., 2006. Potential energy surface and product branching ratios for the reaction of dicarbon, $\mathrm{C}_{2}\left(\mathrm{X}^{1} \Sigma_{g}^{+}\right)$, with methylacetylene, $\mathrm{CH}_{3} \mathrm{CCH}\left(\mathrm{X}^{1} \mathrm{~A}_{1}\right)$ : An ab initio/RRKM study. J. Phys. Chem. A 110 (7), 2421-2433.

Mebel, A. M., Lin, M. C., Yu, T., Morokuma, K., 1997. Theoretical study of potential energy surface and thermal rate constants for the $\mathrm{C}_{6} \mathrm{H}_{5}+\mathrm{H}_{2}$ and $\mathrm{C}_{6} \mathrm{H}_{6}+$ H reactions. J. Phys. Chem. A 101 (17), 3189-3196.

Mendes, M., Buhr, H., Berg, M., Froese, M., Grieser, M., Heber, O., Jordon-Thaden, B., Krantz, C., Novotny, O., Novotny, O., Orlov, D., Petrignani, A., Rappaport, M. L., Repnow, R., Schwalm, D., Shornikov, A., Sttzel, J., Zajfman, D., Wolf, A., 2012. Cold electron reactions producing the energetic isomer of hydrogen cyanide in interstellar clouds. Astrophys. J. $746(1), \mathrm{L} 8$.

Mertens, J. D., Chang, A. Y., Hanson, R. K., Bowman, C. T., 1989. Reaction kinetics of NH in the shock tube pyrolysis of HNCO. Int. J. Chem. Kin. 21 (11), $1049-1067$.

Michael, J. V., Osborne, D. T., Suess, G. N., 1973. Reaction $\mathrm{H}+\mathrm{C}_{2} \mathrm{H}_{4}$ : Investigation into the effects of pressure, stoichiometry, and the nature of the third body species. J. Chem. Phys. 58 (7), 2800-2806.

Miller, J. A., Klippenstein, S. J., 2004. The $\mathrm{H}+\mathrm{C}_{2} \mathrm{H}_{2}(+\mathrm{M}) \leftrightarrow \mathrm{C}_{2} \mathrm{H}_{3}(+\mathrm{M})$ and $\mathrm{H}+\mathrm{C}_{2} \mathrm{H}_{2}(+\mathrm{M}) \leftrightarrow \mathrm{C}_{2} \mathrm{H}_{5}(+\mathrm{M})$ reactions: Electronic structure, variational transition-state theory, and solutions to a two-dimensional master equation. Phys. Chem. Chem. Phys. 6 (6), $1192-1202$.

Miller, J. A., Senosiain, J. P., Klippenstein, S. J., Georgievskii, Y., 2008. Reactions over multiple, interconnected potential wells: Unimolecular and bimolecular reactions on a $\mathrm{C}_{3} \mathrm{H}_{5}$ potential. J. Phys. Chem. A 112 (39), 9429-9438.

Mitchell, M., Nava, D., Stief, L., 1986. Rate constant for the reaction of $\mathrm{O}\left({ }^{3} \mathrm{P}\right)$ with diacetylene from 210 to 423 K. J. Chem. Phys. 85 (6), 3300.

Monks, P., Romani, P., Nesbitt, F., Scanlon, M., Stief, L., 1993. The kinetics of the formation of nitrile compounds in the atmospheres of Titan and Neptune. J. Geophys. Res. - Planet. 98 (E9), 17115-17122.

Monks, P. S., Nesbitt, F. L., Payne, W. A., Scanlon, M., Stief, L. J., Shallcross, D. E., 1995. Absolute rate constant and product branching ratios for the reaction between $\mathrm{H}$ and $\mathrm{C}_{2} \mathrm{H}_{3}$ at $\mathrm{T}=213$ and $298 \mathrm{~K}$. J. Phys. Chem. 99 (47), 17151-17159.

Moreno, R., Lellouch, E., Lara, L. M., Courtin, R., Bockelée-Morvan, D., Hartogh, P., Rengel, M., Biver, N., Banaszkiewicz, M., González, A., Dec. 2011. First detection of hydrogen isocyanide (HNC) in Titan's atmosphere. Astronomy and Astrophysics 536, L12.

Moreno, R., Lellouch, E., Lara, L. M., Feuchtgruber, H., Rengel, M., Hartogh, P., Courtin, R., Nov. 2012. The abundance, vertical distribution and origin of $\mathrm{H}_{2} \mathrm{O}$ in Titan's atmosphere: Herschel observations and photochemical modelling. Icarus 221, 753-767.

Moriyama, M., Tsutsui, Y., Honma, K., 1998. Vacuum ultraviolet photodissociation dynamics of acetonitrile. J. Chem. Phys. 108 (15), 6215-6221.

Morris, E.D., J., Niki, H., 1973. Reaction of methyl radicals with atomic oxygen. Int. J. Chem. Kinet. 5 (5), $47-53$

Moses, J., Fouchet, T., Bézard, B., Gladstone, G., Lellouch, E., Feuchtgruber, H., 2005. Photochemistry and diffusion in Jupiter's stratosphere: Constraints from ISO observations and comparisons with other giant planets. J. Geophys. Res. - Planet. 110 (E8), E08001.

Moskaleva, L. V., Xia, W. S., Lin, M. C., 2000. The $\mathrm{CH}+\mathrm{N}_{2}$ reaction over the ground electronic doublet potential energy surface: a detailed transition state search. Chem. Phys. Lett. $331(2-4), 269-277$.

Mu, X., Lu, I. C., Lee, S.-H., Wang, X., Yang, X., 2004. Photodissociation dynamics of 1,2-butadiene at 157 nm. J. Chem. Phys. 121 (10), 4684-4690.

Mullen, C., Smith, M. A., 2005. Low temperature $\mathrm{NH}\left(\mathrm{X}^{3} \Sigma^{-}\right)$radical reactions with $\mathrm{NO}$, saturated, and unsaturated hydrocarbons studied in a pulsed supersonic laval nozzle flow reactor between 53 and $188 \mathrm{~K}$. J. Phys. Chem. A 109 (7), 1391-1399.

Murphy, J., Vakhtin, A., Leone, S., 2003. Laboratory kinetics of $\mathrm{C}_{2} \mathrm{H}$ radical reactions with ethane, propane, and n-butane at $\mathrm{T}=96-296 \mathrm{~K}$ : Implications for Titan. Icarus $163(1), 175-181$.

Nava, D. F., Mitchell, M. B., Stief, L. J., 1986. The reaction $\mathrm{H}+\mathrm{C}_{4} \mathrm{H}_{2}$ : Absolute rate constant measurement and implication for atmospheric modeling of Titan. J. Geophys. Res. - Space Phys. 91 (A4), 4585-4589.

Nesbitt, F. L., Monks, P. S., Scanlon, M., Stief, L. J., 1994. Absolute rate constants for the reactions of $\left.\mathrm{F}^{2} \mathrm{P}\right)$ with $\mathrm{C}_{2} \mathrm{H}_{2}$ and $\mathrm{C}_{2} \mathrm{H}_{4}$ at T $=298 \mathrm{~K} . \mathrm{J}$. Phys. Chem. 98 (16), 4307-4311.

Nesbitt, F. L., Thorn, R. P., Payne, W. A., Tardy, D. C., 1999. Absolute rate constant and product branching fractions for the reaction between $\mathrm{F}$ and $\mathrm{C}_{2} \mathrm{H}_{4}$ at $\mathrm{T}=202-298 \mathrm{~K}$. J. Phys. Chem. A 103 (23), 4470-4479.

Newby, J. J., Stearns, J. A., Liu, C.-P., Zwier, T. S., 2007. Photochemical and discharge-driven pathways to aromatic products from 1,3-Bbutadiene. J. Phys. Chem. A $111(43), 10914-10927$

Nguyen, H., Zhang, S., Peeters, J., Truong, T., Nguyen, M., 2004. Direct ab initio dynamics studies of the reactions of HNO with H and OH radicals. Chem. Phys. Lett. $388(1-3), 94-99$. 
Nguyen, M. T., Sengupta, D., Ha, T., 1996. Another look at the decomposition of methyl azide and methanimine : How is HCN formed? J. Phys. Chem. 100 (16), $6499-6503$.

Nguyen, T. L., Mebel, A. M., Kaiser, R. I., 2001a. A theoretical investigation of the triplet carbon atom $\left.\mathrm{C}^{3}{ }^{3} \mathrm{P}\right)+\mathrm{vinyl}$ radical $\mathrm{C}_{2} \mathrm{H}_{3}\left({ }^{2} \mathrm{~A},\right)$ reaction and thermochemistry of $\mathrm{C}_{3} \mathrm{H}_{n}(n=1-4)$ species. J. Phys. Chem. A 105 (13), 3284-3299.

Nguyen, T. L., Mebel, A. M., Lin, S. H., Kaiser, R. I., 2001b. Product branching ratios of the $\left.\mathrm{C}_{(}{ }^{3} \mathrm{P}\right)+\mathrm{C}_{2} \mathrm{H}_{3}\left({ }^{2} \mathrm{~A},\right)$ and $\left.\mathrm{CH}_{(}{ }^{2} \Pi\right)+\mathrm{C}_{2} \mathrm{H}_{2}\left({ }^{1} \Sigma_{g}^{+}\right)$reactions and photodissociation of $\mathrm{H}_{2} \mathrm{CCCH}\left({ }^{2} \mathrm{~B}_{1}\right)$ at 193 and $242 \mathrm{~nm}$ : An ab initio/RRKM Study. J. Phys. Chem. A 105 (51), $11549-11559$.

Nguyen, T. L., Vereecken, L., Hou, X. J., Nguyen, M. T., Peeters, J., 2005. Potential energy surfaces, product distributions and thermal rate coefficients of the reaction of $\left.\mathrm{O}^{3} \mathrm{P}\right)$ with $\mathrm{C}_{2} \mathrm{H}_{4}\left(\mathrm{X}^{1} \mathrm{~A} g\right)$ : A comprehensive theoretical study. J. Phys. Chem. A 109 (33), 7489-7499.

Nixon, C. A., Jennings, D. E., Bézard, B., Vinatier, S., Teanby, N. A., Sung, K., Ansty, T. M., Irwin, P. G. J., Gorius, N., Cottini, V., Coustenis, A., Flasar, F. M., Oct. 2013. Detection of Propene in Titan's Stratosphere. The Astrophysical Journal Letters 776, L14.

Nizamov, B., Leone, S., 2004a. Kinetics of $\mathrm{C}_{2} \mathrm{H}$ reactions with hydrocarbons and nitriles in the 104-296 K temperature range. J. Phys. Chem. A 108 (10), 1746-1752.

Nizamov, B., Leone, S. R., 2004b. Rate coefficients and kinetic isotope effect for the $\mathrm{C}_{2} \mathrm{H}$ reactions with $\mathrm{NH}_{3}$ and $\mathrm{ND}_{3}$ in the $104-294 \mathrm{~K}$ temperature range. J. Phys. Chem. A $108(17), 3766-3771$.

North, S. W., Hall, G. E., 1996. The radical photodissociation channel of acrylonitrile. Chem. Phys. Lett. 263 (1-2), $148-153$.

Ohmori, K., Miyoshi, A., Matsui, H., Washida, N., 1990. Studies on the reaction of acetaldehyde and acetyl radicals with atomic hydrogen. J. Phys. Chem. 94 (8), $3253-3255$. Oka, K., Cvetanovic, R., 1979. Determination of rates of hydrogen atom reactions with alkenes at 298 K by a double modulation technique. Can. J. Chem. 57 (7),

Okabe, H., 1978. Photochemistry of small molecules. Wiley Interscience. Wiley.

Okabe, H., 1983. Photochemistry of acetylene at $1849 \AA$. The Journal of Chemical Physics 78 (3), 1312-1317.

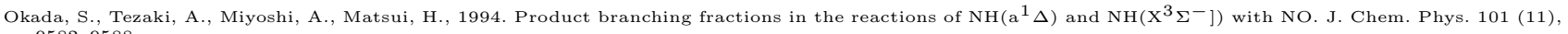
$9582-9588$.

Opansky, B. J., Leone, S. R., 1996. Rate coefficients of $\mathrm{C}_{2} \mathrm{H}$ with $\mathrm{C}_{2} \mathrm{H}_{4}, \mathrm{C}_{2} \mathrm{H}_{6}$, and $\mathrm{H}_{2}$ from 150-359 K. J. Phys. Chem. 100 (51), $19904-19910$.

Osamura, Y., Petrie, S., 2004. NCCN and $\mathrm{NCCCCN}$ formation in Titan's atmosphere: 1. Competing reactions of precursor $\mathrm{HCCN}\left({ }^{3} \mathrm{~A},\right)$ with $\mathrm{H}\left({ }^{2} \mathrm{~S}\right)$ and $\mathrm{CH}{ }_{3}\left({ }^{2} \mathrm{~A},\right)$. J. Phys. Chem. A $108(16), 3615-3622$.

Ouk, C. M., Zvereva-Loete, N., Bussery-Honvault, B., 2011. Towards a converged barrier height for the entrance channel transition state of the N $\left({ }^{2} \mathrm{D}\right)+\mathrm{CH} 4$ reaction and its implication for the chemistry in Titan's atmosphere. Chem. Phys. Lett. 515 (1-3), 13-18.

Pagsberg, P. B., Eriksen, J., Christensen, H. C., 1979. Pulse radiolysis of gaseous ammonia-oxygen mixtures. J. Phys. Chem. 83 (5), $582-590$.

Pang, J. L., Xie, H. B., Zhang, S. W., Ding, Y. H., Tang, A. Q., 2009. Gaseous reaction mechanism between two $\mathrm{H}_{2}$ CN radicals. Phys. Chem. Chem. Phys. 11 (21), $4326-4334$.

Paramo, A., Canosa, A., Le Picard, S. D., Sims, I. R., 2008. Rate coefficients for the reactions of $\mathrm{C}_{2}\left(\mathrm{a}^{3} \Pi_{u}\right)$ and $\mathrm{C}_{2}\left(\mathrm{X}^{1} \Sigma_{g}^{+}\right)$with various hydrocarbons $\left(\mathrm{CH}_{4}\right.$, $\mathrm{C}_{2} \mathrm{H}_{2}, \mathrm{C}_{2} \mathrm{H}_{4}, \mathrm{C}_{2} \mathrm{H}_{6}$, and $\mathrm{C}_{3} \mathrm{H}_{8}$ ): A gas-phase experimental study over the temperature range 24-300 K. J. Phys. Chem. A 112 (39), $9591-9600$.

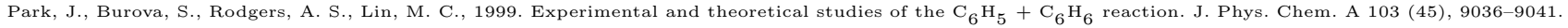

Park, J., Zhu, R. S., Lin, M. C., 2002. Thermal decomposition of ethanol. I. Ab Initio molecular orbital/Rice-Ramsperger-Kassel-Marcus prediction of rate constant and product branching ratios. J. Chem. Phys. 117 (7), 3224-3231.

Parker, J. K., Payne, W. A., Cody, R. J., Stief, L. J., 2004. Kinetics of the reaction of atomic hydrogen with cyanoacetylene from T $=200$ to 298 K. J. Phys. Chem. A $108(11), 1938-1945$.

Payne, W. A., Monks, P. S., Nesbitt, F. L., Stief, L. J., 1996. The reaction between $\left.\mathrm{N}^{4} \mathrm{~S}\right)$ and $\mathrm{C}_{2} \mathrm{H}_{3}$ : Rate constant and primary reaction channels. J. Chem. Phys. $104(24), 9808-9815$.

Payne, W. A., Stief, L. J., 1976. Absolute rate constant for the reaction of atomic hydrogen with acetylene over an extended pressure and temperature range. J. Chem. Phys. $64(3), 1150-1155$.

Petrie, S., 2002. Reactivity of HNC with small hydrocarbon radicals. J. Phys. Chem. A 106 (46), 11181-11189.

Petrie, S., Osamura, Y., 2004. NCCN and NCCCCN formation in Titan's atmosphere: 2. HNC as a viable precursor. J. Phys. Chem. A 108 (16), 3623-3631.

Phillips, L. F., 1978. Reaction of $\mathrm{H}$ with $\mathrm{C}_{2} \mathrm{~N}_{2}$ at pressures near 1 Torr. Int. J. Chem. Kinet. 10 (8), 899-904.

Pimentel, A. S., Payne, W. A., Nesbitt, F. L., Cody, R. J., Stief, L. J., 2004. Rate constant for the reaction $\mathrm{H}^{+} \mathrm{C}_{2} \mathrm{H}_{5}$ at $\mathrm{T}=150-295$ K. J. Phys. Chem. A $108(35), 7204-7210$.

Pitts, W. M., Pasternack, L., McDonald, J. R., 1982. Temperature dependence of the $\mathrm{C}_{2}\left(\mathrm{X}^{1} \Sigma_{g}^{+}\right)$reaction with $\mathrm{H}_{2}$ and $\mathrm{CH}_{4}$ and $\mathrm{C}_{2}\left(\mathrm{X}^{1} \Sigma_{g}^{+}\right.$and a ${ }^{3} \Pi_{u}$ equilibrated states) with $\mathrm{O}_{2}$. Chem. Phys. 68 (3), 417-422. 
Plessis, S., Carrasco, N., Dobrijevic, M., Pernot, P., May 2012. Production of neutral species in Titan's ionosphere through dissociative recombination of ions, Icarus $219,254-266$

Prozument, K., Shaver, R. G., Ciuba, M. A., Muenter, J. S., Park, G. B., Stanton, J. F., Guo, H., Wong, B. M., Perry, D. S., Field, R. W., 2013. A new approach toward transition state spectroscopy. Faraday Disc. 163, 33-57.

Rannou, P., Lebonnois, S., Hourdin, F., Luz, D., 2005. Titan atmosphere database. Advances in Space Research 36, 2194-2198.

Redondo, P., Pauzat, F., Ellinger, Y., 2006. Theoretical survey of the $\mathrm{NH}+\mathrm{CH}_{3}$ potential energy surface in relation to Titan atmospheric chemistry. Planet. Space Sci. $54(2), 181-187$.

Reisler, H., Mangir, M. S., Wittig, C., 1980. Kinetics of free radicals generated by IR laser photolysis. IV. Intersystem crossings and reactions of $\mathrm{C}_{2}\left(\mathrm{X}^{1} \Sigma_{g}^{+}\right)$and $\mathrm{C}_{2}\left(\mathrm{a}^{3} \Pi_{u}\right)$ in the gaseous phase. J. Chem. Phys. $73(5), 2280-2286$.

Rianda, R., Frueholz, R. P., Kuppermann, A., 1984. Singlet $\rightarrow$ triplet transitions in C $\equiv$ N containing molecules by electron impact. J. Chem. Phys. 80 (9), 4035-4043. Richardson, S. L., Francisco, J. S., 1994. A computational study of the reaction of $\mathrm{C}_{2}$ with $\mathrm{CH}_{4}$. Mol. Phys. 83 (5), $1041-1044$

Röhrig, M., Wagner, H. G., 1994a. A kinetic study about the reactions of $\mathrm{NH}\left(\mathrm{X}^{3} \Sigma^{-}\right)$with hydrocarbons. Part 2: Ethene, propene, and 2,3-dimethyl-2-butene. Ber. Bunsen-Ges. Phys. Chem. 98 (6), 864-868.

Röhrig, M., Wagner, H. G., 1994b. The reactions of $\mathrm{NH}\left(\mathrm{X}^{3} \Sigma^{-}\right)$with the water gas components $\mathrm{CO}_{2}$, $\mathrm{H}_{2} \mathrm{O}$, and $\mathrm{H}_{2}$. Symp. Int. Combust. Proc. 25 (1), $975-981$

Sabbah, H., Biennier, L., Sims, I. R., Georgievskii, Y., Klippenstein, S. J., Smith, I. W. M., 2007. Understanding reactivity at very low temperatures: The reactions of oxygen atoms with alkenes. Science $317(5834), 102-105$

Samuelson, R. E., Mayo, L. A., Knuckles, M. A., Khanna, R. J., Aug. 1997. C ${ }_{4} \mathrm{~N}_{2}$ ice in Titan's north polar stratosphere. Planet. Space Sci. 45, 941-948.

Sander, S. P., Abbatt, J., Barker, J. R., Burkholder, J. B., Friedl, R. R., Golden, D. M., Huie, R. E., Kolb, C. E., Kurylo, M. J., Moortgat, G. K., Orkin, V. L., Wine, P. H., 2011. Chemical Kinetics and Photochemical Data for Use in Atmospheric Studies, Evaluation Number 17. JPL Publication 10-6.

Sangwan, M., Chesnokov, E. N., Krasnoperov, L. N., 2012. Reaction $\mathrm{CH}_{3}+$ OH Studied over the 294-714 K temperature and 1-100 bar pressure ranges. J. Phys. Chem. A $116(34), 8661-8670$

Sato, K., Misawa, K., Kobayashi, Y., Matsui, M., Tsunashima, S., Kurosaki, Y., Takayanagi, T., 1999. Measurements of thermal rate constants for the reactions of $\mathrm{N}\left({ }^{2} \mathrm{D}-{ }^{2} \mathrm{P}\right)$ with $\mathrm{C}_{2} \mathrm{H}_{4}$ and $\mathrm{C}_{2} \mathrm{D}_{4}$ between 225 and $292 \mathrm{~K}$. J. Phys. Chem. 103 (43), 8650-8656.

Satyapal, S., Bersohn, R., 1991. Photodissociation of acetylene at 193.3 nm. J. Phys. Chem. 95 (21), $8004-8006$

Savee, J. D., Welz, O., Taatjes, C. A., Osborn, D. L., 2012. New mechanistic insights to the $\mathrm{O}\left({ }^{3} \mathrm{P}\right)+$ propene reaction from multiplexed photoionization mass spectrometry. Phys. Chem. Chem. Phys. 14, 10410-10423.

Sayah, N., Li, X., Caballero, J. F., Jackson, W. M., 1988. Laser induced fluorescence studies of CN reactions with alkanes, alkenes and substituted aliphatic species. J. Photochem. Photobiol. A $45(2), 177-194$

Scherzer, K., Claus, P., Karwath, M., 1985. Untersuchungen zur Kinetik und zum Mechanismus der Addition von Methylradicalen an Vinylacetylen. Z. Phys. Chem. $266(2), 321-328$

Schofield, K., 1973. Evaluated chemical kinetic rate constants for various gas phase reactions. J. Phys. Chem. Ref. Data 2, 25-84.

Schwanebeck, W., Warnatz, J., 1975. Reaktionen des Butadiins. I. Die reaktion mit Wasserstoffatomen. Ber. Bunsenges. Phys. Chem. 79 (6), 530-535.

Schwell, M., Jochims, H.-W., Baumgrtel, H., Leach, S., 2008. VUV photophysics of acetonitrile: Fragmentation, fluorescence and ionization in the 7-22eV region. Chem. Phys. $344(1-2), 164-175$

Seakins, P. W., Robertson, S. H., Pilling, M. J., Slagle, I. R., Gmurczyk, G. W., Bencsura, A., Gutman, D., Tsang, W., 1993. Kinetics of the unimolecular decomposition of iso- $\mathrm{C}_{3} \mathrm{H}_{7}$ : Weak collision effects in helium, argon, and nitrogen. J. Phys. Chem. $97(17), 4450-4458$

Seidler, V., Temps, F., Wagner, H. G., Wolf, M., 1989. Kinetics of the reactions of methylene $\left(\tilde{\mathrm{X}}^{3} \mathrm{~B}_{1}\right)$-radicals with NO and NO 2. J. Phys. Chem. 93 (3), 1070-1073. Seki, K., He, M., Liu, R., Okabe, H., 1996. Photochemistry of cyanoacetylene at 193.3 nm. J. Phys. Chem. 100 (13), 5349-5353.

Seki, K., Nakashima, N., Nishi, N., Kinoshita, M., 1986. Photochemistry of acetylene at 193 nm: Two pathways for diacetylene formation. J. Chem. Phys. 85 (1), $274-279$.

Seki, K., Okabe, H., 1993. Photochemistry of acetylene at 193.3 nm. J. Phys. Chem. 97 (20), 5284-5290.

Sekine, Y., Imanaka, H., Matsui, T., Khare, B. N., Bakes, E. L. O., McKay, C. P., Sugita, S., 2008a. The role of organic haze in Titan's atmospheric chemistry: I. Laboratory investigation on heterogeneous reaction of atomic hydrogen with Titan tholin. Icarus $194(1), 186-200$.

Sekine, Y., Lebonnois, S., Imanaka, H., Matsui, T., Bakes, E. L. O., McKay, C. P., Khare, B. N., Sugita, S., 2008b. The role of organic haze in Titan's atmospheric chemistry: II. Effect of heterogeneous reaction to the hydrogen budget and chemical composition of the atmosphere. Icarus 194 (1), $201-211$.

Semaniak, J., Minaev, B. F., Derkatch, A. M., Hellberg, F., Neau, A., Rosn, S., Thomas, R., Larsson, M., Danared, H., Paal, A., Af Ugglas, M., 2001. Dissociative recombination of $\mathrm{HCNH}^{+}$: Absolute cross-sections and branching ratios. Astrophys. J. Suppl. Ser. 135 (2), 275-283

Shafir, E. V., Slagle, I. R., Knyazev, V. D., 2003. Kinetics of the self-reaction of $\mathrm{C}_{2} \mathrm{H}_{5}$ radicals. J. Phys. Chem. A 107 (35), 6804-6813. 
Shemansky, D. E., Stewart, A. I. F., West, R. A., Esposito, L. W., Hallett, J. T., Liu, X., May 2005. The Cassini UVIS stellar probe of the Titan atmosphere. Science $308,978-982$.

Shen, D., Pritchard, H., 1991. On the dynamics of free-radical disproportionation reactions. Theor. Chim. Acta 78 (4), $241-246$.

Shepler, B. C., Yang, B. H., Kumar, T. J. D., Stancil, P. C., Bowman, J. M., Balakrishnan, N., Zhang, P., Bodo, E., Dalgarno, A., 2007. Low energy H + CO scattering revisited. Astron. Astrophys, 475 (2), L15-L18.

Shin, K. S., Michael, J. V., 1991. Rate constants (296-1700 K) for the reactions ethynyl radical + acetylene $\rightarrow \mathrm{C}_{4} \mathrm{H}_{2}+\mathrm{H}$ and $\mathrm{C}_{2} \mathrm{D}+\mathrm{C}_{2} \mathrm{D}_{2} \rightarrow \mathrm{C}_{4} \mathrm{D}_{2}+\mathrm{D} \mathrm{J}$. Phys. Chem. 95 (15), 5864-5869.

Silva, R., Gichuhi, W. K., Kislov, V. V., Landera, A., Mebel, A. M., Suits, A. G., 2009. UV photodissociation of cyanoacetylene: A combined ion imaging and theoretical investigation. J. Phys. Chem. A $113(42), 11182-11186$.

Sims, I. R., Queffelec, J. L., Travers, D., Rowe, B. R., Herbert, L. B., Karthauser, J., Smith, I. W. M., 1993. Rate constants for the reactions of CN with hydrocarbons at low and ultra-low temperatures. Chem. Phys. Lett. $211(4-5), 461-468$.

Slack, M. W., 1976. Kinetics and thermodynamics of the CN molecule. III. Shock tube measurement of CNdissociation rates. J. Chem. Phys. 64 (1), 228-236.

Slagle, I. R., Gutman, D., Davies, J. W., Pilling, M. J., 1988. Study of the recombination reaction methyl + methyl $\rightarrow$ ethane. 1. Experiment. J. Phys. Chem. $92(9), 2455-2462$.

Smith, G. P., 2003. Rate theory of methyl recombination at the low temperatures and pressures of planetary atmospheres. Chem. Phys. Lett. 376 (3-4), 381-388.

Smith, I. W. M., Talbi, D., Herbst, E., 2001. The production of HCN dimer and more complex oligomers in dense interstellar clouds. Astron. Astrophys. 369 (2), $611-615$.

Stewart, P., Smith, G., Golden, D., 1989. The pressure and temperature dependence of methane decomposition. Int. J. Chem. Kinet. 21 (10), 923-945.

Stief, L. J., DeCarlo, V. J., Mataloni, R. J., 1965. Vacuum-ultraviolet photolysis of acetylene. J. Chem. Phys. 42 (9), 3113-3121.

Stief, L. J., Nesbitt, F. L., Payne, W. A., Kuo, S. C., Tao, W., Klemm, R. B., 1995. Rate constant and reaction channels for the reaction of atomic nitrogen with the ethyl radical. J. Chem. Phys. $102(13), 5309-5316$.

Stief, L. J., Payne, W. A., Klemm, R. B., 1975. A flasch photolysis-resonance fluorescence study of the formation of $O\left({ }^{1} \mathrm{D}\right)$ in the photolysis of water and the reaction of $\mathrm{O}\left({ }^{1} \mathrm{D}\right)$ with $\mathrm{H}_{2}$, Ar, and He. J. Chem. Phys. 62 (10), 4000-4008.

Stoliarov, S. I., Knyazev, V. D., Slagle, I. R., 2000. Experimental study of the reaction between vinyl and methyl radicals in the gas phase. Temperature and pressure dependence of overall rate constants and product yields. J. Phys. Chem. A 104 (43), 9687-9697.

Stothard, N., Humpfer, R., Grotheer, H. H., 1995. The multichannel reaction $\mathrm{NH}_{2}+\mathrm{NH}_{2}$ at ambient temperature and low pressures. Chem. Phys. Lett. 240 (5-6), $474-480$

Stranges, D., O'Keeffe, P., Scotti, G., Santo, R. D., Houston, P. L., 2008. Competing sigmatropic shift rearrangements in excited allyl radicals. J. Chem. Phys. 128 (15), 151101-151104.

Sumathi, R., Nguyen, M. T., 1998. A theoretical study of the $\mathrm{CH}_{2} \mathrm{~N}$ system: Reactions in both lowest lying doublet and quartet states. J. Phys. Chem. A 102 (41), $8013-8020$.

Sun, Q., Yang, D. L., Wang, N. S., Bowman, J. M., Lin, M. C., 1990. Experimental and reduced dimensionality quantum rate coefficients for $\mathrm{H}_{2}\left(\mathrm{D}_{2}\right)+\mathrm{CN} \rightarrow$ $\mathrm{H}(\mathrm{D}) \mathrm{CN}+\mathrm{H}(\mathrm{D})$. J. Chem. Phys. $93(7), 4730-4739$

Takahashi, K., Takayanagi, T., 2006. Theoretical study on $\operatorname{HNC}\left({ }^{1} \Sigma\right)$ production from the $\mathrm{C}_{2}\left(\mathrm{X}^{1} \Sigma_{g}^{+}\right)+\mathrm{NH}\left(\mathrm{X}^{3} \Sigma^{-}\right.$reaction. Chem. Phys. Lett. $429(4-6)$, 399-404.

Takahashi, K., Takayanagi, T., 2007. Production of HNC from the $\mathrm{CH}\left(\mathrm{X}^{2} \Pi\right)+\mathrm{NH}\left(\mathrm{X}^{3} \Sigma^{-}\right)$reaction: Direct dynamics study. J. Mol. Struct. - THEOCHEM 817 (1-3), $153-160$.

Takayanagi, T., Kurosaki, Y., 1999. Direct ab initio classical trajectory calculations for the $\mathrm{N}\left({ }^{2} \mathrm{D}\right)+\mathrm{CH}_{4}$ insertion reaction. J. Mol. Struct. - THEOCHEM $492(1-3), 151-158$.

Takayanagi, T., Kurosaki, Y., Misawa, K., Sugiura, M., Kobayashi, Y., Sato, K., Tsunashima, S., 1998. Measurements of thermal rate constants and theoretical calculations for the $\mathrm{N}\left({ }^{2} \mathrm{D}^{2} \mathrm{P}\right)+\mathrm{C}_{2} \mathrm{H}_{2}$ and $\mathrm{C}_{2} \mathrm{D}_{2}$ reactions. J. Phys. Chem. A $102(31), 6251-6258$.

Takayanagi, T., Kurosaki, Y., Sato, K., Misawa, K., Kobayashi, Y., Tsunashima, S., 1999. Kinetic studies on the $\left.\mathrm{N}^{2} \mathrm{D}^{2} \mathrm{P}\right)+\mathrm{CH}_{4}$ and $\mathrm{CD} 4$ reactions: The role of nonadiabatic transitions on thermal rate constants. J. Phys. Chem. A 103 (2), 250-255.

Talbi, D., 1999. An extensive ab-initio study of the $\mathrm{C}+\mathrm{NH}_{2}$ and $\mathrm{N}+\mathrm{CH}_{2}$ reactions in relation to the HCN/HNC space abundance ratios. Chem. Phys. Lett. $313(3-4), 626-632$

Talbi, D., Ellinger, Y., 1996. Isomerization versus hydrogen exchange reaction in the HNC $\leftrightarrow$ HCNconversion. Chem. Phys. Lett. 263 (3-4), 385-392

Talbi, D., Smith, I. W. M., 2009. A theoretical analysis of the reaction between CN radicals and $\mathrm{NH}_{3}$. Phys. Chem. Chem. Phys. 11 (38), 8477-8483.

Teanby, N. A., de Kok, R., Irwin, P. G. J., Osprey, S., Vinatier, S., Gierasch, P. J., Read, P. L., Flasar, F. M., Conrath, B. J., Achterberg, R. K., Bézard, B., Nixon, C. A., Calcutt, S. B., Dec. 2008. Titan's winter polar vortex structure revealed by chemical tracers. Journal of Geophysical Research (Planets) 113 (E12), 12003.

Teanby, N. A., Irwin, P. G. J., de Kok, R., Jolly, A., Bézard, B., Nixon, C. A., Calcutt, S. B., Aug. 2009. Titan's stratospheric C ${ }_{2} \mathrm{~N}_{2}$, C ${ }_{3} \mathrm{H}{ }_{4}$, and C ${ }_{4} \mathrm{H}{ }_{2}$ 

Teanby, N. A., Irwin, P. G. J., de Kok, R., Nixon, C. A., 2010. Mapping Titan's HCN in the far infra-red: implications for photochemistry. Faraday Discussions
147, 51.

Teanby, N. A., Irwin, P. G. J., de Kok, R., Nixon, C. A., Coustenis, A., Bézard, B., Calcutt, S. B., Bowles, N. E., Flasar, F. M., Fletcher, L., Howett, C., Taylor, F. W., Mar. 2006. Latitudinal variations of $\mathrm{HCN}, \mathrm{HC}_{3} \mathrm{~N}$, and $\mathrm{C}_{2} \mathrm{~N}_{2}$ in Titan's stratosphere derived from Cassini CIRS data. Icarus $181,243-255$.

Teanby, N. A., Irwin, P. G. J., de Kok, R., Vinatier, S., Bézard, B., Nixon, C. A., Flasar, F. M., Calcutt, S. B., Bowles, N. E., Fletcher, L., Howett, C., Taylor, F. W., Feb. 2007. Vertical profiles of HCN, $\mathrm{HC}_{3} \mathrm{~N}$, and $\mathrm{C}_{2} \mathrm{H}_{2}$ in Titan's atmosphere derived from Cassini/CIRS data. Icarus 186, $364-384$

Teanby, N. A., Irwin, P. G. J., Nixon, C. A., Courtin, R., Swinyard, B. M., Moreno, R., Lellouch, E., Rengel, M., Hartogh, P., Jan. 2013. Constraints on Titan's middle atmosphere ammonia abundance from Herschel/SPIRE sub-millimetre spectra. Planet. Space Sci. $75,136-147$.

Teslja, A., Nizamov, B., Dagdigian, P. J., 2004. The electronic spectrum of methyleneimine. J. Phys. Chem. A 108 (20), 4433-4439.

Thiesemann, H., Clifford, E. P., Taatjes, C. A., Klippenstein, S. J., 2001. Temperature dependence and deuterium kinetic isotope effects in the CH (CD) $+\mathrm{C}_{2} \mathrm{H}_{4}$ $\left(\mathrm{C}_{2} \mathrm{D}_{4}\right)$ reaction between 295 and $726 \mathrm{~K}$. J. Phys. Chem. A $105(22), 5393-5401$.

Thiesemann, H., MacNamara, J., Taatjes, C., 1997. Deuterium kinetic isotope effect and temperature dependence in the reactions of CH $\left.{ }^{2} \Pi\right]$ with methane and acetylene. J. Phys. Chem. A $101(10), 1881-1886$

Thorn, R. P., Payne, W. A., Chillier, X. D. F., Stief, L. J., Nesbitt, F. L., Tardy, D. C., 2000. Rate constant and RRKM product study for the reaction between $\mathrm{CH}_{3}$ and $\mathrm{C}_{2} \mathrm{H}_{3}$ at $\mathrm{T}=298 \mathrm{~K}$. Int. J. Chem. Kinet. $32(5), 304-316$.
.

Tomeczek, J., Gradon, B., 2003. The role of $\mathrm{N}_{2} \mathrm{O}$ and NNH in the formation of NO via HCN in hydrocarbon flames. Combust. Flame 133 (3), $311-322$.

Toon, O. B., McKay, C. P., Griffith, C. A., Turco, R. P., Jan. 1992. A physical model of Titan's aerosols. Icarus $95,24-53$.

Tsang, W., 1987. Chemical kinetic database for combustion chemistry. 2. Methanol. J. Phys. Chem. Ref. Data 16 (3), 471-508.

Tsang, W., 1988. Chemical kinetic database for combustion chemistry. Part 3. Propane. J. Phys. Chem. Ref. Data 17 (2), 887-952.

Tsang, W., 1990. Chemical kinetic database for combustion chemistry Part 4. Isobutane. J. Phys. Chem. Ref. Data 19 (1), 1-68.

Tsang, W., 1991. Chemical kinetic database for combustion chemistry. Part 5. Propene. J. Phys. Chem. Ref. Data 20 (2), 221-273.

Tsang, W., 1992. Chemical kineticdata base for propellant combustion. II. Reactions involving CN, NCO, and HNCO. J. Phys. Chem. Ref. Data 21 (4), 753-791. Tsang, W., Hampson, R., 1986. Chemical kinetic database for combustion chemistry. 1. Methane and related-compounds. J. Phys. Chem. Ref. Data 15 (3),
1087-1279.

Tsang, W., Herron, J., 1991. Chemical kinetic database for propellant combustion. I. Reactions involving $\mathrm{NO} \mathrm{NO}_{2}$, $\mathrm{HNO}, \mathrm{HNO}{ }_{2}$, $\mathrm{HCN}$ and $\mathrm{N}_{2} \mathrm{O}$. J. Phys. Chem. Ref. Data $20(4), 609-663$

Tsuboi, T., Hashimoto, K., 1981. Shock tube study on homogeneous thermal oxidation of methanol. Combust. Flame $42,61-76$.

Umemoto, H., Asai, T., Hashimoto, H., Nakae, T., 1999. Reactions of $\left.\mathrm{N}^{2}{ }^{2} \mathrm{D}\right)$ with $\mathrm{H}_{2} \mathrm{O}$ and $\mathrm{D}_{2} \mathrm{O}$; Identification of the two exit channels, NH(ND) + OH(OD) and H(D) $+\mathrm{HNO}(\mathrm{DNO})$. J. Phys. Chem. A $103(6), 700-704$.

Umemoto, H., Hachiya, N., Matsunaga, E., Suda, A., Kawasaki, M., 1998. Rate constants for the deactivation of N $\left({ }^{2} \mathrm{D}\right)$ by simple hydride and deuteride molecules. Chem. Phys. Lett. 296 (1-2), 203-207.

Vakhtin, A. B., Heard, D. E., Smith, I. W. M., Leone, S. R., 2001a. Kinetics of $\mathrm{C}_{2} \mathrm{H}$ radical reactions with ethene, propene and 1-butene measured in a pulsed Laval nozzle apparatus at $\mathrm{T}=103$ and $296 \mathrm{~K}$. Chem. Phys. Lett. 348 (1-2), 21-26.

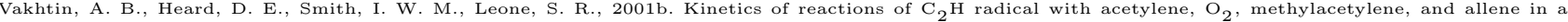
pulsed Laval nozzle apparatus at $\mathrm{T}=103 \mathrm{~K}$. Chem. Phys. Lett. $344(3-4), 317-324$

Vakhtin, A. B., Lee, S., Smith, I. W. M., Leone, S. R., 2001c. Low-temperature kinetics of reactions of the OH radical with propene and 1-butene studied by a pulsed Laval nozzle apparatus combined with laser-induced fluorescence. J. Phys. Chem. A 105 (33), $7889-7895$.

Vervack, R. J., Sandel, B. R., Strobel, D. F., Jul. 2004. New perspectives on Titan's upper atmosphere from a reanalysis of the Voyager 1 UVS solar occultations. carus $170,91-112$

Vinatier, S., Bézard, B., Nixon, C. A., Nov. 2007. The Titan ${ }^{14} \mathrm{~N} /{ }^{15} \mathrm{~N}$ and ${ }^{12} \mathrm{C} /{ }^{13} \mathrm{C}$ isotopic ratios in HCN from Cassini/CIRS. Icarus $191,712-721$.

Vinatier, S., Bézard, B., Nixon, C. A., Mamoutkine, A., Carlson, R. C., Jennings, D. E., Guandique, E. A., Teanby, N. A., Bjoraker, G. L., Michael Flasar, F., Kunde, V. G., Feb. 2010. Analysis of Cassini/CIRS limb spectra of Titan acquired during the nominal mission. I. Hydrocarbons, nitriles and CO 2 vertical mixing ratio profiles. Icarus $205,559-570$.

Vinckier, C., 1979. Determination of the rate constant of the reaction $\mathrm{CH}+\mathrm{O} \rightarrow \mathrm{CHO}^{+}+\mathrm{e}^{-}$at 295 K. J. Phys. Chem. 83 (9), $1234-1235$.

Vinckier, C., Debruyn, W., 1979. Temperature dependence of the reactions of methylene with oxygen atoms, oxygen, and nitric oxide. J. Phys. Chem. 83 (16), $2057-2062$.

von Gehring, M., Hoyermann, K., Wagner, H., Wolfrum, J., 1971. Die Reaktion von Atomarem Wasserstoff mit Hydrazin. Ber. Bunsen-Ges. Phys. Chem. 75 (12), $1287-1294$

Vuitton, V., Lavvas, P., Yelle, R. V., Galand, M., Wellbrock, A., Lewis, G. R., Coates, A. J., Wahlund, J.-E., Nov. 2009. Negative ion chemistry in Titan's upper atmosphere. Planet. Space Sci. 57, 1558-1572. 
Vuitton, V., Yelle, R. V., Anicich (Retired), V. G., Aug. 2006. The Nitrogen Chemistry of Titan's Upper Atmosphere Revealed. The Astrophysical Journal Letters $647, \mathrm{~L} 175-\mathrm{L} 178$.

Vuitton, V., Yelle, R. V., Lavvas, P., Klippenstein, S. J., 2012. Rapid association reactions at low pressure: Impact on the formation of hydrocarbons on Titan. Astrophys. J. $744(1), 11$.

Vuitton, V., Yelle, R. V., McEwan, M. J., Nov. 2007. Ion chemistry and N-containing molecules in Titan's upper atmosphere. Icarus 191, 722-742.

Wagner, A. F., Bowman, J. M., 1987. The addition and dissociation reaction atomic hydrogen + carbon monoxide $\rightleftarrows$ oxomethyl. 1. Theoretical RRKM studies. J. Phys. Chem. $91(20), 5314-5324$

Waite, J. H., Bell, J., Lorenz, R., Achterberg, R., Flasar, F. M., Sep. 2013. A model of variability in Titan's atmospheric structure. Planet. Space Sci. 86, 45-56.

Wakelam, V., Herbst, E., Loison, J.-C., Smith, I. W. M., Chandrasekaran, V., Pavone, B., Adams, N. G., Bacchus-Montabonel, M.-C., Bergeat, A., Béroff, K., Bierbaum, V. M., Chabot, M., Dalgarno, A., van Dishoeck, E. F., Faure, A., Geppert, W. D., Gerlich, D., Galli, D., Hébrard, E., Hersant, F., Hickson, K. M., Honvault, P., Klippenstein, S. J., Le Picard, S., Nyman, G., Pernot, P., Schlemmer, S., Selsis, F., Sims, I. R., Talbi, D., Tennyson, J., Troe, J., Wester, R., Wiesenfeld, L., Mar. 2012. A KInetic Database for Astrochemistry (KIDA). The Astrophysical Journal Supplement 199, 21

Wang, B., Fockenberg, C., 2001. Direct measurement of the rate constant for the $\mathrm{CH}_{2}\left(\tilde{X}^{3} \mathrm{~B}_{1}\right)+\mathrm{CH}_{3}$ reaction at $300 \mathrm{~K} . \mathrm{J}$. Phys. Chem. A $105(37), 8449-8455$.

Wang, H., Frenklach, M., 1994. Calculations of rate coefficients for the chemically activated reactions of acetylene with vinylic and aromatic radicals. J. Phys. Chem. $98(44), 11465-11489$

Wang, H., Frenklach, M., 1997. A detailed kinetic modeling study of aromatics formation in laminar premixed acetylene and ethylene flames. Combust. Flame $110(1-2), 173-221$.

Wang, H. Y., Eyre, J. A., Dorfman, L. M., 1973. Activation energy for the gas phase reaction of hydrogen atoms with carbon monoxide. J. Chem. Phys. 59 (9), $5199-5200$.

Wang, J., Ding, Y.-h., Sun, C.-c., 2006. Cyanomethylidyne: A reactive carbyne radical. ChemPhysChem 7 (3), $710-722$.

Wang, Z.-X., Huang, M.-B., 1998. Insertion of methylidyne into the C-H bond of ethylene. Chem. Phys. Lett. 291 (3-4), 381-386.

Weissman, M. A., Benson, S. W., 1988. Rate parameters for the reactions of vinyl and butadienyl radicals with hydrogen and acetylene. J. Phys. Chem. 92 (14), $4080-4084$.

West, G. A., Berry, M. J., 1974. CN photodissociation and predissociation chemical lasers: Molecular electronic and vibrational laser emissions. J. Chem. Phys. $61(11), 4700-4716$

Westmoreland, P. R., Dean, A. M., Howard, J. B., Longwell, J. P., 1989. Forming benzene in flames by chemically activated isomerization. J. Phys. Chem. 93 (25), 8171-8180.

Whyte, A. R., Phillips, L. F., 1983. Rates of reaction of $\mathrm{NH}_{2}$ with $\mathrm{N}$, NO and $\mathrm{NO}_{2}$. Chem. Phys. Lett. 102 (5), $451-454$.

Whyte, A. R., Phillips, L. F., 1984. Products of reaction of nitrogen atoms with $\mathrm{NH}_{2}$. J. Phys. Chem. 88 (23), $5670-5673$.

Whytock, D. A., Payne, W. A., Stief, L. J., 1976. Rate of the reaction of atomic hydrogen with propyne over an extended pressure and temperature range. J. Chem. Phys. 65 (1), 191-195

Wilhelm, M. J., Nikow, M., Letendre, L., Dai, H.-L., 2009. Photodissociation of vinyl cyanide at 193 nm: Nascent product distributions of the molecular elimination channels. J. Chem. Phys. $130(4), 044307-12$

Wilson, A. V., Parker, D. S. N., Zhang, F., Kaiser, R. I., 2012. Crossed beam study of the atom-radical reaction of ground state carbon atoms $\left(\right.$ C $\left.\left({ }^{3} P\right)\right)$ with the vinyl radical $\left(\mathrm{C}_{2} \mathrm{H}_{3}\left(\mathrm{X}^{2} A^{\prime}\right)\right)$. Phys. Chem. Chem. Phys. $14(2), 477-481$.

Wilson, E., Atreya, S., 2004. Current state of modeling the photochemistry of titan's mutually dependent atmosphere and ionosphere. J. Geophys. Res. - Planets 109 (E6), E06002.

Woon, D., Herbst, E., 1996. On the stability of interstellar carbon clusters: The rate of the reaction between C 3 and O. Astrophys. J. 465, $795-799$.

Woon, D. E., Park, J.-Y., 2009. Modeling chemical growth processes in Titan's atmosphere 2. Theoretical study of reactions between $\mathrm{C}_{2} \mathrm{H}$ and ethene, propene, 1-butene, 2-butene, isobutene, trimethylethene, and tetramethylethene. Icarus 202 (2), 642-655.

Xu, Z.-F., Fang, D.-C., Fu, X.-Y., 1997. Ab initio study on the reaction $\mathrm{NH}+\mathrm{NH} \rightarrow \mathrm{NH}_{2}+$ N. Chem. Phys. Lett. 275 (3-4), 386-391.

Xu, Z.-F., Li, S.-M., Yu, Y.-X., Li, Z.-S., Sun, C.-C., 1999. Theoretical studies on the reaction path dynamics and variational transition-state theory rate constants of the hydrogen-abstraction reactions of the $\mathrm{NH}\left(\mathrm{X}^{3} \Sigma^{-}\right)$radical with methane and ethane. J. Phys. Chem. A 103 (25), $4910-4917$.

Yang, D. L., Yu, T., Lin, M. C., Melius, C. F., 1992a. CN radical reactions with hydrogen cyanide and cyanogen: Comparison of theory and experiment. J. Chem. Phys. 97 (1), 222-226.

Yang, D. L., Yu, T., Lin, M. C., Melius, C. F., 1993. The reaction of CN with $\mathrm{CH}_{4}$ and $\mathrm{CD}_{4}$ : an experimental and theoretical study. Chem. Phys. 177 (1), 271-280.

Yang, D. L., Yu, T., Wang, N. S., Lin, M. C., 1992b. Temperature dependence of cyanogen radical reactions with selected alkanes: CN reactivities towards primary, secondary and tertiary $\mathrm{C}-\mathrm{H}$ bonds. Chem. Phys. $160(2), 307-315$

Yang, Y., Zhang, W., Pei, S., Shao, H., Huang, W., Gao, X., 2005. Theoretical study on the mechanism of the N $\left({ }^{4} \mathrm{~S}\right)+\mathrm{C}_{2} \mathrm{H}_{5}$ reaction. J. Mol. Struct. - THEOCHEM $725(1-3), 133-138$.

Yelle, R. V., Cui, J., Müller-Wodarg, I. C. F., Oct. 2008. Methane escape from Titan's atmosphere. Journal of Geophysical Research (Planets) 113 (E12), 10003. 
Yelle, R. V., Griffith, C. A., Nov. 2003. HCN fluorescence on Titan. Icarus 166, 107-115.

Yelle, R. V., Vuitton, V., Lavvas, P., Klippenstein, S. J., Smith, M. A., Horst, S. M., Cui, J., 2010. Formation of $\mathrm{NH}_{3}$ and $\mathrm{CH}_{2} \mathrm{NH}_{\text {in }}$ Titan's upper atmosphere. Faraday Discuss. 147, 31-49.

Yu, T., Yang, D., Lin, M., 1993. Kinetics of CN radical reactions with formaldehyde and 1,3,5-trioxane. Int. J. Chem. Kinet. 25 (12), $1053-1064$.

Yu, Y., Li, S., Xu, Z., Li, Z., Sun, C., 1998. An ab initio study on the reaction $\mathrm{NH}_{2}+\mathrm{CH}_{4} \rightarrow \mathrm{NH}_{3}+\mathrm{CH}_{3}$. Chem. Phys. Lett. 296 (1-2), 131-136.

Zabarnick, S., 1989. Kinetics of $\mathrm{CN}\left(\mathrm{X}^{2} \Sigma^{+}\right)$radical reactions with $\mathrm{HCN}, \mathrm{BrCN}$ and $\mathrm{CH}_{3} \mathrm{CN}$. Chem. Phys. 134 (1), $185-191$.

Zabarnick, S., Fleming, J., Lin, M., 1988. Temperature dependence of $\mathrm{CH}$ radical reactions with $\mathrm{H}_{2} \mathrm{O}$ and $\mathrm{CH}_{2} \mathrm{O}$. Symp. Int. Combust. Proc. 21 (1), $713-719$.

Zabarnick, S., Fleming, J., Lin, M., 1989a. Kinetics of $\mathrm{CH}$ radical reactions with $\mathrm{N}_{2} \mathrm{O}, \mathrm{SO}_{2}$, OCS, $\mathrm{CS}_{2}$, and $\mathrm{SF}_{6}$. Int. J. Chem. Kinet. 21 (9), $765-774$.

Zabarnick, S., Fleming, J. W., Lin, M. C., 1989b. Kinetics of methylidyne ( $\left.\mathrm{CHX}^{2} \Pi\right)$ radical reactions with ammonia and methylamines. Chem. Phys. 132 (3), $407-411$. Zabarnick, S., Fleming, J. W., Lin, M. C., 1991. Direct measurement of rate constants for the reactions of CH and CD with HCN and DCN. Chem. Phys. 150 (1),
109-115.

Zhang, W., Du, B., Feng, C., 2004a. Theoretical investigation of reaction mechanism for $\mathrm{CH}_{2}\left(\tilde{\mathrm{X}}^{3} \mathrm{~B}_{1}\right)$ with NO radical. J. Mol. Struct. - THEOCHEM 679 (1-2), $121-125$.

Zhang, X., Zou, S., Harding, L. B., Bowman, J. M., 2004b. A global ab initio potential energy surface for formaldehyde. J. Phys. Chem. A 108 (41), $8980-8986$.

Zhao, Y., Truhlar, D. G., 2008. Exploring the limit of accuracy of the global hybrid meta density functional for main-group thermochemistry, kinetics, and noncovalent interactions. J. Chem. Theory Comput. 4 (11), 1849-1868.

Zhou, J., Schlegel, H. B., 2009. Ab initio classical trajectory study of the dissociation of neutral and positively charged methanimine $\left(\mathrm{CH}{ }_{2} \mathrm{NH}^{\mathrm{n}}+\mathrm{n}=0-2\right) . \mathrm{J}$ Phys. Chem. A 113 (37), 9958-9964.

Zhu, L., Talukda, R., Burkholder, J., Ravishankara, A., 2008. Rate Coefficients for the OH + Acetaldehyde $\left(\mathrm{CH}_{3} \mathrm{CHO}\right)$ Reaction Between 204 and $373 \mathrm{~K}$. International Journal of Chemical Kinetics 40, 635-646.

Zhu, Z., Ji, M., Zhang, S. W., Chen, Y., 2003a. Temperature-dependent kinetics of the reactions of the $\mathrm{CCN}\left(\mathrm{X}_{2} \Pi\right)$ radical with $\mathrm{C}_{2} \mathrm{H}_{2}$ and $\mathrm{C}_{2} \mathrm{H}_{4}$. http://oasys2.confex.com/acs/235nm/techprogram/P1157562.HTM.

Zhu, Z., Zhang, Z., Huang, C., Pei, L., Chen, C., Chen, Y., 2003b. Kinetics of CCN radical reactions with a series of normal alkanes. J. Phys. Chem. A. 107 (48), $10288-10291$.

Zwier, T. S., Allen, M., 1996. Metastable diacetylene reactions as routes to large hydrocarbons in Titan's atmosphere. Icarus 123 (2), $578-583$. 